\title{
Experimental and Theoretical Investigation of a Sliding Vane Compressor-Expander Unit for an R-134a Automotive Vapour Compression Refrigeration System
}

\author{
By \\ Chukwudi Azih \\ A thesis submitted to \\ The Faculty of Graduate Studies and Research \\ in partial fulfilment of \\ the degree requirements of \\ Masters of Applied Science \\ Ottawa-Carleton Institute for \\ Mechanical and Aerospace Engineering \\ Department of Mechanical and Aerospace Engineering \\ Carleton University \\ Ottawa, Ontario, Canada \\ August 2007 \\ Copyright $(\odot$ \\ 2007 - Chukwudi Azih
}




$\begin{array}{ll}\begin{array}{l}\text { Library and } \\ \text { Archives Canada }\end{array} & \begin{array}{l}\text { Bibliothèque et } \\ \text { Archives Canada }\end{array} \\ \begin{array}{l}\text { Published Heritage } \\ \text { Branch }\end{array} & \begin{array}{l}\text { Direction du } \\ \text { Patrimoine de l'édition }\end{array} \\ \begin{array}{l}\text { 395 Wellington Street } \\ \text { Ottawa ON K1A ON4 }\end{array} & \begin{array}{l}\text { 395, rue Wellington } \\ \text { Ottawa ON K1A ON4 } \\ \text { Canada }\end{array}\end{array}$

Your file Votre référence ISBN: 978-0-494-33636-6 Our file Notre référence ISBN: 978-0-494-33636-6

NOTICE:

The author has granted a nonexclusive license allowing Library and Archives Canada to reproduce, publish, archive, preserve, conserve, communicate to the public by telecommunication or on the Internet, loan, distribute and sell theses worldwide, for commercial or noncommercial purposes, in microform, paper, electronic and/or any other formats.

The author retains copyright ownership and moral rights in this thesis. Neither the thesis nor substantial extracts from it may be printed or otherwise reproduced without the author's permission.
AVIS:

L'auteur a accordé une licence non exclusive permettant à la Bibliothèque et Archives Canada de reproduire, publier, archiver, sauvegarder, conserver, transmettre au public par télécommunication ou par l'Internet, prêter, distribuer et vendre des thèses partout dans le monde, à des fins commerciales ou autres, sur support microforme, papier, électronique et/ou autres formats.

L'auteur conserve la propriété du droit d'auteur et des droits moraux qui protège cette thèse. $\mathrm{Ni}$ la thèse ni des extraits substantiels de celle-ci ne doivent être imprimés ou autrement reproduits sans son autorisation.
In compliance with the Canadian

Privacy Act some supporting forms may have been removed from this thesis.

While these forms may be included in the document page count, their removal does not represent any loss of content from the thesis.
Conformément à la loi canadienne sur la protection de la vie privée, quelques formulaires secondaires ont été enlevés de cette thèse.

Bien que ces formulaires aient inclus dans la pagination, il n'y aura aucun contenu manquant.

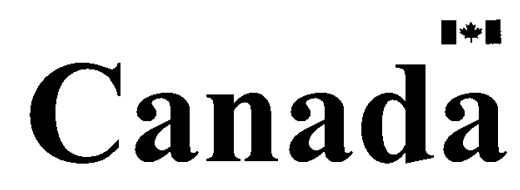




\begin{abstract}
The incorporation of the compressor and expander into one mechanism is a compact and useful method for recovering some energy from the expansion/throttling stage of the refrigeration cycle. This thesis aims to experimentally and theoretically investigate the performance of the overall refrigeration system with emphasis on the compressorexpander unit. Experimental work is carried out over several working conditions. An investigation in the related effects on the cycle COP, volumetric efficiency, compressor power loss and other system operating conditions is conducted as well. The experimental setup includes the compressor-expander, a condenser, a variable orifice expansion valve, an evaporator and an accumulator.

A compressor-expander theoretical model involving detailed modelling of the compressor-expander geometry and solving basic mass and energy conservation equations with justified assumptions developed. Analytical models for the condenser, expansion device and evaporator work in tandem with the compressor-expander model to predict the fluid conditions in all parts and sections of the cycle.
\end{abstract}




\section{Acknowledgements}

In completing this work, I owe a great deal of gratitude to my supervisor, colleagues, departmental staff, the Refrigeration Development Company in Deep River Ontario and my family, who have supported and encouraged me with their comments, questions and insights.

I especially want to thank Dr. Junjie Gu, my supervisor for his professional attitude and insight over the course of completing this work and Mr. Ian Glen of the Refrigeration development company for the knowledge he shared from his years of experience in this field as well as his financial input to the project and provision of experimental hardware.

My gratitude also extends to Mr. Shujun Wang, who helped oversee the experimental side of this work, as well as the staff in the departmental machine shop for their assistance in machining and manufacturing components. I also extend a special thank you to the staff at the departmental office for ensuring that administrative issues went smoothly.

My fellow colleagues completing the Masters of Applied Science along side me also deserve a special mention. And last, but certainly not least, I thank my family - for all the encouragement I received in this journey.

Thank you!

Chukwudi Azih

iv 


\section{Table of Contents}

Abstract

Acknowledgements iv

Table of Contents $\quad$ v

List of Tables $\quad$ ix

List of Figures $\quad$ x

$\begin{array}{ll}\text { Nomenclature } & \text { xii }\end{array}$

Chapter 1: Introduction $\quad 1$

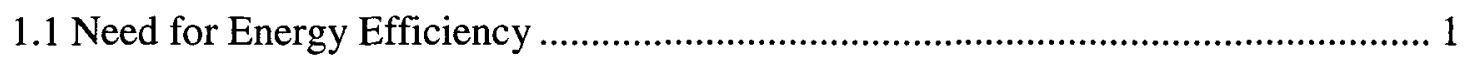

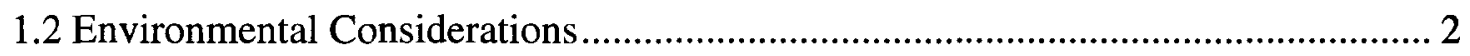

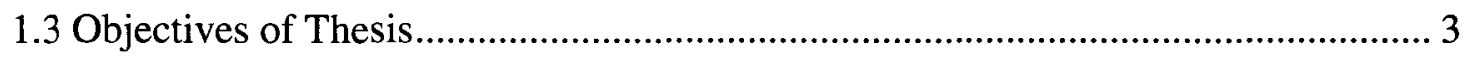

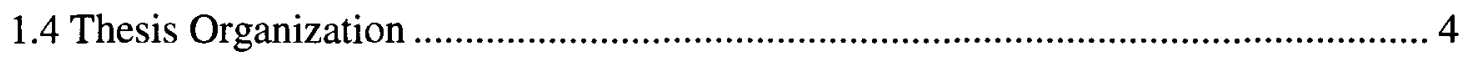

Chapter 2: Background and Literature Review 6

2.1 Fundamentals of the Conventional Vapour Compression Cycle ............................ 6

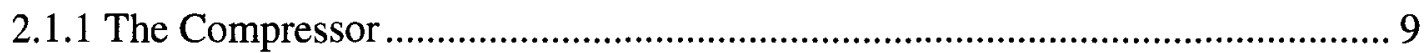

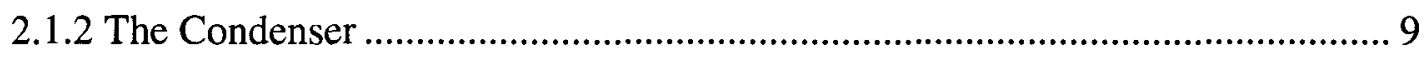

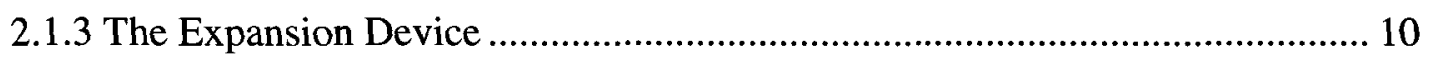

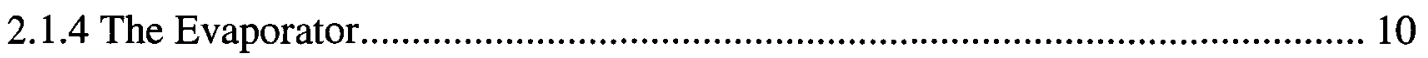

2.2 Some Additions to the Conventional Cycle ........................................................ 11

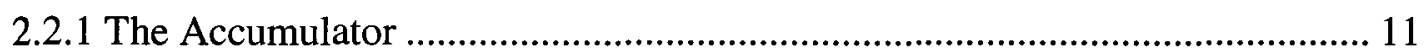




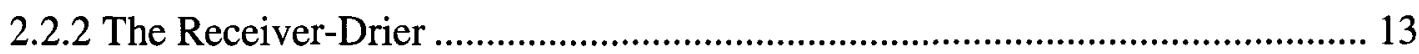

2.2.3 The Liquid Line Suction Line Heat Exchanger (LLSLHX) ............................ 14

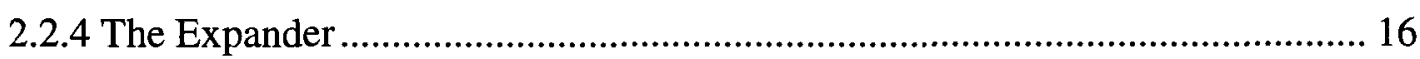

2.3 Main Types of Automobile A/C Systems ............................................................. 16

2.4 Mechanism of the Vane Compressor ..................................................................... 18

2.5 Review of Compressor-Expander Designs and Cycles ........................................... 19

2.6 Review of Vane Compressor Modelling .............................................................. 25

Chapter 3: Experimental Setup $\quad 28$

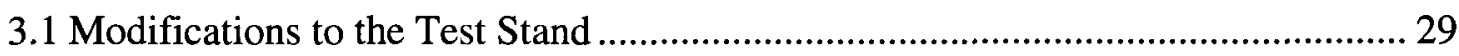

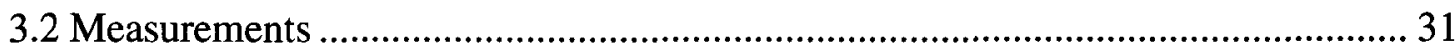

3.3 Data Acquisition and Signal Processing ………………........................................ 33

3.3.1 Standard Controls Window............................................................................. 34

3.3.2 Standard Measurement Window.................................................................... 35

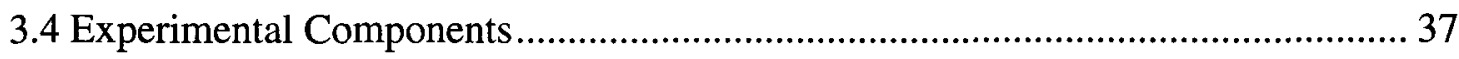

3.4.1 Compressor-Expander.................................................................................. 37

3.4.2 Condenser ................................................................................................ 40

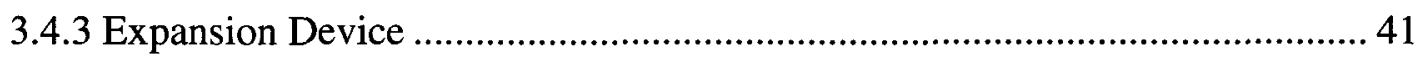

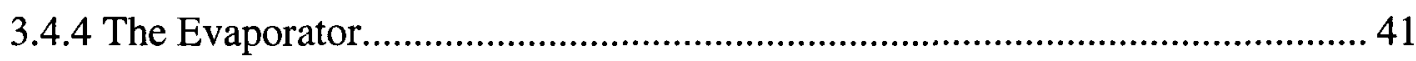

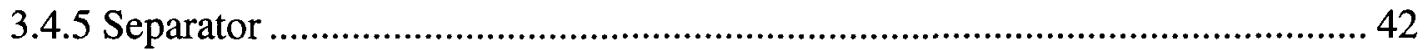

3.5 Experimental Calculations ................................................................................. 43

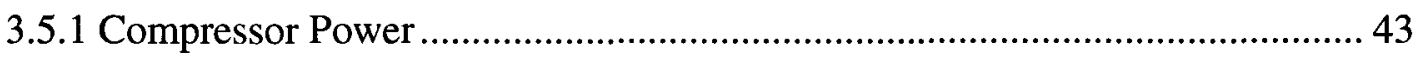

3.5.2 Flow Quality and Torlon Leakage ………………….................................... 43

3.5.3 Coefficient of Performance............................................................................ 44

3.5.4 Efficiencies ............................................................................................. 44

Chapter 4: Theoretical Analysis $\quad 47$

4.1 Analysis of the Compressor-Expander …………................................................ 47

4.1.1 Compressor-Expander Geometry.................................................................... 48

4.1.2 Pressure Distribution on the Vane ................................................................. 52

vi 


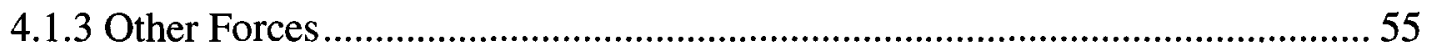

4.1.4 Leakage and Outlet Model.......................................................................... 57

4.1.5 Governing Equations and Tip Friction Calculation .......................................... 60

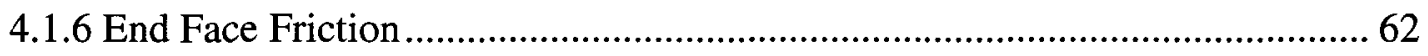

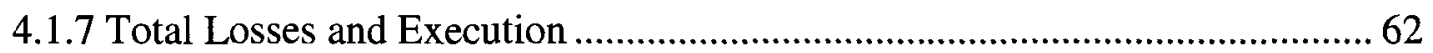

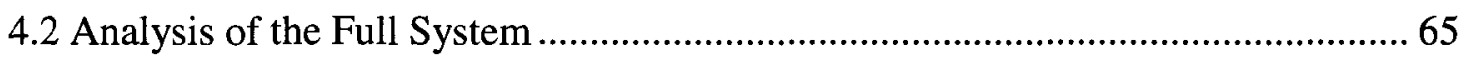

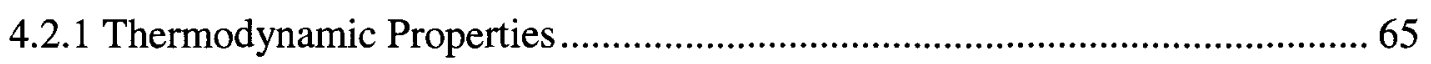

4.2.2 Pressure Losses and External Heat Transfer Coefficients .................................. 66

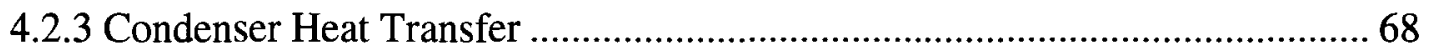

4.2.4 Expansion Device Pressure Drop............................................................. 72

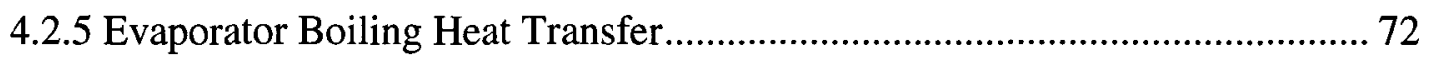

4.2.6 Execution of the Full System Model ............................................................ 76

$\begin{array}{lr}\text { Chapter 5: Results and Discussion } & \mathbf{8 0}\end{array}$

5.1 Grid and Loop Convergence ............................................................................. 80

5.1.1 Rotor Mesh Convergence ........................................................................... 80

5.1.2 Heat Exchanger Convergence...................................................................... 81

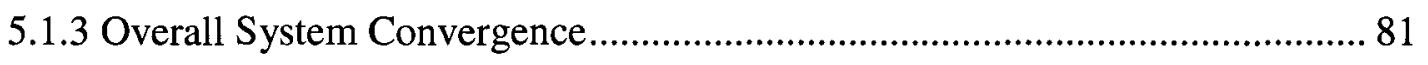

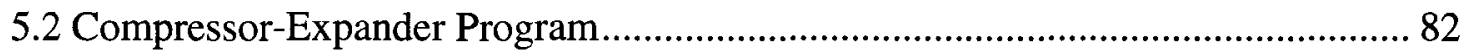

5.2.1 Compressor-Expander Simulation Results ................................................... 82

5.2.2 Discussion of Compressor-expander Simulation Results ................................ 86

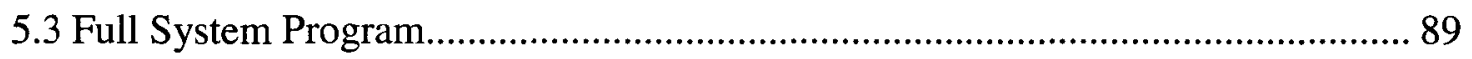

5.3.1 Full System Simulation Results of Current Settings ........................................ 89

5.3.2 Discussion of the Full System Simulation Results with Current Settings....... 95

5.3.3 Full System Simulation Results for Proposed Improvements .......................... 96

5.3.4 Discussion of Full System Simulation Results for Proposed Improvements .. 98

$\begin{array}{ll}\text { Chapter 6: Conclusions and Recommendations } & 100\end{array}$

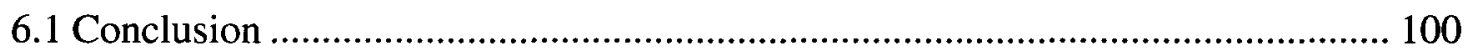

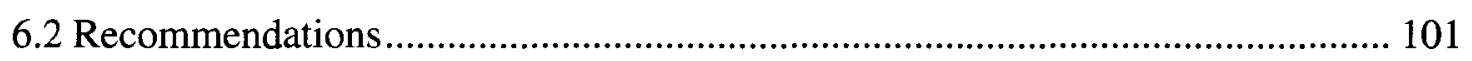

vii 


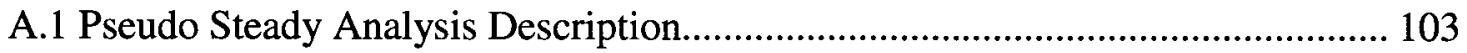

A.2 Calculation of Percent Errors and Differences ................................................. 104

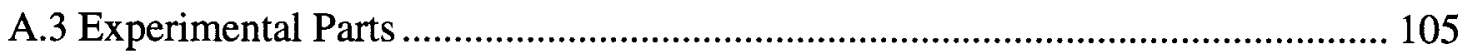

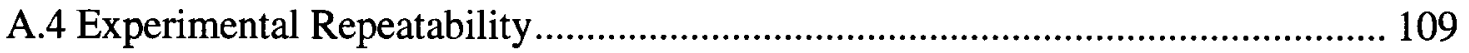

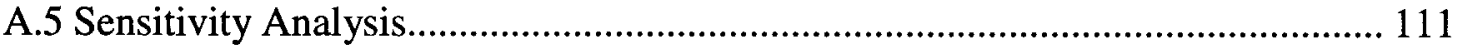

A.6 Liquid Equation of State Constants ............................................................. 114

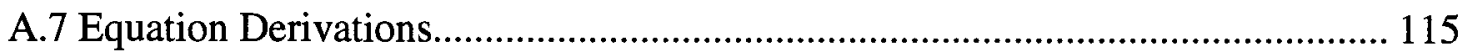

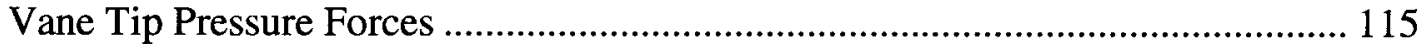

Rotor Spinning Viscous Losses ................................................................ 116

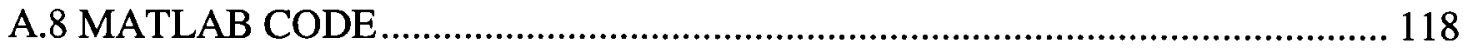

$\begin{array}{ll}\text { REFERENCES } & 191\end{array}$

viii 


\section{List of Tables}

Table 3-1 Property Measurements in the Experimental Setup .................................... 32

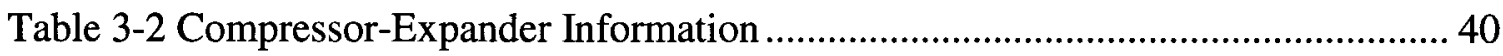

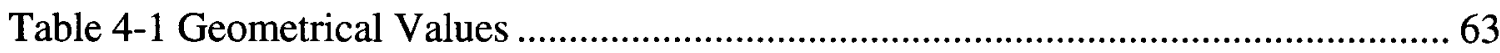

Table 5-1 Points Tested Experimentally.................................................................... 90

Table 5-2 COP Improvement with End-Face Gap Change (Experimental) ....................95

Table 5-3 Effect of Torlon Seal Leakage on the COP @ 1000 RPM............................. 97

Table 5-4 Effect of Torlon Seal Leakage on the COP @ 1500 RPM............................. 97

Table 5-5 Effect of Lubrication on the COP @ 1500 RPM............................................ 98

Table A-1: Repeatability Results as Standard Deviations from Mean .......................... 110

Table A-2: Repeatability Results as Percentage of Mean......................................... 110

Table A-3 Effect of Several Parameters on COP @ 1250RPM .................................... 111

Table A-4 Effect of Several Parameters on Power Loss @ 1250RPM .......................... 112 


\section{List of Figures}

Figure 2.1 Typical Single-Stage Vapour Compression Refrigeration Cycle [6] ............... 7

Figure 2.2 Pressure-Enthalpy Diagram for a Vapour Compression Cycle ........................ 7

Figure 2.3 A Schematic of the J-tube Accumulator [10] ............................................. 12

Figure 2.4 Schematic of a Typical Receiver-Drier [11] (modified) ............................... 14

Figure 2.5 Presure-enthalpy Diagram of IHX System [12] (modified) ........................... 15

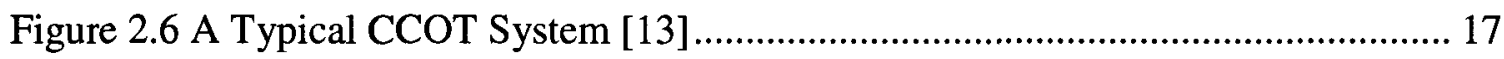

Figure 2.7 Schematic of a Balanced and Unbalanced Vane Compressor........................ 19

Figure 2.8: Expressor Flow Diagram by Brasz [18] ...................................................... 23

Figure 3.1 ATS Automobile Air Conditioning Test Stand ............................................. 29

Figure 3.2 A Schematic of Experimental Setup............................................................. 31

Figure 3.3 The Thermocouple and Pressure Transducer .............................................. 33

Figure 3.4 Standard Controls Window [28].............................................................. 35

Figure 3.5 Standard Measurement Window [28]....................................................... 37

Figure 3.6 Disassembled Compressor-Expander...................................................... 38

Figure 3.7 Compressor-Expander Rotor and Vanes ................................................ 39

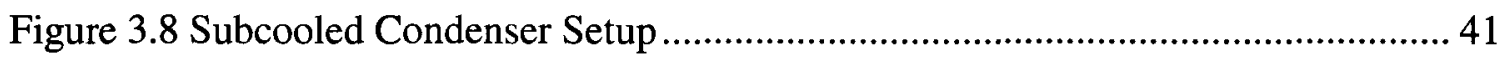

Figure 3.9 Separator Setup for Measuring Gas or Total Flowrate.................................. 42

Figure 3.10 Depiction of Closed-to-Inlet and Open-to-Outlet Volumes ......................... 45

Figure 4.1 Geometry Nomenclature for Vane Compressor ......................................... 48

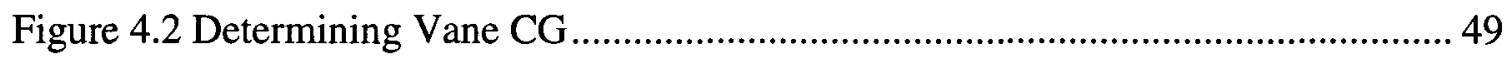

Figure 4.3 Chamber Area that Determines the Control Volume ................................... 51

Figure 4.4 Pressure Distribution on the Vane .............................................................. 53

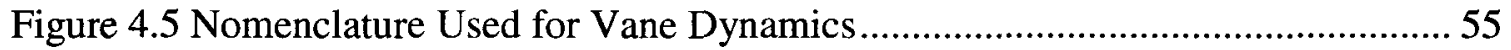

Figure 4.6 Leakage Paths on the Rotor ............................................................ 57 
Figure 4.7 Mass Lost from Outlet Chambers................................................................. 58

Figure 4.8 Nomenclature for Rotor Face Leakage........................................................ 59

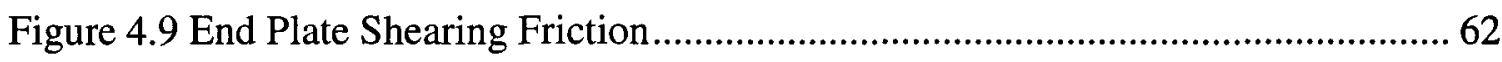

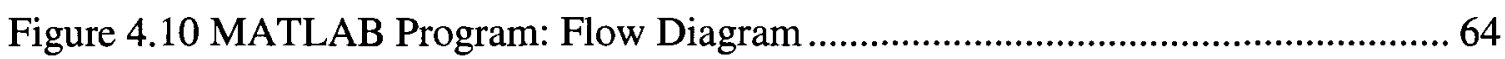

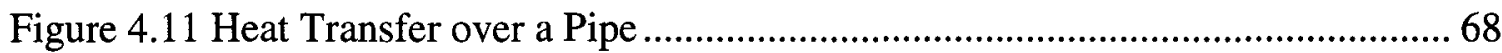

Figure 4.12 Flow Diagram for Determining Condensation Onset...................................... 70

Figure 4.13 Nodes Used in the Full System Analysis .................................................... 76

Figure 4.14 Flow Diagram of Full System Analysis ...................................................... 77

Figure 4.15 MATLAB Output to Excel (excerpt) …………………………………..... 78

Figure 5.1 Rotor Mesh (Output Pressure in MPa) ………….......................................... 80

Figure 5.2 Results of Power Loss Estimation .................................................................. 82

Figure 5.3 Compressor Pressure Ratio vs. Compressor RPM ........................................... 83

Figure 5.4 Predicted Effect of Vane Lubrication on Compressor Power Loss................. 84

Figure 5.5 Predicted Effect of Rotor End Face Clearance on Power Loss ........................ 84

Figure 5.6 Effect of RPM on Volumetric Efficiency, $\mathrm{h}_{0}=25$ microns .............................. 85

Figure 5.7 Power Loss vs. RPM for Improved End-Face Clearance................................ 86

Figure 5.8 The Evaporator Cooling Load's Effect on COP, Experimental ...................... 90

Figure 5.9 COP vs. RPM at Evaporator Chamber Temperature of $40^{\circ} \mathrm{C}$......................... 91

Figure 5.10 COP vs. RPM at Evaporator Chamber Temperature of $60^{\circ} \mathrm{C}$....................... 92

Figure 5.11 Evaporator Temperature vs. RPM................................................................ 93

Figure 5.12 Cooling Load vs. RPM at Evaporator Chamber Temperature of $40^{\circ} \mathrm{C}$......... 94

Figure 5.13 Compressor Inlet Quality vs. RPM ……………………......................... 94

Figure A.1 Pseudo Steady Analysis............................................................................ 103

Figure A.2 Vane Tip Pressure Resolution ................................................................... 115

Figure A.3 Rotor Spining Viscous Losses.................................................................. 117 


\section{Nomenclature}

$a$

$A, B, C, Z$

Ac

$A p$

Area

COP

$C p$

Cst

$d$

Dsp

$f$

E

F

G

$h$

$h^{*}$

ho
Acceleration

$\mathrm{m} / \mathrm{s}^{2}$

Defined constants

Cross-sectional area

Perimeter or surface area

Area in chamber between two vanes

Coefficient of performance

Specific heat at constant pressure

Orifice constant

Diameter

Compressor displacement per vane chamber

Friction factor

Energy

Force

Mass fluxrate

Specific enthalpy

Vane height

End-face clearance $\mathrm{m}^{2}$

$\mathrm{m}^{2}$

$\mathrm{m}^{2}$

$\mathrm{J} / \mathrm{kg} \cdot \mathrm{K}$

$\mathrm{m}$

$\mathrm{m}^{3} /$ vanes

J

$\mathrm{N}$

$\mathrm{kg} / \mathrm{m}^{2} \cdot \mathrm{s}$

$\mathrm{kJ} / \mathrm{kg}$

$\mathrm{m}$

$\mathrm{m}$

xii 
Geometry loss or Expansion valve constant

Vane length

$\mathrm{m}$

Lo

Channel length

m

$m$

Mass

$\mathrm{kg}$

$\dot{m}$

Mass flowrate

$\mathrm{kg} / \mathrm{s}$

$N$

Mesh size

$p$

Pressure

$\mathrm{Pa}$

$P$

Power

W

$\operatorname{Pr}$

Prandtl number

$\dot{Q}$

Heat transfer rate

$\mathrm{J} / \mathrm{s}$

$r$

Radius

m

$R$

Fixed radius

$\mathrm{m}$

$\mathrm{Re}$

Reynolds number

$R P M$

Compressor speed: revolutions per minute

$\mathrm{rev} / \mathrm{min}$

$s$

Specific entropy

$\mathrm{J} / \mathrm{kg} \cdot \mathrm{K}$

$T$

Temperature

K

$\vec{T}$

Torque

$\mathrm{N} \cdot \mathrm{m}$

$u$

Convective heat transfer coefficient

$\mathrm{W} / \mathrm{m}^{2} \cdot \mathrm{K}$

$U$

Overall heat transfer coefficient

$\mathrm{W} / \mathrm{m}^{2} \cdot \mathrm{K}$

$v$

Volume

$\mathrm{m}^{3}$

xiii 
Vane width

$\mathrm{m}$

wo

Channel width

m

$x$

Quality

$x x$

Cartesian dependent variable

$y$

Cartesian independent variable

$z$

Number of vanes

vanes

\section{Greek}

$\gamma$

$\varepsilon$

$\eta$

$\theta$

$\mu$

$v$

$\rho$

$\sigma$

\section{Subscript}

1

2
Specific heat ratio

Surface roughness height

$\mathrm{m}$

Efficiency

Vane location angle

$\operatorname{rad}$

Viscosity

$\mathrm{Pa} \cdot \mathrm{s}$

Coefficient of friction

Density

$\mathrm{kg} / \mathrm{m}^{3}$

Surface tension

$\mathrm{N} / \mathrm{m}$ 
Vane tip

B

Back

$b$

Boiling

Bear

Bearing

$c$

Carnot

comp

Compressor

cond

Condenser, Condensation

$c p$

Centrifugal

cr

Coriolis

cv

Compressor vane

$e v$

Expander vane

evap

Evaporator

$\exp$

Expander

$f$

Friction

fg

Liquid -vapour

$g$

Gravitational

H

High pressure vane side

$i$

Inner

$i b$

Incipient boiling

id

Ideal

in

Inlet

$\mathrm{XV}$ 


\begin{tabular}{|c|c|}
\hline$l$ & Liquid \\
\hline$L$ & Low pressure vane side \\
\hline loss & Property loss \\
\hline$m$ & Mean \\
\hline$n$ & New \\
\hline$N$ & Normal \\
\hline oil & Oil \\
\hline$O R$ & Outlet orifice \\
\hline$o$ & Outer \\
\hline out & Outlet \\
\hline$p$ & Previous \\
\hline$P$ & Pipe \\
\hline$r$ & Radiation \\
\hline rel & Relative \\
\hline$R F$ & Rotor face \\
\hline sat & Saturated property \\
\hline st & Static \\
\hline$s u b c$ & Subcooled \\
\hline th & Thermal \\
\hline$t l$ & Torlon \\
\hline$v$ & Vapour \\
\hline$v c$ & Valve closed \\
\hline
\end{tabular}

$\mathrm{xvi}$ 
Valve opened

Wall

$\mathrm{x}$-coordinate property

y-coordinate property

Surrounding

xvii 


\section{Chapter 1: Introduction}

Refrigeration and space cooling have become a critical aspect of today's industrialised society. In conditioning the quality of the air in a fixed living space or preserving food to allow for overseas transportation, refrigeration technology is vital. However, the associated environmental side effects and energy consumption are of growing concern. It is no surprise then that there is room for economically viable improvements to the systems currently used across the globe. The industrial incentive drives towards the search for more environmentally friendly and energy efficient solutions to current technology. This means that reducing system losses, recovery of waste energy and reducing emissions are paramount. Some of these possibilities for improvement serve as the working basis of this thesis.

\subsection{Need for Energy Efficiency}

In 1928, General Motors Research Laboratories (GMCL) publicly announced the synthesizing of the first chlorofluorocarbon (CFC), Dichlorodifluoronethane (R-12), which was a significant improvement from the refrigerants that preceded it such as propane and ammonia and methyl chloride [1]. These refrigerants were either directly toxic to humans or very flammable. Not surprisingly, in the 1930's the first burst in air conditioning equipped cars occurred as the GMCL devised a concept for a vehicle 
mounted vapour compression refrigeration system. The working refrigerant for this pioneering system was R-12 and the estimated cooling load of about 200 BTU per minute [1]. The 1940's and 1950's saw a rapid increase in the use of automobile air conditioning although still only available to affluent persons and usually came as an add-on to the car. In the 1960's HVAC (Heating, Ventilating and Air Conditioning) systems started to become a standard equipment in vehicles. At about the 1980's period, approximately half the cars in the US were equipped with reliable air conditioning systems and by 1994 only $1 \%$ of cars did not have a HVAC unit. In fact a car without a HVAC unit today has to be specially ordered. In addition to the drastic increase in the application of automotive air conditioning, the cooling capacity has also more than doubled from the initial 1930 estimate [2].

In spite of these improvements in demand and performance of air conditioning systems it is still necessary to improve the efficiency of the system. Inclusions such as liquid line-suction line heat exchangers (LLSLHX) and expanders to recover throttling work are applied in several refrigeration industries. Accumulators and receivers are also seen to improve the system performance and are widely applied in car systems. The main stumbling block to installing the LLSLHX and expanders is space limitations. In recent years several researchers have sacrificed effort into solutions for these issues [3], [4].

\subsection{Environmental Considerations}

It is now the norm to consider the effect that any machine has on the environment. Many international conferences have been held to discuss regulations that would help ensure that the environment is not neglected in favour of human comfort. Prior to the 1930's 
most of refrigerants that were used were toxic to humans or easily combustible in air such that leaks were very deadly. In 1928 the development of the first CFC for a vapour compression cycle resulted in the ousting of the other refrigerants. Over the years more CFCs, HCFCs and HFCs were developed. As realization of CFCs detriment to the environment became imminent, the consideration of alternate refrigerants increased. In the 80's R-134a - an HFC - was decided to be the ideal replacement for the CFCs since HFCs do not have the ozone depletion capabilities. The 1990 Montréal protocol proposed the ousting of CFCs before 2000 and has been largely successful. However new movements are calling for a steady ousting of R-134a. Although R-134a is not an ozone depleting chemical, it is a greenhouse gas with over a thousand times the global warming potential of carbon dioxide [5].

More research attention now goes towards the use of carbon dioxide and some other refrigerants as the working refrigerants in air conditioning systems.

\subsection{Objectives of Thesis}

Work on carbon dioxide systems has shown the importance of energy recovery from the expansion process. However, this energy recovery can be applied any system regardless of the working refrigerant. As interest in recovering energy has increased, several researches have studied various possible designs for expanders. This research work mainly aims to investigate the feasibility of a compact sliding vane compressor-expander for automotive air conditioning. The overall objectives of this thesis can be summarized as follows: 
- Investigate the performance of a current prototype of a sliding vane compressorexpander for automobiles.

- Develop a mathematical model that predicts the mechanical behaviour of the compressor-expander as well as the thermodynamic process experienced by the fluid inside it.

- Predict and implement possibilities for improvements to the compressorexpander.

- Analyze the overall refrigeration system with the compressor-expander both theoretically and experimentally.

\subsection{Thesis Organization}

This thesis presents studies of analytical and experimental investigations on a vapour compression refrigeration cycle with energy recovery features.

Chapter 1 Introduction: this chapter introduces the refrigeration concept and provides some background for the motivation of this research work.

Chapter 2 Background and Literature Review: this chapter gives some technical background into the mechanics of refrigeration cycles and discusses the components. It then discusses several research findings on different designs for compressor-expanders.

Chapter 3 Experimental Setup: this chapter discusses the details of the experimental arrangement. A discussion of the loop and each component is included as well as the system's measurement and signal processing. 
Chapter 4 Theoretical Analysis: in this chapter a theoretical framework is presented for modelling the compressor-expander as well as for an overall refrigeration system model. In the overall system model each component is separately modelled and then integrated together.

Chapter 5: Results and Discussion: A discussion of experimental and theoretical analyses is presented in this section. The compressor-expander model is discussed and compared with the experiments. The full loop analysis is then presented.

Chapter 6: Conclusion and Recommendations: The thesis is summarized in this section and recommendations for future improvements and alternate directions worth investigating are proposed. 


\section{Chapter 2: Background and Literature Review}

Significant effort has gone towards improving refrigeration and air conditioning (A/C) systems over the years. This includes addition of new components and exploration of alternate refrigerants. To tackle these subjects it is imperative that a basic understanding of the underlying conventional refrigeration system is acquired.

\subsection{Fundamentals of the Conventional Vapour Compression Cycle}

There are four essential components necessary for implementing a vapour compression cooling process. These are the compressor, condenser, expansion device and evaporator. 


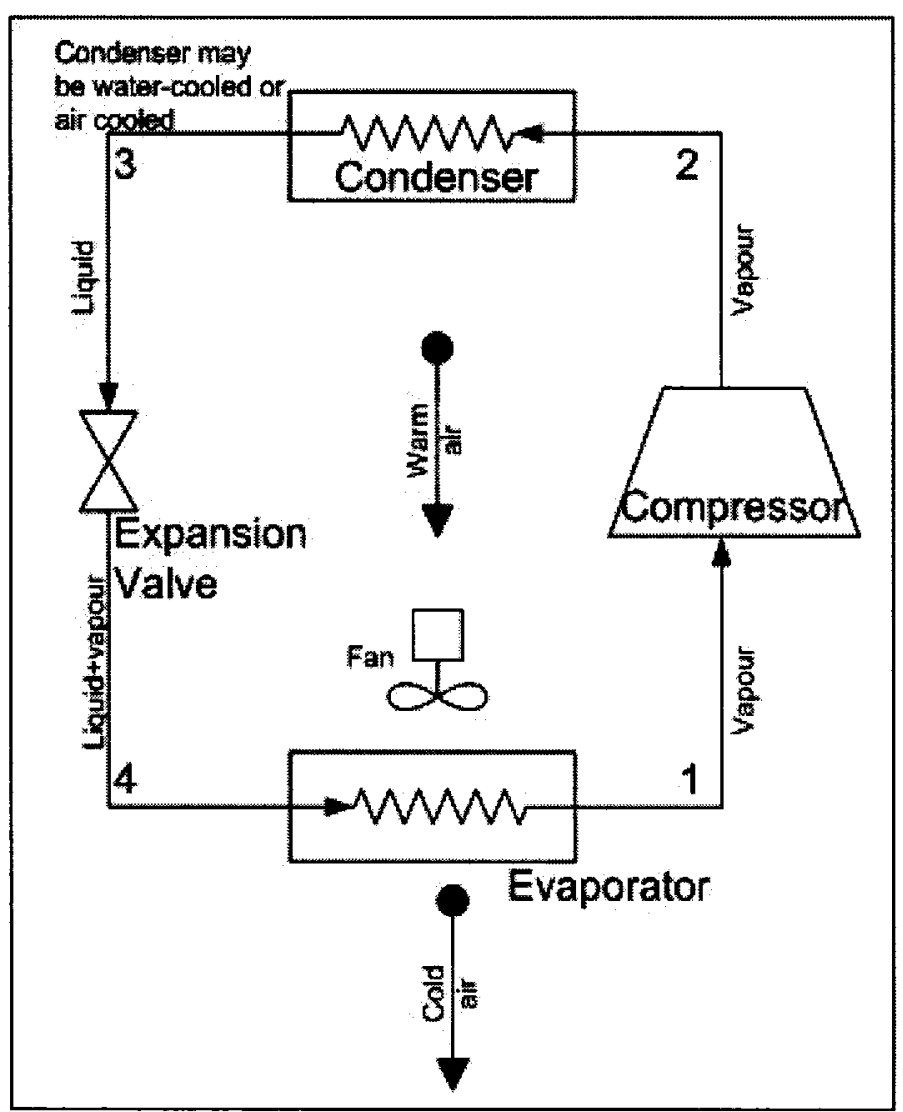

Figure 2.1 Typical Single-Stage Vapour Compression Refrigeration Cycle [6]

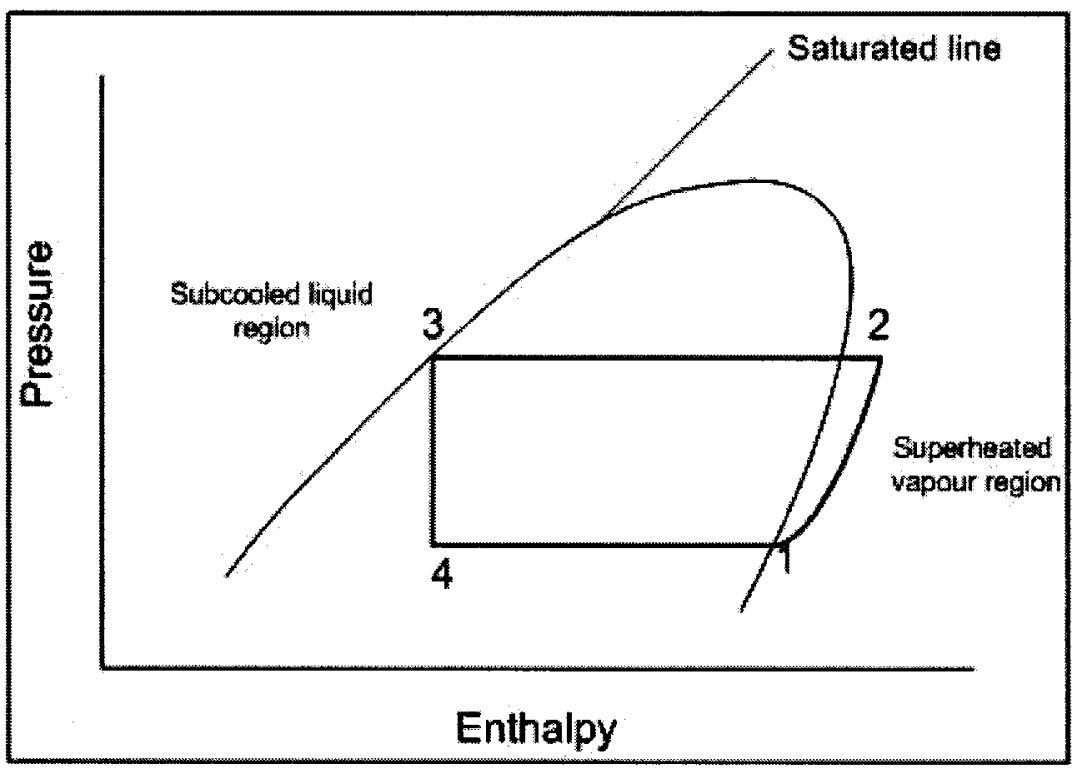

Figure 2.2 Pressure-Enthalpy Diagram for a Vapour Compression Cycle 
Figure 2.1 shows the refrigerant loop and the order in which the refrigerant flows through the components. Figure 2.2 is a representation of the pressure-enthalpy diagram of the system. Ideally we would have isentropic compression between states 1 and 2 followed by isobaric condensation between states 2 and 3 . This is then followed conventionally by an isenthalpic expansion (meaning no energy transferred to and or from the fluid) and then an isobaric evaporation. The energy transferred within any stage is the product of the mass flowrate and change in enthalpy. Using the convention of positive energy as the energy being transferred into the fluid, the compressor work is then defined as:

$$
P_{\text {comp }}=\dot{m}\left(h_{2}-h_{1}\right)
$$

And the cooling capacity, which represents the rate at which heat is removed from the space being cooled, is defined as such:

$$
\dot{Q}_{\text {evap }}=\dot{m}\left(h_{4}-h_{3}\right)
$$

The heat exchange from the condenser is given by

$$
\dot{Q}_{\text {evap }}=\dot{m}\left(h_{3}-h_{2}\right)
$$

And the energy transferred in the expansion stage is given by Equation (2.4)

$$
\dot{E}=\dot{m}\left(h_{4}-h_{3}\right)
$$

As shown in Figure 2.2 most of the processes occur within the perimeter of the saturated line. This region is a two phase region in which boiling and condensation take place and in which liquid and gas coexist at equilibrium. This region preferred for heat transfer because the boiling and condensation heat transfer coefficients are very high. 


\subsubsection{The Compressor}

The compressor takes in low temperature (usually just below the temperature of the space being chilled) and low pressure refrigerant. At this point the refrigerant may be either superheated or an almost-dry saturated fluid (i.e. quality is close to unity). After the compression process, the refrigerant becomes superheated and at a high pressure and temperature.

The car's engine drives the compressor via a clutch system to allow for easy engagement and disengagement of the compressor from the drive source. The discretion by which the system is regulated is usually an automated control system. The most common types of compressors available in the car industries are the crankshaft reciprocating compressors, the swash plate reciprocating compressors, scroll compressors and the rotary vane (or sliding vane) compressors [7]. When operating the $\mathrm{A} / \mathrm{C}$, there will usually be a small amount of moisture free refrigerant oil used for lubricating the compressor as well as other seals gaskets and valves. Some of this oil is retained in the compressor while the rest cycles around with the refrigerant. The presence of oil does affect the overall performance of the refrigeration system as discussed by Wang and Gu [8] and Wang et al. [9].

\subsubsection{The Condenser}

The condenser intake consists of the superheated refrigerant that exits the compressor. The condenser's function is to liquefy this gas (ideally without any pressure loss). The final output of the condenser may be subcooled liquid, saturated liquid or low quality-two phase fluid. In the automobile, the condenser is usually mounted in front of the engine 
cooling radiator to ensure that there is adequate cooling air supplied. It is not uncommon for a fan to be mounted which can be cycled on and off when the car speed is not adequate to ensure proper condensation. The most common heat exchange design for the condenser is the fin tube arrangement. Most recently, finned micro-channel structures have been developed for systems using carbon dioxide as a refrigerant

\subsubsection{The Expansion Device}

Expansion devices, commonly referred to as metering devices or throttling devices, Transform high temperature and pressure fluid into lower temperature and pressure fluid. This expansion leads to a reduction in the pressure of the liquid as well as some evaporation of the liquid to form a two phase fluid. Two common expansion devices used in automotive air conditioning are the Thermostatic Expansion Valve (TXV) and the orifice tube or capillary tube. The TXV system regulates the mass flow to the evaporator and the corresponding pressure drop is based on this mass flow. In general a sensor detects the evaporator temperature and adjusts a needle valve in the TXV accordingly. Conversely the capillary tube system provides an almost constant flow resistance (coefficient) to the fluid, and mass flow is regulated by compressor cycling.

\subsubsection{The Evaporator}

The evaporator is the component that dehumidifies and cools the air. In the evaporator, two phase refrigerant is boiled. Ideally this boiling will occur without any drop in pressure. The energy required for boiling is absorbed from an external source. In automotive refrigeration the energy source is provided by air that is vented into the 
passenger compartment. Most designs require a fan or blower to force the air through the evaporator fins and to the subsequent vents leading to the car interior. The design is usually similar to that of the condenser except much denser and thicker to ensure a better heat transfer efficiency.

\subsection{Some Additions to the Conventional Cycle}

In the air conditioning industry, other components that improve the system efficiency or serve other functional purposes are commonly added to the system. Some additions are discussed in this section.

\subsubsection{The Accumulator}

It is not uncommon in automotive air conditioning to use a low side accumulator located between the evaporator outlet and the compressor inlet. The accumulator separates the liquid from the vapour in the flow coming out of the evaporator. The construction usually consists of a J-tube design with a bleed hole on the bottom of the J-tube as shown in Figure 2.3. This hole allows oil and some liquid refrigerant to go to the compressor for lubrication purposes. The main function is to protect the compressor from excess liquid that may cause damages. The deflector ensures that only gas enters through the inlet of the J-tube. 


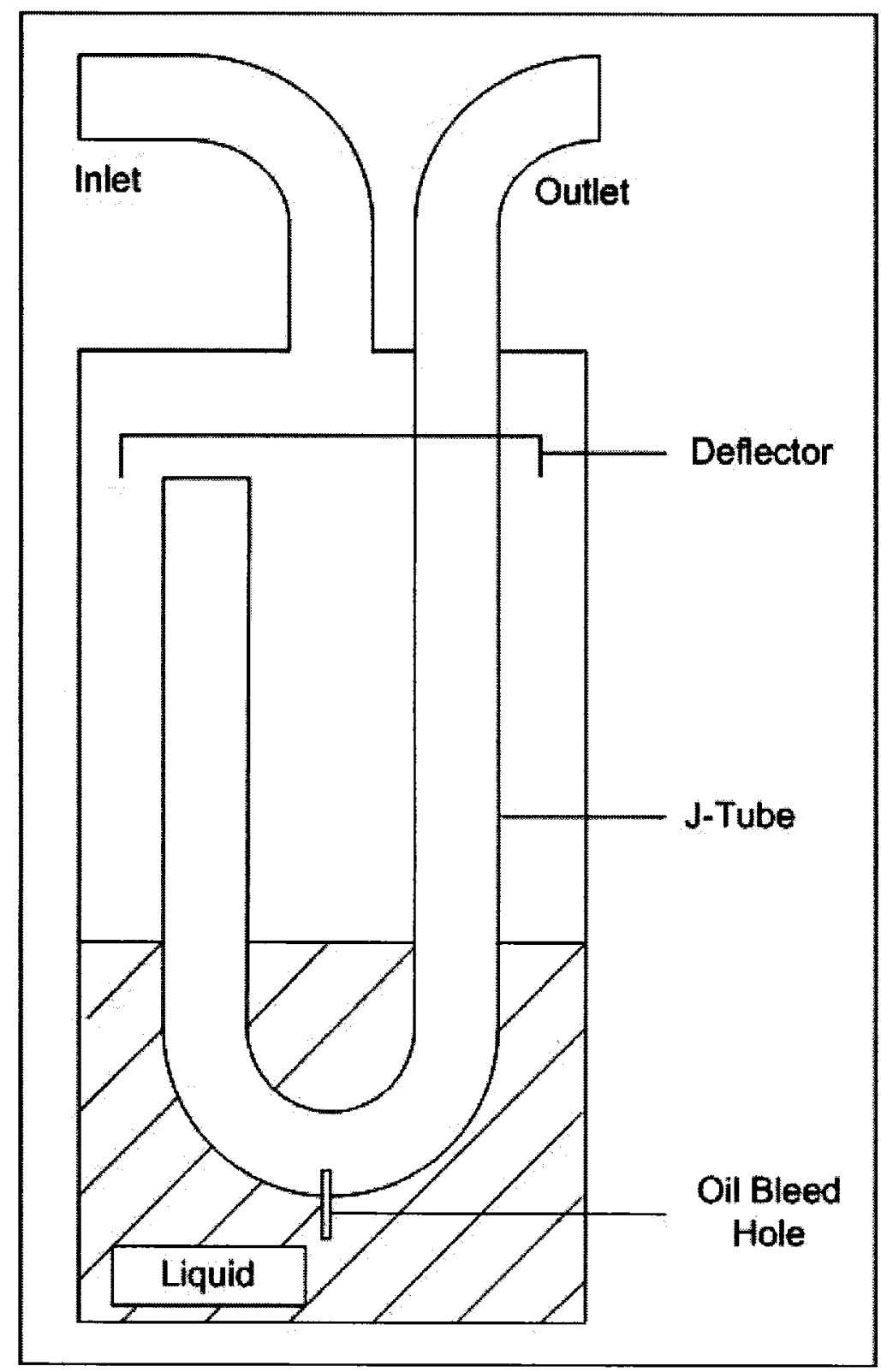

Figure 2.3 A Schematic of the J-tube Accumulator [10]

Other functions of the accumulator are to provide a measured amount of oil for compressor lubrication, act as a storage device for excess liquid refrigerant as well as filter out impurities and moisture from the refrigerant. 


\subsubsection{The Receiver-Drier}

The general idea of the receiver-drier (sometimes simply referred to as the receiver) is similar to that of the accumulator in the sense that it separates vapour from liquid, and serves a lot of the same functions. However the principal difference is in the location of the unit. The receiver-dryer is located between the condenser and the expansion valve. The main function of the receiver-drier is to remove moisture from the system as well as store extra refrigerant. Moisture running in the system may have a tendency to form ice and potentially block the expansion valve orifice thereby impeding the flow of the refrigerant. A silica gel agent is most commonly used in automobiles as the filtering agent as shown in Figure 2.4. It is also common to have a relief valve installed in the receiver to protect the system against extreme pressure conditions [11]. 


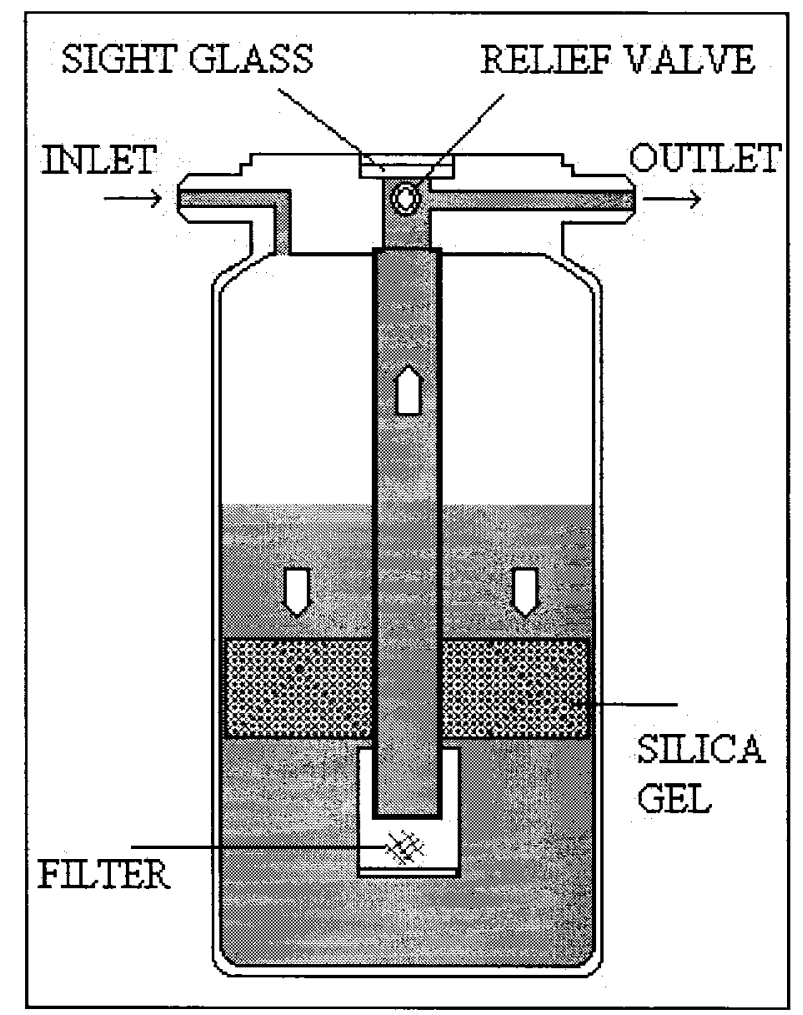

Figure 2.4 Schematic of a Typical Receiver-Drier [11] (modified)

\subsubsection{The Liquid Line Suction Line Heat Exchanger (LLSLHX)}

A heat exchanger may be placed between the liquid line (after the condenser) and the suction line (before the compressor), in order to improve efficiency. With reference to Figure 2.2, this occurs between fluid from state 3 and state 1 . Sometimes this device may simply be referred to as an internal heat exchanger (IHX). When the refrigerant coming out of the evaporator is not dry, the LLSLHX serves a purpose of drying the refrigerant before it enters the compressor - this may lead to superheating of the refrigerant as well. Having the refrigerant dry at the compressor inlet prevents compressor damage as most compressors are poor in dealing with liquids. Proper design employment of the IHX will result in higher COP. Figure 2.5 shows the thermodynamic adjustment of a typical cycle 
when an internal heat exchanger is introduced. Due to the superheated condition at the compressor inlet, the mass flowrate of the overall system is reduced. This is because the inlet density is reduced hence the overall mass flowrate will also be reduced (see Equation (3.4)). The IHX system also features higher evaporating temperature, resulting from additional pressure losses due to the inclusion of the heat exchanger. Also as depicted in Figure 2.5, the enthalpy increase over the evaporator section is larger for the IHX. This leads to a larger cooling capacity if the increase in the enthalpy difference

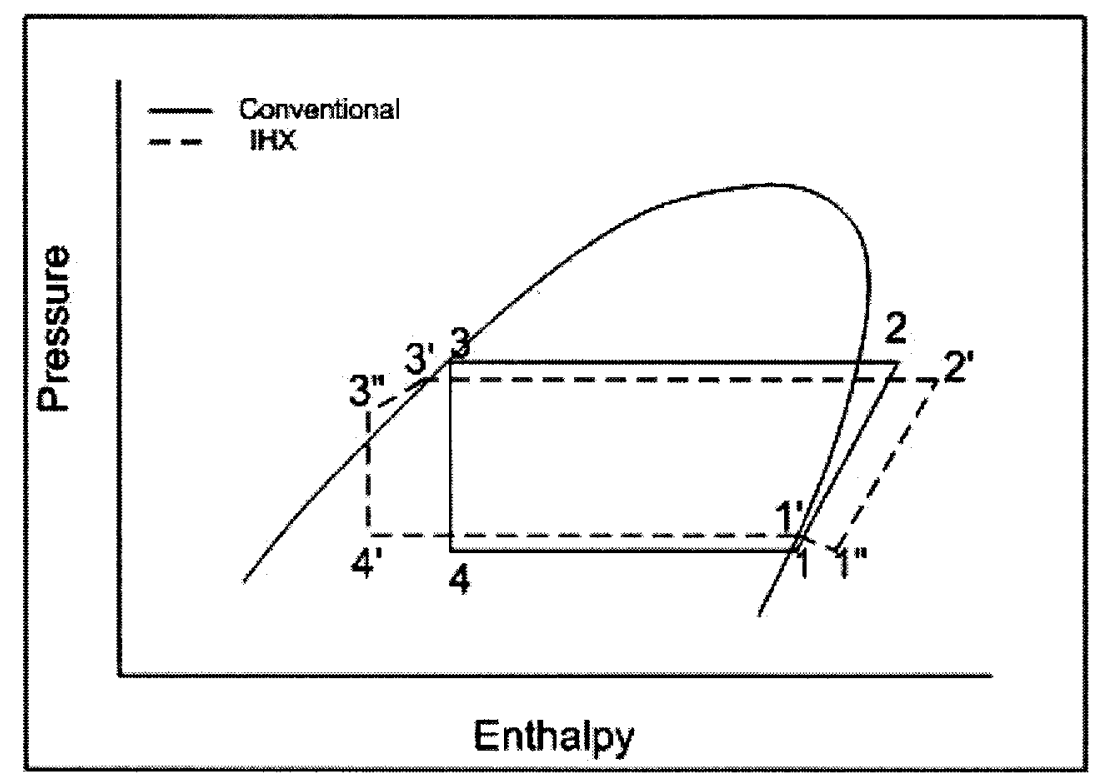

Figure 2.5 Presure-enthalpy Diagram of IHX System [12] (modified)

outweighs the reduction in mass flowrate. The decrease in pressure between 1' and 1" and between 3' and 3" is due to pressure drop incurred by the heat exchanger. Unfortunately LLSLHX usually increase the bulk of the overall cycle components significantly and is therefore not a very common choice in automobile $\mathrm{A} / \mathrm{C}$ systems [12]. 


\subsubsection{The Expander}

The expander is different from the expansion device in that it recovers energy while reducing the pressure and temperature of the refrigerant. It is located in a similar position to the expansion device and may be used parallel to, in series with or instead of an expansion device such as a capillary tube or the TXV. As the inlet quality to the expander goes down, its efficiency reduces. This inefficiency is due to the fact that a gas is more readily expanded than a liquid. Useful work is then more easily recovered in gas expansion. For this reason the expander is more useful in the $\mathrm{CO}_{2}$ systems since part of the expansion in these systems happens in the supercritical zone. Fluids in the supercritical zone have both gaseous and liquid characteristics. The expansion property of $\mathrm{CO}_{2}$ in the supercritical zone is closer to the gaseous behaviour hence energy is easily recovered from expansion. Through a mechanism, this recovered energy is normally used to provide a portion of drive required for the compressor in the same system. This can be done through direct mechanical linkage to the compressor or via an electrical generator that feeds the compressor motor.

\subsection{Main Types of Automobile A/C Systems}

Aside from spatial restrictions, the automotive $\mathrm{A} / \mathrm{C}$ systems possess some unique challenges that differentiate them from other conventional systems. Due to the direct coupling of the compressor to the engine, the speed of the compressor and hence the operating condition of the system is directly related to the car speed. In practice the automobile speed will change constantly hence the operating system of the $A / C$ will also constantly change, if not regulated. 
The two systems commonly used in automobile air conditioning are the Thermal EXpansion Valve system (TXV) and the Clutch Cycling Orifice Tube system (CCOT). A schematic of the CCOT system is shown in Figure 2.6 The CCOT system controls the amount of space cooling by cycling the compressor on and off.

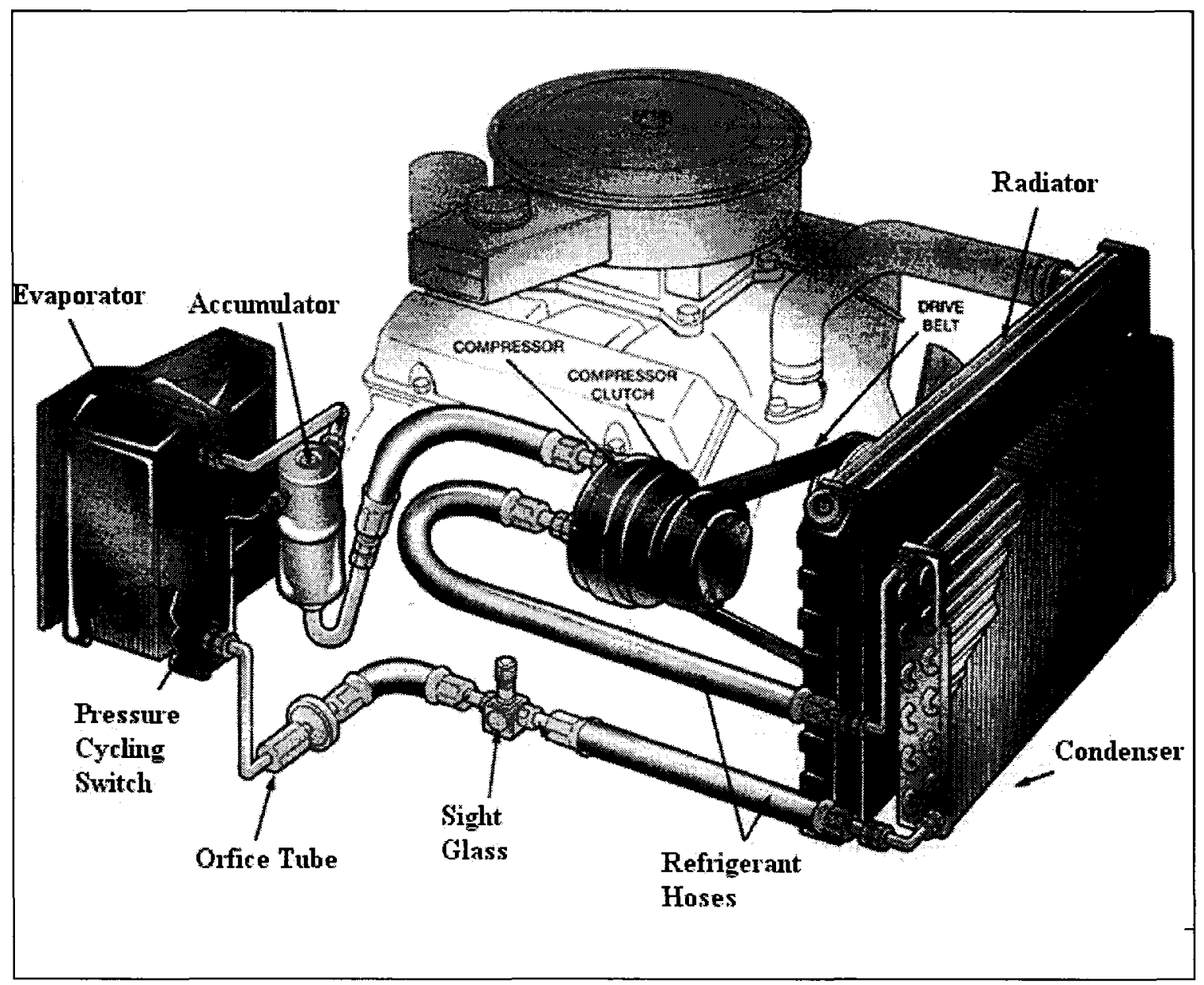

Figure 2.6 A Typical CCOT System [13]

Automobile A/C systems are designed to give reasonable cooling effect when operating at low speeds. Hence, at high speeds the cooling effect may become overwhelming and cause ice formation on the surface of the evaporator. This will reduce the effectiveness of the heat exchange and may also damage the evaporator. The system 
load is hence controlled as the compressor is cycled on and off through a sensory system. In the CCOT system, an orifice tube or capillary tube and an accumulator are the preferred components to integrate into the system. The TXV system utilizes a ReceiverDrier rather and a Thermal Expansion valve to regulate the flow of the refrigerant to the evaporator. The orifice in the expansion is calibrated to allow just enough mass flowrate to obtain the desired cooling effect.

\subsection{Mechanism of the Vane Compressor}

The vane compressor is usually chosen over other compressors for its simple design (hence low cost) and its relative low noise during operation. A representation of the vane compressor is shown in Figure 2.7. As the compressor rotates, the vanes slide in and out of the slots creating chambers of fluid. The mass of fluid at the point where the chamber is closed to the inlet port is the working mass of the compressor. As the rotor rotates from the inlet towards the outlet of the compressor, the volume of the chamber decreases and hence the fluid in the chamber is compressed. In the unbalanced vane compressor design, there will be an unbalanced force on the vane shaft due to the locations of the inlet and outlet ports. Since all the pressure on the outlet half of the shaft will be higher than that on the inlet half there will be a net force constantly pushing the rotor and the drive shaft towards the inlet section. This unbalanced load is reduced in the balanced vane compressor design where the outlet and inlet ports are exactly opposite each other. 


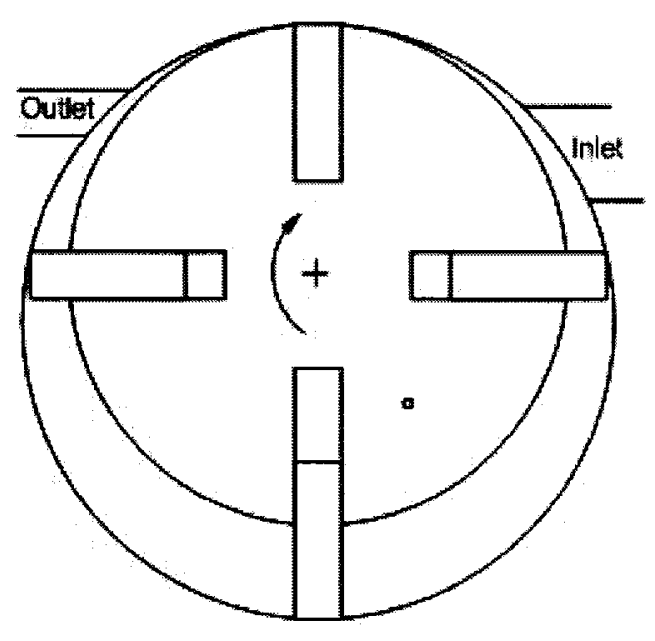

Unbalanced

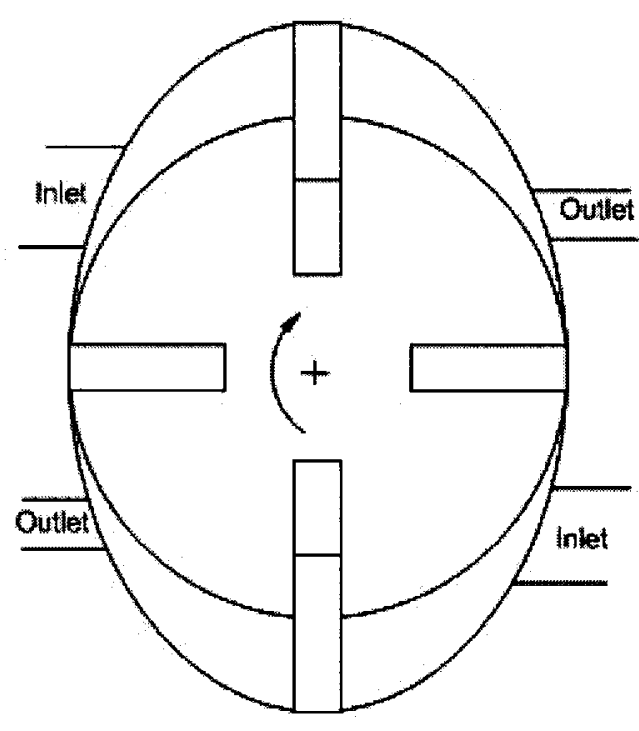

Balanced

Figure 2.7 Schematic of a Balanced and Unbalanced Vane Compressor

\subsection{Review of Compressor-Expander Designs and Cycles}

In the past few years several works have been done on analyzing compressor-expander systems. There are almost as many designs for compressor-expanders as there are compressors designs in the refrigeration industry. The most attractive area of application so far is the carbon dioxide based refrigeration systems.

Kim and Ahn [14] investigated the design and performance of a scroll expander for a carbon dioxide system both experimentally and analytically. Where possible they compared the performance of their system to that of a sliding vane operated system. The attractive feature of the scroll expander is that there is no direct path between the high and low side pressure chambers unlike the vane design. This gives more resistance to fluid leaking from the outlet to the inlet of the compressor. However the geometry of the 
scroll expander is complex leading to significant mechanical losses. A theoretical and experimental analysis was done on the system. The system was able to achieve $80 \%$ volumetric efficiency and $55 \%$ overall efficiency. The concept of using a scroll expander was thus proven and poor results in overall efficiency were attributed to poor manufacturing processes. It is worthy of note that when testing the expander it was decoupled from the compressor. This allows for the options of running the system with and without the expander, however in an integrated system the leakage model will change [14].

Huff and Radermacher [15] discussed the improvements that adding a $\mathrm{CO}_{2}$ expander had on the system and also compared its performance to an R-22 system operating at the same conditions. The $\mathrm{CO}_{2}$ system's $\mathrm{COP}$ was up to $43 \%$ less than that of the $\mathrm{R}-22$ system depending on the ambient conditions. This result is improved when the expander is attached to the system. At conditions below $30^{\circ} \mathrm{C}$ the $\mathrm{CO}_{2}$ system performs $16-27 \%$ better than the R-22 system and $11 \%$ worse at $45^{\circ} \mathrm{C}$. Equal performance in both systems is observed at about $36^{\circ} \mathrm{C}$ ambient temperature. Three compressor-expanders were used in getting these results: A rotary piston, reciprocating piston and scroll compressor. The performances of these compressors are not directly compared due to different mechanical and volumetric efficiencies based on manufacturing processes. However, the scroll expander performed an average of $13 \%$ worse than the other two piston compressors (which displayed similar performance). The performance of the scroll compressor depreciated significantly with increased rotational speed. In addition to these it was also reported that a LLSLHX did not have any noteworthy effect on the overall system. The 
analysis was largely analytical with considerable modelling data taken from other author's experimental results [15].

An extensive analysis of a balanced rotary vane compressor-expander was carried out by Fukuta et al. [16], with carbon dioxide as the working refrigerant. Since the system is coupled, the speed of the compressor and expander will be necessarily the same and hence the expansion efficiency will only be optimum at one design speed. Since the output mass flowrate of the compressor depends on its inlet conditions and the RPM, the massflow going into the expander remains uncontrolled. This means that unless there is a control system that regulates the mass flow into the expander, the expander will always operate at a non-optimum design point. The option of using a parallel (bypass) arrangement with an expansion valve was hence explored. It was discovered that since the expander chamber works at optimum performance when only at certain mass flow and pressures the bypass system improved the system performance. The bypass is set to give the expander the required mass flow based on the input pressure. The experiment was performed using the TXV arrangement. It was seen that the bypass system offered a $30 \%$ improvement at high cooling loads and negligible to no improvement at lower cooling loads. The cycle with the expander had a COP that was 1.5 times that of the cycle when the expander was completely bypassed [16].

A proposal for a decoupled system with a generator attached to the expander is explored by Hiwata et al. The generator, run by the expander power, feeds the compressor motor and the only losses experienced would be line losses. Also a cycle where the expander drives the first stage of a two stage compression process was also 
experimentally investigated. Hiwata et al. [17] found that on average (averaged over design and off design conditions) the two stage setup worked best, working $2 \%$ better than the direct one stage system, $4 \%$ better than the generator system and $16 \%$ better than a system without an expander. At the rated condition all machines performed within $1 \%$ of each other. It was found that the generator was only adequate for heat pump cycles yielding a $5 \%$ better coefficient of performance when compared to the other cycles.

A screw compressor-expander was experimentally tested with R-134a by Brasz [18]. A 6\% improvement in the cycle COP was observed when the expander was integrated. The system was arranged differently from most compressor-expander systems. Figure 2.8 shows a schematic of the system. Flash gas from the expansion process is recompressed and sent back to the condenser inlet. This increases the cooling effect and hence the performance of the system. The biggest detractor to the compressor-expander performance was found to be liquid entrainment into the compression chamber from the expander chamber. A $20 \%$ leakage rendered the machine only $35 \%$ efficient in recovering energy and also meant some liquid was fed to the condenser inlet [18].

Already implemented in industry is Brasz's proposal for expander incorporation into cryogenic applications that use R-134a [19]. 


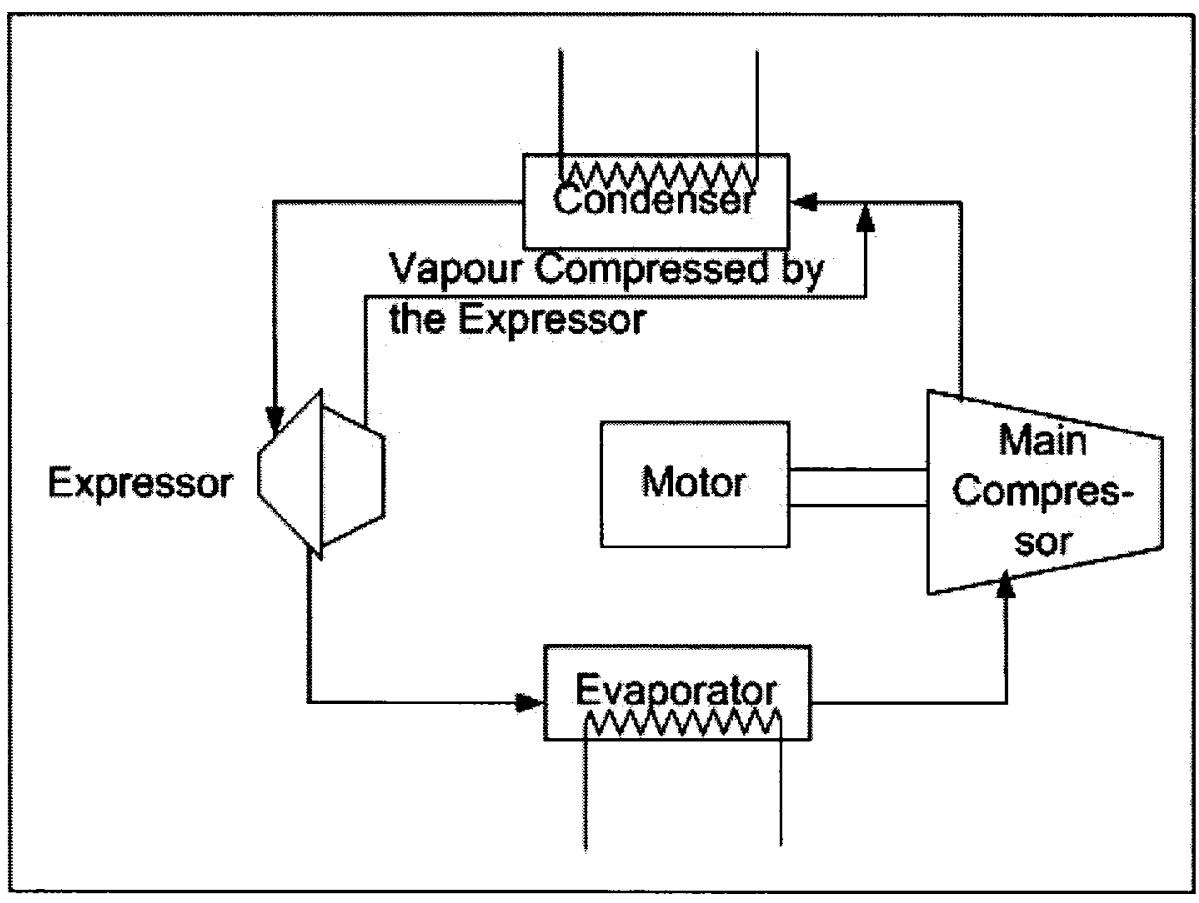

Figure 2.8: Expressor Flow Diagram by Brasz [18]

Driver and Davidson [20] investigated both the $\mathrm{CO}_{2}$ and $\mathrm{R}-134 \mathrm{a}$ cycles using hingedvane positive displacement compressor-expanders. One aim was to explain the reason why the compressor-expander was so much more efficient in the carbon dioxide than the R-134a cycle. Operating at normal outdoor summer conditions, the expander would have to be approximately five times the size of the compressor to process the same mass flow in an R-134a system. For a carbon dioxide this ratio is below two. The improvement in COP for $\mathrm{CO}_{2}$ run cycles was $41 \%$ when the expander was included and only $23 \%$ for the R-134a system. The system shown in Figure 2.8 is a setup that can be used to overcome the problem of unequal volumes required for compression and expansion. The attractiveness of the expressor arrangement is that it is self contained and simple to 
introduce into the current market. However it does increase the size and cost of the system [20].

Nickl et al. [21] discussed the applications of a three stage expander and two stage compression system with the expander's work running the second stage of compression. The improvement in performance of the cycle was found to be higher than $50 \%$ (compared to a cycle that only has throttling) while efficiency of the expansion system was improved by incorporating a separator between the second and third expansion process. Including a separator between the second and first expander also improved the coefficient of performance but not to a degree that would justify such an inclusion [21].

Henderson et al. [22] theoretically analyze the heating process using R-410a as the working refrigerant. A novel vane compressor design was used involving one chamber with a wall separating the compressor and expander side. The heat transfer between the compressor and expander side was found to significantly affect the performance of the compressor. This stressed the importance of having a good seal between the compressor and expander sections. In addition they also attempted a system where all the gas in the two phase mixture was recompressed by a compressor coupled to the expander and sent to the condenser while a "main" compressor compressed the flow out of the evaporator. Although exact figures are not presented, success is claimed in improving the COP of the R-410a run system [22].

Unlike most carbon dioxide based system analyses done prior to their work, Stosic et al. worked on balancing the pressure transferred to the machine's axle for proper operation of a screw expander. Focus is placed on the improvements a compressor- 
expander system can incur with improvements in the mechanical efficiency of the compressor-expander itself. In $\mathrm{CO}_{2}$ systems, the operating pressure is 2-4 times higher $\mathbf{n}$ that experienced in the R-134a systems widely used today. For this reason the mechanical design of the compressors would necessarily have to be more refined. In addition to the high gauge pressures experienced, there is also the high pressure difference the compressor must output. Since the screw expander has no direct path between outlet and inlet, leakage is somewhat minimal when compared to other compressor designs but still significant enough that manufacturing precision is a key to good efficiency. A design is presented in which the loads on the axle are partially balanced by the compressor and expander "chamber" pressures. This balance also prevents bending in the machine and hence the leakage across gaps is kept minimal [23].

It is later discussed that the main improvement due to the pressure balancing is in preventing leakage and thereby improving volumetric efficiency. The result of this system is an improvement in the COP of the overall system as well as a more efficient expansion so that it could accommodate bigger cooling loads [24].

\subsection{Review of Vane Compressor Modelling}

The mechanism of the sliding vane compressor has been modelled by several authors with unique approaches over the years. Of interest is usually the pressure in the chamber as a function of inlet conditions. The power loss due to the vanes sliding, bearing losses and leakage from high side to low side as well as volumetric efficiency are also of some interest. 
Li et al. [25] discussed designing the geometry of the casing's contour to ensure efficient sliding effect of the vanes. The forces on the vane were related to the geometry of the casing and hence could be minimized by a simple optimization analysis. However rather than doing an optimization analysis, three different geometries are analysed to see which would give the best performance. A balanced compressor and conventional compressor are analyzed with trigonometric, elliptical and cubic polynomial defined curves. The trigonometric trajectory gave the best performance in terms of gas pressure with the elliptical and polynomial contours lagging respectively. In addition to the relatively low pressure head, the cubic polynomial contour also produces the highest contact forces leading to higher power losses. In terms of power losses, the trigonometric and the elliptical geometries trail the cubic contour respectively [25].

Wu et al. [26] discussed the dynamics of the vane compressors in refrigeration systems. They obtained good correlation between the experimental and simulated data. The compressor model was for a balanced vane compressor and involved breaking the compressor into four chambers; open to inlet, closed to inlet and outlet, open to outlet and past outlet. In these four chambers the mass transfer between each chamber and its surroundings are modelled. Compression is assumed to be adiabatic hence the pressures can be calculated. Lubrication is assumed to be perfect hydrodynamic lubrication and a constant coefficient of friction is then used to calculate the losses in the compressor. The results for leakage (and hence volumetric efficiency) are found to be within $3 \%$ of the experimentally obtained results. It is also concluded that in vane compressors for 
refrigeration systems the volumetric efficiency is a key to its operation and an aim for efficiencies up to $85 \%$ is recommended [26].

Inaguma and Hibi [27] did a thorough analysis on the mechanical efficiency of vane compressor; once again a balanced vane is used for the analysis. Analyses are theoretical, with significant experimental input and guidance. The compressor model is approximated using the overall head of the system, hence the torque loss can be obtained if we know the expected pressure ratio of the compressor. In this investigation the speed of the system is kept constant at 2000 RPM. It was found that there was a constant torque term that was independent of the pressure head of the compressor. From experiments it was concluded that the torque loss can be modelled as a function of pressure difference, vane width and an experimentally determined constant. This constant is found to be a function of the RPM of the compressor (15\% deviation in experimentally obtained data).

In light of this the vane-tip friction is modelled as it is strongly dependent on the RPM. The coefficient of friction is determined experimentally as a function of the RPM and found to decrease as RPM increases. The vane tip friction's contribution to the mechanical efficiency is found to be almost constant by analytical methods it is then concluded that any further deviation in mechanical efficiency comes from the rubbing of the rotor on the shaft. Conclusion is that improving mechanical efficiency is obtained by reducing the sliding friction coefficient and vane thickness [27]. 


\section{Chapter 3: Experimental Setup}

The CCOT automobile air conditioning setup was implemented in the experiments pertaining to this thesis. A picture of the actual equipment is shown in Figure 3.1. This equipment is the ATS automobile vapour compression refrigeration test stand and was designed by Wang S [28]. The setup contains a compressor, condenser, variable orifice expansion valve, expander, evaporator, accumulator and separator. The system is set in a block-wise configuration to allow for easy access and maintenance. The refrigerant cycled is R-134a with PAG-100 (Polyalkylene Glycol oil) as the lubricant for the compressor. The PAG oil is completely miscible with R-134a liquid. 


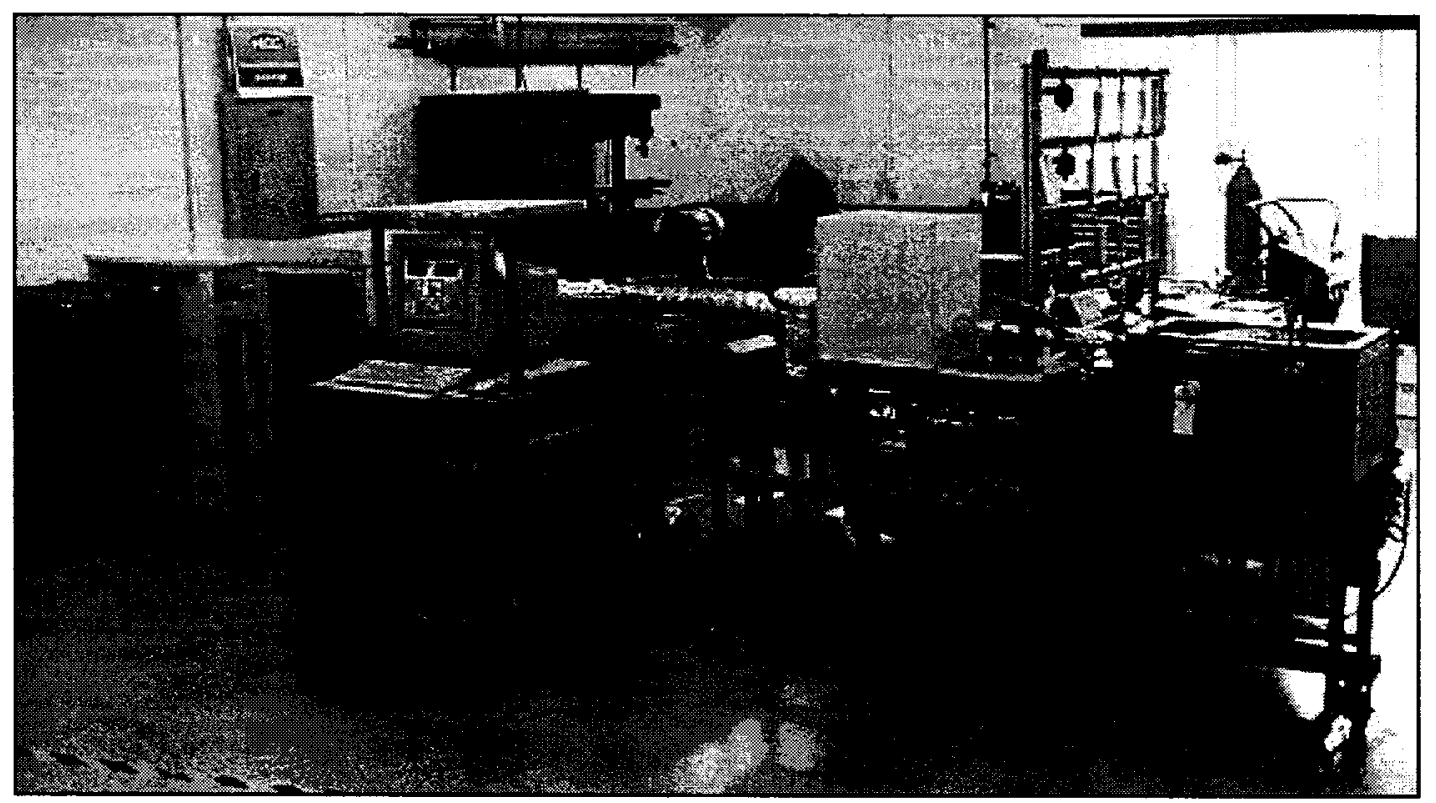

Figure 3.1 ATS Automobile Air Conditioning Test Stand

\subsection{Modifications to the Test Stand}

The refrigeration testing stand shown in Figure 3.1 was devised by Wang S. and detailed in his thesis [28]. The test stand allows for easy integration of other components into the system. The modifications that were done to the system are detailed below. Unless otherwise specified, all piping connections were done using 6061 aluminum tubing with $1 / 2$ in. outer diameter and 0.065 in wall thickness.

- The compressor-expander was connected to the servomotor via an electromagnetic clutch (Model 205-396 Chrysler clutch). The existing compressor connections were connected to the inlet and outlet of the compressor while new piping connections were made for the expander inlet and outlet. 
- The capillary tube that served as the expansion device was replaced by a manually adjustable expansion valve (MEV). The MEV is installed upstream of the expander which allows the condenser outlet liquid to be pre-expanded before it gets to the expander. With the MEV the adjustment of the amount of preexpansion that occurs before entering the expander can be adjusted.

- In the original loop the connection out of the expansion device (capillary tube) went directly to the evaporator chamber. For the compressor-expander system the connection out of the MEV is linked to the expander inlet. The expander outlet is then linked to the evaporator chamber.

- At the exit of the expander a thermocouple and pressure transducer are installed. To be consistent with the existing system the same make of thermocouple and pressure transducer were installed. More details on the measuring system are discussed in Section 3.2 .

- No adjustments were done to the data acquisition system and signal processing system. Post processing was done to determine the quality, power lost in the compressor and the overall efficiency. The methods used in determining these quantities are presented in Section 3.5.

Details on the model specifications and design of modified parts are presented in Appendix A.3 . 


\subsection{Measurements}

A schematic representation of the system is shown in Figure 3.2. The schematic shows the locations of most measurements. Data collected and not included in this figure are reported in Table 3-1.

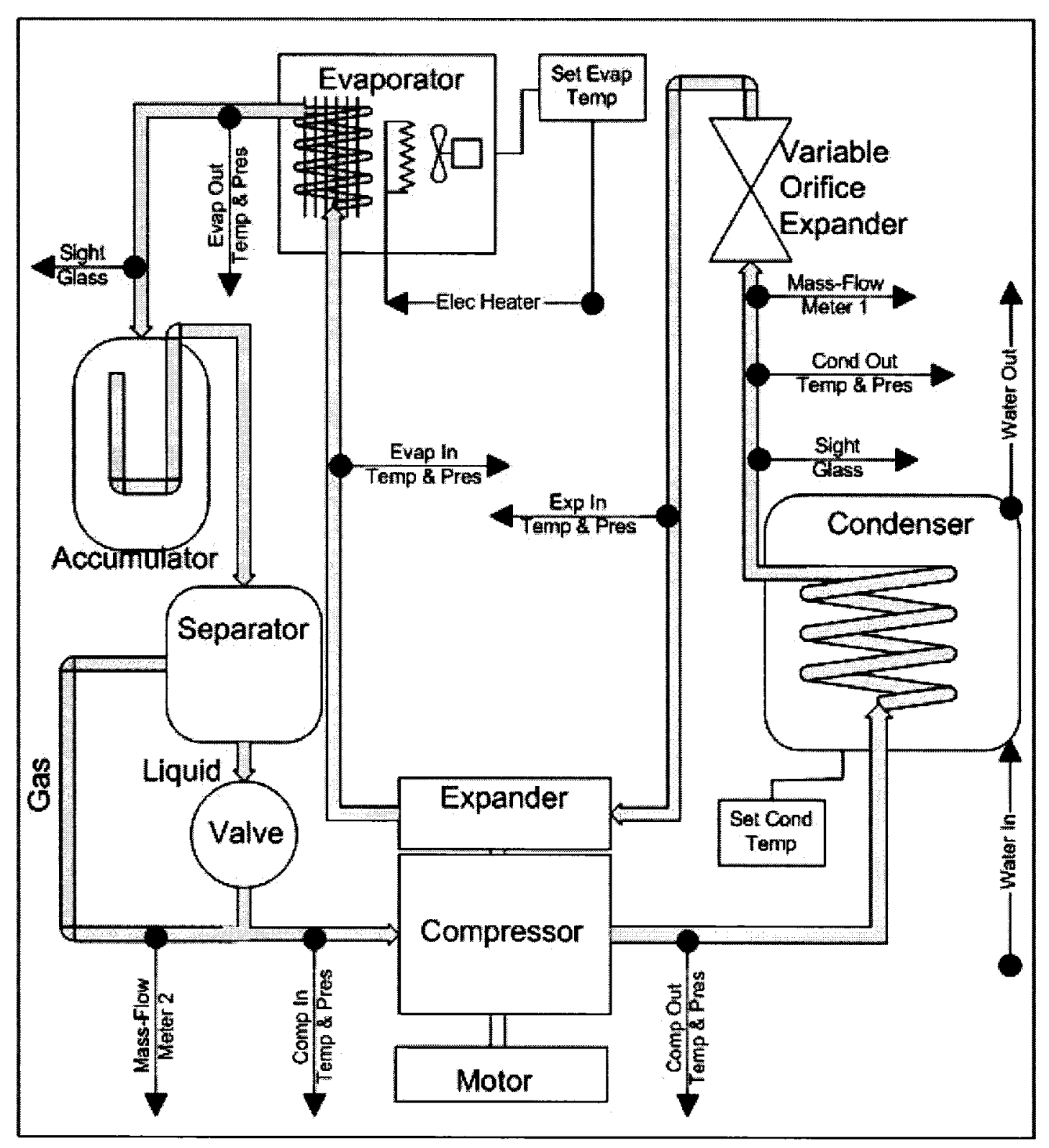

Figure 3.2 A Schematic of Experimental Setup 
Table 3-1 summarizes the measured properties across the loop. The temperature data is collected using thermocouples. The thermocouples are K-type thermocouples with medium sensitivity in the thermocouple range.

Table 3-1 Property Measurements in the Experimental Setup

\begin{tabular}{|c|c|c|c|}
\hline Component & Temperature & Pressure & Other \\
\hline \multirow{4}{*}{$\begin{array}{c}\text { Compressor- } \\
\text { expander }\end{array}$} & Body & Compressor inlet & \multirow{2}{*}{$\begin{array}{l}\text { Compressor- } \\
\text { expander RPM }\end{array}$} \\
\hline & Compressor inlet & Compressor outlet & \\
\hline & Compressor outlet & Expander inlet & \multirow{2}{*}{$\begin{array}{l}\text { Compressor- } \\
\text { expander torque }\end{array}$} \\
\hline & Expander inlet & - & \\
\hline Condenser & Cooling water & - & - \\
\hline Expansion valve & Inlet & Inlet & Massflow in \\
\hline \multirow{2}{*}{ Evaporator } & Outlet & Outlet & \multirow{2}{*}{$\begin{array}{c}\text { Evaporator heater } \\
\text { power }\end{array}$} \\
\hline & Chamber & - & \\
\hline \multirow{2}{*}{ Separator } & Liquid & - & \multirow{2}{*}{ Gas mass flowrate } \\
\hline & Gas & - & \\
\hline \multirow{2}{*}{ Other } & Ambient & - & Oil sump level \\
\hline & - & - & Refrigerant charge \\
\hline
\end{tabular}

The manufacturer's listed error for the K-type thermocouple used is $\pm 0.2^{\circ} \mathrm{C}$ at the operating range used in this experiment. For the pressure transducers, the listed accuracy is $\pm 10 \mathrm{kPa}$. A setup of the temperature and pressure transducers is shown in Figure 3.3. The instruments are set up with their axis at right angles to the flow direction except at bends. At bends, the pressure transducer is installed in the axis of the incoming flow. The mass-flow-meters for measuring liquid and gas flowrates are accurate to $0.1 \mathrm{~kg} / \mathrm{h}$ and the refrigerant charge measuring error is $\pm 0.001 \mathrm{~kg}$. All the reported errors are precision 
errors; bias errors are assumed to be negligible. The thermostats that control the evaporator chamber temperature and the condenser water temperature keep the elements to within $\pm 1^{\circ} \mathrm{C}$ of the set temperature.

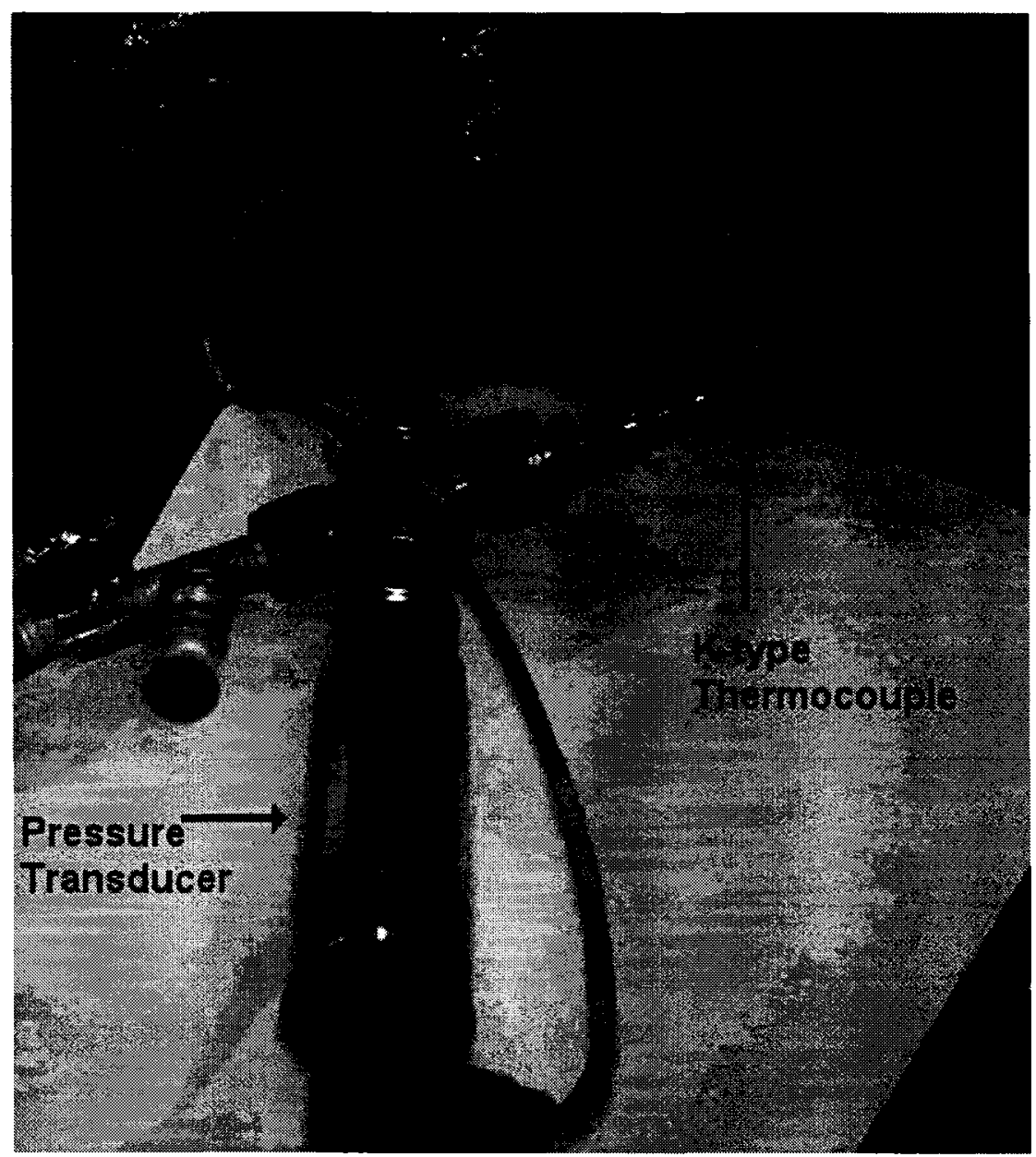

Figure 3.3 The Thermocouple and Pressure Transducer

\subsection{Data Acquisition and Signal Processing}

For the data acquisition and processing an existing system, designed by Wang [28], was fit into the experimental configuration used for this project's setup. A data acquisition system, signal conditioning extensions for instrumentation devices and a computer equipped with LabVIEW software was used to acquire and process the data. The 
LabVIEW program is used to process the data contained (see Table 3-1) as well as calculate some useful parameters (see Section 3.5). The data and parameters are then written to a Microsoft Excel file upon the user's request. Along with the data writing, the data is also available visually via the Graphical User Interface (GUI). In addition the LabVIEW program is also able to perform some control functions on the experimental loop's hardware. The data is stored on the main computer in the Refregeration Laboratory (see Appendix A.3 ) in the directory C:MATlexperimental recordlcompressor-expander.

\subsubsection{Standard Controls Window}

The standard controls window allows for direct control of operational parameters and hardware settings. As shown in Figure 3.4 the following controls are located in the standard controls window.

- Compressor drive controls: This can be used to turn the motor on and off.

- Refrigeration loop controls: This is used to cycle the clutch on and off. In this study the experimental analysis is steady state so the clutch was bypassed and the compressor was directly linked to the motor. However the clutch control can also disengage the clutch from the motor when safety is an issue.

- Evaporator controls: The evaporator controls are used to turn on and off the evaporator heater. Two setting may be selected; the constant heat flux and the constant temperature settings. In this work only the constant temperature setting is used. 
- Condenser controls: The condenser control is used to set the temperature of the cooling water by turning on and off the cycling pumps used to transport the cooling water.

- Set compressor RPM: Can be used to set compressor speed.

- Accumulator stand controls: set accumulator box temperature, heater on/off, fan on/off.

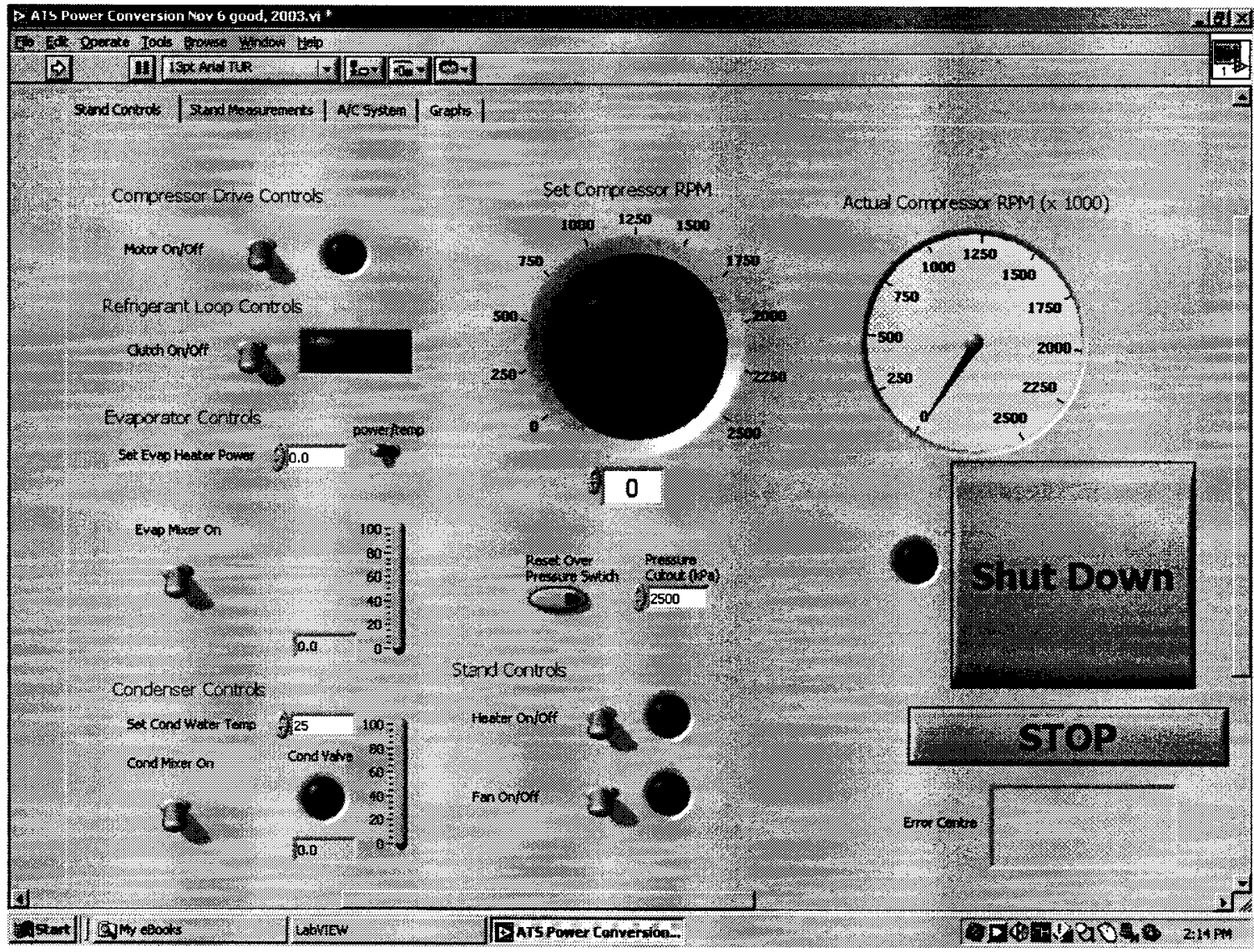

Figure 3.4 Standard Controls Window [28]

\subsubsection{Standard Measurement Window}

The standard measurement window shows the instantaneous values read by the measurement devices. It also shows the values of some of the calculated parameters. In 
addition, the writing frequency can be set to intervals of up to a second. Included in the standard measurement window are the following:

- State switch: The state switch allows the user to choose whether a steady state or a transient analysis is being studied.

- Data view: The data view is used to choose between the on screen viewing option and the write to file option. When writing to the excel file the data is still available on screen.

- Power values: The power values section shows the measured accumulator box power and evaporator heater power. It also shows the calculated COP and compressor power.

- Accumulator: This shows measured accumulator parameters.

- Separator: The gas flowrate (measured at the separator) and the liquid flowrate (measured after the condenser) are displayed in this section. Also the separator gas and liquid temperatures are measured.

- Compressor: Displays the measured compressor properties.

- Heat exchanger: This section shows the measured evaporator, condenser and variable orifice expansion valve data.

- Time recorder: elapsed time since start and reset counter time. This can be used to control how long data is collected for and how long the system has been running to determine if steady state is reached.

- Ambient: This is a recording of the ambient temperature. 


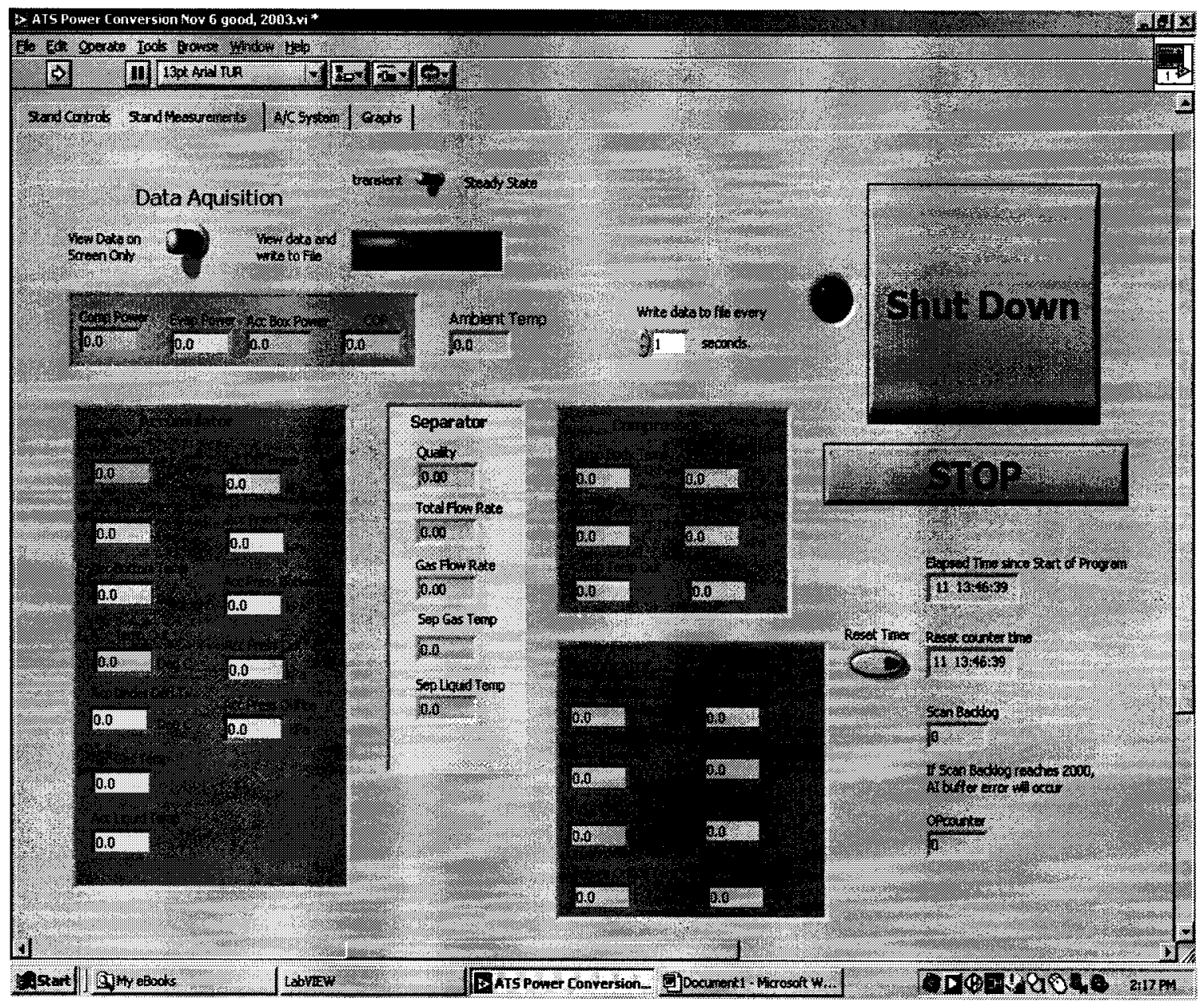

Figure 3.5 Standard Measurement Window [28]

\subsection{Experimental Components}

In this section the components and their particulars that were used in the experiments are presented.

\subsubsection{Compressor-Expander}

The compressor-expander is an unbalanced sliding vane compressor and a sliding vane expander combined into one unit. An unassembled view of the machine is shown in Figure 3.6. The unit was built by the Refrigeration Development Company in Deep 
River, Ontario (See Appendix A.3 for more details). The oil sump filters oil that comes out of the compressor outlet and feeds it to the gap between both the compressor side face and the expander side face of the rotor. It is important to know that if there is no oil in the sump there will be a direct leakage path between the compressor outlet and expander chamber. In addition there will be internal leakage between the compressor outlet port

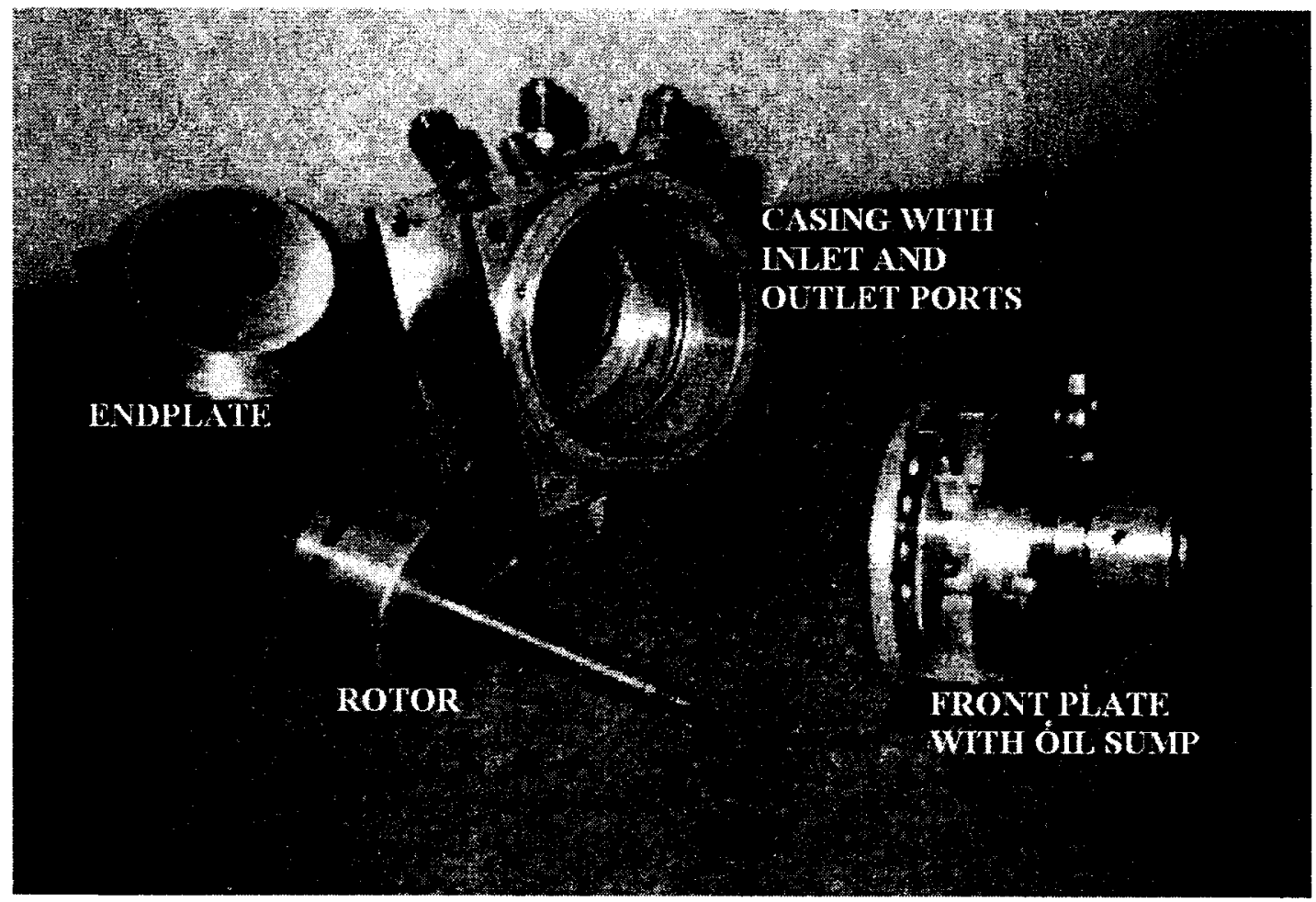

Figure 3.6 Disassembled Compressor-Expander

and the compressor inlet port. This means that having oil in the sump is essential to having a good volumetric efficiency. The oil is also used to lubricate the bearings in the compressor-expander. Located between the expander and compressor chambers is a mechanical seal: the Torlon seal. Experimental measurements of the leakage while running the system on R-134a puts the Torlon seal leakage at $15 \%$ at 1500 RPM. Improvement in the seal design will improve the volumetric efficiency and hence the 
overall performance of the compressor. The rotor and vanes are shown in Figure 3.7. The vanes have groves along the sides. These groves allow for fluid from the high side of the compressor to enter the chamber underneath the vane. As the vane slides down, an extra compression effect is achieved.

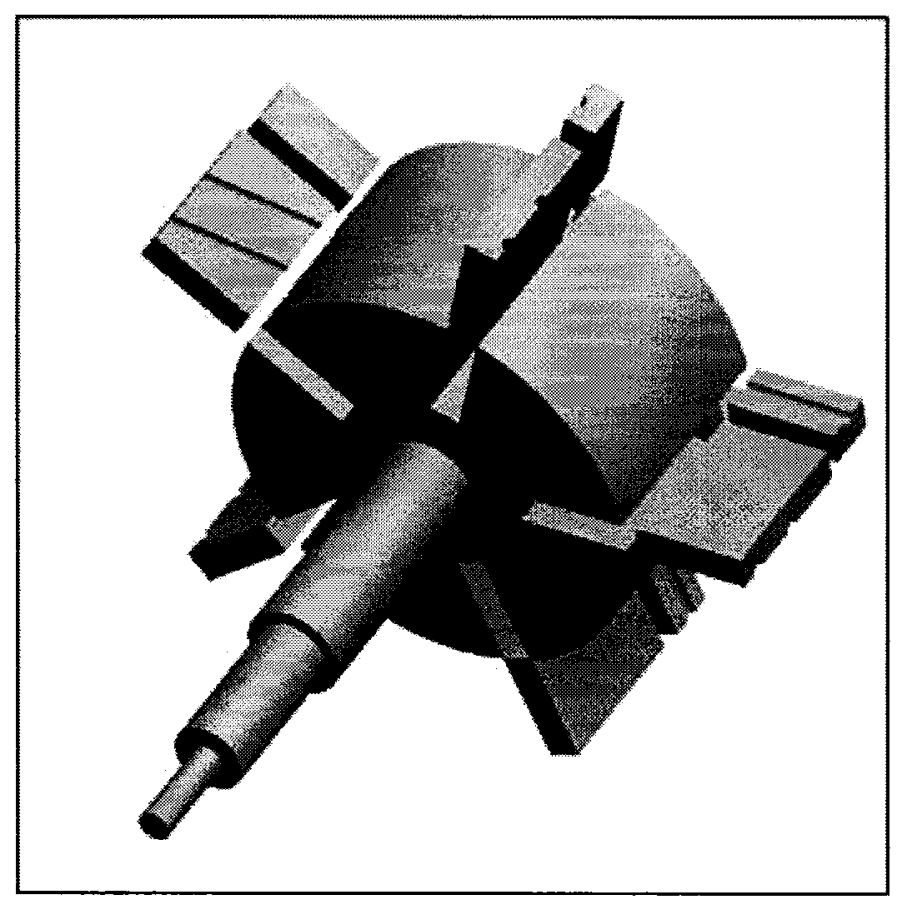

Figure 3.7 Compressor-Expander Rotor and Vanes

As the refrigerant flows through the compressor, it carries some oil along with it. This oil forms a thing film along the perimeter of the compressor's outer casing and acts as a lubricant for the sliding vanes. 
Table 3-2 Compressor-Expander Information

\begin{tabular}{|c|c|c|c|c|c|}
\hline Speed & $\begin{array}{c}\text { Compressor } \\
\text { displacement }\end{array}$ & $\begin{array}{c}\text { Expander } \\
\text { displacement }\end{array}$ & Power input & $\begin{array}{c}\text { Volumetric } \\
\text { efficiency }\end{array}$ & $\begin{array}{c}\text { Compression } \\
\text { ratio }\end{array}$ \\
\hline $\mathrm{RPM}$ & $\mathrm{cc} / \mathrm{rev}$ & $\mathrm{cc} / \mathrm{rev}$ & $\mathrm{kW}$ & $\%$ & \\
\hline 700 & 10.21 & 0.71 & 0.88 & 57 & 1.41 \\
\hline 1000 & 10.21 & 0.71 & 1.70 & 54 & 2.00 \\
\hline 1500 & 10.21 & 0.71 & 3.37 & 52 & 2.31 \\
\hline 2000 & 10.21 & 0.71 & 4.88 & 50 & 2.35 \\
\hline
\end{tabular}

\subsubsection{Condenser}

The condenser is a water-cooled condenser and designed to ensure that the refrigerant comes out sub-cooled. A picture of the condenser coil and schematic of the condenser is shown in Figure 3.8. The desired water temperature can be set using the standard controls window. The system maintains the water temperature within $\pm 1^{\circ} \mathrm{C}$. Once the sensor senses the temperature has dropped below half a degree of the set temperature, both pumps are activated to take out a measured amount of warm water and add a balancing amount of cold water from a reservoir. 


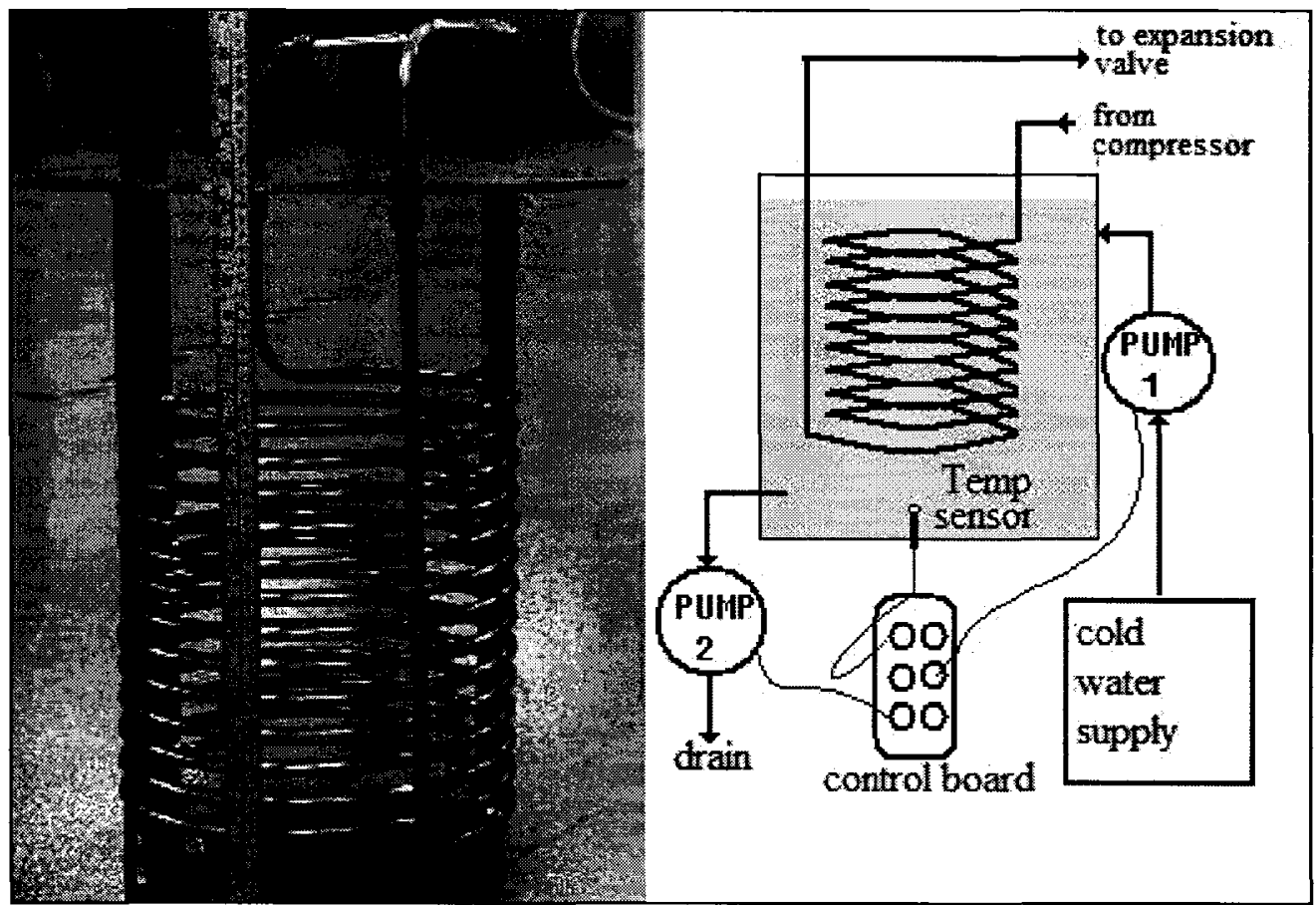

Figure 3.8 Subcooled Condenser Setup

\subsubsection{Expansion Device}

A commercial variable orifice needle expander is used. The size of the orifice is adjusted manually. Although the expansion device has markings that indicate how open or closed the expander is, there is no known relationship to quantify the flow area in the tube using the indicated markings. However its effect can be measured/evaluated from other system parameters.

\subsubsection{The Evaporator}

The evaporator's function is to take heat out of a space. At the evaporator the refrigerant is at low pressure and temperature. The heat absorbed from the space goes into boiling the refrigerant. The setup for this experiment has an evaporator chamber. In this chamber 
air is heated using an electric heater. The circuit can be set to provide a known constant heat flux or a constant chamber temperature. In the constant temperature setting the power supplied by the heater is measured by a powermeter and hence the cooling load of the $\mathrm{A} / \mathrm{C}$ is acquired.

\subsubsection{Separator}

The separator design is shown in Figure 3.9. A mass-flow-meter measures the gas flowrate when the valve is open. When the valve is open the liquid drops into the separator tank and then flows through the bottom piping hence only the gas goes through the mass-flow-meter. If the valve is completely closed, the total flowrate is measured since both the liquid and gas will pass through the mass-flow-meter. The mass-flowmeter works on a coriolis mechanism that allows it to handle both liquid and gas simultaneously.

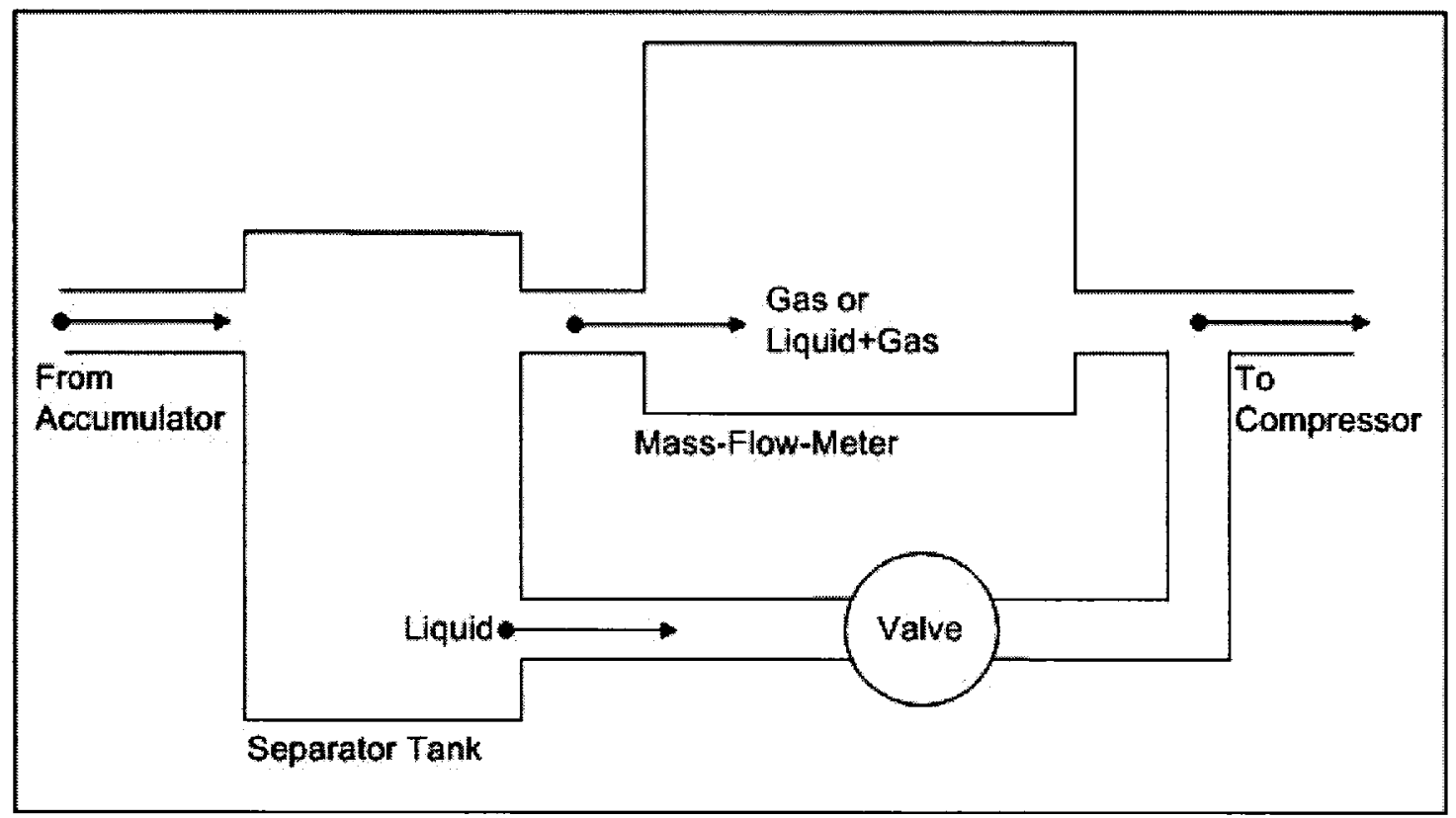

Figure 3.9 Separator Setup for Measuring Gas or Total Flowrate 


\subsection{Experimental Calculations}

This section discusses the parameters calculated directly from the measured experimental data. The parameters help to better understand the performance of the refrigeration system.

\subsubsection{Compressor Power}

The compressor-expander power (in watts) is calculated from the measured torque and speed as shown in the following equation.

$$
P_{\text {comp }}=\pi / 30 \cdot(R P M) \cdot \vec{T}
$$

\subsubsection{Flow Quality and Torlon Leakage}

The quantity labelled quality in Figure 3.5 is not the actual quality coming into the compressor. This misnomer is due to leakage across the Torlon seal that separates the compressor and expander chambers. Without this leakage the quality would simply be a ratio of the flowrates measured from the separator mass-flow-meter and the mass-flowmeter ahead of the condenser (see Figure 3.2). The actual quality is obtained from multiple runs and only valid if the experiments are repeatable. The repeatability of the experiments is discussed in Appendix A.4 One run is done with the separator valve closed and another run is done with the valve open (see Figure 3.2). The actual quality at the evaporator outlet is measured as shown in the following equation as a ratio of the open and closed valve flowrates.

$$
x_{c o m p, i n}=\frac{\dot{m}_{v o}}{\dot{m}_{v c}}
$$


The Torlon seal leakage can be calculated by the difference in the mass flow out of the condenser (mass-flow-meter 1 in Figure 3.2) and the mass flow into the separator with the valve closed.

\subsubsection{Coefficient of Performance}

The coefficient of performance is calculated from the measured evaporator power (or cooling capacity) and the obtained compressor power. The equation describing this relationship is shown below.

$$
C O P=\frac{\dot{Q}_{\text {evap }}}{P_{\text {comp }}}
$$

\subsubsection{Efficiencies}

In order to calculate the volumetric and mechanical efficiencies, thermodynamic data for $\mathrm{R}-134 \mathrm{a}$ needs to be utilized. The properties at various thermodynamics states are obtained using the CoolPack commercial software [29]. The volumetric efficiency is obtained from the rated displacement at the inlet of the compressor. The displacement of a positive displacement pump is defined as the net fluid volume transferred from the closed-to-inlet volume to the open-to-outlet volume in one complete revolution assuming that the volumetric efficiency is unity. The close-to-inlet volume is the volume of fluid in the compression chamber that is just sealed off from the inlet port. The open-to-outlet volume is the volume of fluid that is just open to the outlet port. These volumes are shown in Figure 3.10. 


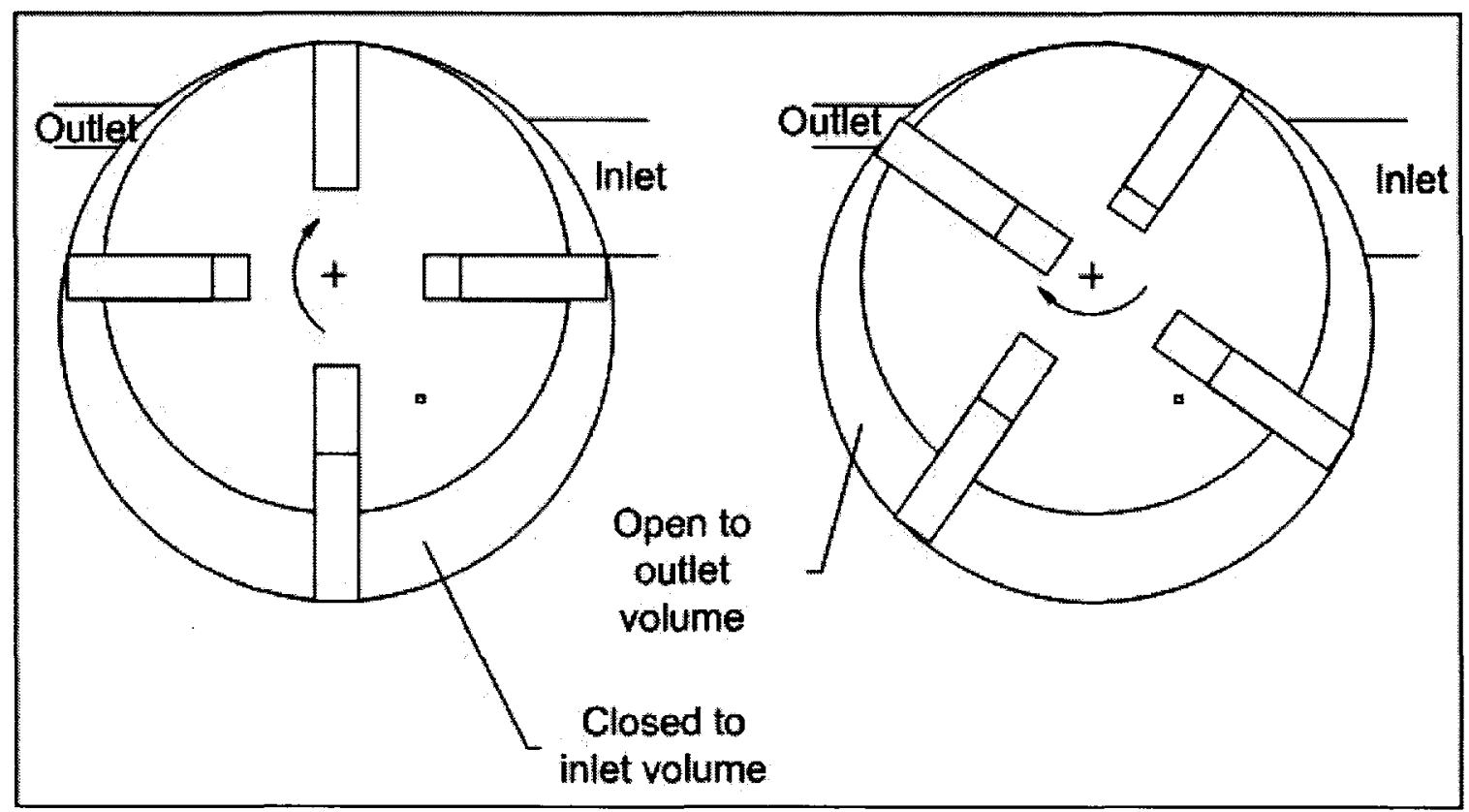

Figure 3.10 Depiction of Closed-to-Inlet and Open-to-Outlet Volumes

The in this work the displacement, $D s p$, is taken per vane chamber. From the density at the close of the inlet section $\rho_{\text {comp,in, }}$, the number of vanes $z$, and the compressor displacement $D s p$, the ideal mass flowrate is known for any given RPM.

$$
m_{i d}=1 / 60 \cdot \rho_{\text {comp }, i n} \cdot D s p \cdot z \cdot R P M
$$

The volumetric efficiency is then the ratio of the measured flowrate and ideal flowrates. Overall efficiency is calculated from the ideal power needed to compress the fluid from the inlet conditions to the outlet conditions and the measured power. This must take into consideration the recovered energy from the expander.

$$
P_{\text {comp }, \text { id }}=\dot{m}\left(h_{\text {comp }, \text { out }}+h_{\text {exp }, \text { out }}-h_{\text {comp }, \text { in }}-h_{\text {exp,in }}\right)
$$

The enthalpies used in Equation (3.5) are also obtained from the CoolPack software. Due to the two-phase nature of the flow the pressure and temperature data is not enough to determine the state of the fluid. In order to get the expander enthalpies some 
assumptions have to be made since these enthalpies cannot be measured directly. Firstly the enthalpy across the expansion valve is assumed to be constant. This means that the inlet enthalpy of the expander is the same as the subcooled condenser outlet enthalpy. Secondly if we assume that the evaporator chamber and lines are perfectly insulated then, knowing the evaporator outlet enthalpy (from the temperature and quality) we can get the inlet enthalpy and hence the expander outlet enthalpy using Equation (3.6).

$$
h_{\text {exp,out }}=h_{\text {evap,out }}-\dot{Q}_{\text {evap }} / \dot{m}
$$

The overall efficiency is then the ratio of the ideal power required and the actual power supplied. 


\section{Chapter 4: Theoretical Analysis}

The purpose of doing a theoretical analysis on the compressor-expander is to learn ways in which the assembly can be improved. If the model can accurately predict the current behaviour of the machine then it can be used to predict the behaviour of the unit when several parameters are changed. The analytical analysis of the compressor-expander system was broken down into two portions. Firstly, an analysis of the compressorexpander alone is done. In this analysis the inlet parameters into the compressor-expander are defined and then the behaviour of the machine is modelled. The second analysis is the full system analysis. This analysis involves a model of the compressor-expander, condenser, evaporator and expansion valve as well as frictional losses due to piping and geometry.

\subsection{Analysis of the Compressor-Expander}

The goal for the compressor-expander model is to mathematically predict the behaviour of key parameters of the unit as well as the properties of the refrigerant inside the unit. The first step to modelling the compressor-expander is to define the geometry mathematically. Since it is assumed that the end wall effects in the compression and expansion chamber are negligible, a two-dimensional analysis of the compressor is then sufficient to describe its behaviour. 


\subsubsection{Compressor-Expander Geometry}

Since the compressor and expander chambers are identical, except for the locations of inlet and outlet ports and the depth of the chambers, a two-dimensional geometrical model would be identical for both chambers. The nomenclature used in defining the geometry is shown in Figure 4.1. The coordinate system used is centered at the center of the rotor. $R_{1}$ and $R_{2}$ are the rotor and stator radii respectively. The angular location of the vane being studied, $\theta$, is defined from the top-dead-center to the vane's center of gravity $(C G)$ in the direction of the vane rotation.

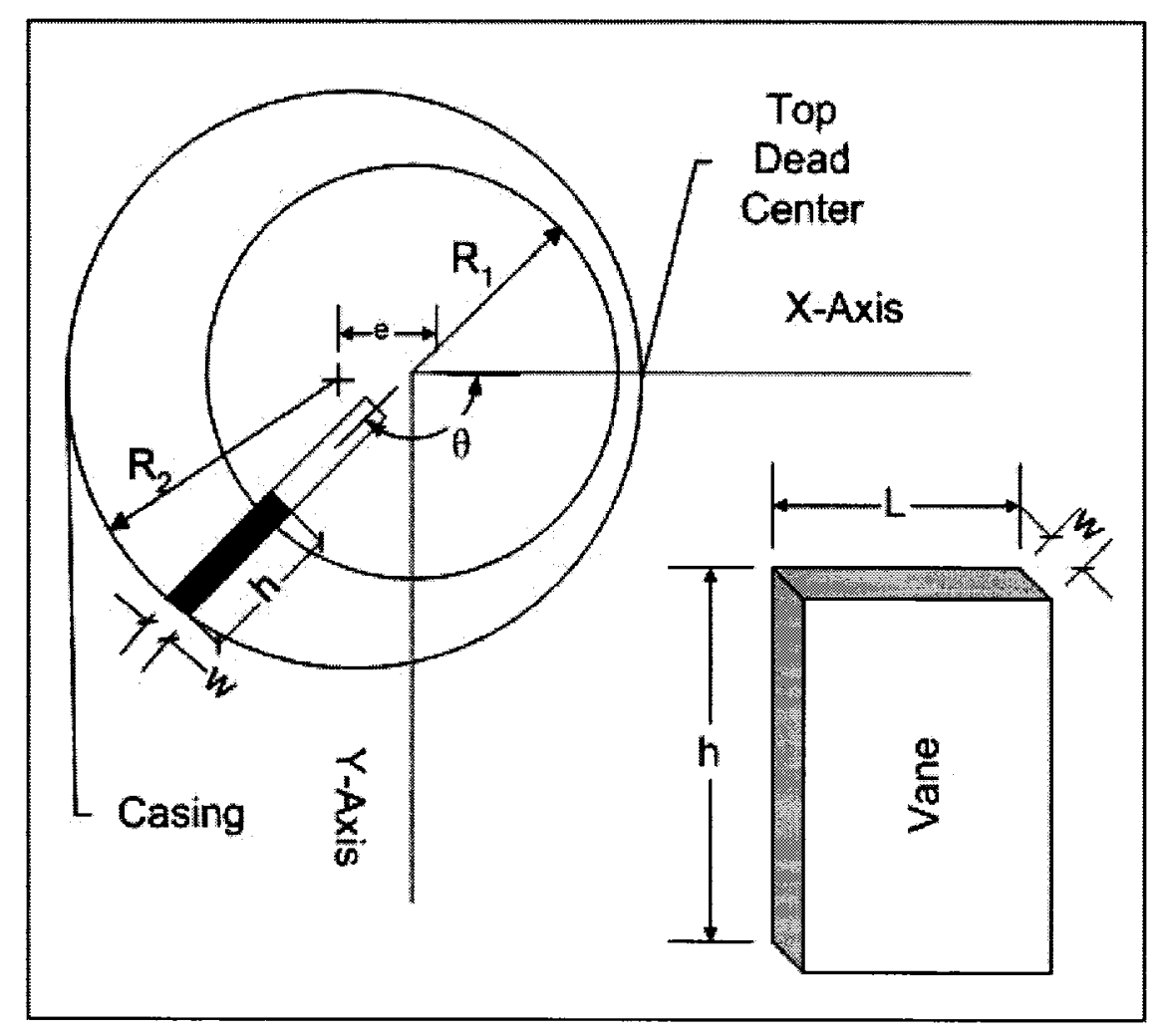

Figure 4.1 Geometry Nomenclature for Vane Compressor

The eccentricity, $e$, is simply the distance between the centers of the rotor and casing. To obtain the center of gravity of the vane as a function of the angular rotation we assume 
that the $\mathrm{CG}$ is coincident with the geometric center (hence the vane is of uniform density). The referring to Figure 4.1 and Figure 4.2 we can solve for the radius of the vane $\mathrm{CG}, r_{g}$, as a function of the rotation angle.

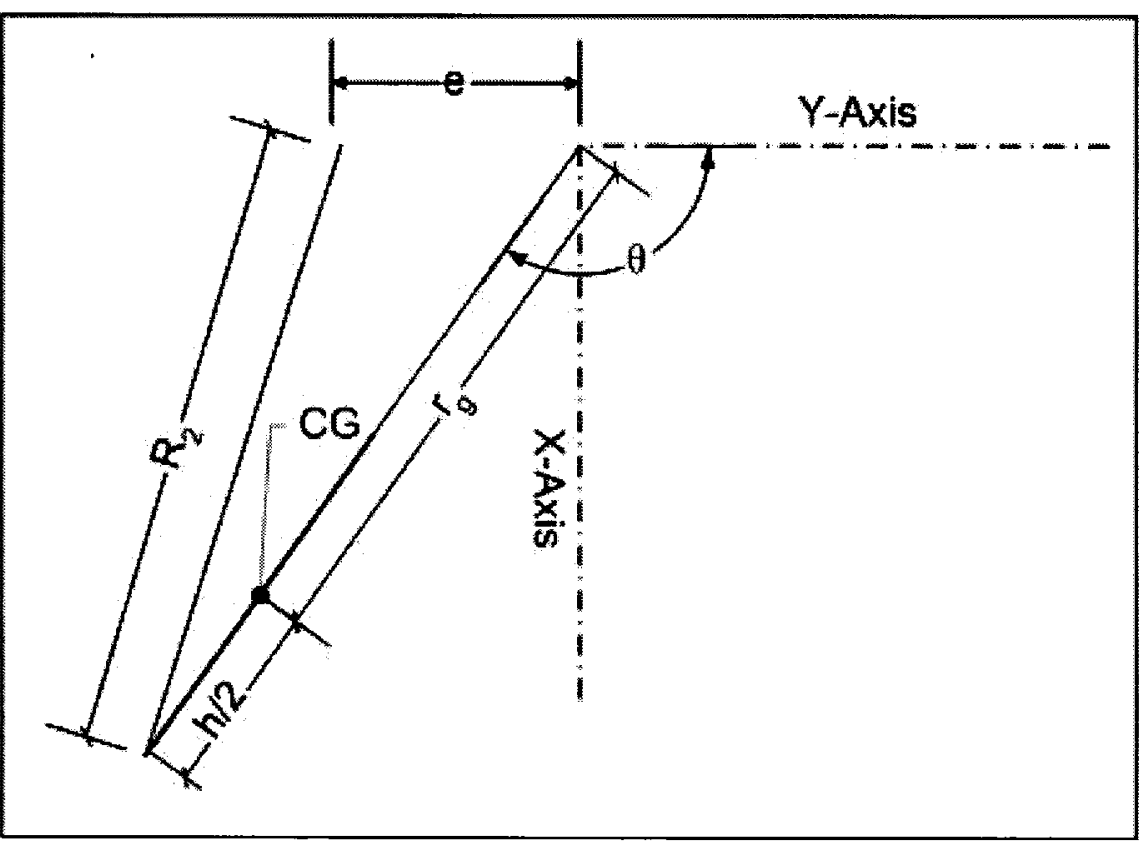

Figure 4.2 Determining Vane CG

$$
\begin{aligned}
& R_{2}=R_{1}+e \\
& x x^{2}+y^{2}=R_{1}{ }^{2} \\
& (x x+e)^{2}+y^{2}=R_{2}{ }^{2} \\
& y=x \cdot \tan \theta \\
& r_{g}=\frac{x}{\cos \theta}-\frac{h}{2}
\end{aligned}
$$

Equation (4.1) to Equation (4.5) represents five equations and unknowns that can be solved to give the radius of the center of mass as a function of the rotation angle. The equations are derived simply from the Cartesian equations of a circle and some coordinate transformation equations. The result is Equation (4.6). 


$$
r_{g}=\frac{e \pm \sqrt{e^{2}-\left(1+\tan ^{2} \theta\right)\left(e^{2}-R_{2}^{2}\right)}}{\left(1+\tan ^{2} \theta\right) \cos \theta}-\frac{h}{2}
$$

If four parameters are defined as shown in Equation (4.7) to Equation (4.10), then most of the parameters needed to describe the compressor-expander can be simplified in terms of A, B, C and Z.

$$
\begin{aligned}
& A=\frac{\tan \theta\left(1+\tan ^{2} \theta\right)\left(e^{2}-R_{2}^{2}\right)}{\cos \theta \sqrt{e^{2}-\left(1+\tan ^{2} \theta\right)\left(e^{2}-R_{2}^{2}\right)}} \\
& B=\frac{2 \tan \theta}{\cos \theta}-\left(1+\tan ^{2} \theta\right) \sin \theta \\
& C=-e \pm \sqrt{e^{2}-\left(1+\tan ^{2} \theta\right)\left(e^{2}-R_{2}^{2}\right)} \\
& Z=\cos \theta
\end{aligned}
$$

The vane center of mass defined above can be reduced to Equation (4.11) using the parameters in Equation (4.9) and (4.10):

$$
r_{g}(\theta)=C \cdot Z-\frac{h}{2}
$$

Of interest is also the area in the chamber between two vanes. In polar coordinates the area between two curves is given by:

$$
\text { Area }=1 / 2 \int_{\alpha}^{\beta}\left([f(\theta)]^{2}-[g(\theta)]^{2}\right) d \theta
$$




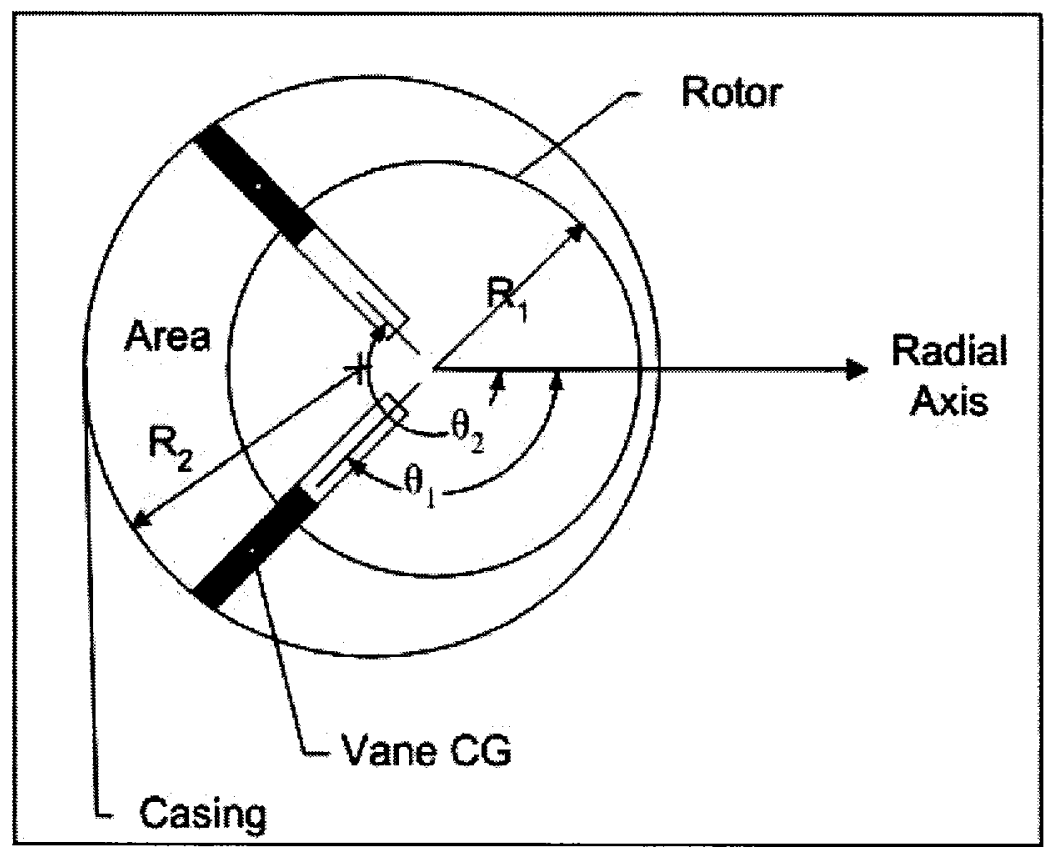

Figure 4.3 Chamber Area that Determines the Control Volume

The two curves are defined by the perimeter of the outer casing and the perimeter of the rotor. Referring to Figure 4.2 it can be seen that the outer casing radius is simply half of the vane height added to the vane CG location. It then follows that:

$$
\text { Area }=1 / 2 \int_{\theta 1}^{\theta 2}\left((C \cdot Z)^{2}-R 1^{2}\right) d \theta
$$

As shown in Figure 4.3 the area described by Equation (4.13) does not include the space underneath the vanes. Also, the area taken up by the vane must be subtracted from the total area. However the area taken up by the vane is equal to the area underneath the vane. Since the slots in the vane allow fluid to get underneath the vane, both effects cancel out. This means Equation (4.13) can be used as it is. The volume in the chamber is then simply the area calculated by Equation (4.13) multiplied by the length, $L$, shown in Figure 4.1. 


\subsubsection{Pressure Distribution on the Vane}

The pressure distribution on the sliding vane at any arbitrary angle is shown in Figure

4.4. Since the groves are on the leading face of the vane, the back pressure, $\mathrm{p}_{\mathrm{b}}$, is equal to the leading face pressure, $\mathrm{p}_{\mathrm{H}}$. Due to the unbalanced pressure acting on both sides of the vane, the vane will be tilted and thereby in contact with the rotor in two places. The first contact is from the bottom of the leading face and the inside of the rotor slot. The second contact is between the top edge of the rotor slot and the trailing face of the vane. Since the back pressure in the slot and the front-face pressure are equal, the unbalanced pressure resisting the vanes rotation only comes from the main chamber. The pressure in the slot only contributes to pushing the vane against the outer casing. It is important to note that the difference in width between the vane and the slot is small enough that we can consider the vane to be aligned with the slot. This is a useful assumption when breaking the forces into components. 


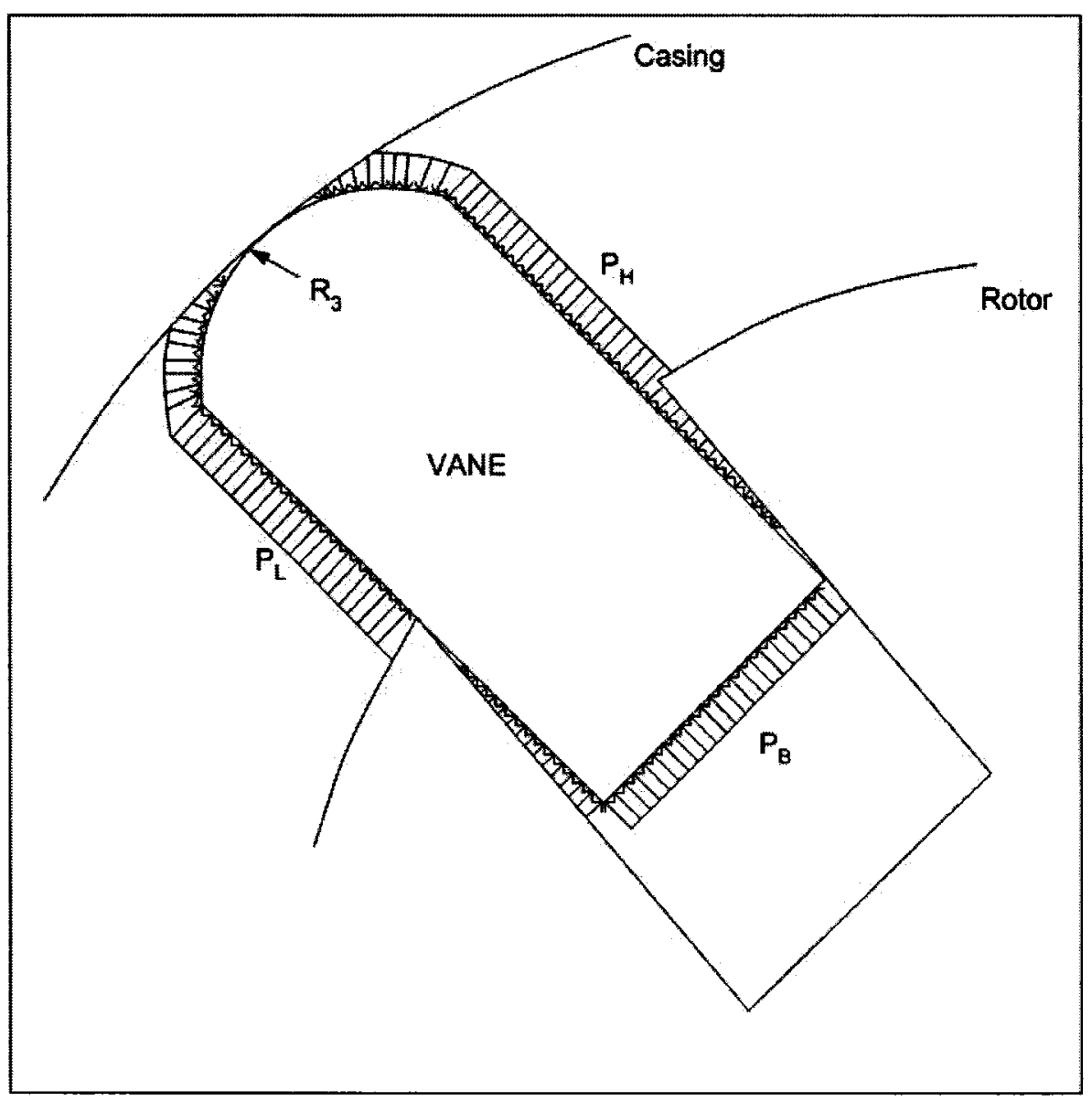

Figure 4.4 Pressure Distribution on the Vane

The vane tip is rounded at a known radius, $R_{3}$. The resultant pressure force on this part acts towards the center of the tip arc. It can then be shown (Appendix A.7) using the Cartesian coordinates described in Figure 4.2 that the forces on the vane tip are:

$$
\begin{aligned}
& F_{x x}=\left(p_{H}-p_{L}\right) \cdot w / 4 R_{3} \cdot L \cdot\left(R_{3}-\sqrt{R_{3}{ }^{2}-w^{2} / 4}\right) \\
& F_{y}=\left(p_{H}+p_{L}\right) \cdot w / 2 R_{3} \cdot L \cdot \sqrt{R_{3}{ }^{2}-w^{2} / 16}
\end{aligned}
$$

To obtain the pressures $\mathrm{p}_{\mathrm{H}}$ and $\mathrm{p}_{\mathrm{L}}$, a relationship between the pressure and the volume of the fluid is needed. The fluid properties can be obtained by solving the Navier-Stokes 
equations. However, in this work some simplifying assumptions are made. It is assumed that the speed of compression is fast enough to ensure that no heat is lost during the compression process. This means that the compression process is adiabatic and the pressure volume relationship is polytropic.

$$
p \cdot v^{\gamma}=\text { const }
$$

Knowing the relationship between the volume change and rotational angle (Equation (4.13)) the pressure can then be calculated for each rotational angle. In order to use these relations the mass in the chamber must be assumed to be constant, Section 4.1.4 shows how leakage is integrated.

Not a lot of work has gone into expander thermodynamics modelling. For the most cases empirical compressor-specific data is used. In the expander, the two phases have to be taken into account and it can be approximated using a simplified energy equation according to Shih [30]. The liquid equation of state is taken as:

$$
p_{n}=B B(s)\left[\left(\frac{v(T, r e f)}{v_{l, o u t}(T, p)}\right)^{n}-1\right]
$$

Where $n$ and $B B(S)$ are determined experimentally (see Appendix A.6 ). It then follows that if the process is externally adiabatic (which allows for transfer of heat between the phases) then

$$
v_{v, o u t}+v_{l, o u t}=v
$$

If the pressure is assumed to be equal in the two phases then we can close the loop by using Equation (4.16) along with the following equation 
$p_{n}=p_{\text {in }}\left(\frac{v_{\text {in }}}{v_{n}}\right)^{\gamma}$

The three unknowns in Equations (4.17) to (4.19) are $\mathrm{P}_{\text {out }}, v_{\mathrm{v}, \text { out }}$ and $v_{\text {l,out }}$ and can hence be solved for. The total volume, $v$, in Equation (4.18) is acquired from the geometry of the expander.

\subsubsection{Other Forces}

The forces on the vane are shown in Figure 4.5. The pressure force is simply the pressure multiplied by the area over which it acts. The gravitational force is the product of the

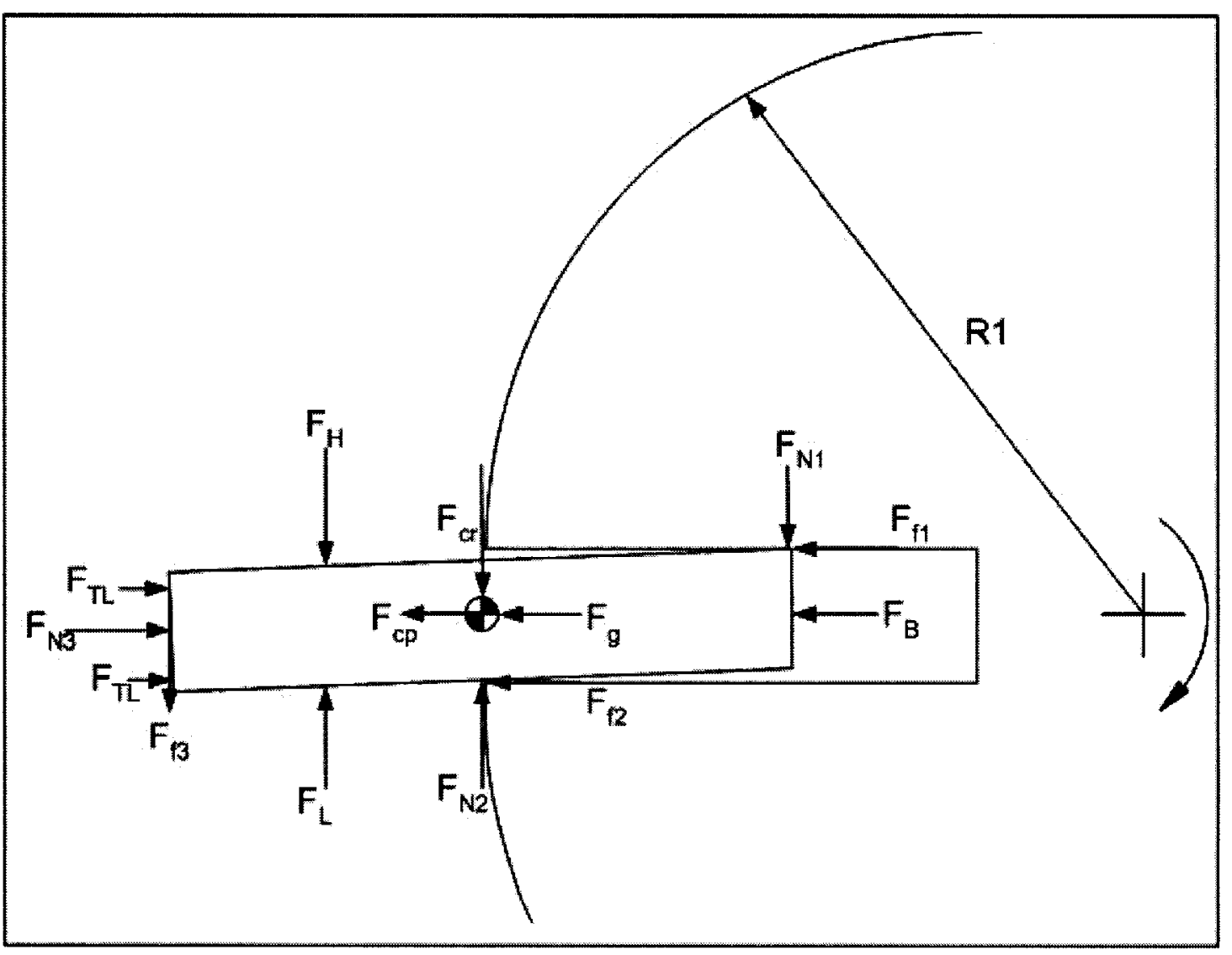

Figure 4.5 Nomenclature Used for Vane Dynamics

mass and the acceleration due to gravity. Since the coordinates used rotates with the vane gravitational force will have to be broken down into components based on the rotational 
angle. The coriolis force is also accounted for and simply a cross product of twice the rotational velocity and the relative sliding velocity along the slot. The relative velocity of the vane as it slides in the slot is simply the rate of change of the center of gravity of the vane $r_{g}$ and is given by:

$$
V_{r e l}(\theta)=\frac{d r_{g}}{d \theta}=\omega \cdot(A-B \cdot C) Z^{2}
$$

The only unknowns left are the normal and frictional forces on the three contact points of the vane. These six unknowns can be reduced to three unknowns by knowing the relationship between the normal and fictional forces. If lubrication is ideal, then the frictional model would be one of boundary lubrication or a hydrodynamic lubrication model. However with poor lubrication techniques, the friction behaves similar to the coulomb dry friction for which the relationship is as shown in Equation (4.21).

$$
F_{f}=v \cdot F_{N}
$$

The coefficient of friction is a function of the sliding velocity. The relationship used to relate this sliding velocity and the friction coefficient is given by Inaguma and Hibi and shown in Equation (4.22) [27].

$$
v=\left(9 \cdot 10^{-9} \cdot \mathrm{RPM}^{2}-4 \cdot 10^{-5} \cdot \mathrm{RPM}\right)+v_{\mathrm{st}}
$$

Where $v_{\mathrm{st}}$ is the static coefficient of friction determined experimentally. With this relationship, the system has only three unknowns which can be solved with force and moment balance equations. 


\subsubsection{Leakage and Outlet Model}

When calculating the pressures using Equation (4.16) and Equation (4.13), it is assumed that the mass in the chamber is constant. In the actual machine there is leakage between

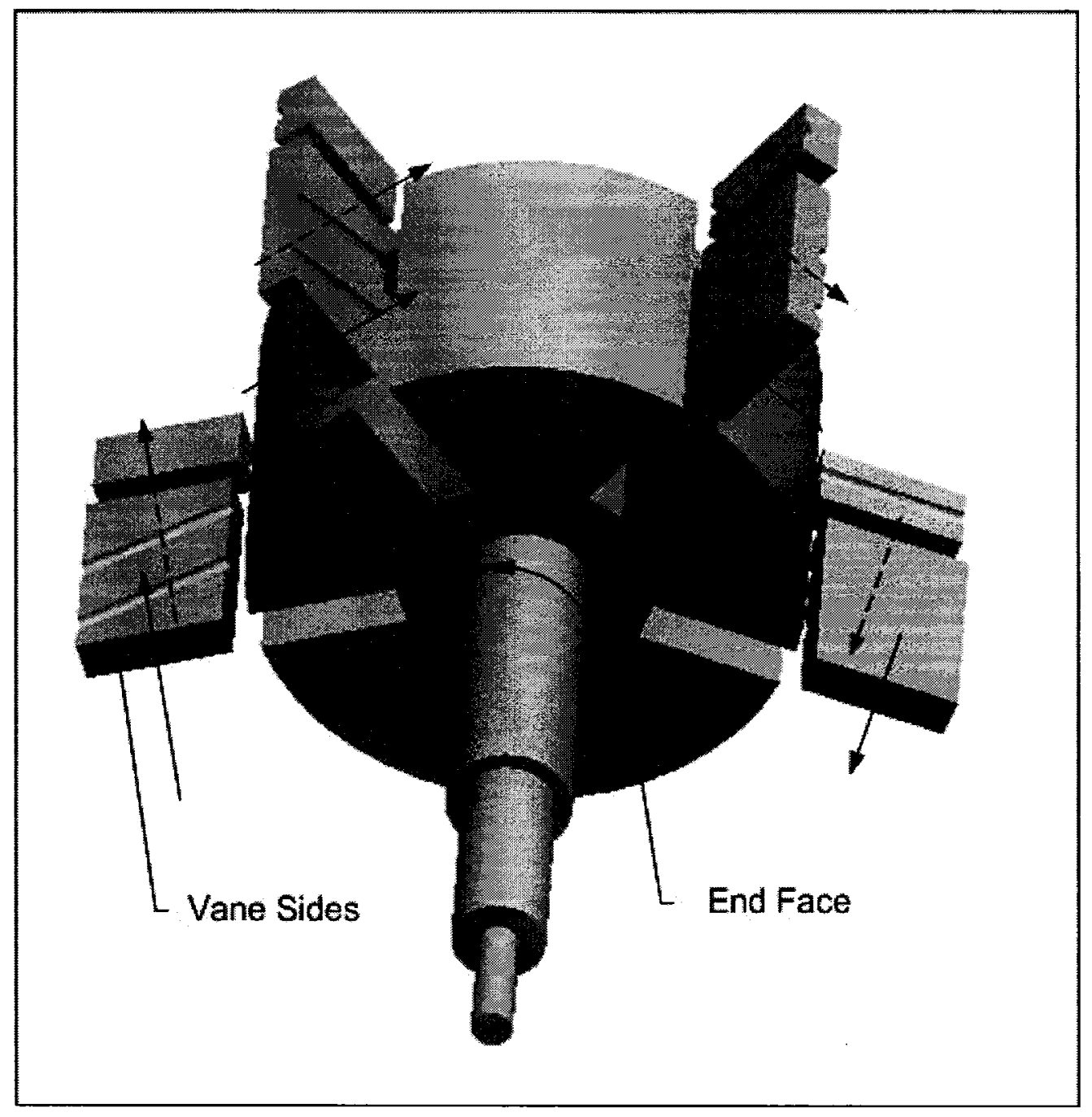

Figure 4.6 Leakage Paths on the Rotor

the rotor's end face and the faces of the front and end plates. Also, between sides of the vane and the casing fluid can leak from a higher pressure chamber to a lower pressure chamber. The latter of these two leakages is not modelled. 
Several assumptions are used in the modelling of the leakage losses and these assumptions also carry-on into the model used for the outlet of the compressor. It is assumed that the flow path on the end face is as shown in Figure 4.7.

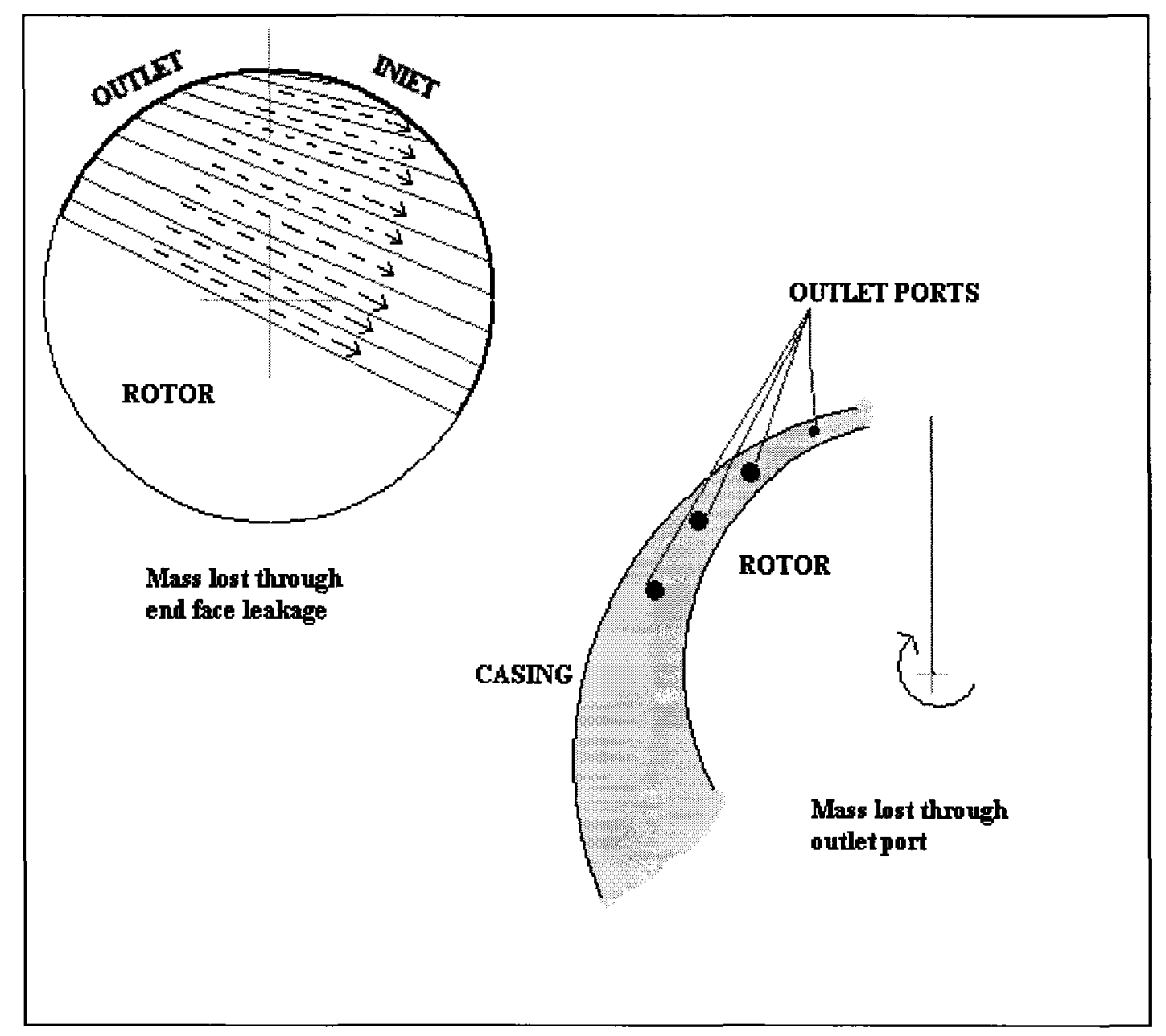

Figure 4.7 Mass Lost from Outlet Chambers

With the gap between the faces in the order of a thousandth of an inch, the flow is then a pressure driven laminar channel flow. This type of flow is referred to as a plane Poiselle flow. A closed form solution for this kind of flow exists. The mass lost in a channel is as described in Equation (4.23) [31]. The value of mass loss predicted by this equation is checked with the choked condition at which the peak max flux occurs. 


$$
\begin{aligned}
& \dot{m}_{l o s s, R F}=\frac{\rho_{o} \cdot L o}{3 \mu}\left[\frac{h o}{2}\right]^{3} \frac{\Delta p}{w o} \\
& L o=R 1\left(\theta_{o, p}-\theta_{o, n}\right) \\
& w o=2 R 1 \sin \left(\frac{2 \pi-\theta_{o}+\theta_{j}}{2}\right)
\end{aligned}
$$

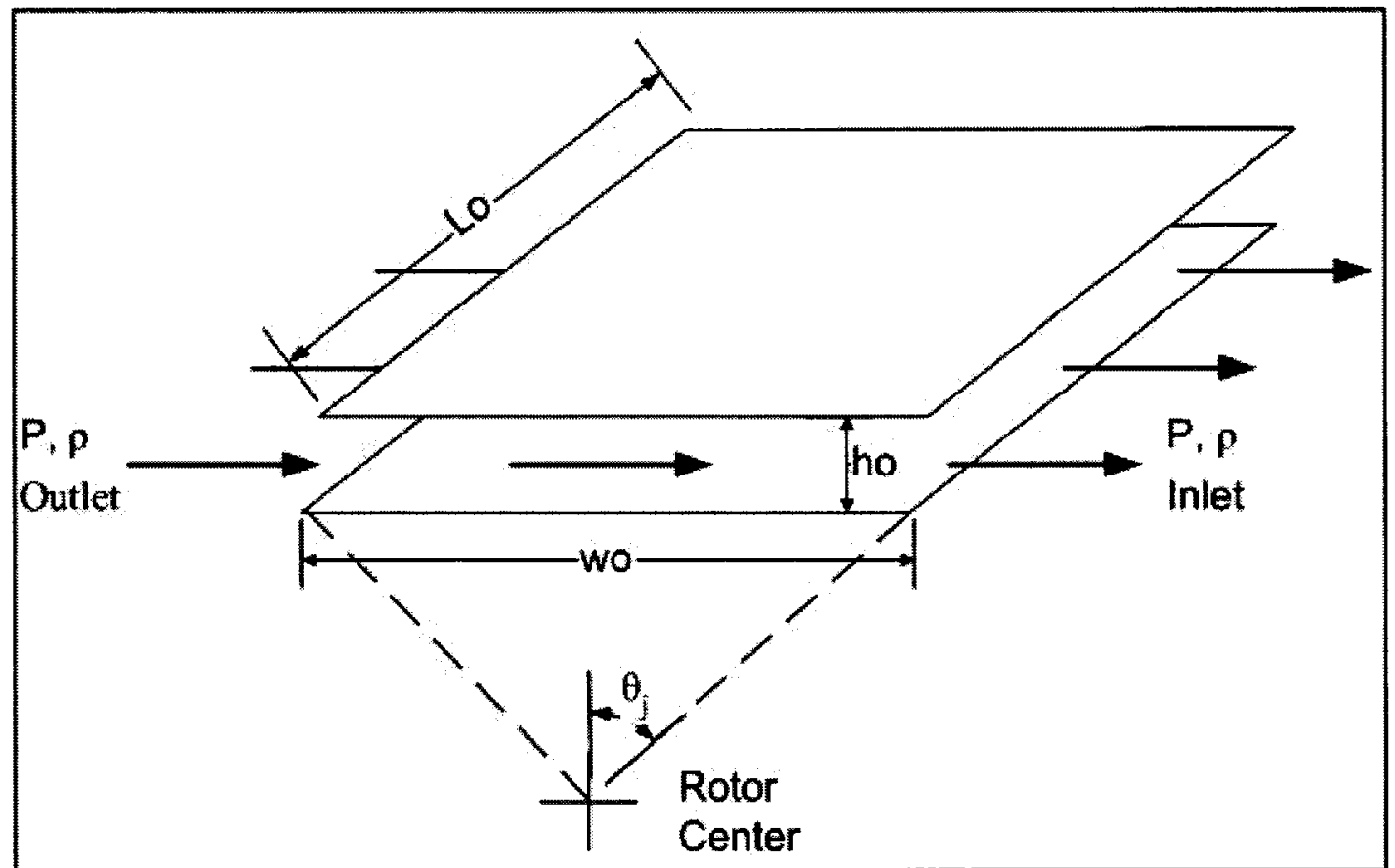

Figure 4.8 Nomenclature for Rotor Face Leakage

The value determined from Equation (4.23) is compared to the leakage that would occur at sonic speed and the lower of the two values is chosen.

Due to the conditions at the outlet port, the flow through the orifice is choked and hence mass exists from the compression chamber at sonic speeds. The function describing choked orifice flow is shown in Equation (4.26) [31].

$$
m_{l o s s, O R}=\rho \cdot C s t \cdot A \cdot \frac{2 \pi}{\omega N} \sqrt{k \cdot \rho \cdot P\left(\frac{2}{k+1}\right)^{\frac{k+1}{k-1}}}
$$


The total mass loss is simply a sum of the two mass losses. With these two losses calculated we are poised to be able to predict the mass loss and the pressure in the chamber at the outlet region.

\subsubsection{Governing Equations and Tip Friction Calculation}

In order to calculate the friction at the tip the rotor is divided into an angular mesh. The method in determining the properties is a pseudo steady method (see Appendix 1). At every angle the properties of the fluid and the amount of fluid lost from the chamber are calculated. The mass in the new angular interval is then calculated from the mass lost in the previous interval.

$$
\begin{aligned}
& A_{n}=A\left(\theta_{n}\right) \\
& m_{n}=m_{p}-m_{\text {loss }} \\
& \rho_{n}=\frac{m_{n}}{L \cdot A_{n}} \\
& p_{n}=p_{p}\left(\frac{\rho_{n}}{\rho_{p}}\right)^{\gamma}
\end{aligned}
$$

The frictional forces are calculated by balancing the forces in the $\mathrm{x}$ and $\mathrm{y}$ directions (See Figure 4.5) as well as balancing the moment about the 2-D plane. When the vane is sliding inwards, the force balance results in the following equation (Equation (4.33)).

$$
\vec{A} \cdot \vec{b}=\left[\begin{array}{ccc}
1 & -1 & v \\
v & v & -1 \\
R 1-r_{g}+\frac{h}{2}-v \cdot w & 0 & \frac{w}{2}-v(R 2-R 1)
\end{array}\right]\left[\begin{array}{c}
F_{N 1} \\
F_{N 2} \\
F_{N 3}
\end{array}\right]
$$




$$
\vec{C}=\left[\begin{array}{c}
-2 m_{g} \cdot \omega \cdot V_{r e l}-m_{g} \cdot g \cdot \sin \theta+\left(p_{H}-p_{L}\right)\left(r_{g}+\frac{h}{2}-R 1\right)+F x x \\
-p_{H} \cdot w \cdot L-m_{g} \cdot \omega^{2} \cdot r_{g}+m_{g} \cdot g \cdot \cos \theta-F_{y}+m_{g} \cdot a_{r e l} \\
\left(r_{g}-r_{1}\right)\left(m_{g}\left(2 \cdot w^{2} \cdot V_{r e l}-g \cdot \sin \theta\right)+\left(p_{H}-p_{L}\right)\left(r_{g}+\frac{h}{2}-R 1\right)\right. \\
\frac{x}{2}\left(m_{g} \cdot \omega^{2} \cdot r_{g}+m_{g} \cdot g \cdot \cos \theta\right)-p_{H} \cdot \frac{w^{2}}{2} \cdot L-\ldots \\
\left(3 p_{H}-P_{L}\right)\left(\frac{w^{2} \cdot L}{8} \sqrt{R_{3}^{2}-w^{2} / 16}\right)+F_{x x}\left(R_{2}-R_{1}\right)
\end{array}\right]+\ldots
$$

$\vec{A} \cdot \vec{b}=\vec{C}$

A similar equation is derived for when the vane is sliding outwards. The above equation will give values for $F_{N 1}, F_{N 2}$ and $F_{N 3}$ from which we can get the resulting frictional forces at any given angle, $\theta$, by using Coulomb's equation for dry friction (Equation (4.21)). Realizing that there are multiple vanes the power loss is averaged over each vane friction cycle (one revolution divided by the number of vanes). The power loss is then:

$$
P_{l o s s, V T}=\omega \cdot \sum_{\theta=0}^{2 \pi / z}\left(\sum_{1}^{z} F_{f} \times\left(r_{g}+\frac{h}{2}\right)\right) \frac{z}{2 \pi}
$$

The angular increment is directly related to the angular mesh size as there will be a friction value for each point in the mesh. 


\subsubsection{End Face Friction}

Due to the fact that the rotor rotates as the fluid leaks over the end face (See Figure 4.9), there is friction created by the shearing of the fluid. If we assume that the fluid between the plates is stationary then we can calculate the power loss due to shearing from first principles. The resulting equation is Equation (4.35) (see AppendixA.7 for derivation).

$$
P_{l o s s, R F}=\frac{\pi}{2 h o} \mu_{o i l} \cdot \omega^{2}\left(R 1^{4}-R_{B e a r}^{4}\right)
$$

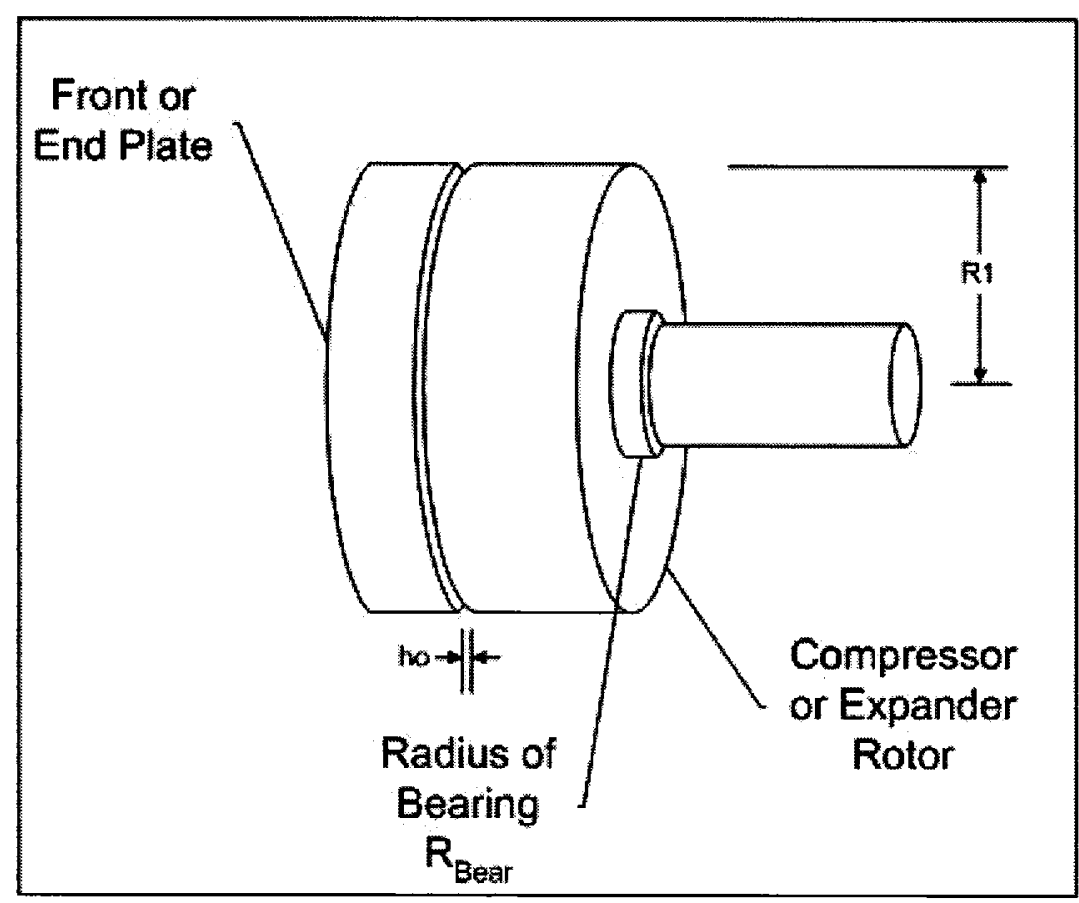

Figure 4.9 End Plate Shearing Friction

\subsubsection{Total Losses and Execution}

The total power lost from the machine due to friction is the sum of the vane tip losses and the rotor face losses. The total mass lost is the combination of the mass lost across the rotor face and the mass carried over through the top dead center. In order to get the exit pressure of the whole fluid, a linear mixture principle is applied. As discussed in Section 
4.1.4, the exit section mass loss through the orifice is calculated at each element of the outlet mesh. Also the exit pressure at the intervals is also known (after accounting for geometrical losses). The total outlet pressure is then a weighted average of the pressure based on the mass loss and is shown in Equation (4.36)

$$
p_{\text {out }, \text { comp }}=\frac{m_{\text {loss }, \text { OR }, 1} \cdot p_{\text {out }, 1}+m_{\text {loss }, \text { OR }, 2} \cdot p_{\text {out }, 2}+\ldots+m_{\text {loss }, \text { OR }, N} \cdot p_{\text {out }, N}}{\sum_{1}^{n} m_{\text {loss }, \text { OR }}}
$$

The compressor outlet temperature is then acquired using the isentropic-polytropic equation. A flow diagram of the MATLAB program code is shown below in Figure 4.10. The program starts of by accepting geometrical inputs the inputs and values used are shown in Table 4-1. This code can be found on the main ATS computer at C:Locuments and Settings\AdminlChuk\A3program [43].

Table 4-1 Geometrical Values

\begin{tabular}{|c|c|c|}
\hline Quantity & Value & Units \\
\hline$v_{\mathrm{st}}$ & 0.09 & - \\
\hline $\mathrm{m}_{\mathrm{cv}}$ & 36.58 & $\mathrm{~g}$ \\
\hline $\mathrm{m}_{\mathrm{ev}}$ & 12.08 & $\mathrm{~Pa} \cdot \mathrm{s}$ \\
\hline$\mu_{\mathrm{oil}}$ & 0.00431 & $\mathrm{~mm}$ \\
\hline $\mathrm{h}$ & 22.873 & $\mathrm{~mm}$ \\
\hline $\mathrm{w}$ & 6.55 & $\mathrm{~mm}$ \\
\hline 1 & 32.74 & $\mathrm{~mm}$ \\
\hline ho & 88.9 & \\
\hline
\end{tabular}

\footnotetext{
${ }^{*}$ Value has since been reduced by a factor of 3
} 


\begin{tabular}{|c|c|c|}
\hline R1 & 42.52 & $\mathrm{~mm}$ \\
\hline $\mathrm{R} 2$ & 50.78 & $\mathrm{~mm}$ \\
\hline $\mathrm{R} 3$ & 11.93 & $\mathrm{~mm}$ \\
\hline $\mathrm{R}_{\text {bear }}$ & 15.61 & $\mathrm{~mm}$ \\
\hline $\mathrm{z}$ & 5 & \\
\hline
\end{tabular}

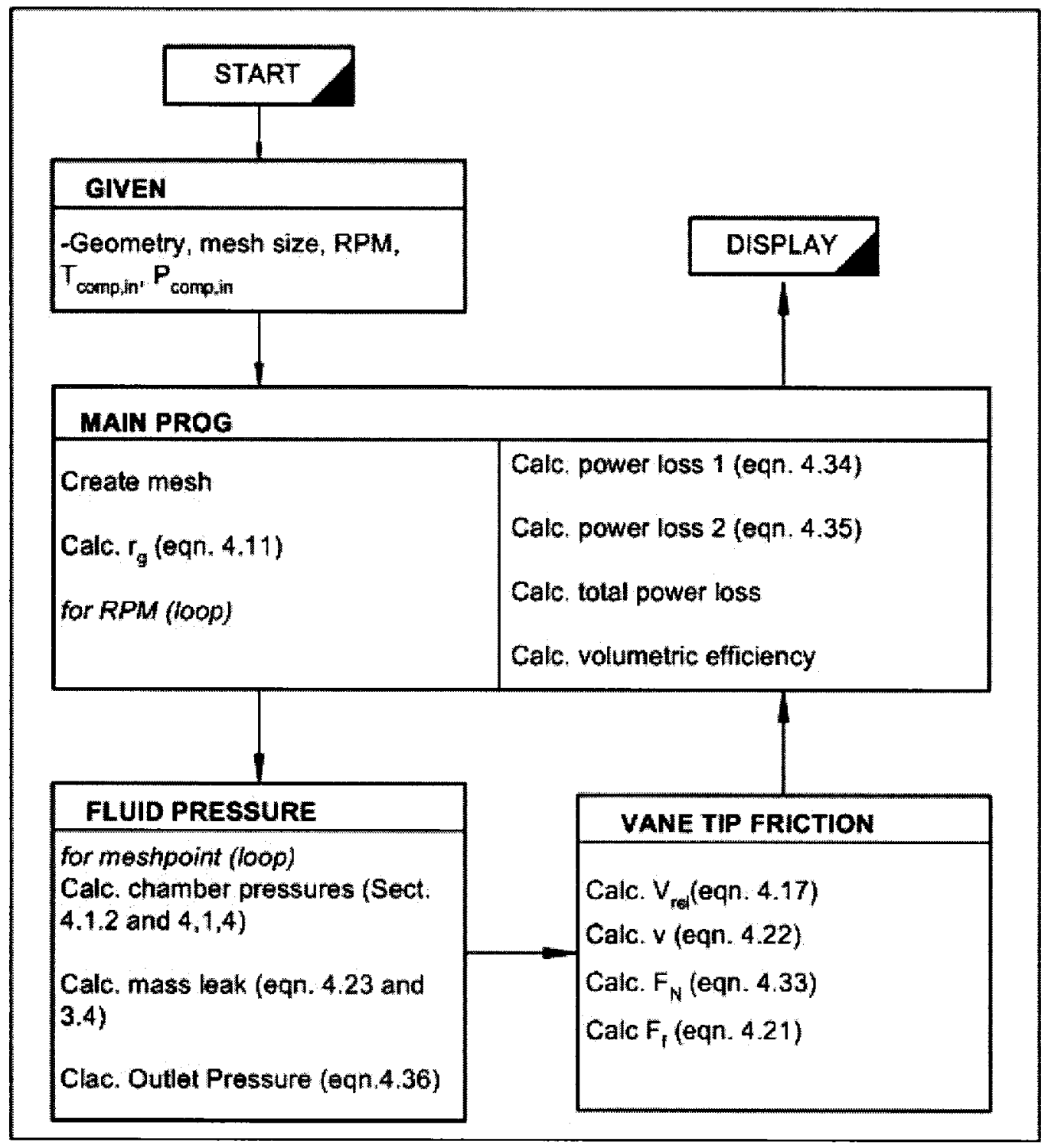

Figure 4.10 MATLAB Program: Flow Diagram 


\subsection{Analysis of the Full System}

The full system model uses the compressor model and integrates it into a model that has the condenser, expansion valve and evaporator as well as pipe losses. The accumulator is not modelled. The full system analysis aims to predict the COP, Carnot efficiency, volumetric efficiency and cooling capacity. In addition improvements to the compressor can be extrapolated to find the effects on the overall system. The inputs to the simulation are the same as the inputs to the experimental setup. The RPM, the evaporator chamber setting and the condenser fluid temperature. Geometrical parameters that describe the equipment are also needed.

\subsubsection{Thermodynamic Properties}

With a known temperature and quality or pressure the external refrigerant property program shown in Figure 4.10 is used to determine the specific volume enthalpy and entropy of the refrigerant. The Yaw's Handbook of Thermodynamic and Physical Properties of Chemicals is used to determine most of the other properties needed [32].

The specific heats are given as:

$$
\begin{aligned}
& C p_{v v}=\left(\begin{array}{l}
8.4290+34.996 T-3.3281 \times 10^{-4} T^{2}+\ldots \\
1.560 \times 10^{-7} T^{3}-2.9839 \times 10^{-11} T^{4}
\end{array}\right) \cdot 0.102032 \\
& C p_{l}=\left(\begin{array}{l}
49.523+66.134 \mathrm{~T}-2.7351 \times 10^{-3} \mathrm{~T}^{2}+\ldots \\
5.4918 \times 10^{-6} * \mathrm{~T}^{3}
\end{array}\right) \cdot 0.102032
\end{aligned}
$$

The viscosities are given as:

$$
\mu_{v}=\left(-10.861+0.4392 \mathrm{~T}-1.0316 \times 10^{-4} \mathrm{~T}^{2}\right) \cdot 10^{7}
$$




$$
3 \log _{10} \mu_{l}=\left(3107.5-\frac{3.3361 \times 10^{5}}{T}-9.6102 \mathrm{~T}+9.8587 \times 10^{-3} * \mathrm{~T}^{2}\right)
$$

The thermal conductivities are given as:

$$
\begin{aligned}
& \mathrm{k}_{\mathrm{v}}=-1.2331 \times 10^{-2}+8.5663 \times 10^{-5} \mathrm{~T}-4.6250 \times 10^{-9} * \mathrm{~T}^{2} \\
& k_{l}=0.1797-1.3521 \times 10^{-4} \mathrm{~T}-5.9505 \times 10^{-7} \mathrm{~T}^{2}
\end{aligned}
$$

And finally, the surface tension is given by:

$$
\sigma=90.588\left(1+\frac{T}{380}\right)^{1.3044}
$$

The units are Pa's for the viscosities, $\mathrm{W} / \mathrm{m} \cdot \mathrm{K}$ for the conductivities $\mathrm{N} / \mathrm{m}$ for the surface tension and $\mathrm{J} / \mathrm{kg} \cdot \mathrm{K}$ for the specific heats. As discussed in Shih's [30] work the two phase viscosity and conductivity may be determined as follows.

$$
\begin{aligned}
& \mu=\frac{v_{l} \mu_{l}}{v}+\frac{x}{v}\left(v_{v} \mu_{v}-v_{l} \mu_{l}\right) \\
& k=\frac{v_{l} k_{l}}{v}+\frac{x}{v}\left(v_{v} k_{v}-v_{l} k_{l}\right)
\end{aligned}
$$

The vapour volume is calculated according to Equation (4.19) and the liquid volume is then a simple subtraction between the total volume and the vapour volume fraction.

\subsubsection{Pressure Losses and External Heat Transfer Coefficients}

Turbulences and shear in pipes contribute to some pressure drop along the length of the pipe. The pressure drop is proportional to the length and usually some function of the Reynolds number and surface roughness. The pressure drop is defined as:

$$
\Delta p=f \frac{l}{d} \rho \frac{V_{m}^{2}}{2 g}
$$


Several correlations exist for quantifying the friction factor, $f$. in this work, the correlation used is taken from Holman's heat transfer text [34]:

$$
f=\left\{\begin{array}{cc}
1.325\left(\ln \left(\frac{\varepsilon}{3.7 d}+\frac{5.74}{\operatorname{Re}_{d}{ }^{0.9}}\right)\right)^{-2} & \mathrm{Re}>5000 \\
\frac{64}{\operatorname{Re}_{d}} & \operatorname{Re}<5000
\end{array}\right\}
$$

From experimental observations through several sight glasses located throughout the apparatus, it is seen that the two phase flow is stratified flow along the lines. For the two phase flows the liquid losses and the gaseous losses are treated separately over a segment of the pipe. At the end of each segment a mixture law is applied to ensure uniform pressure over the field. A finer segment will improve the results and the mesh is defined according to the required accuracy of the user. This method is similar to Martinelli's method which is one of the common methods of dealing with two phase friction [33]. As it turns out the Reynolds numbers are always well into the turbulent region in this work.

Geometrical pressure losses also occur in piping systems. This happens at bends, expansions, contractions and valves. The pressure drop is given by Equation (4.48) where the constant, $K$, is determined according to the report from Western Dynamics Company [35].

$$
\Delta p=K \frac{\rho V^{2}}{2}
$$




\subsubsection{Condenser Heat Transfer}

The heat transfer in the condenser is done in two or three stages. Firstly the superheated vapour is cooled to its saturated pressure. Then the saturated vapour is condensed to a saturated liquid and finally the liquid is sub-cooled.

In this work all the heat exchange will involve an internal and an external heat transfer process. The internal process refers to the heat transfer between the refrigerant and the pipe that contains it. And the external heat transfer refers to the transfer of heat to or from the pipe to the surroundings. Figure 4.11 is a schematic of the heat transfer over a pipe.

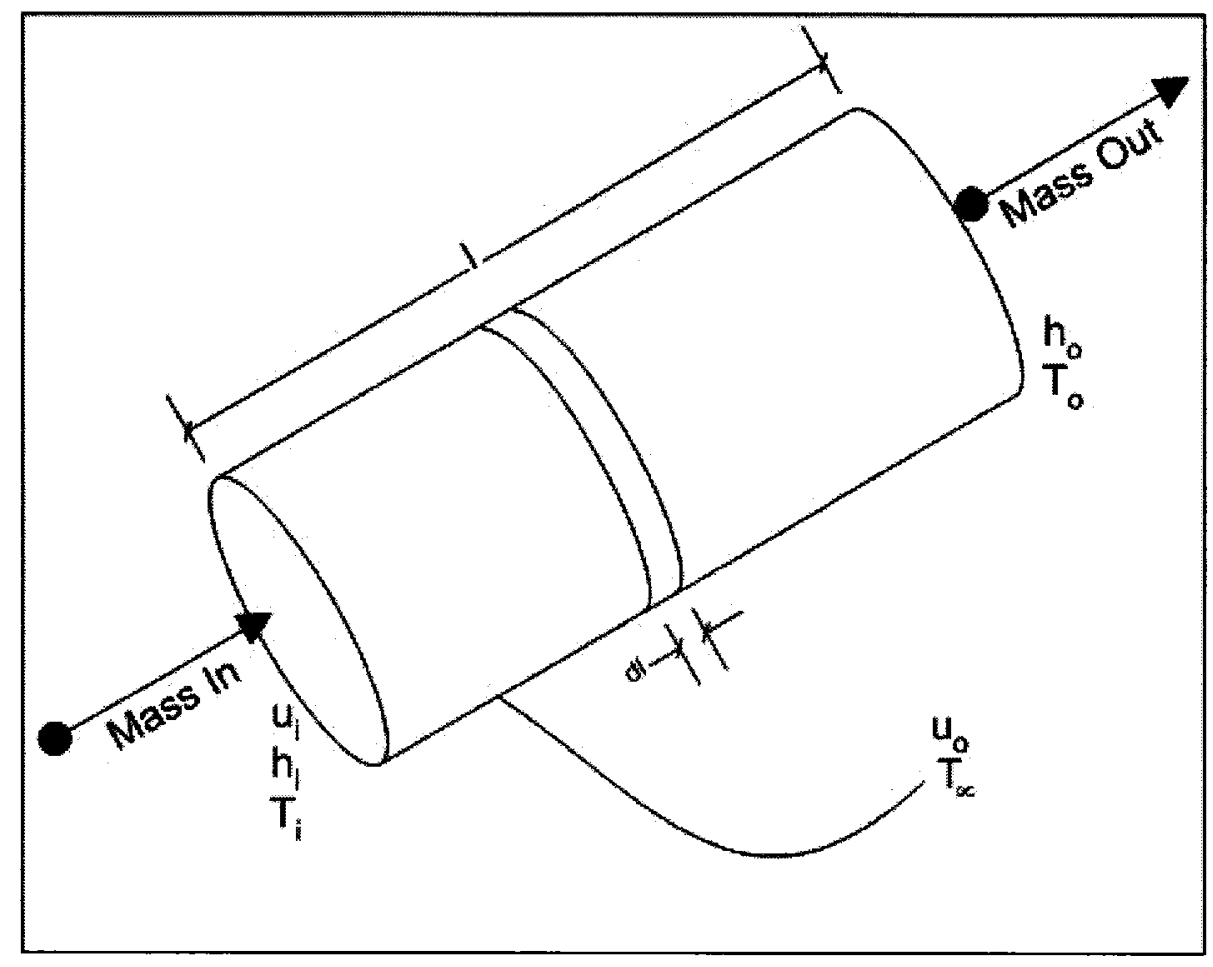

Figure 4.11 Heat Transfer over a Pipe

Using the overall heat transfer coefficient we can write [34]: 


$$
U=\frac{1}{\frac{1}{u_{i}}+\frac{A p \cdot \ln \left(R_{p, o} / R_{p, i}\right)}{2 \pi k l}+\frac{1}{u_{o}}}
$$

It is proposed that the external heat transfer coefficient is constant. This means that for a given setup we can predict the external heat transfer coefficient if we can determine the other parameters. Equation (4.50) is used to determine the external heat transfer coefficient. The internal coefficient is derived from simulated results, while the heat transfer, temperature and geometry data are measured experimentally.

$$
u_{o}=\frac{1}{\frac{A p \cdot \Delta T}{\dot{Q}}-\frac{1}{u_{i}}-\frac{A p \cdot \ln \left(R_{p, o} / R_{p, i}\right)}{2 \pi k l}}
$$

For the superheated region of the condenser the aim is to find the length over which the refrigerant remains superheated. This is done through an iterative process. Referring to Figure 4.11 the heat transfer can be described as:

$$
\dot{m} \cdot C p \cdot d T_{m}=U \cdot 2 \pi \cdot r\left(T_{\infty}-T_{m}\right) d l
$$

Of which the solution in terms of length is:

$$
\Delta L=\frac{\dot{m} \cdot C p}{U \cdot \pi \cdot d} \ln \left(\frac{T_{\text {in }}-T_{\text {out }}}{T_{\text {in }}-T_{\infty}}\right)
$$

For this stage the outlet temperature, $T_{o}$, is assumed to be the saturated temperature at constant pressure. The surrounding temperature, $T_{\infty}$, is the water temperature. All that is left is to determine the overall heat transfer coefficient of which the internal heat transfer convective coefficient, $u_{i}$, is the only unknown (Equation 4.49). The Sieder and Tate heat transfer coefficient for laminar or turbulent gas flow is shown below [34]. 


$$
u_{\text {conv }}=\left\{\begin{array}{cc}
\frac{k}{d}\left(1.86\left(\operatorname{Re}_{d} \cdot \operatorname{Pr}\right)^{1 / 3}\left(\frac{d}{l}\right)^{1 / 3}\left(\frac{\mu}{\mu_{w}}\right)^{0.14}\right. & \operatorname{Re}<3000 \\
\frac{k}{d} 0.027 \operatorname{Re}_{d}^{0.8} \cdot \operatorname{Pr}^{1 / 3}\left(\frac{\mu}{\mu_{w}}\right)^{0.14} & \operatorname{Re}>3000
\end{array}\right\}
$$

The length is then found using Equation (4.52). With this length a pressure drop is calculated according to the procedure described in Section 4.2.2. With the new value for the saturated pressure, the saturated temperature, $T_{0}$, can be found using a refrigerant property program. The whole loop is repeated again until the length and the pressure converges. A flow diagram is shown below.

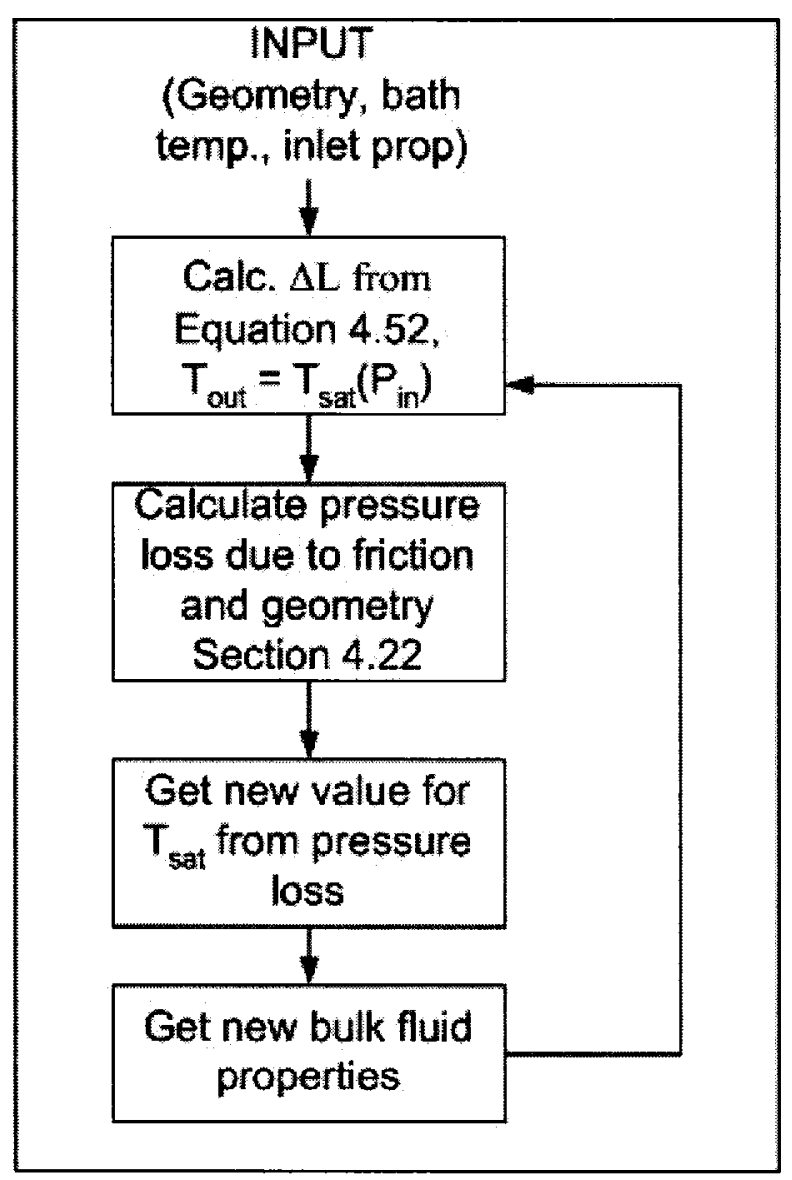

Figure 4.12 Flow Diagram for Determining Condensation Onset 
At this point condensation begins. If the Reynolds number of the vapour (described in Equation (4.54)) is less than 35000 , Chato [36] showed that the condensation convective heat transfer is not significantly dependent on the quality of the refrigerant and can be written as shown in Equation (4.55).

$$
\begin{aligned}
& \operatorname{Re}_{d, v}=\left(\frac{\rho_{v} \cdot V_{m, v} \cdot d}{\mu_{v}}\right) \\
& u_{\text {cond }}=0.555\left(\frac{g \cdot \rho_{l}\left(\rho_{l}-\rho_{v}\right) k_{l}^{3} \cdot h_{f g}^{\prime}}{\varpi_{v}\left(T_{\text {sat }}-T_{w}\right) d}\right)^{1 / 4} \\
& h_{f g}^{\prime}=h_{f g}+3 / 8 C p_{l}\left(T_{\text {saat }}-T_{w}\right)
\end{aligned}
$$

For situations where the Reynolds number supersedes this value Akers et al. recommended a different correlation [37].

$$
\begin{aligned}
& u_{\text {cond }}=\frac{k_{l}}{d} 0.026 \operatorname{Pr}_{l}^{1 / 3} \cdot \operatorname{Re}_{m}^{0.8} \\
& \operatorname{Re}_{m}=\frac{d}{\mu_{l}}\left(\frac{\dot{m}_{l}}{A c}+\frac{\dot{m}_{v}}{A c}\left(\frac{\rho_{l}}{\rho_{v}}\right)^{1 / 2}\right)
\end{aligned}
$$

If the fluid becomes subcooled the Dittus and Boelter correlation is used to determine the convective heat transfer coefficient. This is simply Equation (4.57) but the Reynolds number is calculated for just the liquid and the power on the Prandtl number is 0.3 . The enthalpy out of the condenser and the quality out of the condenser are then calculated as follows:

$$
\begin{aligned}
& h_{\text {cond }, n}=h_{\text {cond }, p}-\frac{U \cdot \pi \cdot d \cdot l}{\dot{m}}\left(T_{\text {saat }}-T_{w}\right) \\
& x=\frac{h_{\text {cond }, n}-h_{l}}{h_{f g}}
\end{aligned}
$$


A pressure drop due to the friction and geometry is calculated over the condenser length. It is however assumed that the pressure drop is linear over the length. The tubing is then meshed into several segments and at each segment the above correlations are applied. At the end of each segment an enthalpy and new saturated temperature are calculated and the whole process is repeated until the exit section (see Appendix A.1).

\subsubsection{Expansion Device Pressure Drop}

As proposed by Koury et al. [38], if the expansion device is assumed to be adiabatic and isenthalpic then the process can be modelled as shown in Equation (4.61).

$$
\Delta P=\left(\frac{\dot{m}_{l}}{K}\right)^{2} \frac{1}{\rho_{l}}
$$

The value of $K$ should ideally be constant and obtained from experimental data with the orifice in question. In a variable orifice expansion the value of $\mathrm{K}$ would have to be determined for each setting of the orifice. In this work the value of $\mathrm{K}$ was observed to be related to the inlet pressure. Equation was used as the value of $\mathrm{K}$ with a $5 \%$ error when compared to experimental values.

$$
K \times 10^{6}=2.2814 \ln \left(P_{i n} / 10^{3}\right)-13.079
$$

\subsubsection{Evaporator Boiling Heat Transfer}

Modelling boiling heat transfer is in general a complex exercise. The rate of boiling heat transfer depends on countless factors. In this work the aim is to balance simplicity and accuracy. A lot of literature exists in the proper way to predict boiling. Accuracy of prediction can be achieved if the exact mode of boiling is known (i.e. film boiling, nucleate boiling etc.). The method used in this work requires an initial prediction of the 
boiling heat flux. This heat flux may vary as much as $40 \%$ from the actual predicted heat flux, but with the right order of magnitude it is sufficient in calculation some parameters used to predict the boiling heat flux.

The heat transfer equation for convective boiling is taken as the same as that of convective heat transfer

$$
\dot{Q}=U \cdot A c \cdot \Delta T
$$

The internal heat transfer coefficient is calculated as a function of the boiling heat transfer coefficient as though there was no flow and the convective heat transfer coefficient as though there was no boiling. For the estimate of the heat transfer, the internal heat transfer coefficient is assumed to be a function of a radiation and boiling component[34]. These heat transfer coefficient are give as:

$$
\begin{aligned}
& u_{b}=0.62\left(\frac{k_{v}^{2} \cdot \rho_{v}\left(\rho_{l}-\rho_{v}\right) \cdot g\left(h_{f g}+0.4 C p_{v}\right)}{d \cdot \mu_{v} \cdot\left(T_{w}-T_{s a t}\right)}\right)^{1 / 4} \\
& u_{r}=\sigma b \frac{\left(T_{w}^{4}-T_{\text {sat }}^{4}\right)}{T_{w}-T_{\text {sat }}} \\
& u_{i}=u_{b}\left(u_{b} / u_{i}\right)^{1 / 3}+u_{r}
\end{aligned}
$$

Equation (4.66) is an implicit function of the internal heat transfer coefficient, $u_{i}$ and is solved using the Newton-Raphson method. From the internal heat transfer coefficient the overall coefficient is calculated in the same manner as in the condensation section. Then the boiling heat transfer is calculated using Equation (4.63). For the main boiling analysis it is found that the boiling heat transfer is dependent on the quality of the system. 
In the low quality region the Kandikar correlation [39] could be used. This correlation has the advantage of describing the right trends in the prediction of the heat transfer. Although it is not as accurate as the Winterton correlation over some specific ranges, it is better over a wide range of data especially at lower qualities [39]. In this correlation the forced convective coefficient and the boiling coefficient are calculated separately and then combined to get the total heat transfer. In this work, the Winterton correlation is only used for quality higher than 0.96 . For the lower quality the Rohsenow correlations are used [40]. The forced convective coeffcients are acquired as follows:

$$
\begin{aligned}
& u_{F C, 0}=0.023\left(\frac{G \cdot d}{\mu_{l}}\right)^{0.8}\left(\frac{\mu_{l} \cdot C p_{m}}{k_{m}}\right)^{1 / 3} \frac{k_{l}}{d} \\
& u_{F C, 0.6}=\frac{\operatorname{Re}_{d, l}^{0.9} \cdot \operatorname{Pr}_{l} \cdot H\left(X_{t t}\right) \cdot k_{l}}{F 2 \cdot d}
\end{aligned}
$$

Where:

$$
\begin{aligned}
& \operatorname{Re}_{d, l}=\frac{G \cdot d(1-x)}{\mu_{l}} \\
& H\left(X_{t t}\right)=0.15\left(\frac{1}{X_{t t}}+2\left(\frac{1}{X_{t t}}\right)^{0.32}\right) \\
& X_{t t}=\left(\frac{\rho_{v}}{\rho_{l}}\right)^{0.5}\left(\frac{\mu_{l}}{\mu_{v}}\right)^{0.1}\left(\frac{1-x}{x}\right)^{0.9} \\
& F 2=\left\{\begin{array}{cc}
5 \operatorname{Pr}_{l}+5 \ln \left(1+5 \operatorname{Pr}_{l}\right)+2.5 \ln \left(0.0031 \operatorname{Re}_{d, l}^{0.812}\right) & \operatorname{Re}_{d, l}>1125 \\
5 \operatorname{Pr}_{l}+5 \ln \left(1+\operatorname{Pr}_{l}\left(0.0964 \operatorname{Re}_{d, l}^{0.585}-1\right)\right) & 50<\operatorname{Re}_{d, l} \leq 1125 \\
0.0707 \operatorname{Pr}_{l} \operatorname{Re}_{d, l}^{0.5} & \operatorname{Re}_{d, l}<50
\end{array}\right\}
\end{aligned}
$$

The boiling portion for the heat transfer is derived from the following correlations: 


$$
u_{b, 0}=\frac{B M \cdot \mu_{l} \cdot h_{f g} \cdot k_{l}^{1 / 2} \cdot \rho_{l}^{17 / 8} \cdot C p_{l}^{19 / 8} \cdot \rho_{v}^{1 / 8}}{\mu_{m} \cdot h_{f g}^{7 / 8}\left(\rho_{l}-\rho_{v}\right)^{9 / 8} \cdot \sigma^{5 / 8} \cdot T_{s a t}^{1 / 8}}\left(\frac{g\left(\rho_{l}-\rho_{v}\right)}{g_{o} \cdot \sigma}\right)\left(T_{w}-T_{s a t}\right)^{2}
$$

The constant BM is $3.09 \times 10^{-14}$ for R-134a and for SI unit, $g_{0}$ is unity. Now using the Winterton correlations we get:

$$
\begin{aligned}
& u_{b, 0.96}=u_{b, l} \cdot C 1 \cdot C o^{C 2}\left(25 F r_{l e}\right)^{C 5}+C 3 B o^{C 4} \cdot F f l \\
& B o=\frac{\dot{Q}}{G \cdot h_{f g}} \\
& F r_{l e}=\frac{G^{2}}{\rho_{l}^{2} \cdot g \cdot d}
\end{aligned}
$$

In determining the quantity $B o$ a value for the heat transfer rate is required. The value used is that from the heat transfer approximation in Equations (4.63) to (4.66). All the values of the $C$ constants as well as $F f l$ can be obtained from Rohsenow's text [39]. When the flow becomes superheated, the Dittus and Boetler correlation is used to model the heat transfer. When the heat transfer coefficient is dependent on the quality, the pseudo steady analysis described in Appendix A.1 is used. In summary the internal convective coefficients are as shown below.

$$
u_{i}=\left\{\begin{array}{cc}
{\left[u_{F C, 0}^{2}+u_{b, 0}^{2}\left(1-\left(\frac{\Delta T_{\text {sat }, i b}}{T_{w}-T_{\text {sat }}}\right)^{3}\right)^{2}\right]^{1 / 2}} & 0<x<0.6 \\
u_{F C, 0.6}+u_{b, 0}\left(1-\left(\frac{\Delta T_{s a t, i b}}{T_{w}-T_{s a t}}\right)^{3}\right) & 0.6 \leq x<0.96 \\
u_{b, 0.96} & 0.96 \leq x<1 \\
0.024 \operatorname{Re}_{d}^{0.8} \operatorname{Pr}_{l}^{0.4} & x \geq 1
\end{array}\right\}
$$




\subsubsection{Execution of the Full System Model}

For the full system model an iterative process is used until convergence is reached. The conditions at the inlet of the compressor are guessed. In this case the temperature and the

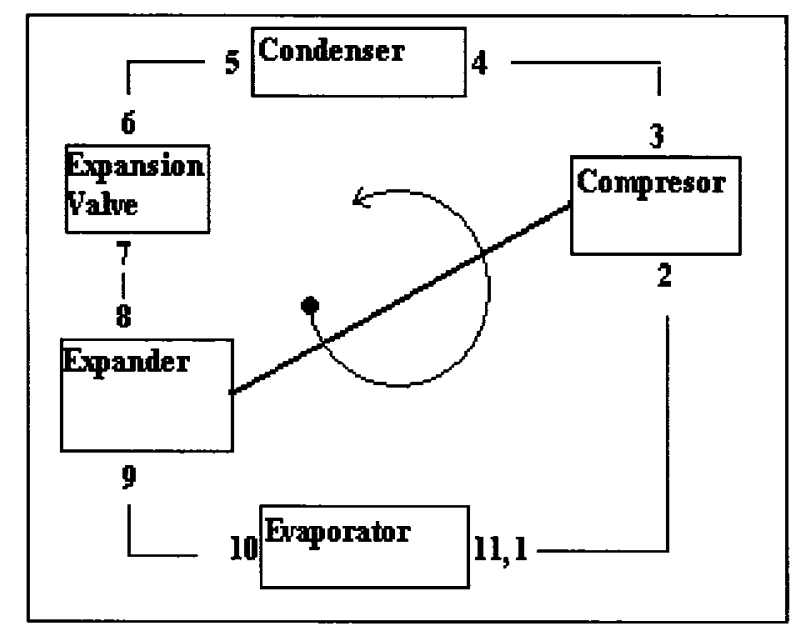

Figure 4.13 Nodes Used in the Full System Analysis

quality are the approximated components. The loop shown in Figure 4.14 is started off by a temperature and quality guess which is then compared to the output of the evaporator. If the difference in the values does not meet a loop exit criteria, the evaporator output is the fed-back into the compressor and the loop continues until the convergence criteria is met. The convergence criteria used in this work is discussed in Section 5.1.3. This loop was programmed using MATLAB code. The wall temperature, which is a required input for the heat exchangers, is unknown. The chamber temperatures are used to approximate the wall temperature in these cases. The MATLAB program outputs the variables into an Excel file as shown in Figure 4.15. The location of the program is on the main ATS computer at C:IDocuments and Settings\Admin $\backslash$ Chuk\A3program and the Excel results are in C:Documents and Settings\AdminlChuk\A3program|Results [43]. 


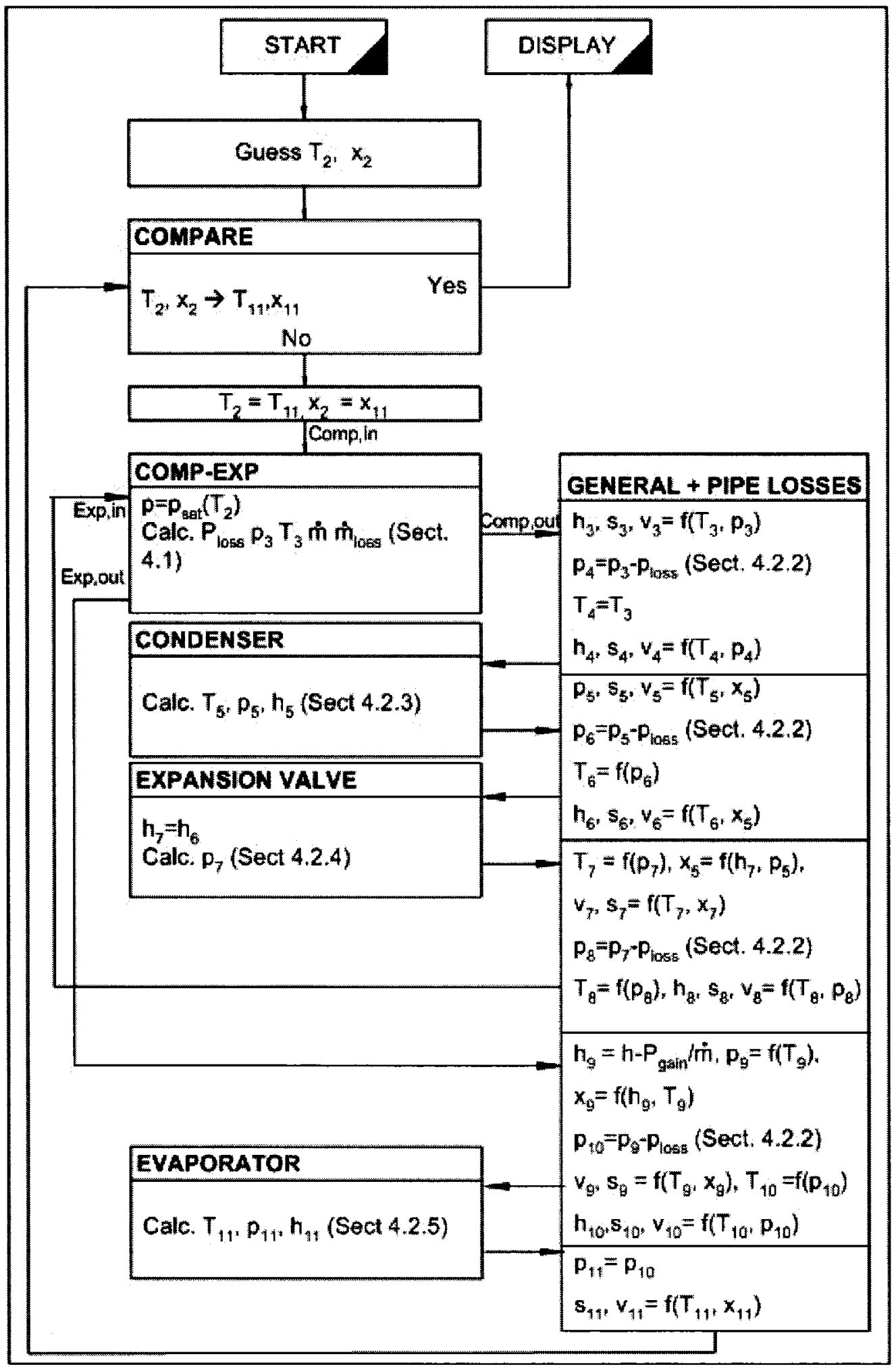

Figure 4.14 Flow Diagram of Full System Analysis 


\begin{tabular}{|c|c|c|c|c|}
\hline 3 & A & 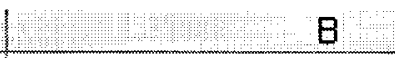 & c & D \\
\hline 1 & & & & \\
\hline 2 & \multirow{5}{*}{ Input } & Temperature $(\mathrm{K})$ & T1 & 295.9676 \\
\hline 3 & & Pressure (Pa) & P1 & 0 \\
\hline 4 & & Enthalpy (J/kg) & h1 & 0 \\
\hline 5 & & Specific volume $\left(m^{n} 3 / \mathrm{kg}\right)$ & v1 & 0 \\
\hline 5 & & quality & $\times 1$ & 1.004235 \\
\hline 7 & & & & 0 \\
\hline 8 & \multirow{5}{*}{ Compressor Inlet } & Temperature $(\mathrm{K})$ & $\mathrm{T} 2$ & 295.9676 \\
\hline 9 & & Pressure $(\mathrm{Pa})$ & P2 & 625980.2 \\
\hline 10 & & Enthalpy (J/kg) & h2 & 411340.4 \\
\hline 11 & & Specific volume $\left(\mathrm{m}^{n} 3 / \mathrm{kg}\right)$ & $\sqrt{2}$ & 0.032895 \\
\hline 12 & & quality & $\times 2$ & 1.004235 \\
\hline 13 & & & & 0 \\
\hline 14 & \multirow{5}{*}{ Compressor Outlet } & Temperature $(\mathrm{K})$ & T3 & 312.8339 \\
\hline 15 & & Pressure (Pa) & P3 & 987684.6 \\
\hline 16 & & Enthalpy (J/kg) & h3 & 419988.9 \\
\hline 17 & & Specific volume $\left(\mathrm{m}^{n} 3 / \mathrm{kg}\right)$ & $\sqrt{3}$ & 0.020824 \\
\hline 18 & & quality & $\times 3$ & 2 \\
\hline 19 & & & & 0 \\
\hline 20 & \multirow{5}{*}{ Condensner Inlet } & Temperature $(\mathrm{K})$ & $\mathrm{TH}$ & 312.8339 \\
\hline 21 & & Pressure (Pa) & P4 & 985054 \\
\hline 22 & & Enthalpy (J/kg) & h4 & 420046.5 \\
\hline 23 & & Specific volume $\left(\mathrm{m}^{n} 3 / \mathrm{kg}\right)$ & v4 & 0.020894 \\
\hline 24 & & quality & $x 4$ & 0 \\
\hline 25 & & & & 0 \\
\hline 26 & \multirow{5}{*}{ Condenser Outlet } & Temperature $(\mathrm{K})$ & T5 & 311.8286 \\
\hline 27 & & Pressure ( $\mathrm{Pa}$ ) & P5 & 984765.4 \\
\hline 28 & & Enthalpy (J/kg) & h5 & 304216.6 \\
\hline 29 & & Specific volume ( $\left.\mathrm{m}^{n} 3 / \mathrm{kg}\right)$ & 45 & 0.00682 \\
\hline 30 & & quality & $x 5$ & 0.301149 \\
\hline 31 & & & & 0 \\
\hline
\end{tabular}

Figure 4.15 MATLAB Output to Excel (excerpt)

Several parameters are calculated in the Excel spreadsheet. The items highlighted in yellow are empty rather than having a value of zero. The cooling capacity is calculated as:

$$
P_{\text {evap }}=\dot{m}\left(h_{11}-h_{10}\right)
$$


The power input to the compressor is acquired from the power required to compress the fluid, the power lost to friction and the power gained from the expander. The expression used to calculate the compressor power is shown below.

$$
P_{\text {comp }}=\dot{m}\left(h_{3}-h_{2}\right)+P_{\text {loss,comp }}-P_{\text {gain }}
$$

The COP is then defined as:

$$
C O P=\frac{P_{\text {evap }}}{P_{\text {comp }}}
$$

The cycle is compared to the ideal Carnot cycle in which the heat exchanges operate isobarically and the compressor operates isentropically. This efficiency is usually quoted as the second-law efficiency and is given as follows

$$
\eta_{c}=\frac{C O P}{T_{\text {evap }, \text { out }} /\left(T_{\text {cond }, \text { out }}-T_{\text {evap }, \text { out }}\right)}
$$




\section{Chapter 5: Results and Discussion}

In this section the results of the experimental work and the analytical work is presented and discussed. Convergence of the simulation is also discussed. In addition a comparison of the experimental and theoretical work is performed.

\subsection{Grid and Loop Convergence}

\subsubsection{Rotor Mesh Convergence}

The grid used for the rotor as described in section 4.5.1 was initially treated as a uniform mesh but later the outlet section was meshed separately from the rest of the rotor as shown in Figure 5.1.

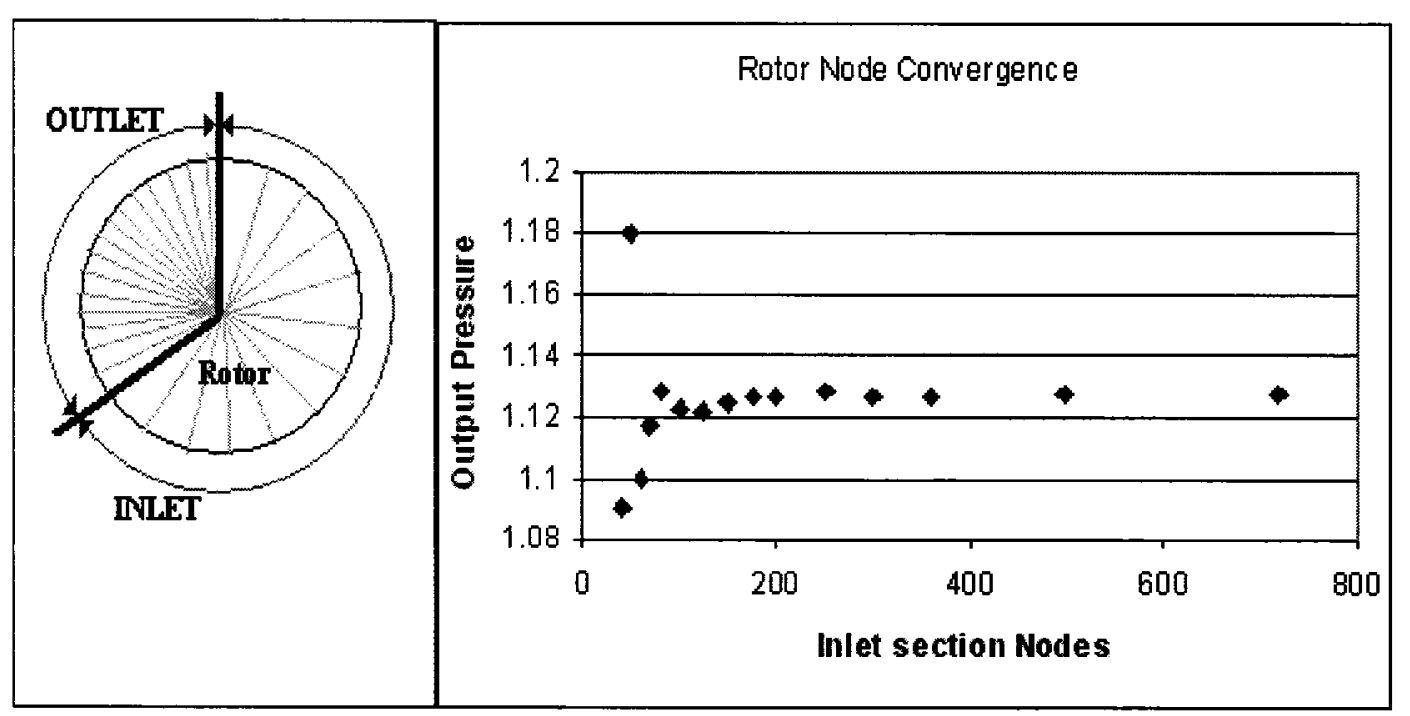

Figure 5.1 Rotor Mesh (Output Pressure in MPa) 
The density of the outlet mesh is defined to be three times that of the rest of the rotor. As shown in Figure 5.1, the output pressure calculated at 1500 RPM converges at about 200 nodes to $\pm 0.005 \mathrm{MPa}$. In this work, 208 nodes are used for the inlet portion and 456 nodes for the outlet section.

\subsubsection{Heat Exchanger Convergence}

With regards to the condenser and evaporator, the tube is divided in segments and then the heat transfer in each segment calculated and totalled. For the condenser, the heat transfer rate converges to $\pm 0.001 \mathrm{~kW}$ when the heat exchanger is divided into segments of $1.3 \mathrm{~mm}$. In this work $1 \mathrm{~mm}$ is used as the segment length. At lengths of $1 \mathrm{~mm}$ the boiling heat transfer rate converges to $\pm 0.007 \mathrm{~kW}$.

\subsubsection{Overall System Convergence}

The overall system the loop shown in Figure 4.14 is terminated when the temperature converges within $\pm 0.001 \mathrm{~K}$ and the quality converges to within \pm 0.05 . The loop diverges for unreasonable predictions of the temperature and quality. This means that the first estimates must be within a reasonable range. In this work room temperature is used as the starting temperature. The number of iterations to convergence depends on the original prediction. It was found that at 1500 RPM convergence was obtained in 5 iterations, however this is attributed to the fact that the predicted evaporator temperature of 25 Celsius was close to the final evaporator temperature. At 700 RPM 102 iterations were needed before convergence was achieved and at 2000 RPM, 38 iterations were required. 


\subsection{Compressor-Expander Program}

This section presents the results for the compressor-expander program alone. Over the course of the experiments modifications were made to the compressor-expander. Of significant importance, the end face clearance, ho, was reduced from $88.9 \mu \mathrm{m}$ (3.5 thou) to $25 \mu \mathrm{m}$ (1 thou).

\subsubsection{Compressor-Expander Simulation Results}

The work presented in this section is the compressor-expander simulated results. Figure 5.2 shows how the analytical model compares with results derived experimentally in predicting the power loss. The analytical model predicts the power loss based on compressor inputs and geometry alone. The experimental data is taken at various RPMs and various repetitions. The value of ho is $88.9 \mu \mathrm{m}$ at this point.

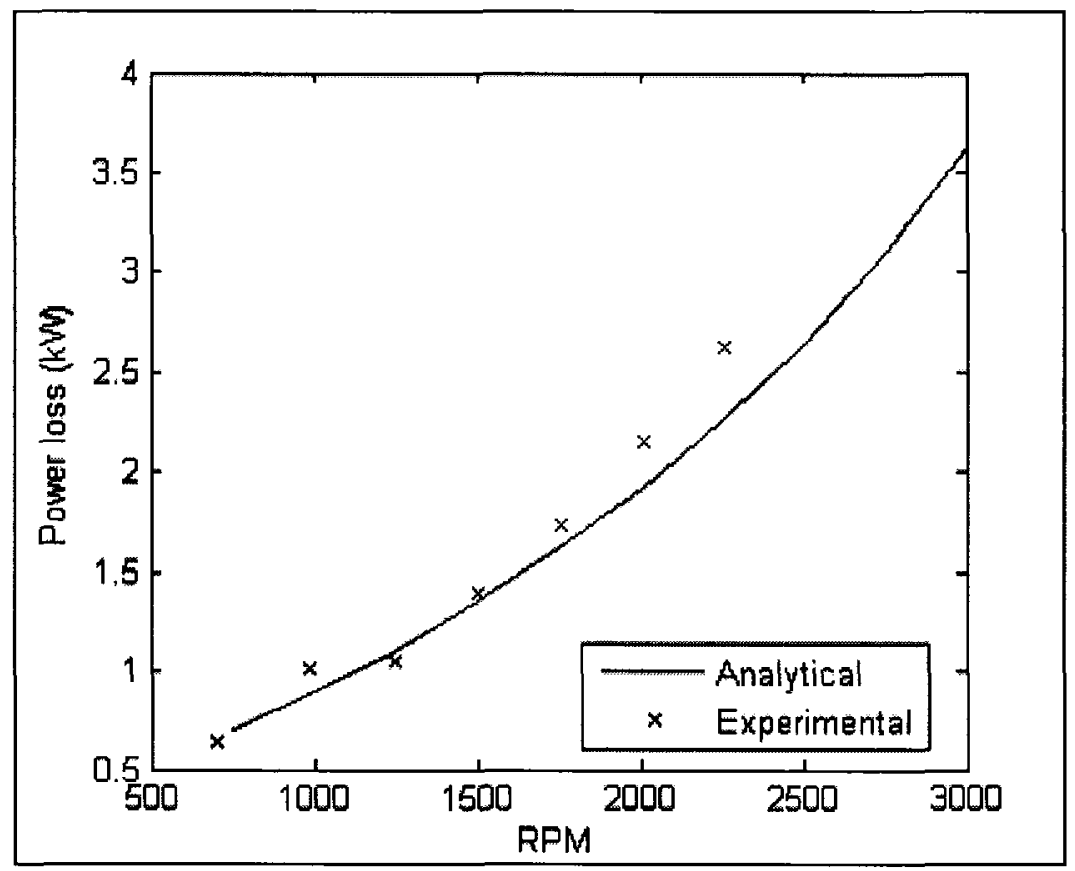

Figure 5.2 Results of Power Loss Estimation 


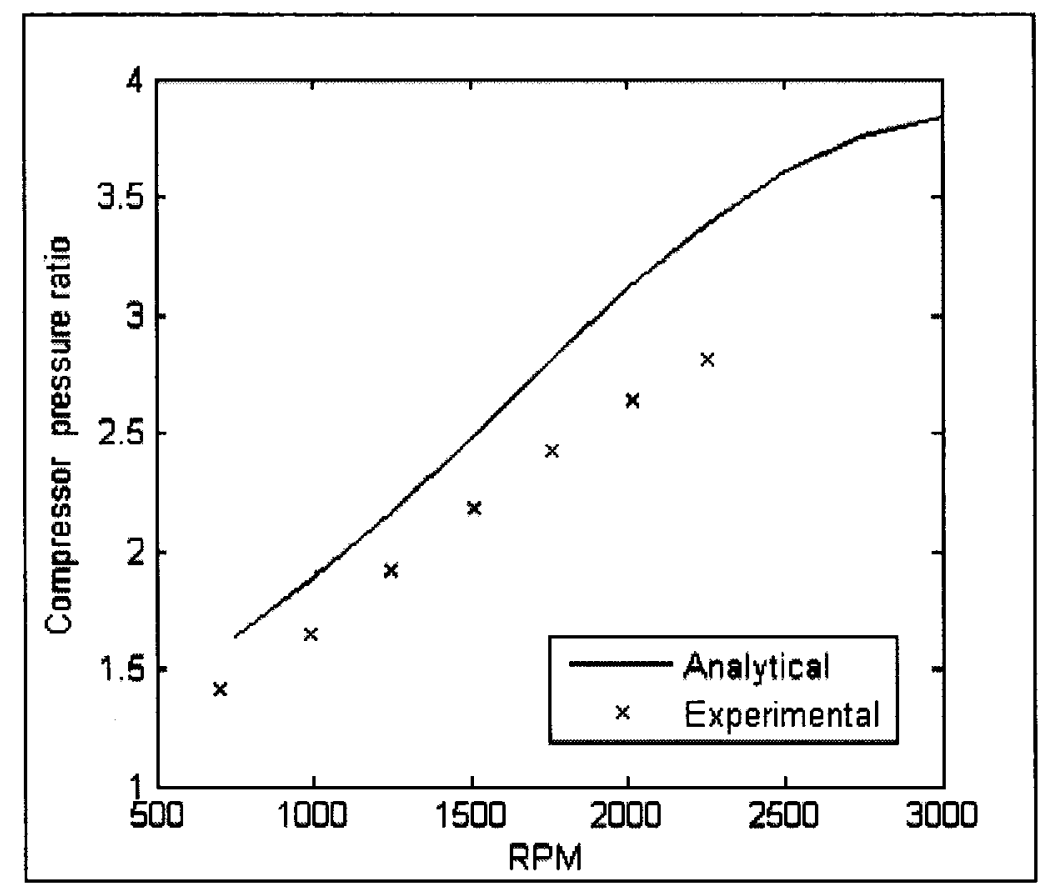

Figure 5.3 Compressor Pressure Ratio vs. Compressor RPM

Figure 5.3 compares the adiabatically predicted pressure ratio of the compressor and experimentally obtained data for the pressure ratio. The results are plotted against the compressor RPM as well. Figure 5.4 and Figure 5.5 show results from using simulation to predict the effect of change in the sliding coefficient of friction (better internal lubrication) and change in the end face gap between the rotor and the case (see Figure 4.9). 


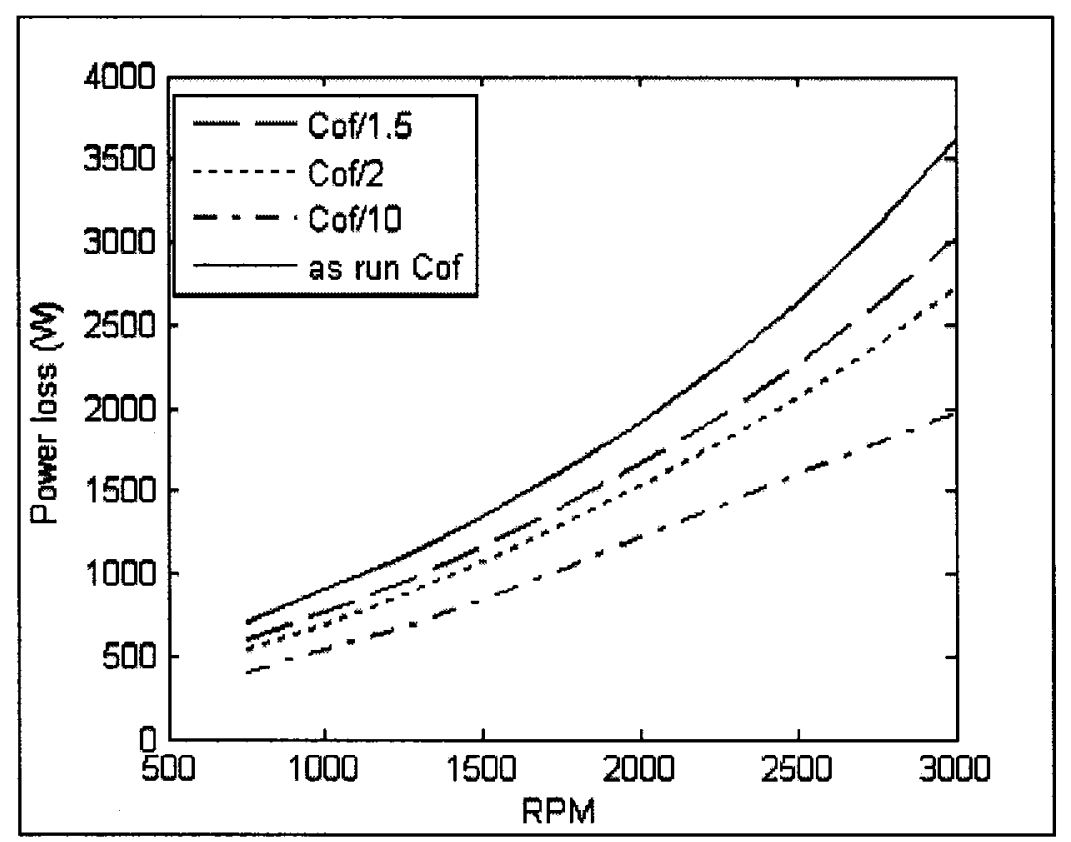

Figure 5.4 Predicted Effect of Vane Lubrication on Compressor Power Loss

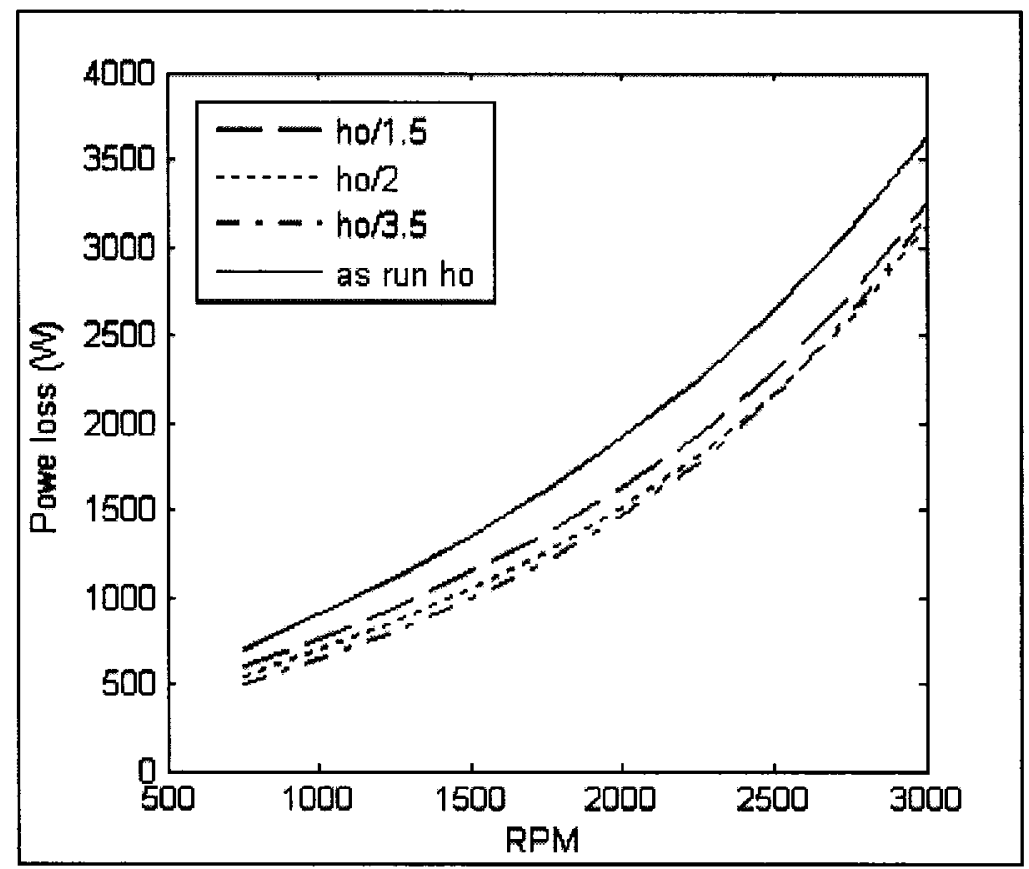

Figure 5.5 Predicted Effect of Rotor End Face Clearance on Power Loss 
The predicted volumetric efficiency is shown as a function of RPM and compared to experimental results in Figure 5.6. After improvement in the value of the end-face clearance from $88.9 \mu \mathrm{m}$ to $25 \mu \mathrm{m}$, the power loss and RPM are checked to see if there is any credibility in the simulation's predictions. The result of this check is represented in Figure 5.7.

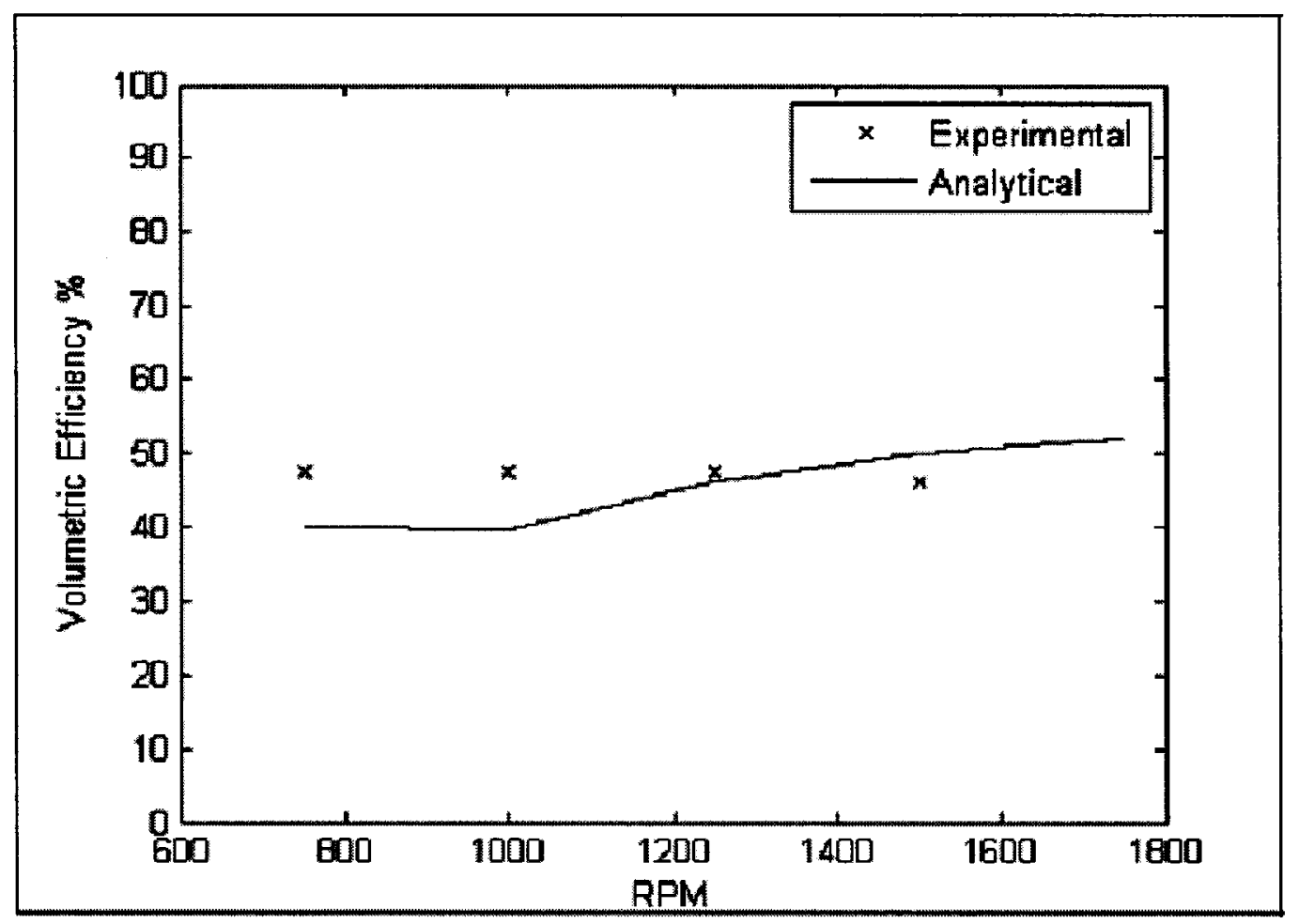

Figure 5.6 Effect of RPM on Volumetric Efficiency, $h_{0}=25$ microns 


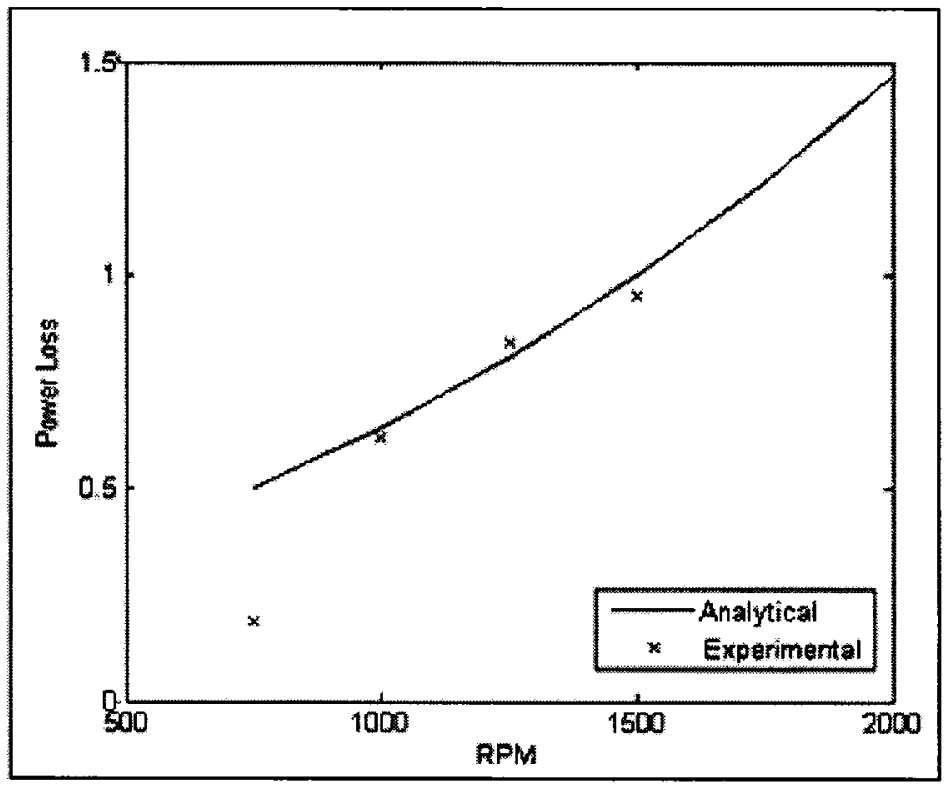

Figure 5.7 Power Loss vs. RPM for Improved End-Face Clearance

\subsubsection{Discussion of Compressor-expander Simulation Results}

As seen in Figure 5.2, the results of the simulation compares very well with experimental data in predicting the power loss of the compressor-expander unit. The predicted losses are a slightly conservative estimate. Both the trend and the magnitude of the power loss are predicted accurately. The average error in predicting the power loss is $5.6 \%$ with a maximum error occurring at 1000 RPM of $13 \%$. Although the coefficient of friction (COF) decreases as sliding speed increases (according to Equation (4.22)), the power loss increases with the increase in RPM. This can be attributed to the increase in the normal centrifugal forces and as well as the back pressure force i.e. in Equation (4.21), $F_{N}$ increases faster than $v$ decreases as the compressor RPM is set to higher speeds.

As expected, the adiabatic compression ratio is larger than the experimentally determined compression ratio. As seen in Figure 5.3, the average over-prediction of 
pressure ratio is $20 \%$. From experimental observation, body temperature of the unit is in the order of $50^{\circ} \mathrm{C}$. This means that heat is being lost through the compressor body hence the adiabatic assumption is not completely valid. However not all of this heat comes from the compressing of the fluid, some of the heat is from the rubbing of components in the compressor such as the vane tip on the inner wall of the compressor-expander casing. Also the output pressure increases as the compressor speed is increased which is expected from the nature of the compressor exit design. As the speed increases the fluid has less time to exit the compressor chamber. Since there is a maximum flowrate at which the fluid can leave the chamber (choked flow), the fluid is compressed more.

As a result of the good agreement with the predictions of power loss, we can simulate compressor performance with improved properties and have reasonable confidence in the results. Figure 5.4 shows how a reduction in the sliding coefficient of friction affects the power loss. The experimental apparatus has steel vanes rubbing on an aluminium casing with a static COF of 0.09 under poor lubrication conditions. If boundary lubrication can be achieved, the COF can be improved significantly [41]. Boundary lubrication refers to a mode where a thin stable film of oil forms between the two solid surfaces in contact. The thickness of this film is in the order of tens of microns. Several designs to improve the lubrication conditions of the compressor-expander are currently being investigated.

Reducing the clearance between the rotor and end face is also seen to help reduce the power loss. From Figure 5.5 it is seen that at a certain RPM the effect of reducing the gap height diminishes. This can be explained by the fact that the viscous shear from the spinning of the rotor increases as the gap size decreases and as the RPM increases (see 
Equation (4.35)). Hence for a given RPM there is an optimum gap clearance in which the best balance between reduction in leakage and reduction in viscous shear is achieved. At an RPM of 2000 the optimum gap clearance is calculated to be $23 \mu \mathrm{m}$. The tested compressor-expander was then re-machined to reflect the optimum gap clearance at 2300 RPM.

At this point, issues pertaining to the mechanical efficiency have been the focus of discussion. However, the volumetric efficiency of the expander was also investigated. The predicted volumetric efficiency is of the same magnitude as the actual volumetric efficiency; the analytical efficiency, however, tends to rise with RPM while the experimentally measured efficiency is more or less constant over the range of RPMs measured. This trend is seen in Figure 5.6. The discrepancy in the trend is likely due to the 1-D assumption made while solving channel flow problem. The flow through the gap between the rotor and the casing faces is actually two dimensional. Fluid from the outlet does not leak into the inlet alone but also to neighbouring compression chambers. The aim of calculating the mass loss was to get a rough estimate to use while running the simulations and hence it is deemed that the prediction is acceptable.

After the rotor gap clearance was machined to 25 microns, full loop simulations were run. A comparison of the new power losses to the predicted power losses is presented in Figure 5.7. As shown in the figure the simulation predicted the improvement in the power loss. Referring to Figure 5.2 we see there is much scatter in the experimental data around the simulated line. Assuming this also applicable with the improved system, we can then say Figure 5.7 also predicts the right trend in power loss. No experimental data was 
collected at RPMs greater than 1500 due to lubrication issues in the machine. This modification yielded an average of $23 \%$ decrease in the power loss. Predictions show that if the lubrication issue can be solved then a further $40 \%$ can be decreased in the power loss. An improvement in the power loss of the compressor-expander directly correlates to an improvement in the overall system COP (see Equations (4.79) and (4.80)).

\subsection{Full System Program}

This section presents and discusses the results for the full component system program. The volumetric efficiency, coefficient of performance, cooling load and the like are analyzed. In addition, the analytically calculated results are compared to the experimentally obtained results. The effect of improvements such as the reduction in the end face gap and the improvement in lubrication conditions are also presented and discussed.

\subsubsection{Full System Simulation Results of Current Settings}

The work presented in this section discusses the results of the compressor-expander program. A comparison of the simulation results and the experimental results are presented in this section. The compressor inlet quality, evaporator temperature, cooling load, and coefficient of performance are some of the factors that are analyzed. The simulation was run at the same conditions for the evaporator chamber temperature, condenser water temperature and compressor speeds as those set in experiments. These conditions are summarized in Table 5-1. 
Most of the discussion focuses on the improved system with the smaller end face clearance. The effect of the system cooling load on the COP is shown in Figure 5.8. The evaporator chamber temperature is a representation of the system cooling load.

Table 5-1 Points Tested Experimentally

\begin{tabular}{|c|c|c|c|}
\hline $\begin{array}{l}\text { End Face } \\
\text { Clearance }\end{array}$ & $\begin{array}{l}\text { Evaporator } \\
\text { Chamber } \\
\text { Temperature }\end{array}$ & $\begin{array}{c}\text { Compressor- } \\
\text { Expander Speed }\end{array}$ & $\begin{array}{l}\text { Condenser Water } \\
\text { Temperature }\end{array}$ \\
\hline$\mu \mathrm{m}$ & ${ }^{\circ} \mathrm{C}$ & RPM & ${ }^{\circ} \mathrm{C}$ \\
\hline \multirow{2}{*}{88.9} & 40 & \multirow{2}{*}{$\begin{array}{c}750-2250 \\
\text { Increments of } 250\end{array}$} & \multirow{2}{*}{30} \\
\hline & 60 & & \\
\hline \multirow{2}{*}{25} & 40 & $\begin{array}{c}1000-2000 \\
\text { Increments of } 250\end{array}$ & \multirow{2}{*}{30} \\
\hline & 60 & $\begin{array}{c}750-1500 \\
\text { Increments of } 250\end{array}$ & \\
\hline
\end{tabular}

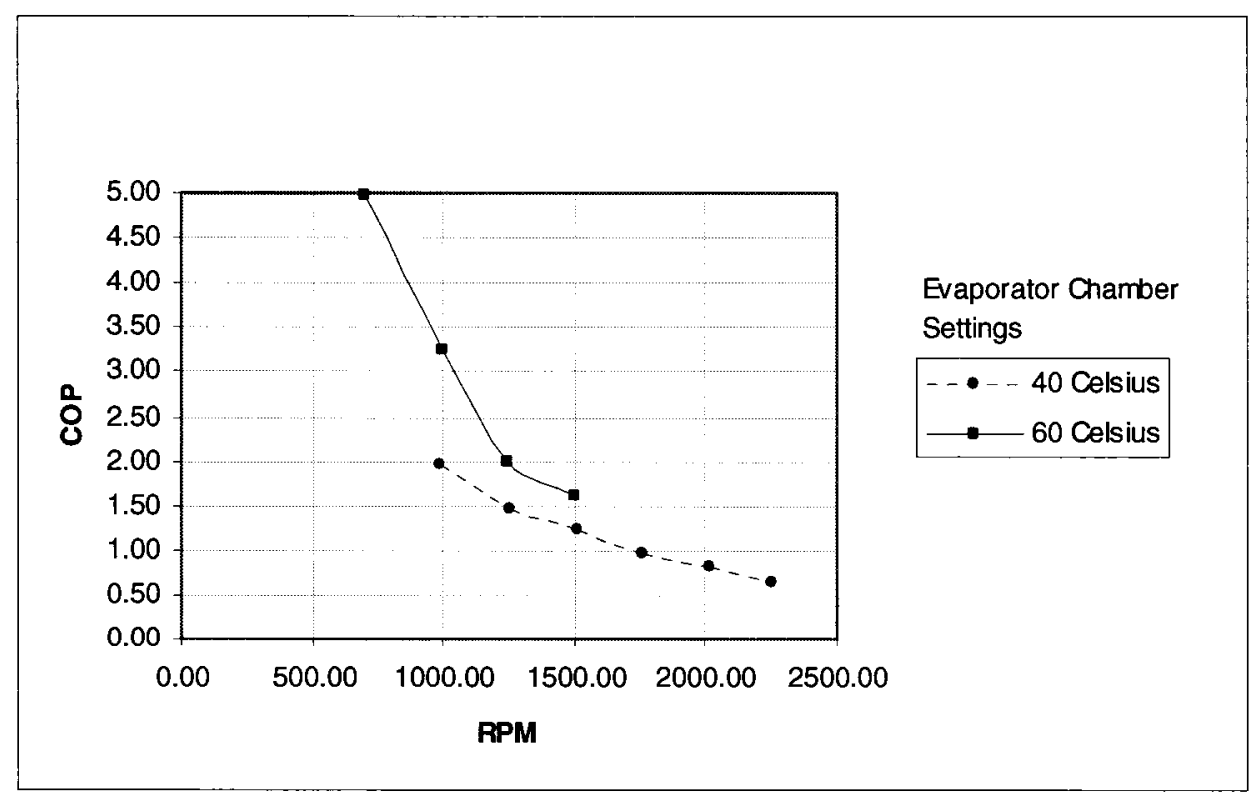

Figure 5.8 The Evaporator Cooling Load's Effect on COP, Experimental 
The COP in both evaporator chamber settings is compared to values obtained from the simulation and presented in Figure 5.9 and Figure 5.10. Figure 5.10 is a comparison of the higher cooling load while Figure 5.9 is a representation of the prediction of the cooling load at an evaporator chamber setting of $40^{\circ} \mathrm{C}$.

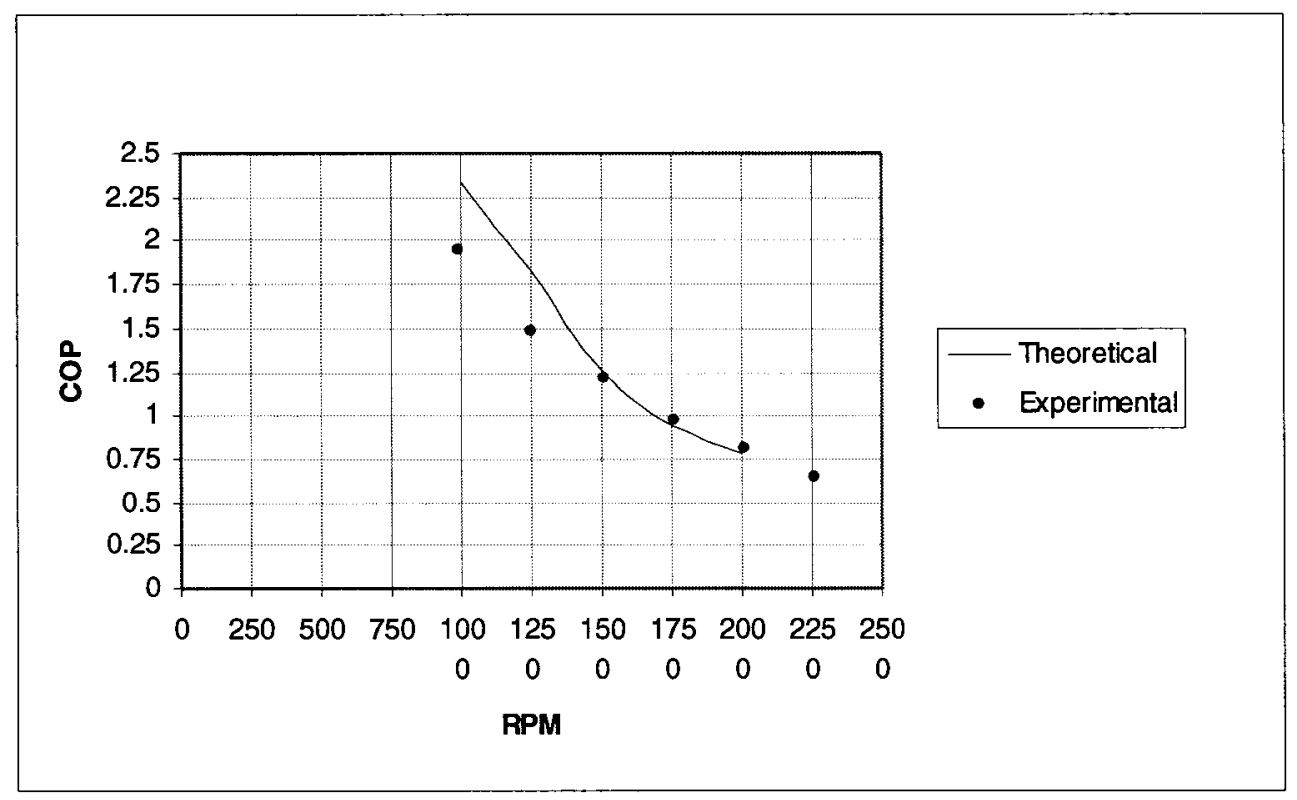

Figure 5.9 COP vs. RPM at Evaporator Chamber Temperature of $40^{\circ} \mathrm{C}$ 


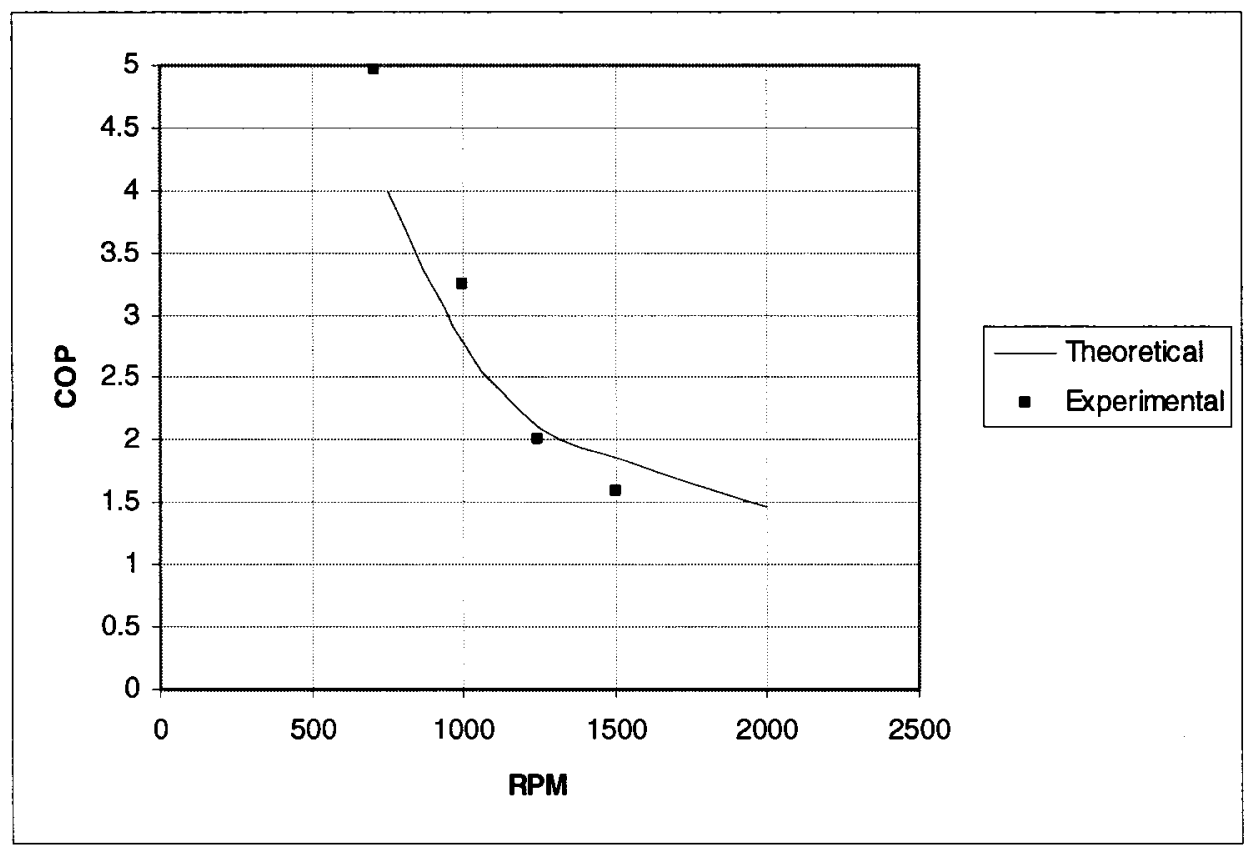

Figure 5.10 COP vs. RPM at Evaporator Chamber Temperature of $60^{\circ} \mathrm{C}$

Figure 5.11 Represents the evaporating temperature at various loop settings. It shows theoretical and experimental values at both the $40^{\circ} \mathrm{C}$ evaporator temperature and $60^{\circ} \mathrm{C}$ evaporator chamber temperature. 


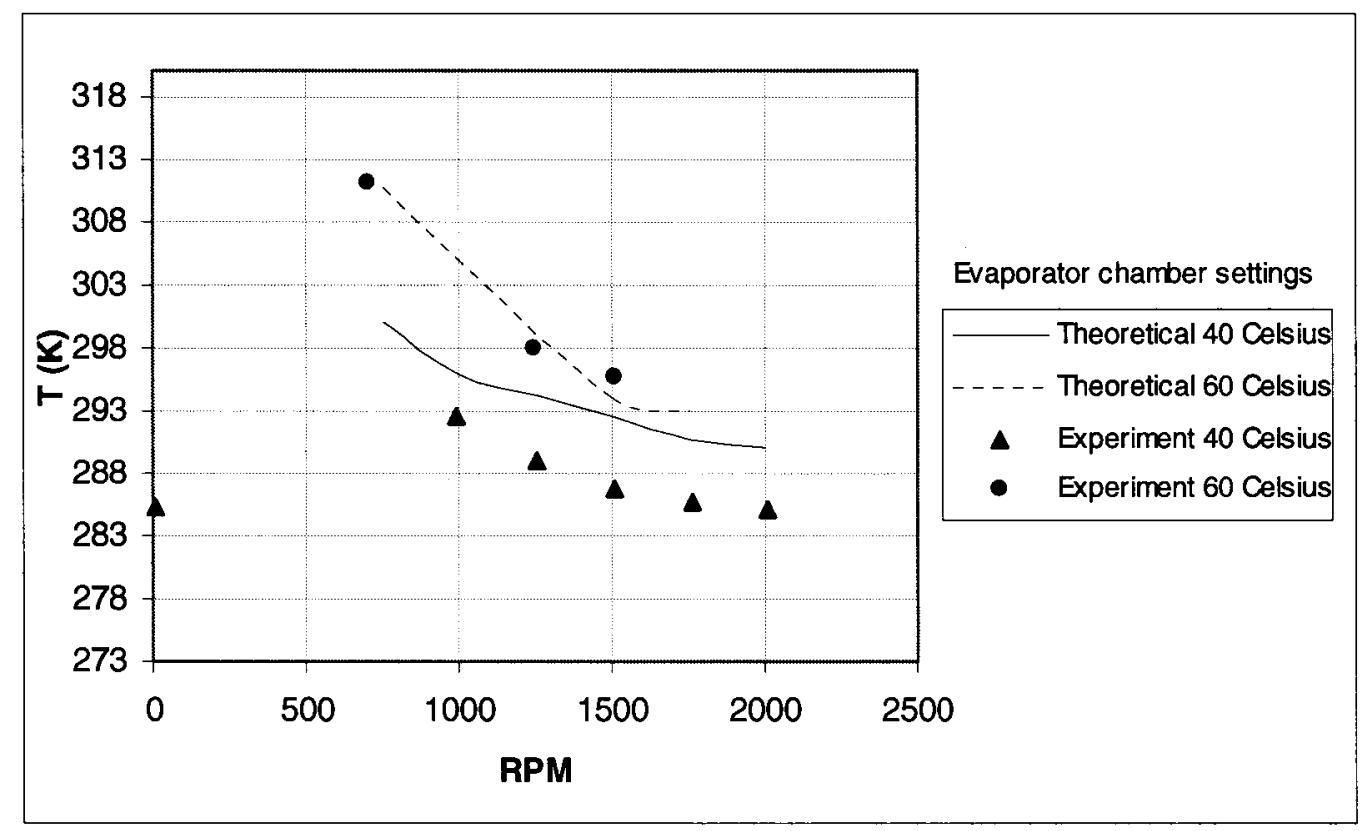

Figure 5.11 Evaporator Temperature vs. RPM

A cooling load vs. RPM curve is shown in Figure 5.12 for the lower evaporator chamber temperature. The cooling load is a measure of the evaporator power supplied to the chamber and a representation of the cooling effect. For the simulation portion, the power is derived from the heat absorbed by the refrigerant. The quality at the outlet of the evaporator is shown in Figure 5.13. 


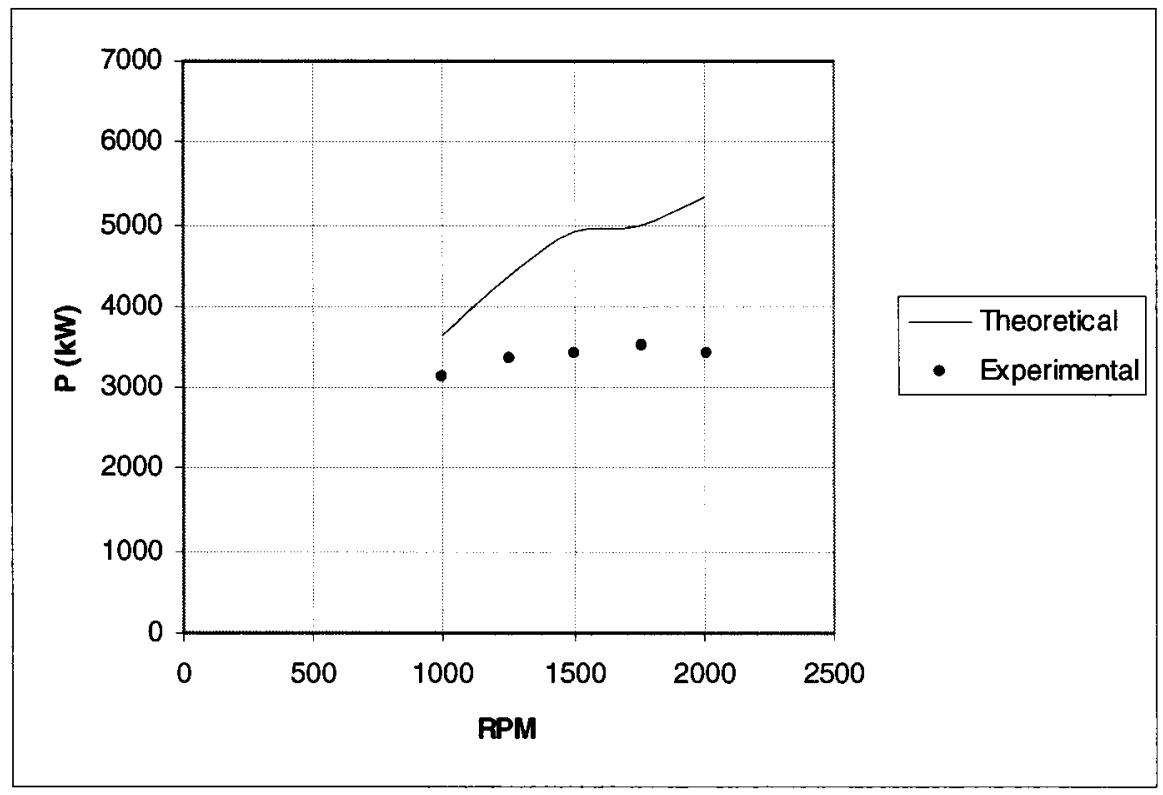

Figure 5.12 Cooling Load vs. RPM at Evaporator Chamber Temperature of $40^{\circ} \mathrm{C}$

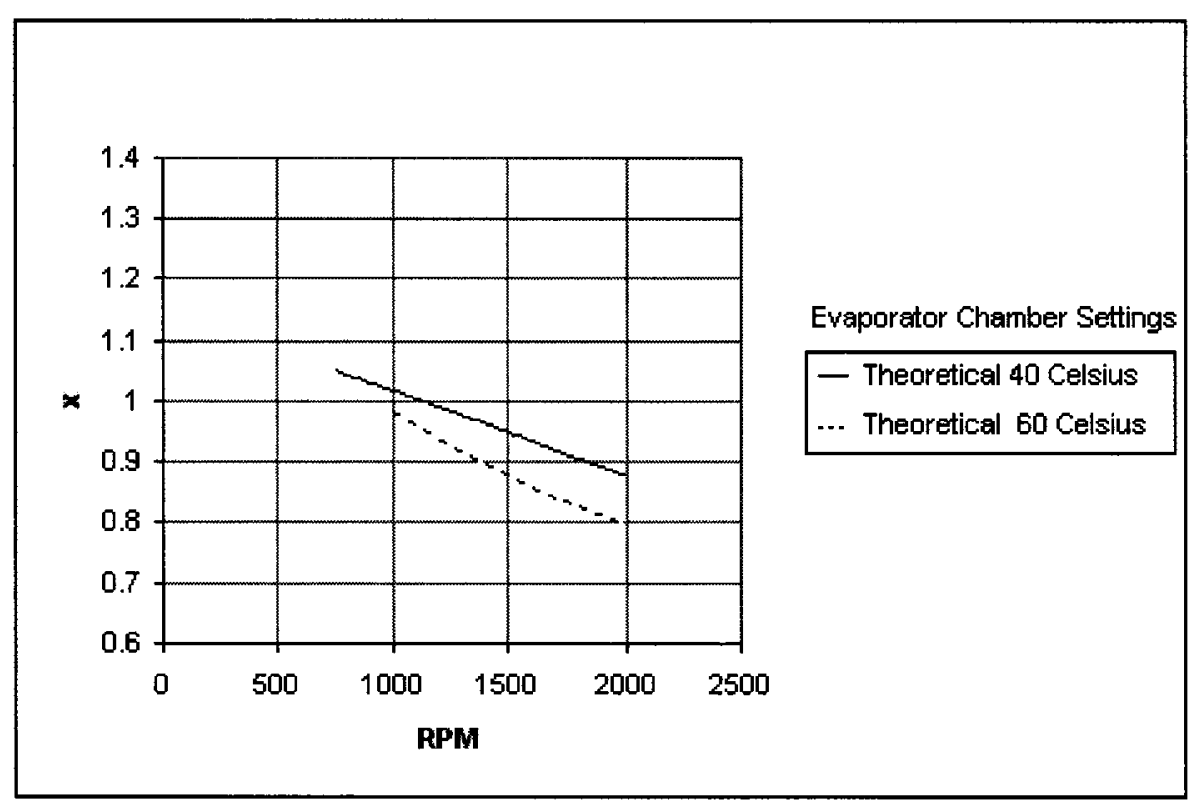

Figure 5.13 Compressor Inlet Quality vs. RPM

The table below is a representation of the change in COP with the improvement in end rotor face gap. 
Table 5-2 COP Improvement with End-Face Gap Change (Experimental)

\begin{tabular}{|c|c|c|c|}
\hline \multirow{2}{*}{$\begin{array}{c}\text { End Face Rotor Gap } \\
\mathbf{h}_{\mathbf{0}}(\boldsymbol{\mu m})\end{array}$} & $700 \mathrm{RPM}$ & $1250 \mathrm{RPM}$ & $1500 \mathrm{RPM}$ \\
\cline { 2 - 4 } & 4.97 & 2.00 & 1.59 \\
\hline 25 & 3.38 & 1.48 & 1.22 \\
\hline 88.9 & & \multicolumn{3}{|c|}{ COP } \\
\hline
\end{tabular}

\subsubsection{Discussion of the Full System Simulation Results with Current Settings}

As seen in Table 5-2 the improvement in the end face gap results in improvement in the COP. This is expected as the power loss is reduced as discussed in Section 5.2.2. Also the gap reduction results in better volumetric efficiency. This means that the cooling load is increased since the mass flowrate of the refrigerant is higher.

The behaviour of the coefficient of performance is shown in Figure 5.9 and Figure 5.10. As the general trend in automobile refrigeration, the COP decreases with increase in the compressor speed. Also it is noticed that for the higher cooling load the COP is higher (Figure 5.8). At lower cooling loads, the COP is over predicted. However at RPMs greater than 1500 , the error in prediction is under $3 \%$. The over prediction is due to the fact that at high qualities the effect of the oil mixed with the refrigerant becomes nonnegligible [9]. Since this work does not take oil effects into account, we observe a discrepancy in the system performance at high quality when compared to experimental data.

In the current compressor-expander design as little liquid as possible is preferred at the inlet of the compressor. The compressor design is specifically for gas compression as a significant portion of the liquid at the outlet is fed into the oil sump and then back to the 
inlet via the rotor end face. This liquid is then re-compressed and hence some compression energy is thus wasted.

Figure 5.13 represents the compressor inlet quality as a function of the compressor RPM. A higher compressor RPM yields a higher mass flowrate through the system. This means that there is less time for the fluid to absorb heat from the evaporator chamber. Although the temperature difference gets higher as the compressor speed increases, it is not enough to offset the effect of the increase in the refrigerant velocity. The cooling load prediction is shown in Figure 5.12. Once again there is an over prediction in the evaporator cooling load. This over-prediction is due to the correlation inaccuracies in the boiling correlations used. Due to the complicated nature of boiling most boiling correlation are specific to the designs tested. The accuracy of the Rohsenow correlations used is in the order of $15 \%$. As the RPM increases, the cooling load increases. This is expected as more power put into the compressor should yield a better refrigeration effect. However as the COPs show, although more cooling effect is achieved, the efficiency gets poorer.

\subsubsection{Full System Simulation Results for Proposed Improvements}

In this section we use simulation to predict improvements to the current compressorexpander design. Since the improvement in the rotor face gap is already modified, optimized and discussed in the previous section, this will not be discussed in this section. A discussion of the effect of diminishing the Torlon seal leakage is presented as well as the effect of improved lubrication conditions on the overall system. The improved lubrication is modelled in the form of a reduction in the vane coefficient of friction. 
The results in this section are presented in the form of tables. Table 5-3 and Table 5-4 represent the effect of the Torlon seal leakage on the overall system. The values shown are for speeds of 1500 RPM and 1000 RPM at both settings for evaporator chamber temperature.

Table 5-3 Effect of Torlon Seal Leakage on the COP @ 1000 RPM

\begin{tabular}{|c|c|c|}
\hline $\begin{array}{c}\text { Torlon Leakage\% of Original } \\
\text { Leakage }\end{array}$ & COP & $\begin{array}{c}\text { Evaporator } \\
\text { Temperature } \\
\text { (Celsius) }\end{array}$ \\
\hline \multirow{2}{*}{$100 \%$} & 2.33 & 40 \\
\hline \multirow{2}{*}{$50 \%$} & 2.77 & 60 \\
\cline { 2 - 3 } & 2.63 & 40 \\
\cline { 2 - 3 } & 2.87 & 60 \\
\cline { 2 - 3 } $6 \%$ & 2.87 & 40 \\
\cline { 2 - 3 } & 3.91 & 60 \\
\hline
\end{tabular}

Table 5-4 Effect of Torlon Seal Leakage on the COP @ 1500 RPM

\begin{tabular}{|c|c|c|}
\hline $\begin{array}{c}\text { Torlon Leakage\% of Overall } \\
\text { Massflow }\end{array}$ & COP & $\begin{array}{c}\text { Evaporator } \\
\text { Temperature } \\
\text { (Celsius) }\end{array}$ \\
\hline \multirow{2}{*}{$100 \%$} & 1.26 & 40 \\
\hline \multirow{2}{*}{$50 \%$} & 1.85 & 60 \\
\cline { 2 - 3 } & 1.50 & 40 \\
\hline \multirow{2}{*}{$6 \%$} & 2.77 & 60 \\
\cline { 2 - 3 } & 1.61 & 40 \\
\cline { 2 - 3 } & 3.01 & 60 \\
\hline
\end{tabular}

Table 5-5 shows the predicted improvement in COP due to better lubrication. The comparison is done with the evaporator chamber temperature set to $60^{\circ} \mathrm{C}$ and at the compressor speed of $1500 \mathrm{RPM}$ 
Table 5-5 Effect of Lubrication on the COP @ 1500 RPM

\begin{tabular}{|c|c|c|}
\hline $\begin{array}{c}\text { Coefficient of Friction } \\
\text { (\% of Current Value) }\end{array}$ & COP & $\begin{array}{c}\text { Evaporator } \\
\text { Temperature } \\
\text { (Celsius) }\end{array}$ \\
\hline $100 \%$ & 1.85 & 60 \\
\hline $75 \%$ & 1.93 & 60 \\
\hline $50 \%$ & 2.16 & 60 \\
\hline $10 \%$ & 2.51 & 60 \\
\hline
\end{tabular}

\subsubsection{Discussion of Full System Simulation Results for Proposed Improvements}

Significant improvement can be achieved if the volumetric efficiency of the compressorexpander is improved. As shown in Table 5-3 and Table 5-4 the efficiency is improved by an average of $12.5 \%$ with a $50 \%$ decrease in the Torlon seal leakage. At higher RPMs the improvement in the COP increases. With a $94 \%$ decrease in the Torlon seal leakage, a $23 \%$ improvement in COP is observed from simulations. Another noticeable trend is that the improvement in performance increases with increasing cooling load. In practice a $50 \%$ improvement in the Torlon seal leakage is more viable. The model does not account for increased rubbing that might result from a better (tighter) seal design. This rubbing will contribute to frictional power loss and hence reduce the COP. This means that the COP improvements discussed are most likely over predictive.

Also analyzed is the effect of the improvement in lubrication conditions on the COP. As discussed in Section 5.2.2 better lubrication improves the power loss property of the unit as it runs. The resulting improvement in the COP is shown in Table 5-5. If the coefficient of friction can be halved, the COP can be improved by up to $15 \%$. When the friction coefficient is improved by $94 \%$ which is attributed to perfect boundary 
lubrication, the COP is improved by up to $30 \%$. These improvements may also be combined to achieve even further improvement in the performance of the system and the compressor-expander unit. Currently the lubrication system is not ideal. Experiment show that above 1500 RPM there is no oil being supplied to the compressor except the oil that flows along with the refrigerant. 


\section{Chapter 6: Conclusions and Recommendations}

A novel automobile refrigeration system using R-134a as the working fluid was tested. This system features some energy recovery techniques using the vane compressor design. Another feature is that the compressor and expander are integrated into one machine.

\subsection{Conclusion}

The goal of this work was to experimentally and theoretically test the compressorexpander unit.

- The experimental analysis of the design of the vane compressor-expander shows that there is room for improvement in the mechanical design of the machine. More precise machining of the parts will ensure smaller gaps for leakage as predicted by the analytical model.

- The losses due to friction and poor lubrication as well as the poor volumetric efficiency offset the power gained by the expander and must be solved for this equipment to be an economically viable option. Reducing the friction factor by ten is predicted to decrease the unit's power loss bay a factor of two

- Simulations show that the compressor-expander's behaviour can be effectively predicted using current engineering knowledge. The model of the 
compressor-expander can also be successfully integrated into an overall system loop model.

- The predicted improvement in performance due to reducing the end face rotor gap was verified experimentally. Several quantities such as the COP, cooling load and volumetric efficiencies are predicted with good accuracy compared to experimental data. Most of the theoretically determined quantities lie within $3 \%$ to $5 \%$ of experimental data.

\subsection{Recommendations}

From current literature available as well as simulation and experimental results achieved in this work, several recommendations are proposed for the improvement of the compressor-expander and the overall system.

- Problems in oil circulation can be solved with several new designs. The use of an oil pump already constructed would force oil into the compressor and assure sufficient lubrication. This oil will then be filtered out at the outlet of the compressor. Another improvement being pursued is the use of an external oil tank which acts as a reservoir for the oil. When the compressor is in transition and needs extra oil, the oil can be supplied from this tank. In addition the grooves in the compressor are being modified to ensure good smearing of the oil on the rotor face. However in order to get any useful improvement in the COP, at leas a $50 \%$ improvement in the lubrication system is necessary. 
- Significant improvement in the Torlon design will result in improvement in the overall system. The current system uses a large diameter seal. This means that the leakage area is larger. A smaller diameter seal is being worked on however this will create four end face rather than the current two end faces. However with the oil tank smearing should minimize the end face losses.

- A test on the compressor chamber alone will give an indication on the improvement incurred by having the expander alongside it. This will show if the losses experienced that are unique to the fact that the compressor and expander are integrated are offset by the energy recovered by the expander.

- In literature several R-134a based compressor-expander systems are arranged in the expressor loop shown in Figure 2.8. A compressor-expander design that lends itself to this system could be investigated. The system is less sensitive to losses across the chamber seals. However it does add an extra component to the whole cycle and may not be ideal for automotive refrigeration. 


\section{Appendix A: Experimental and Theoretical Analysis Support}

\section{A.1 Pseudo Steady Analysis Description}

In this work a pseudo steady analysis is used when the steady assumption cannot be made without incurring too much error. The method used treats the unsteady variable, $t$ as steady within a short interval defined by the user, $X$. an Example is done below.

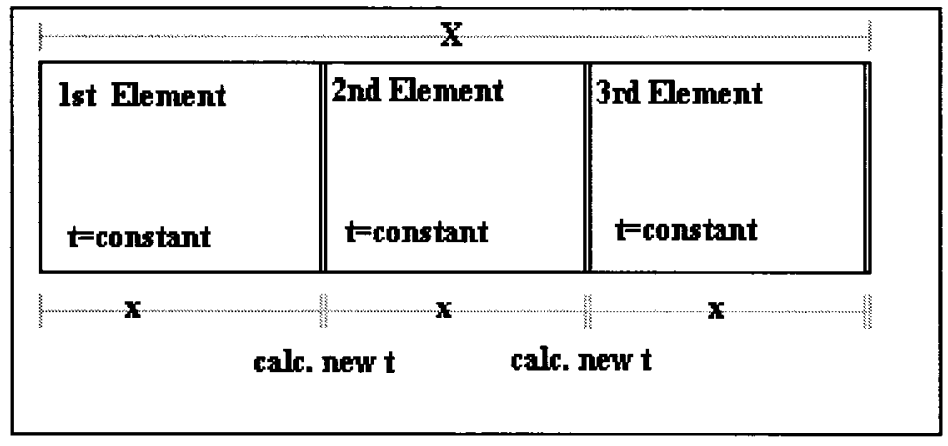

Figure A.1 Pseudo Steady Analysis

Assuming $t$ is the quality of a boiling fluid and $X$ is the pipe length, it is then assumed that the quality can be assumed to be constant within the length $\mathrm{x}$. Using the process defined in Section 4.2.5 we can find the output enthalpy at any interval if we know the quality. A new quality is then calculated from the new enthalpy calculated and then 
applied to the next element. The new quality is simply a function of the new enthalpy, the previous enthalpy and the saturated vapour and liquid enthalpy which are all known.

\section{A.2 Calculation of Percent Errors and Differences}

When experimental and theoretical values are compared, an error is calculated weighted on the experimental value as shown.

$$
\text { \%error }=\frac{\mid \text { experimental_results }- \text { theoretical_results } \mid}{\text { experimental_results }} \cdot 100 \%
$$

When two experimental or two theoretical values are compared, a percent difference is calculated. If comparison is between an original and a modified system then the percent difference (increase or decrease) is calculated as:

$$
\% \text { difference }=\frac{\mid \text { Original_value }- \text { Modified_value } \mid}{\text { Original_value }} \cdot 100 \%
$$

For all other cases it is calculated as

$$
\text { \%difference }=\frac{\mid \text { Bigger_value }- \text { Smaller_value } \mid}{\text { Bigger_value }} \cdot 100 \%
$$




\section{A.3 Experimental Parts}

This section provides details to the parts used in testing the compressor-expander. Unfortunately details on the compressor expander design and modifications cannot be reproduced here due to ownership issues. The details on the design can be obtained form the Refrigeration Development Company Ltd. The design is referred to as the $A 3$ Prototype Compressor-Expander under the Energy Recovery Compressors project. The A3 was tested on the ATS system in the Mechanical and Aerospace Department's Refrigeration Lab (Carleton University) [43]. Details on the parts at documented in the main ATS computer (see part reference below) at C:IDocuments and Settings\Admin $\backslash M y$ Documents|wsj\ATS\ATS report manual. Components not in the computer record, but used for the test are described below.

- Computer: COMPAQ Evo. 1.8Ghz, 256MB RAM, 40GB HD. By: Compaq Computer Corporation

○ Model Number: PD1057P

o Serial Number: 6Y260JYF2506F

- Location

- Compressor Motor: BALDOR premium efficiency motor. 10HP, 1770RPM, 3 phase, 60 Hertz. By: Baldor Electric Company

- Model Number: NP0458E

- Serial Number: F1197 
- Catalogue Number: EM3313T

○ Specification Number: 37F614T853

- Compressor Motor Drive: BALDOR adjustable speed drive. 10HP, $60 \mathrm{Hertz}, 3$ phase, keypad operated. By: Baldor Electric Company

- Model Number: F1F2010C-01

○ Serial Number: 0998Px216M

- Catalogue Number: ID15H210-E

o Specification Number: 37F614Y568

- Compressor Clutch: Chrysler electromagnetic coil clutch. By: Warner Electric, inc.

○ Part Number: 205-369

- Model Number: HB1780

- Mass-Flow-Meter 1: Endress+Hauser promass A series. Stainless steel C-22, high temperature $\left(350^{\circ} \mathrm{C}\right.$ max $)$, high pressure $(400$ bar), Coriolis operation principle. By: Endress+Hauser Corporate

- Model Number: Promass 83A

- Serial Number: 361078

- Order Code: 63A SVW00A2AB1A 
- Mass-Flow-Meter 2: Endress + Hauser promass F series. Universal operation, stainless steel $\mathrm{C}-22$, high temperature $\left(350^{\circ} \mathrm{C} \max \right)$, Coriolis operation principle. By: Endress + Hauser Corporate

- Model Number: Promass 83F

- Serial Number: 11473081

- Order Code: 63F CWW00A2AB1A

- Condenser Pumps: Mastercraft 1/6 HP Laundry tub pump. 1726RPM By: Mastercraft

- SK-U: $62-3002$

○ Serial Number: MOD 5KH39EN5621AX

- Pressure Transducers between Evaporator Inlet and Compressor Inlet: MKS Baratron absolute single ended pressure transducer. 100psi max pressure 1.4 in OD. By: MKS instruments, inc.

○ Model Number: 750B12PBB3GA-S

- Serial: 000241959

- Serail: 000241960

- Serial: 000241961

- Serial: 000241962

- Pressure Transducers between Condenser Outlet and Expander Inlet: MKS Baratron absolute single ended pressure transducer. 500psi max pressure 1.4 in OD. By: MKS instruments, inc.

- Model Number: 750B52PBB3GA-S 
○ Serial: 000231711

- Serial: 000231712

- Pressure Transducers at Condenser Outlet: Honeywell amplified transducer. 750psi max pressure By: Honeywell International, inc.

○ Model Number: FPA/G750-01

○ Serial: 881190

- Thermocouples: Omega quick disconnects $\mathrm{K}$ type thermocouples. By: Omega Engineering, inc.

- Model: CASS18G12 


\section{A.4 Experimental Repeatability}

Several experiments were carried out in the course of this work. The data is located on the main ATS computer (see Appendix A.3 ) at C:LATSlexperimental recordlcompressorexpander. A repeatability test was carried out and the results are shown in Table A-1. It is assumed that the data fits the Gaussian distribution. $95.5 \%$ of the data then fits within two standard deviations, (2SD), of the mean value. A smaller value of $2 \mathrm{SD}$ means better accuracy. Table A-2 represents the same data as Table 3-1Table A-1, however the standard deviation is displayed as a percentage of the mean value to give a better indication of the accuracy. The standard deviation, $s$, is calculated as:

$$
s=\sqrt{\frac{1}{N} \sum_{i=1}^{N}\left(x_{i}-\bar{x}\right)^{2}}
$$

Where $N$ represents the number of tests, and $\bar{x}$ represents the mean value of the quantity studied. The percentage of the mean displayed in Table A-2 is calculated as shown in the Equation A.5.

$$
\text { Parameter }=\frac{s}{\bar{x}} \cdot 100 \%
$$

The tests are done at both $40^{\circ} \mathrm{C}$ and $60^{\circ} \mathrm{C}$ Evaporator chamber temperature settings. The repeatability results presented in the tables below are averaged between both temperatures. 
Table A-1: Repeatability Results as Standard Deviations from Mean

\begin{tabular}{|c|c|c|c|c|c|}
\hline RPM & $\begin{array}{c}\text { Number } \\
\text { of Tests }\end{array}$ & $\begin{array}{c}\text { 2SD of } \\
\text { COP }\end{array}$ & $\begin{array}{c}\text { 2SD of } \\
\text { Compressor } \\
\text { Power (W) }\end{array}$ & $\begin{array}{c}\text { 2SD of } \\
\text { Cooling } \\
\text { Capacity (W) }\end{array}$ & $\begin{array}{c}\text { 2SD of Total } \\
\text { Massflow } \\
(\mathrm{kg} / \mathrm{h})\end{array}$ \\
\hline 750 & 8 & 0.0167 & 28.3 & 160.2 & 6.7 \\
\hline 1000 & 14 & 0.0519 & 87.3 & 103.5 & 8.3 \\
\hline 1250 & 11 & 0.0361 & 135.1 & 72.7 & 12.5 \\
\hline 1500 & 14 & 0.0359 & 172.1 & 296.5 & 4.2 \\
\hline 1750 & 9 & 0.05 & 124.9 & 28.9 & 0.7 \\
\hline 2000 & 8 & 0.045 & 129.6 & 16.9 & 5.6 \\
\hline 2250 & 4 & 0.031 & 120.3 & 39.3 & 5.7 \\
\hline
\end{tabular}

Table A-2: Repeatability Results as Percentage of Mean

\begin{tabular}{|c|c|c|c|c|c|}
\hline RPM & $\begin{array}{c}\text { Number of } \\
\text { Tests }\end{array}$ & $\begin{array}{c}\text { 2SD of } \\
\text { COP } \\
\%\end{array}$ & $\begin{array}{c}\text { 2SD of } \\
\text { Compressor } \\
\text { Power \% }\end{array}$ & $\begin{array}{c}\text { 2SD of } \\
\text { Cooling } \\
\text { Capacity }\end{array}$ & $\begin{array}{c}\text { 2SD of } \\
\text { Total } \\
\text { Massflow }\end{array}$ \\
\hline 750 & 8 & 0.3 & 2.9 & 3.1 & 5.1 \\
\hline 1000 & 14 & 2.4 & 5.6 & 3.6 & 7.1 \\
\hline 1250 & 11 & 2.3 & 5.8 & 2.3 & 7.9 \\
\hline 1500 & 14 & 3.1 & 5.3 & 7.8 & 2.6 \\
\hline 1750 & 9 & 4.6 & 3.5 & 0.8 & 0.4 \\
\hline 2000 & 8 & 5.2 & 3.1 & 0.4 & 3.1 \\
\hline 2250 & 4 & 4.4 & 2.9 & 1.1 & 2.6 \\
\hline
\end{tabular}

The average error in Table A-2 is $3.5 \%$. Sever factors could cause the deviations to be high such as change in the atmospheric conditions, quality of power supply and human alterations when taking out/reinstalling the unit into the testing system. 


\section{A.5 Sensitivity Analysis}

The sensitivity analysis is conducted at speeds of 1250RPM and 1750RPM. Fifteen parameters/variables are tested to see the effects they have on the power loss and the COP. The variables are changed by $1 \%, 5 \%$ and $10 \%$ (both increased and decreased) and the effects on the COP are reported according to the methodology described in Appendix A.2 . The results of the sensitivity analysis are presented in Table A-3 and Table A-4. The percentages differences are averaged between the increase and decrease in the parameters.

Table A-3 Effect of Several Parameters on COP @ 1250RPM

\begin{tabular}{|c|c|c|c|c|}
\hline Parameter & Description & $\begin{array}{c} \pm 1 \% \\
\text { deviation } \\
(\%)\end{array}$ & $\begin{array}{c} \pm 5 \% \\
\text { deviation } \\
(\%)\end{array}$ & $\begin{array}{c} \pm 10 \% \\
\text { deviation } \\
(\%)\end{array}$ \\
\hline $\mathbf{P v ^ { \gamma }}$ & $\begin{array}{l}\text { Constancy in polytropic } \\
\text { assumption eqn. } 4.14\end{array}$ & 0.6 & 1.5 & 4.3 \\
\hline BBS & $\begin{array}{l}\text { Liquid state constant } \\
\text { eqn. } 4.17\end{array}$ & 0.1 & 0.22 & 0.35 \\
\hline $\mathbf{N}$ & $\begin{array}{l}\text { Liquid state exponent } \\
\text { eqn. } 4.17\end{array}$ & 0.1 & 0.5 & 1.1 \\
\hline $\mathbf{m}_{\text {loss }}$ & $\begin{array}{l}\text { Mass lost in end face gap } \\
\text { eqn. } 4.23\end{array}$ & 0 & 0 & 0 \\
\hline Cst & Orifice constant eqn. 4.26 & 0.4 & 0.8 & 1.7 \\
\hline $\mathbf{P}_{\text {loss,RF }}$ & $\begin{array}{l}\text { End face gap power loss } \\
\text { eqn. } 4.35\end{array}$ & 0.03 & 0.18 & 0.4 \\
\hline $\mathbf{F}$ & Friction factor eqn. 4.47 & 0 & 0 & 0.1 \\
\hline $\mathbf{K}$ & Geometry factor eqn. 4.48 & 0.40 & 0.72 & 1.6 \\
\hline $\mathbf{U}_{\mathbf{o}}$ & $\begin{array}{l}\text { External heat transfer } \\
\text { coefficient eqn. } 4.50\end{array}$ & 0.2 & 2.5 & 5.7 \\
\hline $\mathbf{u}_{\text {conv }}$ & Sieder and Tate eqn. 4.53 & 0.04 & 0.4 & 0.3 \\
\hline $\mathbf{u}_{\text {cond }}$ & Chato eqn. 4.55 & 0.08 & 0.6 & 1.1 \\
\hline
\end{tabular}




\begin{tabular}{|l|l|c|c|c|}
\hline $\mathbf{u}_{\text {cond }}$ & Akers eqn. 4.57 & 0.2 & 0.4 & 0.5 \\
\hline $\mathbf{K}$ & $\begin{array}{l}\text { Expansion valve constant } \\
\text { eqn. 4.61 }\end{array}$ & 0.5 & 1 & 1.3 \\
\hline $\mathbf{u}_{\mathbf{i}}$ & Bromley eqn. 4.64 & 0 & 0 & 0 \\
\hline $\mathbf{u}_{\mathbf{i}}$ & $\begin{array}{l}\text { Rohsenow's boiling } \\
\text { correlation eqn. 4.76 }\end{array}$ & 0.5 & 1.5 & 3.3 \\
\hline
\end{tabular}

Table A-4 Effect of Several Parameters on Power Loss @ 1250RPM

\begin{tabular}{|c|c|c|c|c|}
\hline Parameter & Description & $\begin{array}{l} \pm 1 \% \\
\text { deviation }\end{array}$ & $\begin{array}{l} \pm 5 \% \\
\text { deviation }\end{array}$ & $\begin{array}{l} \pm 10 \% \\
\text { deviation }\end{array}$ \\
\hline $\mathbf{P v ^ { \gamma }}$ & $\begin{array}{l}\text { Constancy in polytropic } \\
\text { assumption. Eqn. } 4.14\end{array}$ & 0.32 & 1.4 & 3.02 \\
\hline BBS & $\begin{array}{l}\text { Liquid state constant } \\
\text { eqn. } 4.17\end{array}$ & 0.1 & 0.22 & 0.35 \\
\hline $\mathbf{N}$ & $\begin{array}{l}\text { Liquid state exponent } \\
\text { eqn. } 4.17\end{array}$ & 0.2 & 0.33 & 0.97 \\
\hline $\mathbf{m}_{\text {loss }}$ & $\begin{array}{l}\text { Mass lost in end face gap } \\
\text { eqn. } 4.23\end{array}$ & 0 & 0 & 0 \\
\hline Cst & $\begin{array}{l}\text { Orifice constant eqn. } \\
4.26\end{array}$ & 0.5 & 1.1 & 1.7 \\
\hline $\mathbf{P}_{\text {loss, RF }}$ & $\begin{array}{l}\text { End face gap power loss } \\
\text { eqn. } 4.35\end{array}$ & 0.04 & 0.21 & 0.41 \\
\hline $\mathbf{f}$ & Friction factor eqn. 4.47 & 0 & 0.1 & 0.2 \\
\hline $\mathbf{K}$ & $\begin{array}{l}\text { Geometry factor eqn. } \\
4.48\end{array}$ & 0.02 & 0.04 & 0.04 \\
\hline $\mathbf{U}_{\mathbf{o}}$ & $\begin{array}{l}\text { External heat transfer } \\
\text { coefficient eqn. } 4.50\end{array}$ & 0.07 & 0.15 & 0.3 \\
\hline $\mathbf{u}_{\text {conv }}$ & $\begin{array}{l}\text { Sieder and Tate eqn. } \\
4.53\end{array}$ & 0.02 & 0.02 & 0.08 \\
\hline$u_{\text {cond }}$ & Chato eqn. 4.55 & 0.03 & 0.03 & 0.05 \\
\hline $\mathbf{u}_{\text {cond }}$ & Akers eqn. 4.57 & 0.08 & 0.15 & 0.2 \\
\hline $\mathbf{K}$ & $\begin{array}{l}\text { Expansion valve } \\
\text { constanteqn. } 4.61 \\
\end{array}$ & 0.09 & 0.2 & 0.5 \\
\hline $\mathbf{u}_{\mathbf{i}}$ & Bromley eqn. 4.64 & 0 & 0 & 0.1 \\
\hline
\end{tabular}




\begin{tabular}{|l|l|l|l|l|}
\hline $\mathbf{u}_{\mathrm{i}}$ & $\begin{array}{l}\text { Rohsenow's boiling } \\
\text { correlation eqn. 4.76 }\end{array}$ & 0.2 & 0.32 & 0.41 \\
\hline
\end{tabular}

The results show that at $10 \%$ deviation the maximum effect any of these variables have on the COP is $5.7 \%$. This value corresponds to the external heat transfer coefficient. From the fit to the experimental data, the $\mathrm{K}$ value shown in Equation (4.62) is accurate to $\pm 5 \%$ therefore only a maximum of $2.5 \%$ deviation is expected in the COP. The analysis shows that the assumptions made give accurate results to $\pm 5 \%$ as long as they do not deviate by more than $10 \%$ from the real behavior. There is usually large uncertainties connected to the heat transfer coefficient, sometimes as much as $25 \%$, however we see in Table A-3 that the maximum error at $10 \%$ deviation is 1.1 (ignoring the Rohsenow correlation). The Rohsenow correlation has an accuracy in the order of 5\% from experimental values [40] and hence the maximum expeted error in COP due to implementing this correlation is $1.5 \%$. 


\section{A.6 Liquid Equation of State Constants}

The experimental data for subcooled R-134a is taken from Olivera C., and Wakeham W's work[44]. The value for the constant $n$ is found using Equation (A.6), which is an implicit function of $\mathrm{n}$ and is solved using the Newton-Raphson method.

$$
n=\frac{\ln \left(\frac{p_{1}}{p_{2}}\left(\left(\frac{v_{r e f}}{v\left(p_{2}\right)}\right)^{n}-1\right)+1\right)}{\ln \left(\frac{v_{r e f}}{v\left(p_{2}\right)}\right)}
$$

The value for $\mathrm{n}$ is found to be constant within the temperature range of $283 \mathrm{~K}$ to 333K. The value of BBS is then obtained as:

$$
B B S=0.877 T^{2}-570.77 T+93002
$$

The R-squared value for Equation (A.7) is 0.96. and the equation is not used outside the measured range in Olivera's work. The constant value for $n$ is 0.566 . Equation (A.7) is only valid if BBS is used in units of Mega Pascals. 


\section{A.7 Equation Derivations}

\section{Vane Tip Pressure Forces}

The vane tip pressure forces are resolved using a Cartesian system. Firstly it is realized that the net pressure force on the circular contour will act towards the center of the circle. Using Figure A.2 as an aid, and with Pythagoras theorem in mind we can write derive the following the equations for the vane tip pressure forces.

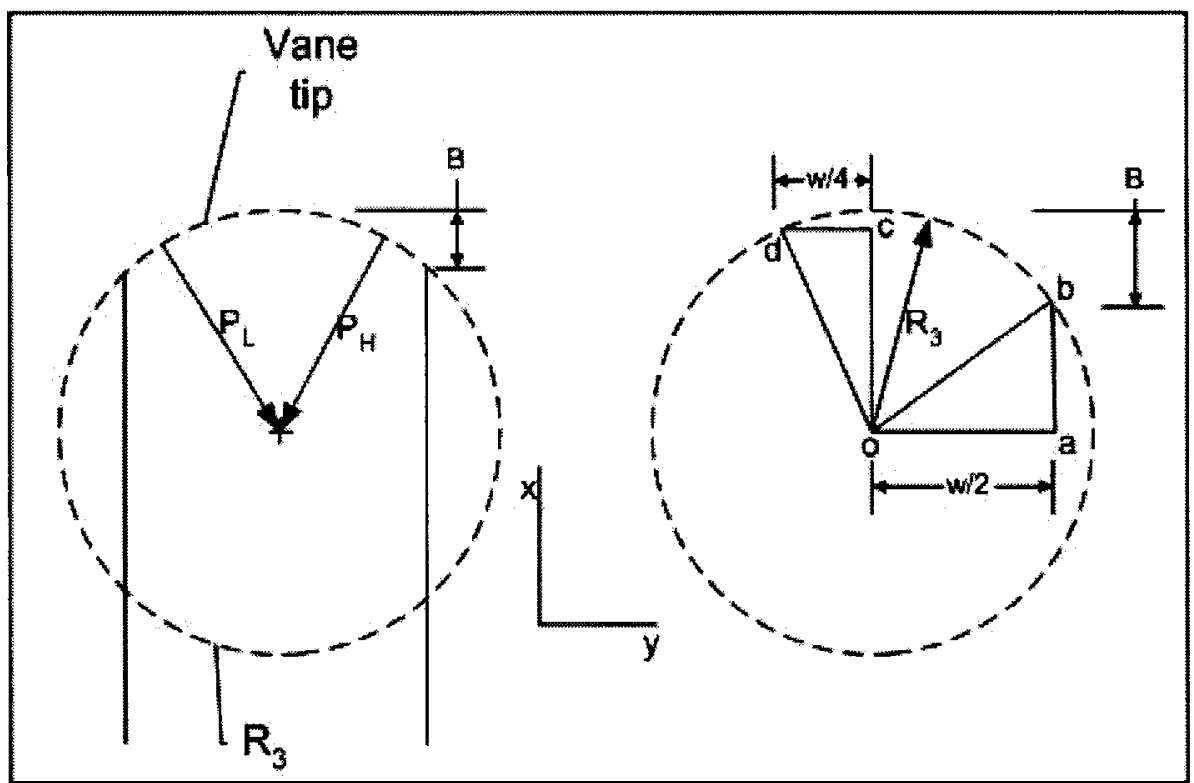

Figure A.2 Vane Tip Pressure Resolution

From triangle o-a-b we can write:

$$
B=R_{3}-\sqrt{R_{3}^{2}-(w / 2)^{2}}
$$

Note that the radius of the circle is the sum of $\mathrm{B}$ and $\mathrm{a}-\mathrm{b}$. The $\mathrm{x}$ direction pressure area is then simply the product of B and the depth of the vane, L. The y direction pressure area is simply w/2 multiplied by the depth. To find the $\mathrm{x}$ component of the pressure force we use triangle o-c-d. We assume that the net force acts midway in the y direction and therefore the length o-c is determined by Pythagoras theorem as: 


$$
l_{o-c}=\sqrt{R_{3}^{2}-(w / 4)^{2}}
$$

It then follows that the pressures can be resolved using similar triangles as shown in Equation (A.10) and Equation (A.11).

$$
\begin{aligned}
\frac{p_{y}}{p} & =\frac{l_{o-c}}{R_{3}} \\
\frac{p_{x}}{p} & =\frac{l_{c-d}}{R_{3}}
\end{aligned}
$$

Then converting the pressures to their equivalent forces we note that we must add the ydirection forces and subtract the $\mathrm{x}$ direction forces. This is because the $\mathrm{x}$-directional forces oppose each other. The result is then that the forces are a product of the combined pressures, the scaling factor (from Equations (A.10) and (A.11)) and the area.

$$
\begin{aligned}
& F_{x x}=\left(p_{H}-p_{L}\right) \cdot w / 4 R_{3} \cdot L \cdot\left(R_{3}-\sqrt{R_{3}{ }^{2}-w^{2} / 4}\right) \\
& F_{y}=\left(p_{H}+p_{L}\right) \cdot w / 2 R_{3} \cdot L \cdot \sqrt{R_{3}{ }^{2}-w^{2} / 16}
\end{aligned}
$$

\section{Rotor Spinning Viscous Losses}

Figure A.3 is the working basis for the derivation of the losses dues to viscous shear in the rotor gap. The velocity at an arbitrary point on the rotor is given by:

$$
u_{\theta}=r \cdot \omega
$$

Where $r$ is the radius of the point and $\omega$ is the angular velocity of the rotor. Assuming the velocity profile in the gap is linear we can then write that:

$$
\frac{d u_{\theta}}{d z}=r \frac{\omega}{h_{o}}
$$




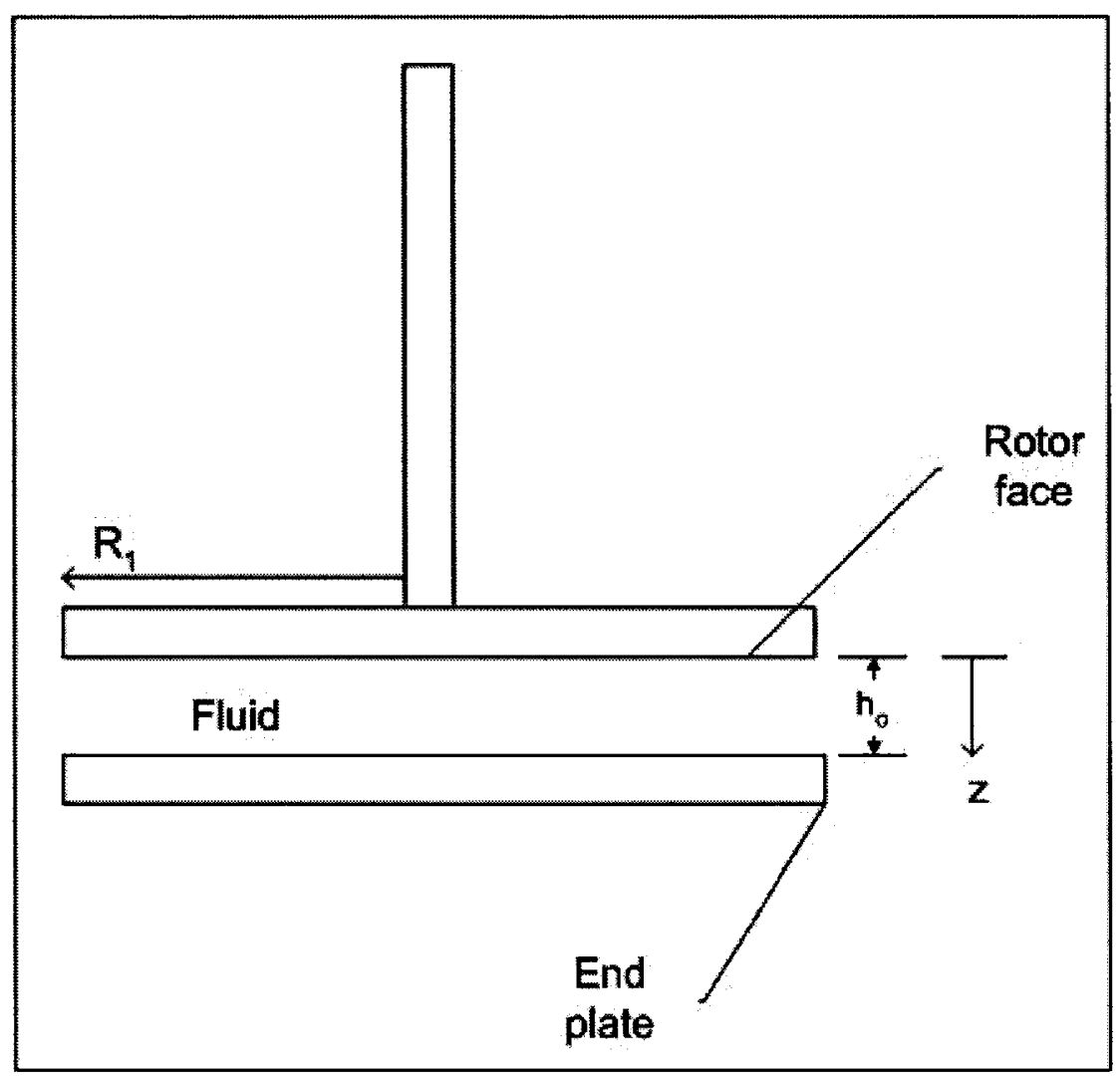

Figure A.3 Rotor Spining Viscous Losses

Now the expression for the differential force is as follows:

$$
d F=\tau \cdot d A=\mu \frac{d u_{\theta}}{d y} d A=\mu \frac{r \cdot \omega}{h_{o}}(2 \pi r \cdot d r)
$$

Where $\mathrm{A}$ is the circular area over which the force acts. The torque, $\mathrm{T}$, created is then calculated as such.

$$
\begin{aligned}
& d T=r \times d F \\
& T=\int \mu \frac{r \cdot \omega}{h_{o}} \cdot r \cdot 2 \pi r \cdot d r
\end{aligned}
$$

Integrating and noting that the power is the product of the torque and the rotational speed we get: 


$$
P_{l o s s, R F}=\frac{\pi}{2 h o} \mu_{o i l} \cdot \omega^{2}\left(R 1^{4}-R_{B e a r}^{4}\right)
$$

\section{A.8 MATLAB CODE}

The code is located on the main ATS computer at C:Documents and Settings\Admin \Chuk\A3program. Listed are the codes in alphabetical order. Page references in the code are not to pages in this thesis.

\section{Boiling Heat Transfer Approximation}

function [qpp] $=$ boilaprox $(\mathrm{T} 1, \mathrm{Tw})$

$\%$ page 58 (green)

\%

\% This program approximates the boiling heat transfer for use in

$\%$ calculating the actual boiling coefficient in the boiling.m program.

$\%$ INPUT

$\% \mathrm{~T} 1$ - inlet saturated temperature

$\%$ TW - Wall temperature

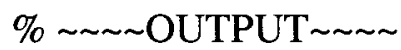

$\%$ qpp - boiling heat transfer

\%--

\%--

$\%$ UNDERSCORE 1 " 1 " REFERS TO THE SATURATED LIQUID PROPERTY

$\%$ UNDERSCORE g "_g" REFERS TO THE SATURATED GAS PROPERTY

$\%$ count - loop counter

$\% \mathrm{Cp}$ - Specific heat

$\% \mathrm{~d}$ - $\quad$ Pipe diameter (internal)

$\% \mathrm{~h}$ - enthalpy

$\% \mathrm{hb}$ - boiling heat transfer coefficient

$\%$ hconv - convective heat transfer coefficient

$\%$ hrad - radiative heat transfer component 
\% ht - total internal heat transfer coefficient

$\% \mathrm{k}$ - thermal conductivity

$\% \mathrm{mu}$ - visosity

$\%$ Psat - Saturated pressure

\% rho - density

\% s - entropy

\% Sigboltz - Boltzmann's constant

$\%$ Tsat - Saturated temperature

$\% \mathrm{v}$ - $\quad$ specific volume

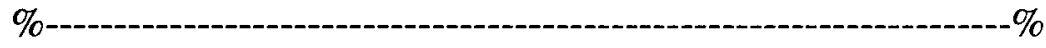

Sigboltz $=5.669 * 10^{\wedge}-8 ;$

$\mathrm{d}=0.25 * 0.0254$

$\mathrm{g}=9.81$;

[state, Psat, Tsat] = SatCheck (3,T1-273, 'T');

Psat $=$ Psat $* 100000$;

Tsat $=$ Tsat +273 ;

[h_l, s_l, v_l, Psat] = t_P_x(Tsat-273,Psat/100000,0);\%bar and celcius

[h_g, s_g, v_g, Psat] = t_P_x(Tsat-273,Psat,1);

Psat $=$ Psat $* 100000 ; \%$ pascals

rho_l=1/v_l;

rho_g=1/v_g;

h_l $=h \_1 * 1000$;

h_g = h_g*1000;

hfg $=$ abs $($ h_g-h_l);

$\mathrm{k} \_\mathrm{g}=-1.2331 * 10^{\wedge}(-2)+8.5663^{*} 10^{\wedge}(-5)^{*} \mathrm{Tsat}-4.6250^{*} 10^{\wedge}(-9) * \mathrm{Tsat}^{\wedge}(2)$;

Cp_g $=\left(8.4290+34.966 *\right.$ Tsat $-3.3281 * 10^{\wedge}(-4) *$ Tsat $^{\wedge} 2+1.560^{*} 10^{\wedge}(-7)^{*}$ Tsat $^{\wedge} 3-\ldots$

$2.9839 * 10^{\wedge}(-11) *$ Tsat $\left.^{\wedge} 4\right) * 0.102032$

$\mathrm{mu} \_\mathrm{g}=\left(-10.861+0.4392 *\right.$ Tsat $\left.-1.0316^{*} 10^{\wedge}(-4) * \mathrm{Tsat}^{\wedge} 2\right) * 10^{\wedge}(-7)$;

$\%$ radiation heat transfer

$\operatorname{hrad}=$ Sigboltz $^{*}\left(\mathrm{Tw}^{\wedge} 4-\mathrm{Tsat}^{\wedge} 4\right) /(\mathrm{Tw}-\mathrm{Tsat})$; 


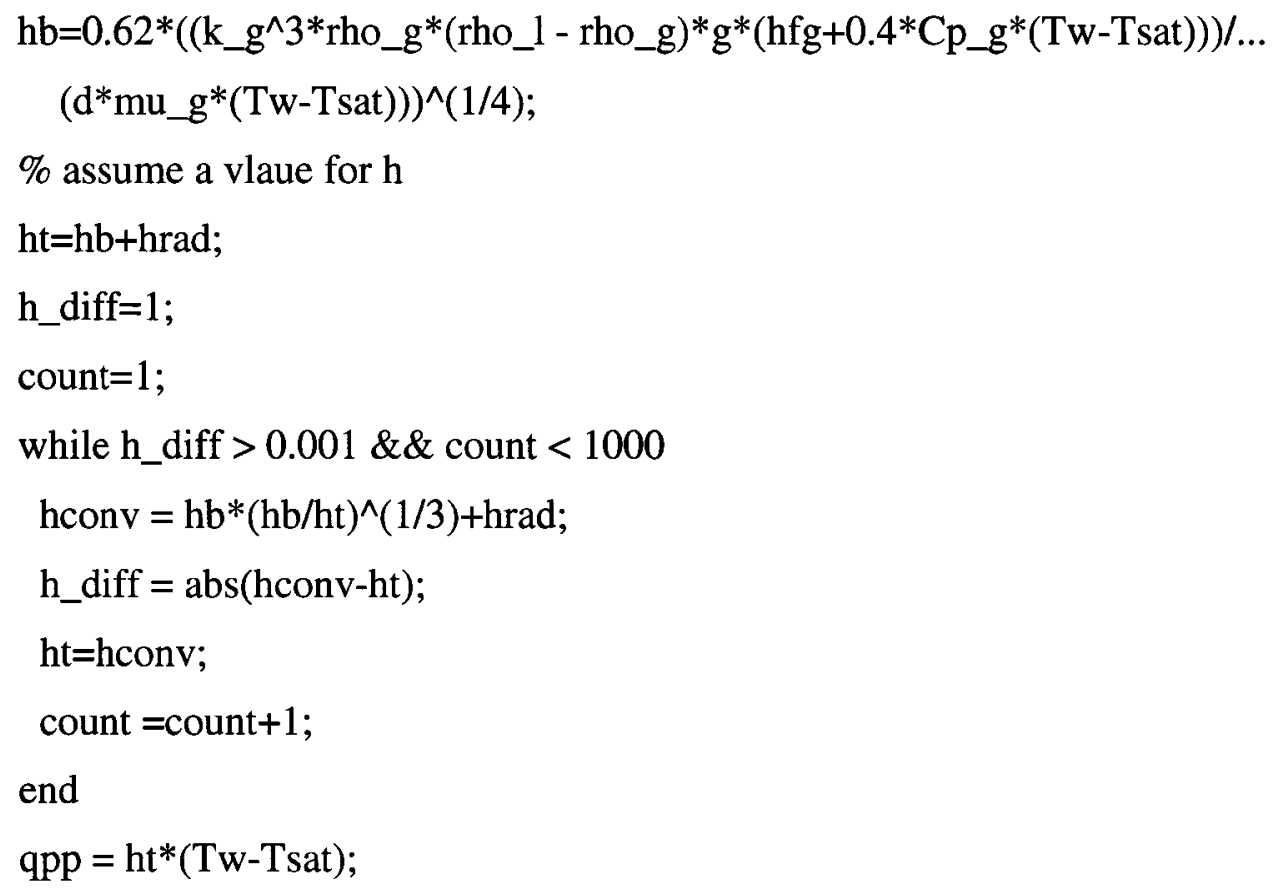

\section{Boiling Heat Transfer}

function $[\mathrm{h} 10]=$ boiling (Tsat, qual, massflow, Tw, setqual)

$\%$ page 58

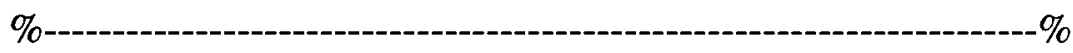

$\%$ This program resolves how much boiling has occured in the evaporator \% INPUT

$\%$ massflow - the massflowrate into the evaporator

$\%$ qual - The quality at the inlet of the evaporator

$\%$ setqual - only use if you want $t$ set a maximum treshhold for the quality $\% \quad$ output

\% Tsat - The temperature at the inlet of the evaporator

$\% \mathrm{Tw}$ - wall or surrounding temperature

$\%$ OUTPUT

$\%$ h10 - The enthalpy at the exit of the evaporator

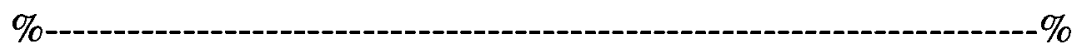

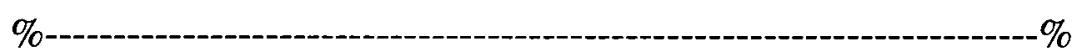




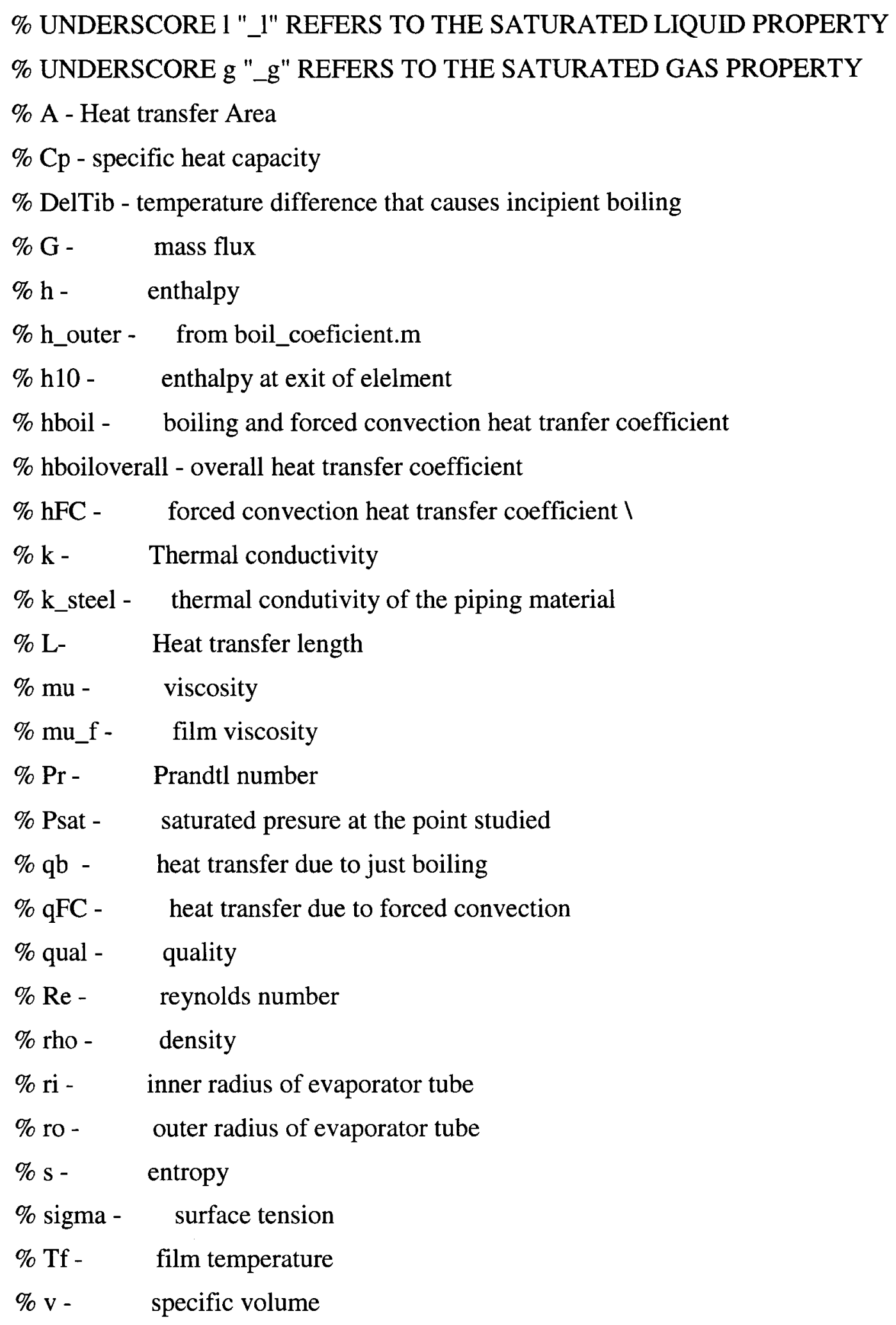


$\%$ $-\%$

$\mathrm{L}=15.8 ; \%$ meters

$\mathrm{ri}=(1 / 2 * 0.0254) / 2$;

ro $=((1 / 2+1 / 8) * 0.0254) / 2$;

k_steel $=16 ; \%$ estimate

$\mathrm{A}=2 * \mathrm{pi}^{*}{ }_{\mathrm{ri}} * \mathrm{~L}$;

h_outer $=401.18 ; \%$ see program boil_coefficient.

$\mathrm{Tf}=(\mathrm{Tw}+\mathrm{Tsat}) / 2$;

$\mathrm{D}=2 * \mathrm{ri}$;

Cp_g $=\left(8.4290+34.966^{*}\right.$ Tsat-3.3281*10^(-4)*Tsat^${ }^{\wedge} 2+1.560^{*} 10^{\wedge}(-7)^{*}$ Tsat $^{\wedge} 3-\ldots$ $2.9839 * 10^{\wedge}(-11)^{*}$ Tsat $\left.^{\wedge} 4\right) * 0.102032$;

Cp_l $=\left(49.253+66.134 * \mathrm{~T}_{\text {sat }}-2.7351^{*} 10^{\wedge}(-3) * \mathrm{Tsat}^{\wedge} 2+5.4918^{*} 10^{\wedge}(-6)^{*} \mathrm{Tsat}^{\wedge} 3\right) * 0.102032$;

$\mathrm{mu} \_\mathrm{l}=\left(10^{\wedge}\left(3107.5-\left(3.3361 * 10^{\wedge} 5\right) / \mathrm{Tsat}-9.6102 * \mathrm{Tsat}+\left(9.8587^{*} 10^{\wedge}(-3)\right)^{*} \mathrm{Tsat}^{\wedge} 2\right)\right)^{*} 10^{\wedge}-3$;

$\%$ pascal seconds

$\mathrm{mu} \_\mathrm{f}=\left(10^{\wedge}\left(3107.5-\left(3.3361 * 10^{\wedge} 5\right) / \mathrm{Tf}-9.6102 * \mathrm{Tf}+\left(9.8587^{*} 10^{\wedge}(-3)\right)^{*} \mathrm{Tf}^{\wedge} 2\right)\right)^{*} 10^{\wedge}-3 ; \%$ pascal seconds

mu_g $=\left(-10.861+0.4392 *\right.$ Tsat- $\left.1.0316^{*} 10^{\wedge}(-4) * \mathrm{Tsat}^{\wedge} 2\right) * 10^{\wedge}(-7)$;

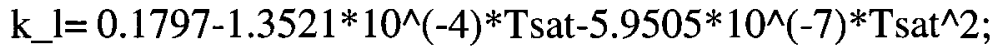

k_g $=-1.2331 * 10^{\wedge}(-2)+8.5663 * 10^{\wedge}(-5)^{*}$ Tsat $-4.6250^{*} 10^{\wedge}(-9)^{*} \operatorname{Tsat}^{\wedge}(2)$;

sigma $=901.588 *(1-\mathrm{Tsat} / 380)^{\wedge} 1.3044 * 0.001 ; \%$ newton meters

[h_l, s_l, v_l, Psat] = t_P_x(Tsat-273,10,0); \%bar and celcius

[h_g, s_g, v_g] = t_P_x(Tsat-273,Psat,1);

rho_l=1/v_l;

rho_g=1/v_g;

h_l $=$ h_l ${ }^{*} 1000$;

h_g $=$ h_g*1000;

hfg =abs (h_g-h_l);

qpp = boilaprox $($ Tsat, $T w)$; 
$\%$ correlation parameters

G_l $=4 *$ massflow/(pi* $\left.\mathrm{D}^{\wedge} 2\right) ; \%$ Reynolds \# as though the fluid took up the whole space

Frle $=$ G_l^2/((rho_l $\left.)^{\wedge} 2 * 9.81 * D\right)$;

Bo $=$ qpp/(G_l*hfg);

$\operatorname{Re}=4 *$ massflow/(pi*mu_l*D);

Re_g $=4^{*}$ massflow/(pi*mu_g*D);

Lsect $=\mathrm{L} / 100$

h10_one $=(1-q u a l) * h \_1+q u a l * h \_g ; \%$ original enthalpy

$\%$ for $\mathrm{n}=1: 100$

$\mathrm{n}=1$;

if nargin $<5$

setqual $=1.5$;

end

while qual $<=$ setqual

$\operatorname{Re} \_1=\mathrm{G} \_1 * \mathrm{D} *(1-$ qual $) / \mathrm{mu} \_\mathrm{l}$;

if qual $>=1$

Re_l =Re*(1-0.99);

end

Pr_l $=$ Cp_l ${ }^{*}$ mu_l/k_l;

Pr_g $=$ Cp_g*mu_g/k_g;

$\mathrm{Co}=((1-q u a l) / \text { qual })^{\wedge} 0.8 *(\text { rho_g/rho_l })^{\wedge} 0.5$;

hboil_l $=0.023 * \operatorname{Re}^{\wedge} 0.8 * \operatorname{Pr} 1^{\wedge} 0.4$;

$\%$ correlation coefficients $\mathrm{C} 1-\mathrm{C} 5$

$\mathrm{C} 4=0.7$;

C5 $=0.3$;

$\mathrm{Ffl}=1.63 ; \%$ page 102 for $\mathrm{R} 134 \mathrm{a}$

if Co $<1 \%$ conv boiling 
$\mathrm{C} 1=1.136$;

C2 $=-0.9$;

C3=667.2;

elseif $\mathrm{Co}>=1 \%$ nuclate boiling

C1=0.6683;

$\mathrm{C} 2=-0.2$;

C3=1058.0;

end

if qual $<0.99$

hboil = hboil2(qual,Re_1, Pr_l, k_l, Cp_l, hfg, mu_g, mu_l, mu_f,rho_l, rho_g, sigma, D, Tw, Tsat);

hboiloverall= $1 /\left(1 / \mathrm{hboil}+\mathrm{A}^{*} \log (\mathrm{ro} / \mathrm{ri}) /\left(2 * \mathrm{pi}^{*} \mathrm{k} \_\right.\right.$steel $\left.{ }^{*} \mathrm{~L}\right)+1 / \mathrm{h} \_$outer $)$;

h10_two=h10_one+hboiloverall*pi*D*Lsect/massflow*(Tw-Tsat);

qual $=\left(\right.$ h10_two $\left.-\mathrm{h} \_\mathrm{l}\right) /(\mathrm{hfg})$;

elseif qual $<1 \& \&$ qual $>=0.99$

hboil = hboil_1 ${ }^{*} \mathrm{C} 1 * \mathrm{Co}{ }^{\wedge} \mathrm{C} 2 *(25 * \mathrm{Frle})^{\wedge} \mathrm{C} 5+\mathrm{C} 3 * \mathrm{Bo}^{\wedge} \mathrm{C} 4 * \mathrm{Ffl}$;

hboiloverall $=1 /\left(1 / \mathrm{hboil}+\mathrm{A} * \log (\right.$ ro/ri $) /\left(2 * \mathrm{pi}^{*} \mathrm{k} \_\right.$steel $\left.{ }^{*} \mathrm{~L}\right)+1 / \mathrm{h} \_$outer $)$;

h10_two=h10_one+hboiloverall*pi*D*Lsect/massflow*(Tw-Tsat);

qual = (h10_two - h_l $) /($ hfg $)$;

elseif qual $>=1$

qual $=1$;

hboil = k_g/D*0.024* $\left(\operatorname{Re} \_g\right)^{\wedge} 0.8 * \operatorname{Pr} \_g \wedge 0.4$;

\%hboil $=(0.0023 / 8)^{*} \operatorname{Re} \_g * \operatorname{Pr} \_g /\left(1.07+12.7 *(0.023 / 8)^{\wedge} 0.5^{*}\left(\operatorname{Pr} \_g^{\wedge}(2 / 3)-1\right)\right)$;

hboiloverall= $1 /\left(1 / \mathrm{hboil}+\mathrm{A} * \log (\mathrm{ro} / \mathrm{ri}) /\left(2 * \mathrm{pi}{ }^{*} \mathrm{k} \_s t e e 1 * \mathrm{~L}\right)+1 / \mathrm{h} \_\right.$outer $)$;

h10_two=h10_one+hboiloverall ${ }^{*} \mathrm{pi}^{*} \mathrm{D} *$ Lsect/massflow $*($ Tw-Tsat $)$;

end

h10_one =h10_two;

$\mathrm{n}=\mathrm{n}+1$;

if $n==100$, break; end

end

h10=h10_two; 
function [hboil] = hboil2(qual,Re_l, Pr_l, k_l, Cp_l, hfg, mu_g, mu_l, mu_f,rho_l, rho_g, sigma, D, Tw, Tsat)

$\mathrm{Xtt}=(\text { rho_g/rho_l })^{\wedge} 0.5 *\left(\mathrm{mu} \_1 / \mathrm{mu} \_\mathrm{g}\right)^{\wedge} 0.1 *((1-\text { qual }) / \text { qual })^{\wedge} 0.9$;

$\mathrm{FXtt}=0.15^{*}\left(1 / \mathrm{Xtt}+2.0^{*}(1 / \mathrm{Xtt})^{\wedge} 0.32\right)$;

if qual $<=0.99 \& \&$ qual $>=0.6$

if $\operatorname{Re} \_1<50$

$\mathrm{F} 2=0.0707 * \operatorname{Pr} 1^{1} * \operatorname{Re}_{-} 1^{\wedge} 0.5$;

elseif $\operatorname{Re} \_1<1125$

$\mathrm{F} 2=5 * \operatorname{Pr} \_1+5 * \log \left(1+\operatorname{Pr} \_l^{*}\left(0.0964 * \operatorname{Re} \_l^{\wedge} 0.585-1\right)\right)$;

else

$\mathrm{F} 2=5 * \operatorname{Pr} \_1+5 * \log \left(1+5 * \operatorname{Pr} \_1\right)+2.5 * \log \left(0.0031 * \operatorname{Re} \_1^{\wedge} 0.812\right) ;$

end

$\mathrm{hFC}=\mathrm{Re} \_\mathrm{l}^{\wedge} 0.9 * \mathrm{Pr} \_\mathrm{l} * \mathrm{FXtt} * \mathrm{k} \_\mathrm{l} /(\mathrm{F} 2 * \mathrm{D}) ;$

elseif qual $<0.6 \& \&$ qual $>=0$

$\mathrm{hFC}=0.023 *\left(\operatorname{Re} \_1 /(1-q u a l) * m u \_1 / m u \_f\right)^{\wedge} 0.8 *\left(m u \_f * C p \_1 / k \_1\right)^{\wedge}(1 / 3)^{*} \mathrm{k} \_1 / \mathrm{D}$;

end

$\mathrm{qFC}=\mathrm{hFC} *(\mathrm{Tw}-\mathrm{Tsat})$

$\%$ incipient of boinling;

delTib $=8 *$ sigma $*$ Tsat*(1/rho_g-1/rho_l $) * h F C / k \_1 / h f g ;$

$\mathrm{BM}=1.89 * 10^{\wedge}-14$

$\% \mathrm{Qb}$ is non dependent on quality

$\mathrm{qb}=\mathrm{BM} * \mathrm{k} \_1^{\wedge}(1 / 2)^{*}$ rho_ $1^{\wedge}(17 / 8)^{*} \mathrm{Cp} \_1^{\wedge}(19 / 8) *$ rho_ $1^{\wedge}(1 / 8)^{*}(\mathrm{Tw}-\mathrm{Tsat})^{\wedge} 3 / \ldots$

$\left(\mathrm{mu} \_{ }^{*} \mathrm{hfg}^{\wedge}(7 / 8)^{*}(\text { rho_l-rho_g })^{\wedge}(9 / 8)^{*} \operatorname{sigma}^{\wedge}(5 / 8)^{*} \operatorname{Tsat}^{\wedge}(1 / 8)\right)^{*} .$.

$\mathrm{mu}$ l $^{*} \mathrm{hfg}^{*}\left(9.81^{*}(\text { rho_l-rho_g }) /(\operatorname{sigma})\right)^{\wedge}(1 / 2)$;

if qual $<=1 \& \&$ qual $>=0.6$

qboil=qFC $+q b *\left(1-(\text { delTib } /(\text { Tw }- \text { Tsat }))^{\wedge} 3\right)$;

elseif qual $<0.6 \& \&$ qual $>=0$

qboil $=\operatorname{sqrt}\left(q F C^{\wedge} 2+q b^{\wedge} 2^{*}\left(1-(\operatorname{delTib} /(\mathrm{Tw}-\mathrm{Tsat}))^{\wedge} 3\right)^{\wedge} 2\right)$; 
end

hboil = qboil/(Tw-Tsat);

$\%$

\section{Integrand for Area Determination}

function [IntGRD] = CalcIntgrand(t,R2,R1,PlusMinus)

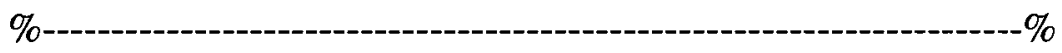

\% This program calculates the integrand needed for the calculation of the

$\%$ area in the chamber between the rotor vanes in conjunction with

\% FluidPressure Program

\% INPUT

$\%$ plusMinus - determines waht quadrant the integrand is being calculated $\%$ for

$\% \mathrm{R} 2$ - case radius

\% R1 - rotor radius

$\% \mathrm{t}$ - integration variable

\% OUTPUT

$\%$ IntGRD - the integrand

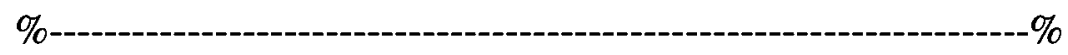

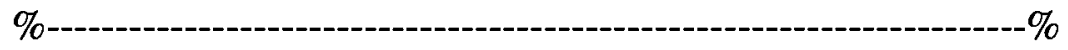

$\%$ e - eccentricity

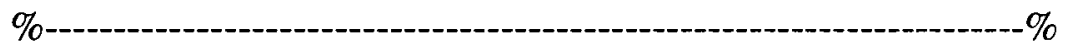

$\%$

$\% 1$ is minus

$\%$ anything else is plus

$\%$ Area between 90 and 270 is minused from quadratic rules.

e =R2-R1;

if PlusMinus == 1

$\operatorname{IntGRD}=\left(\left((-2 * \mathrm{e})-\operatorname{sqrt}\left(4 * \mathrm{e}^{\wedge} 2-4 *\left((\tan (\mathrm{t})) .^{\wedge} 2+1\right)^{*}\left(\mathrm{e}^{\wedge} 2-\mathrm{R} 22^{\wedge} 2\right)\right)\right) . / \ldots\right.$

$\left.\left(2^{*}\left((\tan (\mathrm{t})) \cdot^{\wedge} 2+1\right) \cdot{ }^{*} \cos (\mathrm{t})\right)\right) \wedge^{\wedge} 2-\mathrm{R} 1^{\wedge} 2 ; \%$ integrand (page 38$)$

else 
$\operatorname{IntGRD}=\left(\left(\left(-2^{*} \mathrm{e}\right)+\operatorname{sqrt}\left(4 * \mathrm{e}^{\wedge} 2-4 *\left((\tan (\mathrm{t})) .^{\wedge} 2+1\right)^{*}\left(\mathrm{e}^{\wedge} 2-\mathrm{R} 2{ }^{\wedge} 2\right)\right)\right) . / \ldots\right.$

$\left.\left(2 *\left((\tan (\mathrm{t})) .^{\wedge} 2+1\right) .^{*} \cos (\mathrm{t})\right)\right) .^{\wedge} 2-\mathrm{R} 1^{\wedge} 2 ; \%$ integrand (page 38)

end

\section{Friction Coefficient Determination}

function $\mathrm{mu}=$ CoefFric $(\mathrm{RPM})$

$\mathrm{mu}=\left(9 * 10^{\wedge}-9 .{ }^{*} \mathrm{RPM}^{\wedge} 2-4^{*} 10^{\wedge}-5 . * \mathrm{RPM}+0.09\right)$

$\%$ model based on page 1273 figure 8 , Vane pump theory for mechanical

$\%$ efficiency

\section{Condensation of Superheated Gas}

function [Tsat h5 Itot] = condenser (massflow, T4, P4, Tw, h4)

$\%$ see page 56

$\%$ lsat $=$ length till saturated pres

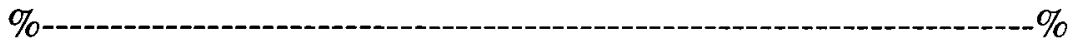

$\%$ this program calculates the heat transfered from the cooling water to the $\%$ refrigerant.

\% INPUT

$\%$ massflow - the massflow of the refrigerant

$\% \mathrm{~T} 4$ - the temperature of the refrigerant at the condenser inlet

$\% \mathrm{P} 4$ - the pressure of the refrigerant at the condenser inlet

$\% \mathrm{Tw}$ - the water temprerature

$\%$ h4 - the enthalpy at the condenser inlet

\% OUTPUT

\% Tsat - the themperature at the exit of the condenser

$\%$ h5 - the enthalpy at the exit of the condenser

$\%$ ltot - the length of the heat transfer area

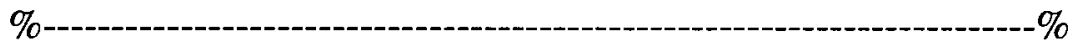

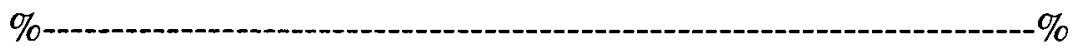


\% UNDERSCORE I "_l" REFERS TO THE SATURATED LIQUID PROPERTY

\% UNDERSCORE g "_g" REFERS TO THE SATURATED GAS PROPERTY

\% A - heat transfer Area

$\% \mathrm{Cp}-\quad$ specific heat capacity

\% D - the tube diameter

$\% \mathrm{G}$ - $\quad$ mass flux

$\% \mathrm{~h}$ - enthalpy

$\%$ h5 - enthalpy at the end of the element

$\%$ hconv - convective heat transfer coefficient

$\%$ hconvoverall - overall heat transfer coefficient including the

$\%$ surroundings

$\%$ hcondoverall - overall heat transfer coefficient including the

$\%$ surroundings

\% h_outer - exteranal coeficient of heat transfer from

$\% \quad$ cond_coefficient.m

$\% \mathrm{k}$ - thermal conductivity

$\% \mathrm{k} \_$steel - thermal conductivity of the pipe

$\% \mathrm{~L}$ - $\quad$ Length (variable usues)

$\%$ lcond - length of condensation section

$\%$ ltot - the total heat transfer length of the pipe

$\% \mathrm{mu}$ - viscosity

\% mu_w - viscosity at the wall

$\% \mathrm{~N}$ - the number of turns of the coil

$\%$ phi - the pitch diameter of the coil

\% Ploss - pressure lost due to friction

\% Pnew - Pressure with friction adjustment

$\% \mathrm{Pr}$ - Prandtl number

\% Psat - the saturated presure of the refrigerant

$\%$ qual - quality

$\% \operatorname{Re}$ - Reynolds number 
\% Rem - $\quad$ modified reynold's number

$\%$ rho - density

$\%$ ri - Pipe's inner radius

\% ro - Pipe's outer raius

$\%$ s - entropy

$\%$ state - contains information on the phase of the fluid

$\% \mathrm{Tf}$ - the film temperature

\% Tsat - The saturated temperature of the refrigerant (at constant

$\%$ pressure)

$\% \mathrm{v}$ - $\quad$ specific volume

$\% \mathrm{Vmv}$ - mean velocity of the vapor

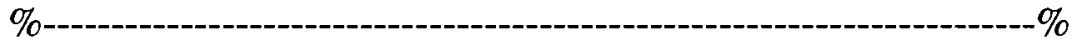

$\%$ .geom prop of condenser.

$\mathrm{D}=1 / 2 * 0.0254$;

$\mathrm{N}=13$;

phi $=18 * 0.0254$;

ltot $=\mathrm{pi}^{*} \mathrm{phi}^{* \mathrm{~N}}$;

$\mathrm{ri}=\mathrm{D} / 2$;

ro $=((1 / 2+1 / 8) * 0.0254) / 2$;

k_steel $=16$;

h_outer $=965.3$;

$\%$ finding the distance to sat.:initializing for loop

ls $=[0.5 ; 1] ; \%$ old $/$ new saturated lengths

[state, Psat, Tsat] = SatCheck (P4/100000,T4-273, 'P');

Psat $=$ Psat $* 100000$;

Tsat = Tsat +273 ;

$\mathrm{Tf}=(\mathrm{T} 4+\mathrm{Tw}) / 2 ; \% \mathrm{~T}$ in kelvin, film temperature

count $=1$;

$\%$ calculating section of superheated heat transfer

while abs(ls(2)-1s(1))>0.01 


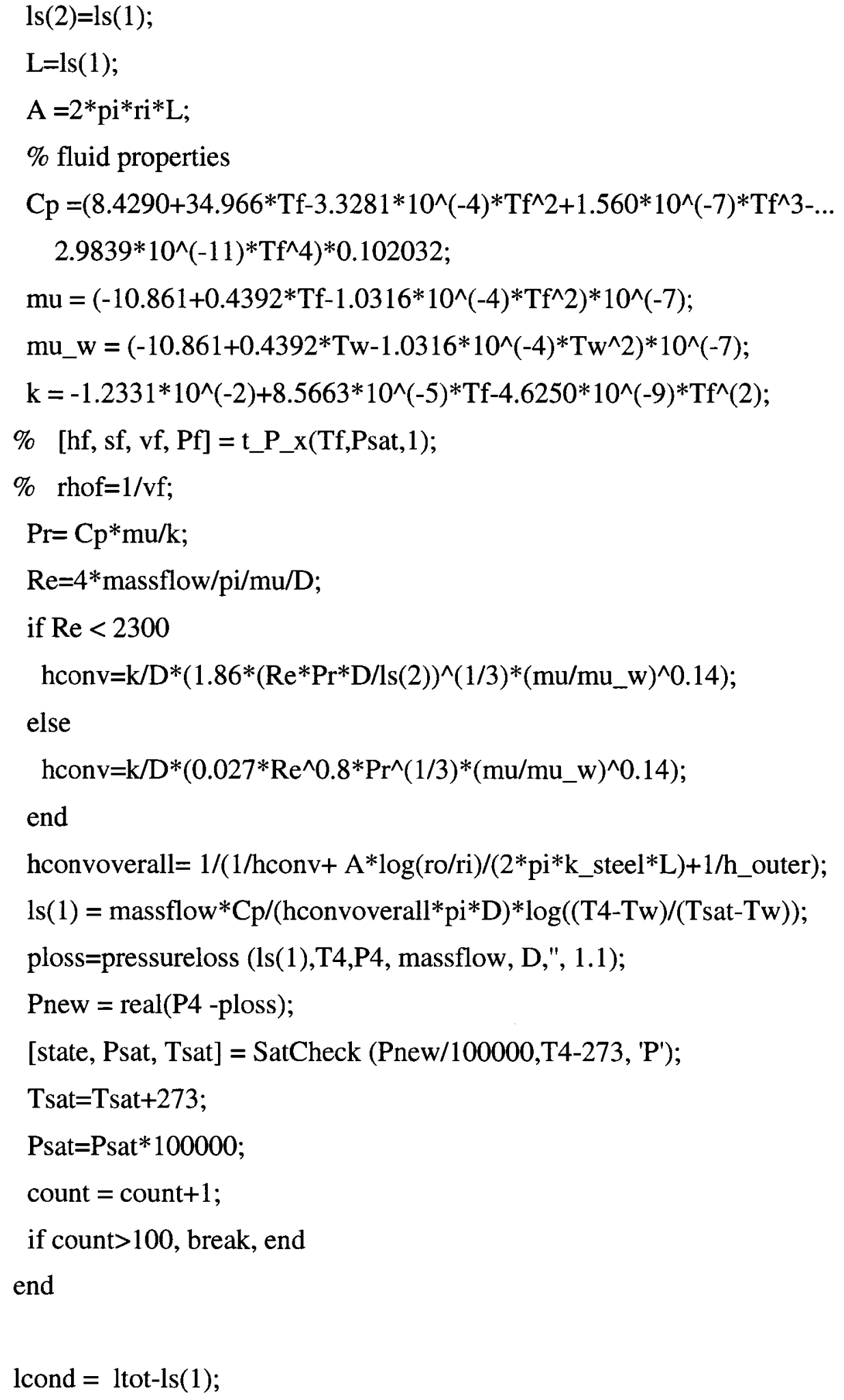


if lcond $<0$

error ('no condensation occured')

end

L=lcond;

$\mathrm{A}=2 * \mathrm{pi}^{*}{ }_{\mathrm{ri}} * \mathrm{~L}$

[h_l, s_l, v_l, Psat] = t_P_x(Tsat-273,Psat/100000,0); \% Psat redefined

[h_g, s_g, v_g] = t_P_x(Tsat-273,Psat,1); \% not Psat redefined above

h_l $=\mathrm{h} \_1 * 1000$;

h_g $=$ h_g* 1000 ;

rho_ll=1/v_l;

rho_g=1/v_g;

hfg =abs(h_g-h_l);

$\mathrm{Cpl}=\left(49.253+66.134 * \mathrm{Tsat}^{2} 2.7351^{*} 10^{\wedge}(-3)^{*} \mathrm{Tsat}^{\wedge} 2+5.4918^{*} 10^{\wedge}(-6)^{*} \mathrm{Tsat}^{\wedge} 3\right)^{*} 0.102032$;

$\mathrm{mu} \_\mathrm{g}=\left(-10.861+0.4392 * \text { Tsat }-1.0316^{*} 10^{\wedge}(-4) * \mathrm{Tsat}^{\wedge} 2\right)^{*} 10^{\wedge}(-7)$;

mu_l $=\left(10^{\wedge}\left(3107.5-\left(3.3361 * 10^{\wedge} 5\right) / \text { Tsat-9.6102*Tsat+ }\left(9.8587^{*} 10^{\wedge}(-3)\right)^{*} \text { Tsat }^{\wedge} 2\right)\right)^{*} 10^{\wedge}-3$;

$\%$ pascal seconds

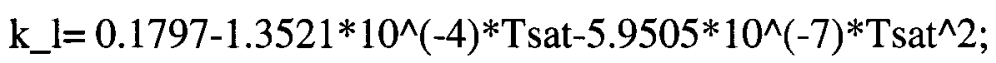

$\mathrm{Vmv}=4 *$ massflow/(rho_g*pi* $\left.\mathrm{D}^{\wedge} 2\right)$;

hfgp $=$ hfg $+3 / 8 * \mathrm{Cpl}^{*}($ Tsat-Tw $) ; \%$ modified hfg

if (rho_g*Vmv*D/mu_g) $<35000$

hcond $=0.555^{*}\left(\left(9.81 * \text { rho_l }{ }^{*}(\text { rho_l-rho_g }) * \mathrm{k} \_{ }^{\wedge} 3 * \mathrm{hfgp}\right) /\left(\mathrm{mu}_{-}{ }^{*}(\mathrm{Tsat}-\mathrm{Tw})^{*} \mathrm{D}\right)\right)^{\wedge}(0.25)$;

hcondoverall $=1 /\left(1 / \mathrm{hcond}+\mathrm{A} * \log (\mathrm{ro} / \mathrm{ri}) /\left(2 * \mathrm{pi}^{*} \mathrm{k} \_s t e e l * \mathrm{~L}\right)+1 / \mathrm{h} \_\right.$outer $)$;

h5 = h_g-hcondoverall*pi*D*lcond/massflow*(Tsat-Tw $)$;

else

$\mathrm{L}=\mathrm{lcond} / 100$;

qual=1;

Pr_l =mu_l $* \mathrm{Cpl} / \mathrm{k} \_\mathrm{l}$;

h5_one=h_g;

for $\mathrm{n}=1: 100$

$\mathrm{Gl}=4 *(1-$ qual $) *$ massflow $/\left(\mathrm{pi}^{*} \mathrm{D}^{\wedge} 2\right) ;$ 


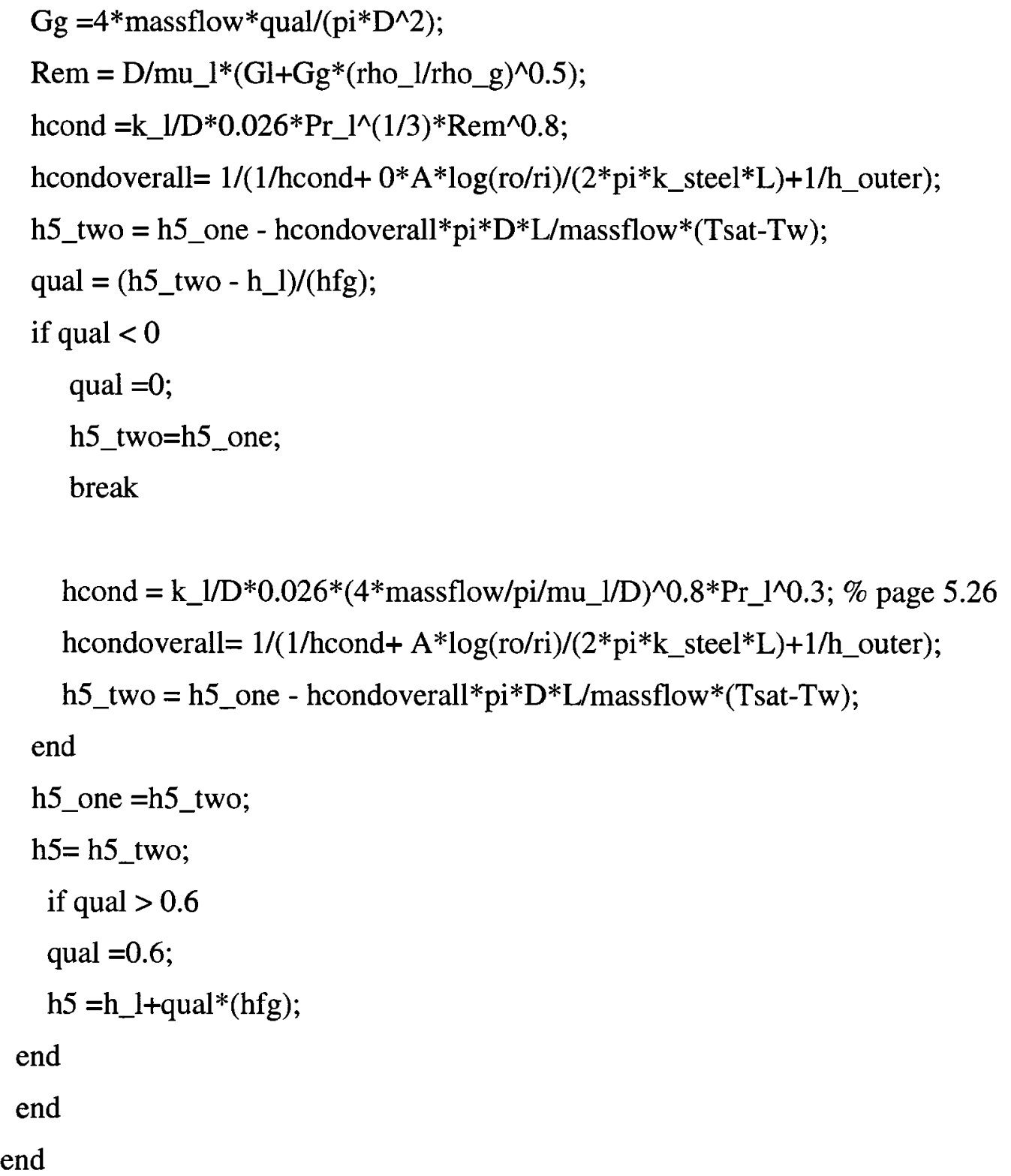

\section{Expander}

function [Pout, Tout, mout, mleak, Ploss] = expander (qual, RPM, P0, T0)

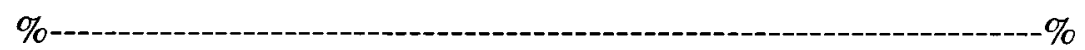

$\%$ This program calculates the properties at the exit of the expander given $\%$ the expander input parameters.

$\% \sim \sim \sim \sim$ INPUT 
$\%$ P0 - the pressure at the inlet of the expander

$\%$ qual - The quality at the inlet of the expander

\% RPM - the speed of the compressor-expander

$\% \mathrm{~T} 0$ - the temperature at the inlet of the expander

$\%$ OUTPUT

$\%$ mleak - the massflow leaking through the expander

$\%$ mout - the output massflow of the expander

$\%$ Ploss - the power lost in the expander due to friction

$\%$ Pout - the output pressure of the expander

$\%$ Tout - the output temperature of the expander

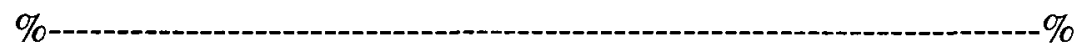

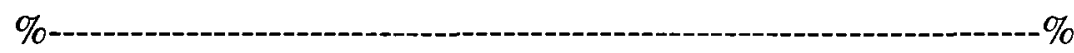

$\%$ AngleFric - sliding Friction at each angle in increment

$\%$ COf - coefficient of friction

$\%$ e - eccentricity

$\% \mathrm{FF}$ - frictional force

$\% \mathrm{FT}$ - frictional torque

$\%$ g- gravitational acceleration

\% gamma - specific heat ratio@ standard conditions

$\% \mathrm{~h}$ - $\quad$ vane height

\% ho - Gap clearance

$\%$ incerment - set fines of the angular mesh

\% 1 - vane length

$\%$ mideal - ideal mass flow output of the compressor

$\%$ mleak - mass lost due to leakage

$\%$ mloss - mass lost percentage

\% Mrot - mass of compressor-expander rotor

$\% \mathrm{Mvc}$ - mass of compressor vane

$\%$ Mve - mass of expander vane

$\% \mathrm{~N}$ - number of vanes 
\% nuo - dynamic viscosity of oil

$\%$ Omega - rotational speed

\% Ploss - power loss

$\%$ Pout - output pressure of the expander

$\% \mathrm{R}$ - vane tip radius

\% R1 - Rotor radius

$\% \mathrm{R} 2$ - Case radius

\% R3 - shaft radius

$\%$ rg - Position of center of gravity with respect to the rotor center.

\% rhoo - density of oil

$\%$ theta - angle increment based on origin at rotor center

$\%$ torque loss - losses due to frictional torque

$\%$ VS - Slot width

$\% \mathrm{w}$ - $\quad$ vane width

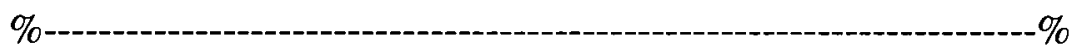

$\%$ to change path : type help path

$\%$ Working predominantly in SI units

global PH TH

$\%$ FF - Frictional Force

$\%$ FT - Frictional Torque

$\%$

$* * * * * * * * * * * * * * * * * * * * * * * * * * * * * * * * * * * * * * * * * * * * * * * * * * * * * * * * * * * * * * * * * * * * * * * * * *$

$\%$ Global variables

$\%$ OPERATING CONDITIONS AND PROPERTIES

$\%$ RPM = 1500;

$\%$ Omega $=\mathrm{RPM} * \mathrm{pi} / 30$;

$\mathrm{g}=9.81 ; \%$ acceleration due to gravity

$\mathrm{COf}=0.08$; \% Measured with slant experiment page 28 , it should be a function of velocity (paper)

$\mathrm{Mvc}=0.03658 ; \%$ compressor vane mass (measured) 
Mve $=0.012081 ; \%$ Exmapnder vane mass(measured)

$\mathrm{Mv}=\mathrm{Mvc}+\mathrm{Mve}$

nuo $=45 * 10^{\wedge}-6 ; \% 100$ PAG oil=100cst @ 40C and 85\% oil

$\%$ might want to consider using graph to get nu_oil(T)

rhoo $=1032.9 ; \%$ measured -- oil density

Mrot $=1.12673 ; \%$ Measured - rotor mass

Gamma = 1.1383411;

$\%$

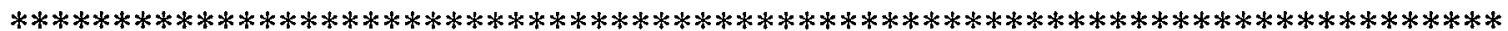

\section{\% GEOMETRY DEFINITIONS}

$\mathrm{h}=0.022873 ; \% 0.9$ inches from drawings

ho $=(0.0035 * 0.0254) ; \% 3.5$ thou: from drawings should be one thou(claearance $b / w$ roator face and case)

$1=0.032741 ; \quad \%$ vane length dimension

$\mathrm{R}=0.011999 ; \quad \%$ vane tip radius

$\mathrm{R} 1=0.04252 ; \% 3.48$ inches diameter

$\mathrm{R} 2=0.050781 ; \% 3.9985$ inches diameter

$\mathrm{R} 3=0.015608 ; \%$ Shaft radius-Measured

$\mathrm{VS}=0.006579 ; \% \mathrm{x}$ in page 32

$\mathrm{w}=0.006553$;

Omega $=\mathrm{RPM} * \mathrm{pi} / 30$;

$\%$

$* * * * * * * * * * * * * * * * * * * * * * * * * * * * * * * * * * * * * * * * * * * * * * * * * * * * * * * * * * * * * * * * * * * * * * * * * * * *$

\section{\% 1. ECCENTRIC DEFINITIONS, OUTER WALL FRICTION}

$\%$ standard SI units

$\%$ Increment - number of angular points between

$\%$ defining mesh

increment $=360 ; \%$ must be a multiple of Number of vanes

theta $=0: 2 * \mathrm{pi} /$ increment $: 2 * \mathrm{pi}$;

$\%$ geometry of compressor 
$\mathrm{N}=5 ; \% 5$ vanes

$\mathrm{rg}=$ vaneCG $(\mathrm{R} 1, \mathrm{R} 2$,theta,h);

$\%$ Calculates sum for $\mathrm{rg}$ for several configurations of the pump

$\%$ see VaneCG for explanation

$\%$ from previous work for 5 vanes there is minimal friction change with

$\%$ angle of rotation so we can take the compressor and any position

$\%$

$\%$

$\%$ friction forom sliding

$\%$ output pressure

$\%$ tip mass loss

$\%$ ideal mass flow rate

[AngleFric, Pout, mloss 1, mideal] $=$ VaneTipFriction $(\mathrm{N}, \mathrm{R}, \mathrm{R} 1, \mathrm{R} 2, \mathrm{~h}, \mathrm{w}, \mathrm{l}, \mathrm{VS}, \ldots$

Mvc, Omega, theta, P0, T0,'exp');

$\%$ compressor friction

for $\mathrm{n}=1$ :increment $/ \mathrm{N}$

TotVTF=0; \% Adding up friction in all five vanes

$\mathrm{m}=\mathrm{n}$;

while $\mathrm{m}<=\max (\operatorname{size}($ AngleFric) $)$

TotVTF = AngleFric $(\mathrm{m})+$ TotVTF; $\quad$ \%VTF Vane tip Friction

$\mathrm{m}=\mathrm{m}+$ increment $/ \mathrm{N}$;

end

AngFricTot(n)= TotVTF;

end

FFl $=\max ($ AngFricTot $)$;

$\% \max (\mathrm{rt})$ selects the angle configuration where maximum rtot occurs

$\mathrm{FT}(1)=\mathrm{FF} 1 * \operatorname{mean}(\operatorname{rg}(1:(\max (\operatorname{size}(\operatorname{rg}))-1)))$; 
\% Torque is sum of friction force times the average radius they act over..

\% $\max \mathrm{x}$ is the same as $\max \mathrm{rg}$ and $\min \mathrm{x}$ is the same as $\min \mathrm{rg}$

$\mathrm{A}(1,1)=\mathrm{FT}(1)$

\%to show contribution of each type of friction

$\%$

$* * * * * * * * * * * * * * * * * * * * * * * * * * * * * * * * * * * * * * * * * * * * * * * * * * * * * * * * * * * * * * * * * * * * * * * * * * * *$

\section{\% 2. SPINNING GAP END FACES}

$\%$ see page $16-17$

$\%$

\% Multiply FT2 by 2 Again

$\%$

$\mathrm{FT}(2)=\left(\mathrm{pi} / 2 /\right.$ ho $^{*}$ nuo $*$ rhoo* Omega $\left.*\left(\mathrm{R} 1^{\wedge} 4-\mathrm{R} 3^{\wedge} 4\right)\right) ; \%$ two faces: compressor and expander

$\mathrm{A}(1,2)=\mathrm{FT}(2) ; \%$ to show contribution of each type of friction

$\%$

$* * * * * * * * * * * * * * * * * * * * * * * * * * * * * * * * * * * * * * * * * * * * * * * * * * * * * * * * * * * * * * * * * * * * * * * *$

\section{\% 3. COMP-EXP SEAL FRICTION}

$\%$ Seal is assumed to bare a third of the load of the rotor.

$\mathrm{FF} 3=\mathrm{COF} *(\mathrm{Mrot} / 3)^{*} \mathrm{~g}$;

$\mathrm{FT}(3)=\mathrm{FF} 3 * \mathrm{R} 2$;

$\mathrm{A}(1,3)=\mathrm{FT}(3)$; \%shows contribution of each type of friction

$\%$

$* * * * * * * * * * * * * * * * * * * * * * * * * * * * * * * * * * * * * * * * * * * * * * * * * * * * * * * * * * * * * * * * * * * * * * * *$

$\%$ power and mass lost at rotor face

if comporexp = 'comp'

[ploss, mloss2] =leakloss (RPM, R1,R2,PH, TH, theta,l,w,h,Pout, ho, P0, T0);

Torqueloss=sum(FT);

Ploss $=$ Torqueloss $*$ Omega + ploss; $\%$ total power lost

mloss $=$ mloss $1+\operatorname{mloss} 2$;

mout $=$ mideal $*(1-$ mloss $/ 100)$;

mleak = mideal-mout;

Tout $=\mathrm{T} 0 *(\mathrm{Pout} / \mathrm{P} 0)^{\wedge}((\mathrm{Gamma}-1) / \mathrm{Gamma}) ;$ 
end

$\%$

$\%$

\% STATIC TORQUE IS 12 IN-LBF =1 FT-LBF must subtract static torque due to $\%$ torlon coz it changes to dynamic

\section{Expansion Device}

function $[$ Pout, Tout $]=$ ExpanDev (massflow, density, Pin)

$\%$ - \%

$\%$ This prgram calculates the presure drop across the exapnsion device \% INPUT

$\%$ density - the inlet density of the refrigerant

$\%$ massflow - the mass flow rate of the refrigerant at the inlet

$\%$ Pin - the inlet pressure of the refriferant

\% OUTPUT

$\%$ Pout - the output pressure of the expansion device

$\%$ Tout - The output temperature of the expansion device 0

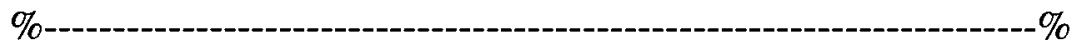

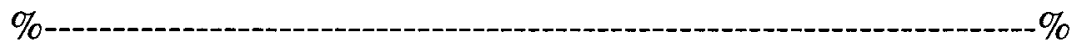

\% DelP - Pressure drop across expansion valve

$\% \mathrm{~K}$ - expansion device constant

$\%$ State - determines the phase of the refrigerant at the given point

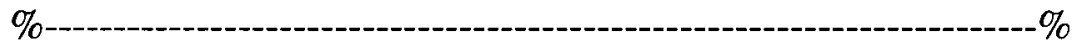

$\mathrm{K}=2.2184 * \log (\mathrm{Pin} / 1000)-13.079$; $\%$ need to fing $\mathrm{K}$ for massflow $=$ massflow $/ 2$

$\mathrm{K}=\mathrm{K}^{*} 10^{\wedge}-6$;

DelP $=(\text { massflow } / K)^{\wedge} 2 /$ density;

if DelP $>500000$

DelP=500000; \% exp shows current exp device cannot go above this value end

Pout $=$ Pin - DelP; 
[state, Pout, Tout] = SatCheck $($ Pout/100000,2, 'P');

Pout $=$ Pout $* 100000$;

Tout $=$ Tout +273 ;

\section{Experimental Input to the Compressor}

function ExpValue = ExpCompute (Omega, VarType, comp_or_exp)

$\%$ computes expermital values based on trends

$\%$ omega is the compressor speed

$\%$ comp_or_exp accepts 'exp' for expander and 'comp' for compressor

\% VarType $=1$ is Gamma

\% VarType $=2$ is P0 in Pascals

$\%$ VarType $=3$ is T0 in Kelvin

\% Equation file: H:Igard\Thesis\Compressor\Dataljune 200609

$\%$ Provides the input for the compressor program when doing the compressor $\%$ expander runs and not the overall system runs

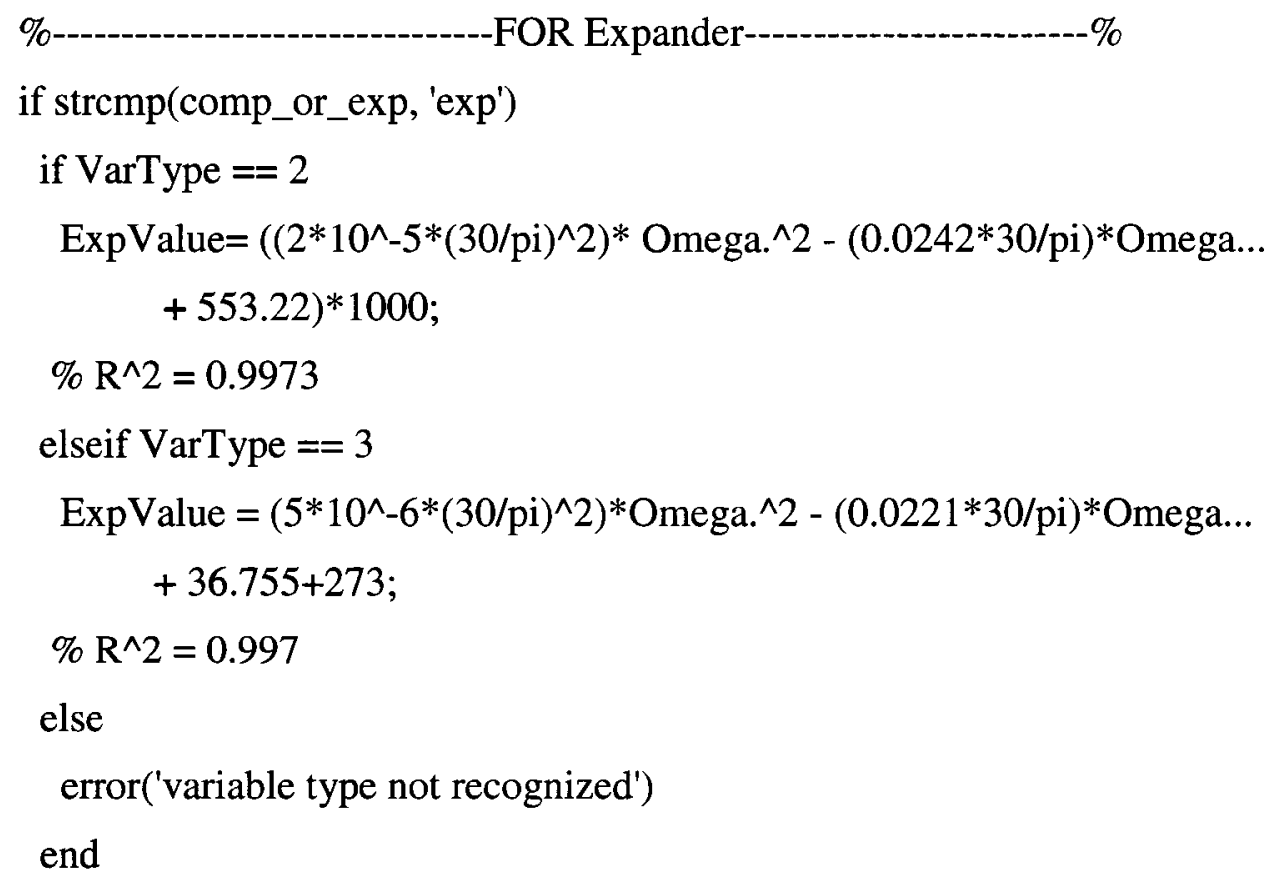


end

\section{Fluid Chamber Pressure}

function [PL, PH, TL, TH, Pout, tipmassloss, massflow] = FluidPressure (w, h, rg, R2, $\mathrm{R} 1,1, \mathrm{~N}$, theta, $\mathrm{P} 0, \ldots$

Gamma, T0, comp_or_exp, Omega)

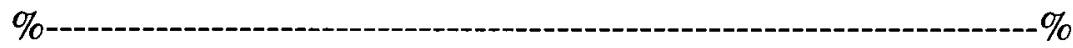

\% This program calculates the pressure on the front and back of the

$\%$ compressor vanes at various angles. The tip mass loss is also calculated.

$\%$ theta are the values of theta corresponding to $\mathrm{rg}$

$\% \mathrm{P} 0$ is the refrence pressure (inlet pressure used as refrence)

\% INPUT

\% comp_or_exp - Used to differenciate between calculations for compressor

$\% \quad$ and exander "exp" for expander "comp" for compressor

$\%$ Gamma - specific heat ratio

$\% \mathrm{~h}$ - Vane height

\% 1 - Vane length

$\% \mathrm{~N}$ - number of vanes

$\%$ Omega - rotational speed

$\% \mathrm{P0}$ - inlet pressure

$\% \mathrm{R} 1$ - $\quad$ Rotor radius

$\% \mathrm{R} 2$ - $\quad$ Case radius

$\%$ rg - Vane center of mass

\% T0 - Temperature at the inlet

$\%$ theta - Angular mesh definition

$\% \mathrm{w}$ - Vane width

$\%$ OUTPUT

\% PH - vane high side pressure at each angle

\% PL - vane low side pressure at each angle

\% TH - vane high side temperature at each angle 
\% TL - vane low side temperture at each angle

$\%$ Pout - the output pressure

$\%$ tipmassloss - the $\%$ of mass lost at the top dead center

$\%$ massflow - massflow rate

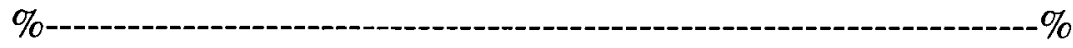

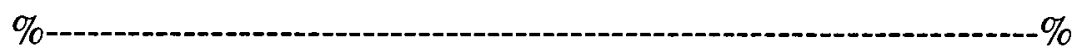

\% A0 - $\quad$ The area of the chamber at the close to inlet stage

$\%$ Aorf - Exit orifice area

\% Area - calculates the area in the chamber as a function of theta.

$\% \quad$ subs $1 \& 2$ used to break up area calculations

\% Arean - New area

\% Areap - Previous area

\% backstep - Used to calculat the pressure on the trailing vane

$\%$ DelP - $\quad$ Pressure difference across the orifice

$\%$ htab - Enthalpy at the inlet of the unit

$\%$ massp - Mass at the close of the inlet

$\%$ mloss - Mass lost through gaps and orfices from the compression

$\%$ Chamber

$\%$ originalmass - Mass of fluid in the chamber at the close of the inlet

$\%$ Porf - Orifice exit pressure

$\%$ rho - Density

\% rhon - New density

\% rhop - Previous density

\% stab - Entropy at the inlet of the unit

\% vtab - Specific volume at the inlet of the unit

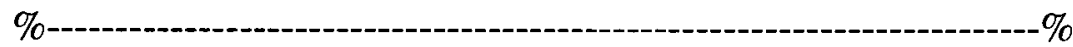

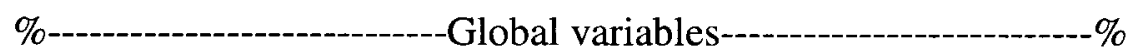

global PH TH PL;

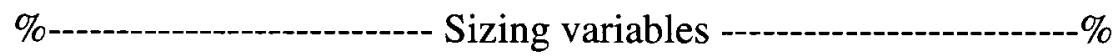

datasize $=\max (\operatorname{size}($ theta $))-1$; 


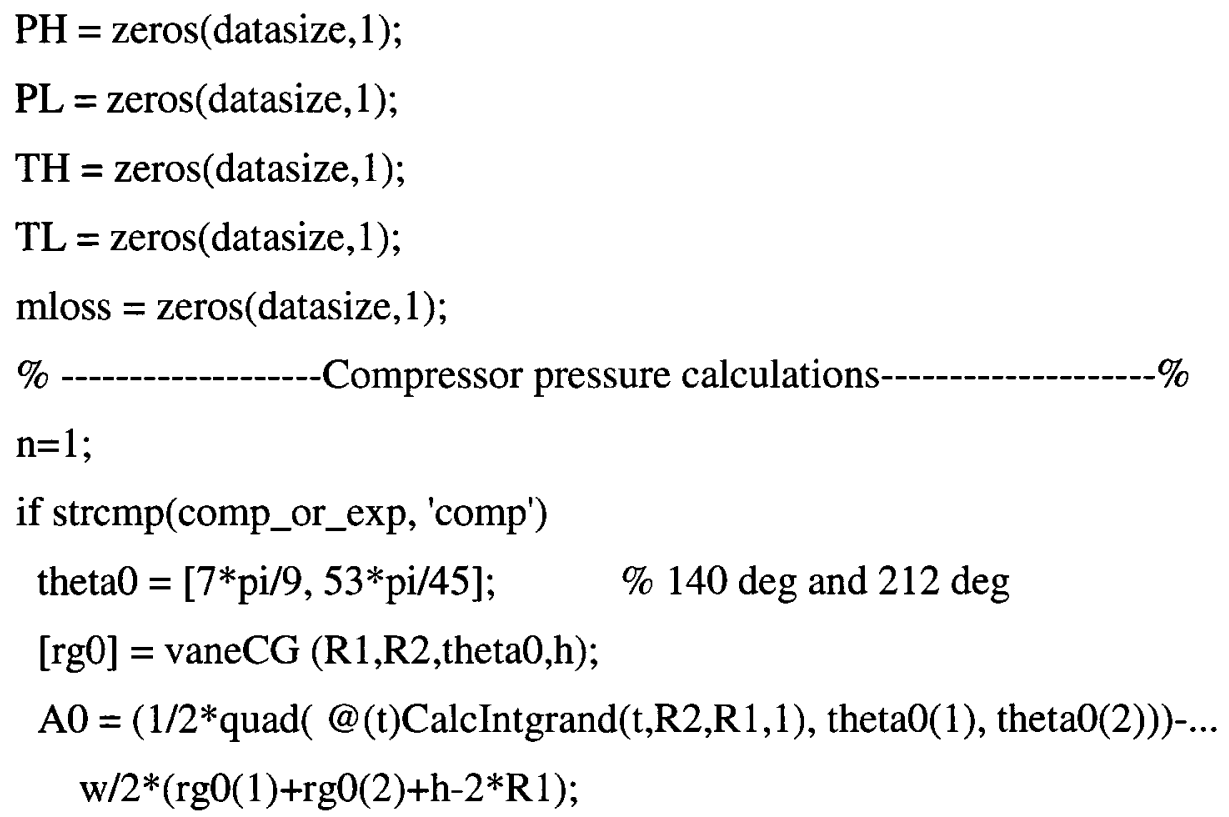

Backstep $=$ datasize $/ \mathrm{N} ; \%$ see page 40

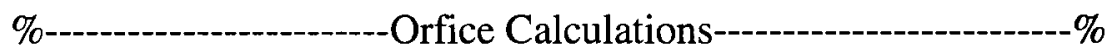

[htab, stab, vtab, Ptab] = t_P_x(T0-273, P0/100000, 1);

massp $=1 / \mathrm{vtab} * 1 * \mathrm{~A} 0 ; \%$ mass at inlet close

massflow $=$ massp $* 5 *$ Omega $* 30 / \mathrm{pi} / 60$;

Aorf $=2.027^{*} 10^{\wedge}-5$;

$\% \mathrm{ke}=0.45$;

while $\mathrm{n}<=(\max (\operatorname{size}($ theta $))-1)$

if $\mathrm{n}<\max ($ size(theta))-Backstep

$\mathrm{m}=\mathrm{n}+$ Backstep;

else

$\mathrm{m}=\mathrm{n}+\mathrm{Backstep}-\max ($ size $($ theta $)) ;$

end

thetaH $=$ theta(n); $\quad \%$ see drawing on page 38

thetaL $=$ thetaH $+2 * \mathrm{pi} / 5 ; \quad \% 72$ degrees in radians

if thetaH $>=0 *$ pi $/ 180 \& \&$ thetaH $<=20^{*}$ pi $/ 180$ 


$$
\begin{aligned}
& \mathrm{PH}(\mathrm{n})=\mathrm{P0} \\
& \mathrm{TH}(\mathrm{n})=\mathrm{T} 0 ; \% \text { just for now, needds to be re-analyzed } \\
& \text { elseif thetaH }>20^{*} \mathrm{pi} / 180 \& \& \text { thetaH }<=140^{*} \mathrm{pi} / 180
\end{aligned}
$$

$\mathrm{PH}(\mathrm{n})=\mathrm{P} 0 ; \%$ pressure is the inlet pressure

$\mathrm{TH}(\mathrm{n})=\mathrm{T} 0$;

elseif thetaH $>140 *$ pi $/ 180 \& \&$ thetaH $<=198 *$ pi $/ 180$

$\%$ Area functions: this stores the Area in fornt of the

$\%$ vane when the vane is at thetaH

Area1 = 1/2*quad( @(t)CalcIntgrand(t,R2,R1,1), thetaH, thetaL);

Area2 $=0$;

\%Area3 $=\mathrm{w} / 2 *(\operatorname{rg}(\mathrm{n})+\mathrm{rg}(\mathrm{m})+\mathrm{h}-2 * \mathrm{R} 1)$;

Area=Area1+Area2\%-Area3; $\%$ vane ocupied area, page 38

$\mathrm{PH}(\mathrm{n})=\mathrm{P} 0 *(\mathrm{~A} 0 / \text { Area })^{\wedge} \mathrm{Gamma}$
$\mathrm{TH}(\mathrm{n})=\mathrm{TH}(\mathrm{n}-1)^{*}(\mathrm{PH}(\mathrm{n}) / \mathrm{PH}(\mathrm{n}-1))^{\wedge}((\mathrm{Gamma}-1) / \mathrm{Gamma}) ;$

elseif thetaH $>198 *$ pi $/ 180 \& \&$ thetaH $<=208 *$ pi $/ 180$

Areal = 1/2*quad( @(t)CalcIntgrand(t,R2,R1,1), thetaH, $3 * \mathrm{pi} / 2)$;

Area2 = 1/2*quad( @(t)CalcIntgrand(t,R2,R1,2), 3*pi/2, thetaL); \% page 38

$\%$ Area3 $=\mathrm{w} / 2 *(\mathrm{rg}(\mathrm{n})+\mathrm{rg}(\mathrm{m})+\mathrm{h}-2 * \mathrm{R} 1)$;

Area=Area1+Area2\%-Area3;

$\mathrm{PH}(\mathrm{n})=\mathrm{PO} *(\mathrm{~A} 0 / \text { Area })^{\wedge} \mathrm{Gamma}$;

$\mathrm{TH}(\mathrm{n})=\mathrm{TH}(\mathrm{n}-1)^{*}(\mathrm{PH}(\mathrm{n}) / \mathrm{PH}(\mathrm{n}-1))^{\wedge}((\mathrm{Gamma}-1) / \mathrm{Gamma})$;

$\%$.....for slot iteration

Arean $=$ Area;

$\%$.... for slot iteration

elseif thetaH $>208 *$ pi $/ 180 \& \&$ thetaH $<=340 *$ pi $/ 180$

$\%$ enter new code here...see page 52 
$\mathrm{PHp}=\mathrm{PH}(\mathbf{n}-1)$;

$\mathrm{THp}=\mathrm{TH}(\mathrm{n}-1)$;

Areap $=$ Arean;

rhop $=\operatorname{massp} /(1 *$ Areap $)$;

if thetaH $<=270 * \mathrm{pi} / 180$

Area1 =1/2*quad( @(t)CalcIntgrand(t,R2,R1,1), thetaH, 3*pi/2);

Area2 = 1/2*quad( @(t)CalcIntgrand(t,R2,R1,2), $3 *$ pi $/ 2$, thetaL); \% page 38

\%Area3 $=\mathrm{w} / 2 *(\mathrm{rg}(\mathrm{n})+\mathrm{rg}(\mathrm{m})+\mathrm{h}-2 * \mathrm{R} 1)$;

Arean $=$ Area $1+$ Area2\%-Area3;

elseif thetaH $<288^{*}$ pi $/ 180$

Area1 =1/2*quad( @(t)CalcIntgrand(t,R2,R1,2), thetaH, thetaL);

\%Area3 $=\mathrm{w} / 2 *(\operatorname{rg}(\mathrm{n})+\mathrm{rg}(\mathrm{m})+\mathrm{h}-2 * \mathrm{R} 1)$;

Arean=Area1\%-Area3;

else

Area1 = 1/2*quad ( @(t)CalcIntgrand(t,R2,R1,2), thetaH, $2 * \mathrm{pi})$;

$\% \operatorname{Area3}=w / 2 *(\operatorname{rg}(\mathrm{n})+\mathrm{h} / 2-\mathrm{R} 1)$;

Arean $=$ Area $1 \%$-Area 3 ;

end

\% delP $=$ rhop $/ 2 *($ Omega*30/(pi*vtab*105.485*3600*rhop*Aorf $))^{\wedge} 2 *$ ke

$\operatorname{delP}=\mathrm{PHp}^{*}\left(1-(2 /(\mathrm{Gamma}+1))^{\wedge}(\mathrm{Gamma} /(\mathrm{Gamma}-1))\right) ;$

Porf = PHp-delP;

if delP $<0$

$\%$ for debugging errors

rhop, Omega, 1/vtab, Aorf

error('Hey now pres cant be below zero')

end

$\operatorname{mloss}(\mathrm{n})=0.007 * 0.62 *$ rhop*Aorf*sqrt $\left(2 * \mathrm{rhop}^{*} \mathrm{PHp}^{*}(2 /(\mathrm{Gamma}+1)) \ldots\right.$

$\wedge(($ Gamma+1)/(Gamma-1) $)) * 2 *$ pi/(Omega*datasize $)$; 
if thetaH $>208^{*}$ pi $/ 180 \& \&$ thetaH $<=228^{*}$ pi $/ 180$

$\operatorname{mloss}(\mathrm{n})=\operatorname{mloss}(\mathrm{n})$;

elseif thetaH $>228^{*}$ pi $/ 180 \& \&$ thetaH $<=248^{*}$ pi $/ 180$

$\operatorname{mloss}(n)=2 * \operatorname{mloss}(n) ;$

elseif thetaH $>248 *$ pi $/ 180 \& \&$ thetaH $<=268 *$ pi $/ 180$

$\operatorname{mloss}(\mathrm{n})=3 * \operatorname{mloss}(\mathrm{n})$;

elseif thetaH $>268 *$ pi $/ 180 \& \&$ thetaH $<=280 *$ pi $/ 180$

$\operatorname{mloss}(\mathrm{n})=3.25 * \operatorname{mloss}(\mathrm{n})$;

elseif thetaH $>280 *$ pi $/ 180 \& \&$ thetaH $<=300 *$ pi $/ 180$

$\operatorname{mloss}(\mathrm{n})=2.25^{*} \operatorname{mloss}(\mathrm{n})$;

elseif thetaH $>300 * \mathrm{pi} / 180 \& \&$ thetaH $<=320 * \mathrm{pi} / 180$

$\operatorname{mloss}(\mathrm{n})=1.25 * \operatorname{mloss}(\mathrm{n})$;

elseif thetaH $>320 *$ pi $/ 180 \& \&$ thetaH $<=340 *$ pi $/ 180$

$\operatorname{mloss}(\mathrm{n})=0.25^{*} \operatorname{mloss}(\mathrm{n})$;

end

if $\mathrm{PHp}<800000$

$\operatorname{mloss}(\mathrm{n})=0 ; \%$ reed valves remain closed, nothing exists

end

$\operatorname{massn}=\operatorname{massp}-\operatorname{mloss}(\mathrm{n})$;

if massn $<0$

massn=massp;

rhon $=\operatorname{massn} /\left(1^{*}\right.$ Arean $)$;

$\mathrm{PHn}=\mathrm{PHp}^{*}(\text { rhon } / \mathrm{rhop})^{\wedge} \mathrm{Gamma}$;

THn=THp* ${ }^{*}(\mathrm{PHn} / \mathrm{PHp})^{\wedge}((\mathrm{Gamma}-1) / \mathrm{Gamma}) ;$

[n, PH, TH, mloss] = allmassgone(n, massn, PH, TH, mloss, datasize,PHn, PHp); yeah $=$ 'right';

end

$\%$ \% comparing mass losses

$\% \quad$ cmloss $=$ checkloss (massp, PHp, Areap, Arean, Gamma); 
$\%$ if cmloss < mloss \& cmloss $>0$

$\%$ mloss

$\%$ cmloss

$\% \quad$ mloss =cmloss;

$\% \quad \operatorname{massn}=\operatorname{massp}-\operatorname{mloss}(\mathrm{n})$;

$\%$ end

rhon $=\operatorname{massn} /(1 *$ Arean $)$;

$\mathrm{PHn}=\mathrm{PHp}^{*}(\text { rhon } / \text { rhop })^{\wedge}$ Gamma;

$\mathrm{THn}=\mathrm{THp}{ }^{*}(\mathrm{PHn} / \mathrm{PHp})^{\wedge}((\mathrm{Gamma}-1) / \mathrm{Gamma})$;

$\mathrm{PH}(\mathrm{n})=\mathrm{PHn}$;

$\mathrm{TH}(\mathrm{n})=\mathrm{THn}$;

mass $=$ =massn; $\mathrm{PHp}=\mathrm{PHn} ; \mathrm{THp}=\mathrm{THn}$;

else

$\mathrm{PH}(\mathrm{n})=\mathrm{PH}(\mathrm{n}-1)$;

$\mathrm{TH}(\mathrm{n})=\mathrm{TH}(\mathrm{n}-1)$;

end

$\mathrm{n}=\mathrm{n}+1$;

end

$\%$ \%--------

originalmass $=1 / \mathrm{vtab} * \mathrm{I} * \mathrm{~A} 0$;

$\%$ thetacheck $=$ theta $(1: \text { datasize })^{\prime}$;

$\% \operatorname{mloss}(1:($ datasize -1$))=\operatorname{mloss}(2:$ datasize $)$;

$\% \quad[\mathrm{PH} / 1000$, thetacheck*180/pi, mloss*1000];

$\% \quad$ [sum(mloss), originalmass];

Pout $=(\operatorname{sum}($ mloss. $* \mathrm{PH}) /(\operatorname{sum}(\operatorname{mloss}))) ; \% *(1-(2 /($ Gamma +1$)) \wedge($ Gamma $/($ Gamma- 1$)))$ tipmassloss $=(1$-sum(mloss $) /$ originalmass $) * 100$;

$\%$ \%--------

$\%$ Getting the equivalent pressures at the other side of the vanes. 
$\%$ see page $40 \ldots$

for $\mathrm{n}=1: \max (\operatorname{size}(\mathrm{PH}))$

if $\mathrm{n}<=$ Backstep

$\mathrm{PL}(\mathrm{n})=\mathrm{P0}$;

$\mathrm{TL}(\mathrm{n})=\mathrm{T} 0$;

elseif n-Backstep $>=1$

$$
\begin{aligned}
& \operatorname{PL}(\mathrm{n})=\operatorname{PH}(\mathrm{n}-\mathrm{Backstep}) \\
& \operatorname{TL}(\mathrm{n})=\operatorname{TH}(\mathrm{n}-\mathrm{Backstep}) \\
& \text { else }
\end{aligned}
$$

$$
\begin{aligned}
& \mathrm{PL}(\mathrm{n})=\operatorname{PH}(\mathrm{n}-\mathrm{Backstep}+\max (\text { size }(\text { theta }))-2) ; \\
& \operatorname{TL}(\mathrm{n})=\operatorname{TH}(\mathrm{n}-\text { Backstep }+\max (\text { size }(\text { theta }))-2) ;
\end{aligned}
$$

end

end

\% ---------------- Exapnder pressure calculations $\%$

$\%$ for expander higher pressure is behind the vane

elseif strcmp(comp_or_exp, 'exp')

theta $0=[80 * \mathrm{pi} / 180,152 * \mathrm{pi} / 180] ; \% 15$ degrees

[rg0] = vaneCG $(\mathrm{R} 1, \mathrm{R} 2$, theta0,h);

$\mathrm{A} 1=(1 / 2 *$ quad $(@(\mathrm{t})$ CalcIntgrand $(\mathrm{t}, \mathrm{R} 2, \mathrm{R} 1,2)$, theta0(1), pi/2))-...

$(\mathrm{w} / 2 *(\operatorname{rg} 0(1)+\mathrm{rg} 0(2)+\mathrm{h}-2 * \mathrm{R} 1)) ;$

$\mathrm{A} 2=(1 / 2 *$ quad $(@(\mathrm{t})$ CalcIntgrand $(\mathrm{t}, \mathrm{R} 2, \mathrm{R} 1,1), \mathrm{pi} / 2$, theta0(2)) $)-\ldots$

$(\mathrm{w} / 2 *(\operatorname{rg} 0(1)+\mathrm{rg} 0(2)+\mathrm{h}-2 * \mathrm{R} 1)) ;$

$\mathrm{A} 0=\mathrm{A} 1+\mathrm{A} 2$;

Backstep $=(\max (\operatorname{size}($ theta $)-1)) / \mathrm{N} ; \%$ see page 40 


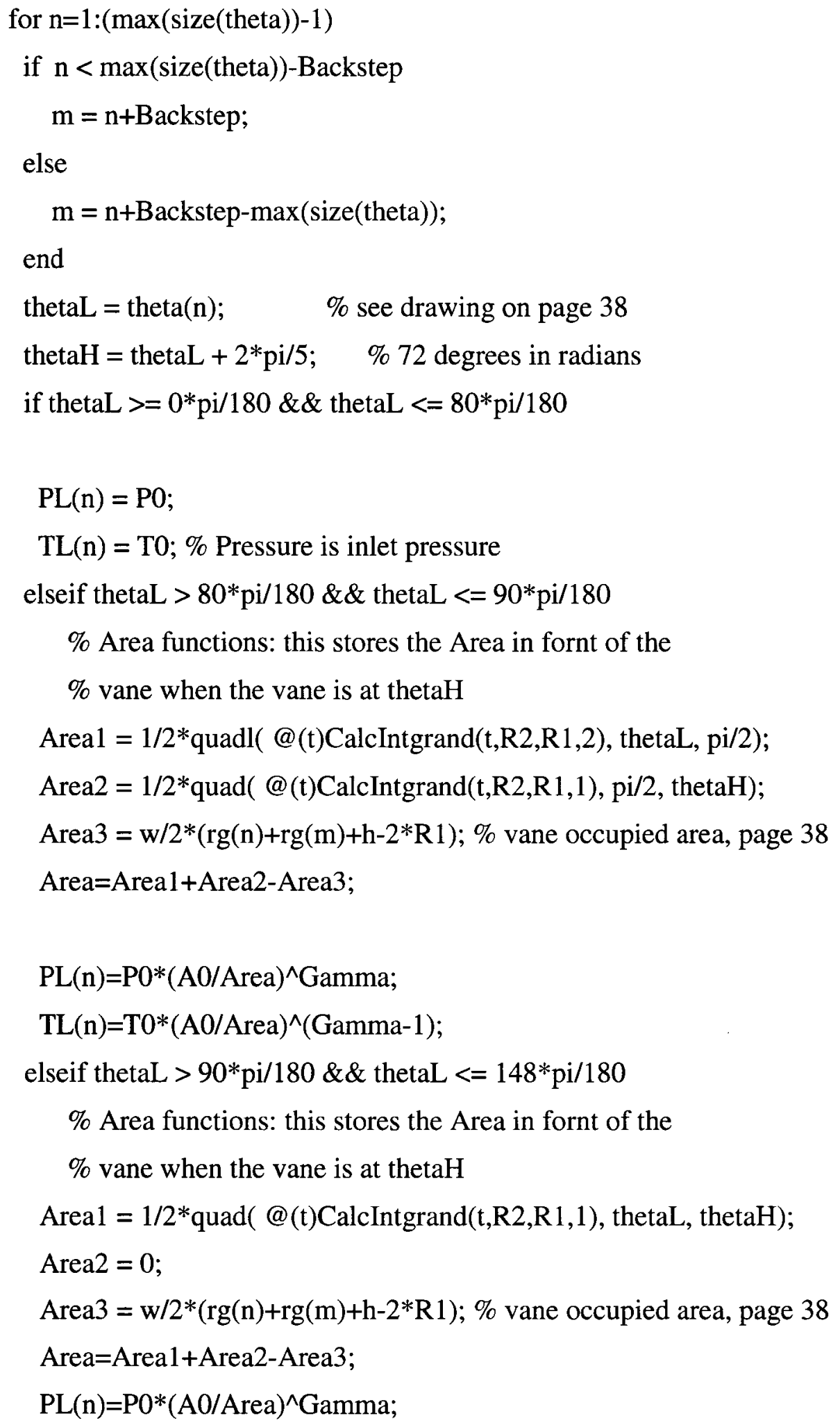




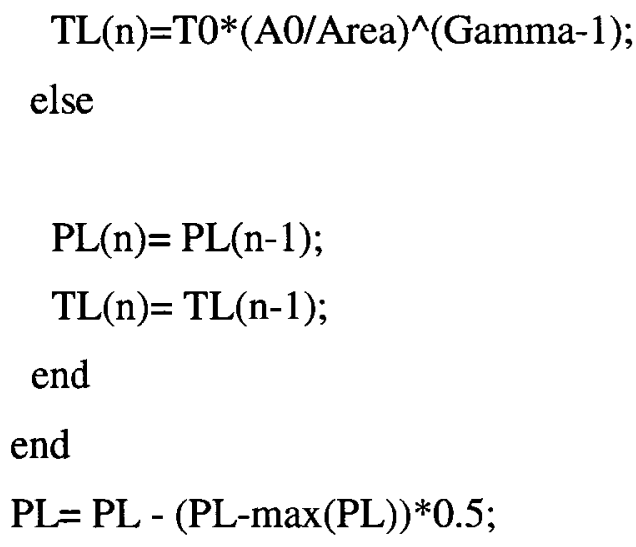

$\%$ Getting the equivalent pressures at the other side of the vanes.

$\%$ see page $40 .$.

for $n=1: \max (\operatorname{size}(P L))$

if $\mathrm{n}<=$ Backstep

$\mathrm{PH}(\mathrm{n})=\mathrm{P0}$;

$\mathrm{TH}(\mathrm{n})=\mathrm{T} 0$;

elseif n-Backstep $>=1$

PH(n) = PL(n-Backstep);

$\mathrm{TH}(\mathrm{n})=\mathrm{TL}(\mathrm{n}-\mathrm{Backstep})$;

else

$\mathrm{PH}(\mathrm{n})=\mathrm{PL}(\mathrm{n}-\mathrm{Backstep}+\max ($ size $($ theta $))-2) ;$

TH(n) = TL(n-Backstep+max (size(theta) $)-2)$;

end

end

Pout $=$ PL(datasize $)$;

tipmasloss $=1$;

massflow $=1 ; \%$ timmass amd massloss are both dunny variables

end

function[n,PH,TH,mloss]=allmassgone(n, massn,PH,TH,mloss, datasize,PHn,THn) 


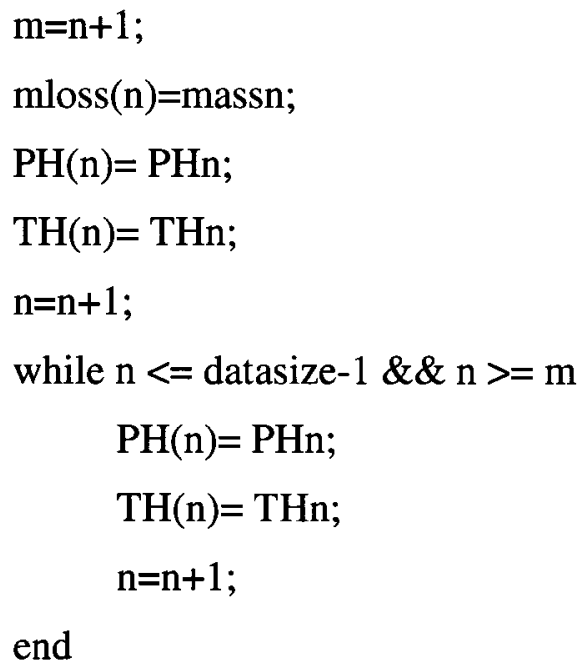

$\%$ function [cmloss] = checkloss (massp, PHp, Areap, Arean, Gamma)

$\%$ cmloss $=$ massp $*\left(1-(800000 / \mathrm{PHp})^{\wedge}(1 /\right.$ Gamma $) *($ Arean/Areap $\left.)\right)$;

$\% \%$ if cmloss $>0$

$\% \% \quad \mathrm{PHp}$

$\% \%$ Arean

$\% \%$ Areap

$\% \%$ end

\section{End face leakage}

function [ploss, leakage]= leakloss (RPM, R1,R2,PH, TH, theta,l,w,h, ppout,hgap, P0, T0) $\%$ see page 50

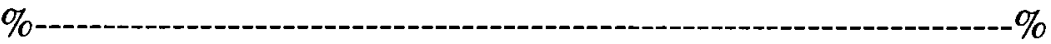

\% This program calculates the leakage loss across the face of the vane

$\% \sim \sim \sim \sim$ INPUT

$\% \mathrm{~h}$ - vane height

$\%$ hgap - endface rotor clearance

$\% 1$ - vane length

$\% \mathrm{P0}$ - inlet pressure

$\% \mathrm{PH}$ - Pressures on leading side of the vane at various angles 
\% ppout - output pressure of the compressor

$\% \mathrm{R} 1$ - Rotor radius

$\% \mathrm{R} 2$ - $\quad$ Case radius

$\%$ RPM - rotational speed

$\%$ T0 - inlet temperature

$\% \mathrm{TH}$ - temperatures on leading side of the vane at various angles

$\%$ theta - angular mesh

$\% \mathrm{w}$ - vane width

$\% \sim \sim \sim$ OUTPUT

\% leakage - massleakage across rotor face in percentage o fmass flow

$\%$ ploss - power lost due to the leakage

\%-

\%--10---10

\% A0 - Chamber area at inlet close

\% AvgoutP - average output presure

\% AvgoutT - average output temperature

$\%$ DelP - pressure difference between the inlet and oulet region

$\%$ Dsize - size of mesh

$\%$ Gamma - specific heat ratio

$\%$ hin - the enthalpy at the inlet

$\%$ hout - the enthalpy at the outlet

$\% \mathrm{~L}$ - length section (see thesis)

$\%$ massflowin - net masflow rate into outlet section

$\%$ mleak - laminar pressure driven poiselle leakage

$\%$ mleak 1 - sonic leakage

$\% \mathrm{mu}$ - viscosity

$\%$ outport - number of mesh points at the outlet

$\%$ rhoout - density at the outlet

$\%$ Sin - the entropy at the inlet

$\%$ Sout - the entropy at the outlet 
$\%$ theta1\&2 - Angular definitions represent the inlet and outlet region

$\%$ vin - the specific volume at the inlet

$\%$ vout - the specific volume at the outlet

$\% \mathrm{~W}$ - length section (see thesis)

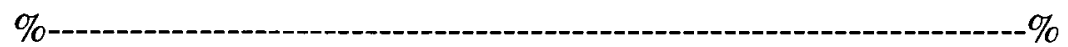

Gamma $=1.1383411$;

$\%$ gap is one thou in inches

$\%$ hgap one thou inches?

$\%$ theta 1 is the outlet angle which is 80 degrees

$\%$ theta 2 is the inlet angle which is 140 degrees

theta $1=80 * \mathrm{pi} / 180$; \%radians

theta $2=140 * \mathrm{pi} / 180$;

Dsize $=\max (\operatorname{size}($ theta $))-1$;

$\%$ outlet portion of data

outport $=$ Dsize - round $($ Dsize $* 80 / 360)$;

$\%$ inlet portion of data

[hin, Sin, vin] = t_P_x(T0-273, P0/100000, 1);

$\%$ inport $=$ round $\left(D_{s i z e} * 140 / 360\right)$;

$\mathrm{L}=2 * \mathrm{R} 1 * \sin ($ theta $1 / 2)$;

$\mathrm{W}=2 * \mathrm{R} 1 * \sin (($ theta $1+$ theta 2$) / 4)$;

\%AvgoutP = mean $(\mathrm{PH}($ outport:Dsize $))$;

\%Avgout $=$ mean $(\mathrm{TH}($ outport $:$ Dsize $))$;

AvgoutP = ppout;

Avgout $\mathrm{T}=\mathrm{T} 0 *(\mathrm{ppout} / \mathrm{P} 0)^{\wedge}((\mathrm{Gamma}-1) / \mathrm{Gamma}) ;$

$\%$ AvginP $=$ mean $(\mathrm{PH}(1$ :inport $))$;

$\%$ Avgin $\mathrm{T}=\operatorname{mean}(\mathrm{TH}(1: \mathrm{inport}))$;

delP = AvgoutP -P0;

[hout, sout, vout] =t_P_x(AvgoutT-273, AvgoutP/100000, 1.1);

rhoout $=1 /$ vout;

$\mathrm{mu}=\left(-10.861+0.4392 * \text { Avgout } \mathrm{T}-1.0316^{*} 10^{\wedge}(-4)^{*} \operatorname{Avgout}^{\wedge} 2\right)^{*} 10^{\wedge}(-7) ; \%$ pascal seconds 
\% laminar mass leakage based on delP, with constant temp leakage

mleak $=$ rhoout $^{*} \mathrm{~L}^{*}$ hgap^ $3 * \operatorname{delP} /\left(24 * \mathrm{mu}^{*} \mathrm{~W}\right)$;

$\%$ sonic leakage

$\mathrm{a}=\operatorname{sqrt}($ Gamma*AvgoutP/rhoout);

mleak $1=$ rhoout ${ }^{*}{ }^{*}$ hgap $*$ ;

\%if mleak $1<$ mleak

mleak =mleak 1 ;

\%end

ploss $=$ mleak $*$ (hout-hin) $* 1000 ; \% \mathrm{~J} / \mathrm{kg}$

theta $0=[7 * \mathrm{pi} / 9,53 * \mathrm{pi} / 45]$

$[\mathrm{rg} 0]=$ vaneCG $(\mathrm{R} 1, \mathrm{R} 2$,theta0,h);

$\mathrm{A} 0=(1 / 2 *$ quad $(@(t)$ CalcIntgrand $(t, R 2, R 1,1)$, theta0(1), theta0(2)))-... $w / 2 *(\operatorname{rg} 0(1)+\operatorname{rg} 0(2)+h-2 * \mathrm{R} 1) ;$

massflowin $=1 /$ vin $* 5 * 1 * A 0 * \mathrm{RPM} * 60 / 3600 ; \%$ page $49 \mathrm{Kg} / \mathrm{s}$

leakage $=$ mleak $/$ massflowin $* 100$;

\section{General Looping Program}

$\%$ gernral loop program

$\%$ see page 57

$\%$ guess value for $\mathrm{T} 1$ and $\mathrm{x} 1$

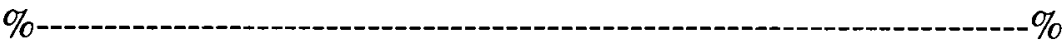

$\%$ This program manages all the other programs and runs through the

$\%$ refrigeration loop. It calculates some important parameters pertaining to

$\%$ the refrigeration loop and writes the results to excel

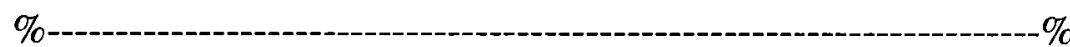

$\% 1$ - after evaporator

$\% 2$ - before compressor

$\% 3$ - after compressor

$\% 4$ - before condenser 
\% 5 - after condenser

$\% 6$ - before expansion device

$\% 7$ - after expansion device

$\% 8$ - before expander

$\% 9$ - after expander

$\% 10$ - before evaporator

$\% 11$ - after evaporator

\%--

$\%$ SUFFIX max - Refers to the saturated gas properties

\% SUFFIX min - Refers to the saturated liquid properties

$\%$ Condbath - Water temperature setting of the condenser bath

\% err_acpt - Convergence criteria

\% Evapcham - Evaporator chamber temperature setting

$\%$ Geom - Pipe geometry information

$\% \mathrm{~h}$ - Enthlapy

$\% 1$ - Length

$\%$ massflow - Massflow output of the compressor

$\%$ mleak - Mass leakage percentage

$\% \mathrm{P}$ - Pressure

$\%$ Ploss - Powerloss

$\%$ presdrop - Pressure drop due to friction anf geometrical parameters

\% RPM - Rotational speed of compressor-expander

$\% \mathrm{~s}$ - Entropy

$\%$ T - Temperature

$\% \mathrm{v}-\quad$ Specific volume

$\% \mathrm{x}$ - Quality

$\%$

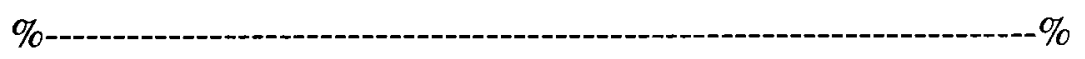

clear all 
close all

warning off all

err_acpt $=1 \mathrm{E}-3$;

$\mathrm{T} 1=0$;

$\mathrm{T} 11=24+273 ; \%$ kelvin

$\mathrm{x} 11=0.89 ; \%$ assume inlet quality is dependent on oil bleed hole

$\%$ and therefore setable

$\mathrm{RPM}=1500$;

$\mathrm{n}=1$;

\% loop starts

while abs(T1-T11) >= err_acpt

$\mathrm{T} 1=\mathrm{T} 11$;

$\mathrm{x} 1=\mathrm{x} 11$;

if $\mathrm{n}>=101$;

disp ('did not converge in 100 iterations')

break

end

Condbath $=273+30$;

Evapcham $=273+60$;

$\%$ Note we have ignored pressure drop between evaporator and compressor $\%$ inlet

$\mathrm{x} 2=\mathrm{x} 1$

$\mathrm{T} 2=\mathrm{T} 1$;

$[\mathrm{h} 2, \mathrm{~S} 2, \mathrm{v} 2, \mathrm{P} 2]=\mathrm{t} \_\mathrm{P} \_\mathrm{x}(\mathrm{T} 2-273,2, \mathrm{x} 2) ; \%$ entered random pressure if $\mathrm{x} 2>1$

$[h 2, S 2, v 2, P 2]=t \_P \_x(T 2-273, P 11 / 100000,1)$;

end

$\mathrm{h} 2=\mathrm{h} 2 * 1000$; 
$\mathrm{P} 2=\mathrm{P} 2 * 100000$

[P3, T3, massflow, mleak, Ploss] = vanecomp1 (min(1, x1), RPM, P2, T2, 'comp');

$\mathrm{x} 3=2 ; \%$ must be superheated out of compressor

$[\mathrm{h} 3, \mathrm{~S} 3, \mathrm{v} 3]=\mathrm{t} \_\mathrm{P} \_\mathrm{x}(\mathrm{T} 3-273, \mathrm{P} 3 / 100000, \mathrm{x} 3)$;

$\mathrm{h} 3=\mathrm{h} 3 * 1000$;

$\%$ between compressor and condenser

Geom $=[$ 'e','e','e','e'];

$1=1.86$;

presdrop $=$ pressureloss $(1, \mathrm{~T} 3, \mathrm{P} 3$, massflow, $0.25 * 0.0254$, Geom, $\mathrm{x} 3)$;

$\mathrm{P} 4=\mathrm{P} 3$-presdrop;

$\mathrm{T} 4=\mathrm{T} 3$;

[h4,S4,v4]=t_P_x(T4-273,P4/100000,x3);

$\mathrm{h} 4=\mathrm{h} 4 * 1000$;

[T5,h5, l] = condenser (massflow, T4, P4, Condbath, h4);

[h5max,S5max,v5max,P5]=t_P_x(T5-273,2,1); \% entered random pressure

[h5min,S5min,v5min,P5]=t_P_x(T5-273,P5,0);

$\mathrm{h} 5 \mathrm{~min}=\mathrm{h} 5 \mathrm{~min} * 1000$;

$\mathrm{h} 5 \max =\mathrm{h} 5 \max * 1000$;

P5=P5*100000;

$\mathrm{x} 5=(\mathrm{h} 5-\mathrm{h} 5 \mathrm{~min}) /(\mathrm{h} 5 \mathrm{max}-\mathrm{h} 5 \mathrm{~min})$;

$\mathrm{S} 5=(1-\mathrm{x} 5) * \mathrm{~S} 5 \mathrm{~min}+\mathrm{x} 5 * \mathrm{~S} 5 \mathrm{max}$;

$\mathrm{v} 5=(1-\mathrm{x} 5) * \mathrm{v} 5 \mathrm{~min}+\mathrm{x} 5 * \mathrm{v} 5 \max$;

if $x 5>1 \| x 5<0 \%$ subcooled

$\mathrm{x} 5=0$;

$\mathrm{h} 5=\mathrm{h} 5 \mathrm{~min} ; \mathrm{S} 5=\mathrm{S} 5 \mathrm{~min} ; \mathrm{v} 5=\mathrm{v} 5 \mathrm{~min}$;

$\%$ use TPX too get subcooled properties 
end

Geom $=\left[{ }^{\prime} e^{\prime}, \mathrm{u}^{\prime}\right]$;

$1=1.30+1 / 3 ; \%$ this includes the pressure lost in the condenser piping.

presdrop $=\min ($ pressureloss $(1, \mathrm{~T} 5, \mathrm{P} 5$, massflow, $0.5 * 0.0254$, Geom, x5), 250000);

P6= P5-presdrop;

[state, P6, T6] = SatCheck $\left(\mathrm{P} 6 / 100000, \mathrm{~T} 5,{ }^{\prime} \mathrm{P}\right) ; \%$ T5 is dunny temperature

$\mathrm{T} 6=\mathrm{T} 6+273$;

$\mathrm{P} 6=\mathrm{P} 6 * 100000$;

$\% \mathrm{~T} 6=\mathrm{T} 5$

[h6,S6,v6,P6]=t_P_x(T6-273,P6/100000,x5);

[h6min,S6min,v6min,P6]=t_P_x(T6-273,P6,0);

$\mathrm{h} 6=\mathrm{h} 6 * 1000 ; \mathrm{h} 6 \mathrm{~min}=\mathrm{h} 6 \mathrm{~min} * 1000$;

$\mathrm{P} 6=\mathrm{P} 6 * 100000$;

$[\mathrm{P} 7, \mathrm{~T} 7]=$ ExpanDev (massflow, 1/v6min, P6);

h7 = h6;

[h7max,S7max,v7max]=t_P_x(T7-273,2,1); \% entered random pressure

$[\mathrm{h} 7 \mathrm{~min}, \mathrm{~S} 7 \mathrm{~min}, \mathrm{v} 7 \mathrm{~min}]=\mathrm{t} \_\mathrm{P} \_\mathrm{x}(\mathrm{T} 7-273, \mathrm{P} 7,0)$;

$\mathrm{h} 7 \mathrm{~min}=\mathrm{h} 7 \mathrm{~min} * 1000$;

$\mathrm{h} 7 \mathrm{max}=\mathrm{h} 7 \mathrm{max} * 1000$;

$\mathrm{x} 7=(\mathrm{h} 7-\mathrm{h} 7 \mathrm{~min}) /(\mathrm{h} 7 \mathrm{max}-\mathrm{h} 7 \mathrm{~min})$;

$\mathrm{S} 7=(1-\mathrm{x} 7) * \mathrm{~S} 7 \mathrm{~min}+\mathrm{x} 7 * \mathrm{~S} 7 \mathrm{max}$

$\mathrm{v} 7=(1-\mathrm{x} 7) * \mathrm{v} 7 \mathrm{~min}+\mathrm{x} 7 * \mathrm{v} 7 \mathrm{max}$;

if $\mathrm{x} 7<0$

$\mathrm{x} 7=0$;

$[\mathrm{h} 7, \mathrm{~S} 7, \mathrm{v} 7, \mathrm{P} 7]=\mathrm{t} \_\mathrm{P} \_\mathrm{x}(\mathrm{T} 7-273, \mathrm{P} 7,-1)$;

end

\% calc some pressure loss later 
$\mathrm{P} 8=\mathrm{P} 7 ; \mathrm{T} 8=\mathrm{T} 7 ; \mathrm{S} 8=\mathrm{S} 7 ; \mathrm{v} 8=\mathrm{v} 7 ; \mathrm{x} 8=\mathrm{x} 7 \mathrm{~h} 8=\mathrm{h} 7$;

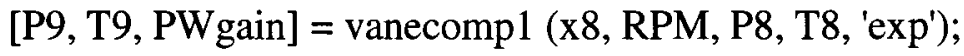

h9= h8- PWgain/massflow;

[h9max,S9max,v9max]=t_P_x(T9-273,2,1); \% entered random pressure

[h9min,S9min,v9min]=t_P_x(T9-273,P9,0);

$\mathrm{h} 9 \min =\mathrm{h} 9 \min * 1000$;

$\mathrm{h} 9 \max =\mathrm{h} 9 \max * 1000$;

$\mathrm{x} 9=(\mathrm{h} 9-\mathrm{h} 9 \min ) /(\mathrm{h} 9 \max -\mathrm{h} 9 \min )$;

$\mathrm{S} 9=(1-\mathrm{x} 9) * \mathrm{~S} 9 \min +\mathrm{x} 9 * \mathrm{~S} 9 \mathrm{max}$;

$\mathrm{v} 9=(1-\mathrm{x} 9) * \mathrm{v} 9 \min +\mathrm{x} 9 * \mathrm{v} 9 \max$;

\% calc pressure loss later

$\mathrm{P} 10=\mathrm{P} 9 ; \mathrm{T} 10=\mathrm{T} 9 ; \mathrm{S} 10=\mathrm{S} 9 ; \mathrm{v} 10=\mathrm{v} 9 ; \mathrm{x} 10=\mathrm{x} 9 ; \mathrm{h} 10=\mathrm{h} 9 ;$

h11 = boiling (T10, x10, massflow, Evapcham, x1);

P11=P10;

$\mathrm{T} 11=\mathrm{T} 10$;

[h11 max,S11max,v11 max]=t_P_x(T11-273,0,1); \% entered random pressure

[h11 min,S11min,v11min]=t_P_x(T11-273,P11,0);

h11 min=h11 min*1000;

h11 max $=h 11 \max * 1000$;

$\mathrm{x} 11=(\mathrm{h} 11$ - h11min)/(h11 max-h11min);

$\mathrm{S} 11=(1-\mathrm{x} 11) * \mathrm{~S} 11 \mathrm{~min}+\mathrm{x} 7 * \mathrm{~S} 11 \mathrm{max}$;

$\mathrm{v} 11=(1-\mathrm{x} 11) * \mathrm{v} 11 \min +\mathrm{x} 7 * \mathrm{v} 11 \max$;

if $\mathrm{x} 11>1$

$\mathrm{T} 11=\mathrm{T} 11+(\mathrm{h} 11-\mathrm{h} 11 \max ) / 1300 ;$

end

Temperature $(\mathrm{n}, 1)=\mathrm{T} 1$; 
quality $(\mathrm{n}, 1)=\mathrm{x} 11$;

$\mathrm{n}=\mathrm{n}+1$;

end

plot(1:n-1, Temperature, 'o:')

figure

plot(1:n-1, quality, 'o:')

Run_results $1=[\mathrm{T} 1 ; 00 ; 00 ; 00 ; \mathrm{x} 1 ; 00 ; \mathrm{T} 2 ; \mathrm{P} 2 ; \mathrm{h} 2 ; \mathrm{v} 2 ; \mathrm{x} 2 ; 00 ; \mathrm{T} 3 ; \mathrm{P} 3 ; \mathrm{h} 3 ; \mathrm{v} 3 ; \mathrm{x} 3 ; 00 ; \ldots$

T4;P4;h4;v4;00;00;T5;P5;h5;v5;x5;00;T6;P6;h6;v6;00;00;...

T7;P7;h7;v7;x7;00;T8;P8;h8;v8;x8;00;T9;P9;h9;v9;x9;00;

T10;P10;h10;v10;x10;00;T11;P11;h11;v11;x11];

Run_results2 = [Evapcham;Condbath;PWgain;Ploss;RPM;massflow;mleak;n];

xlswrite('Results\run_results', Run_results 1, 'Input', 'I2:I66');

xlswrite('Resultstrun_results', Run_results2, 'Input', 'I68:I75');

\section{Pipe Losses}

function [piploss]= pressureloss $(1, \mathrm{~T}, \mathrm{P}$, massflow, $\mathrm{D}$, Geom, qual $)$

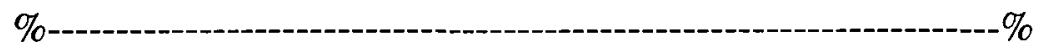

\% This program calculates the pressure losses due to frictional and

$\%$ geometrical factors

\% INPUT

$\% 1$ - length of section

$\% \mathrm{~T}$ - Temperature of the refrigerant

$\% \mathrm{P}$ - Pressure of the refrigerant

$\%$ massflow - massflowrate of the refrigerant

$\% \mathrm{D}$ - Diameter of the piping section

$\%$ Geom - discription of the pipe geometry

$\%$ qual - quality

\% OUTPUT

$\%$ piplooss - presure loss

\%--1.-- 


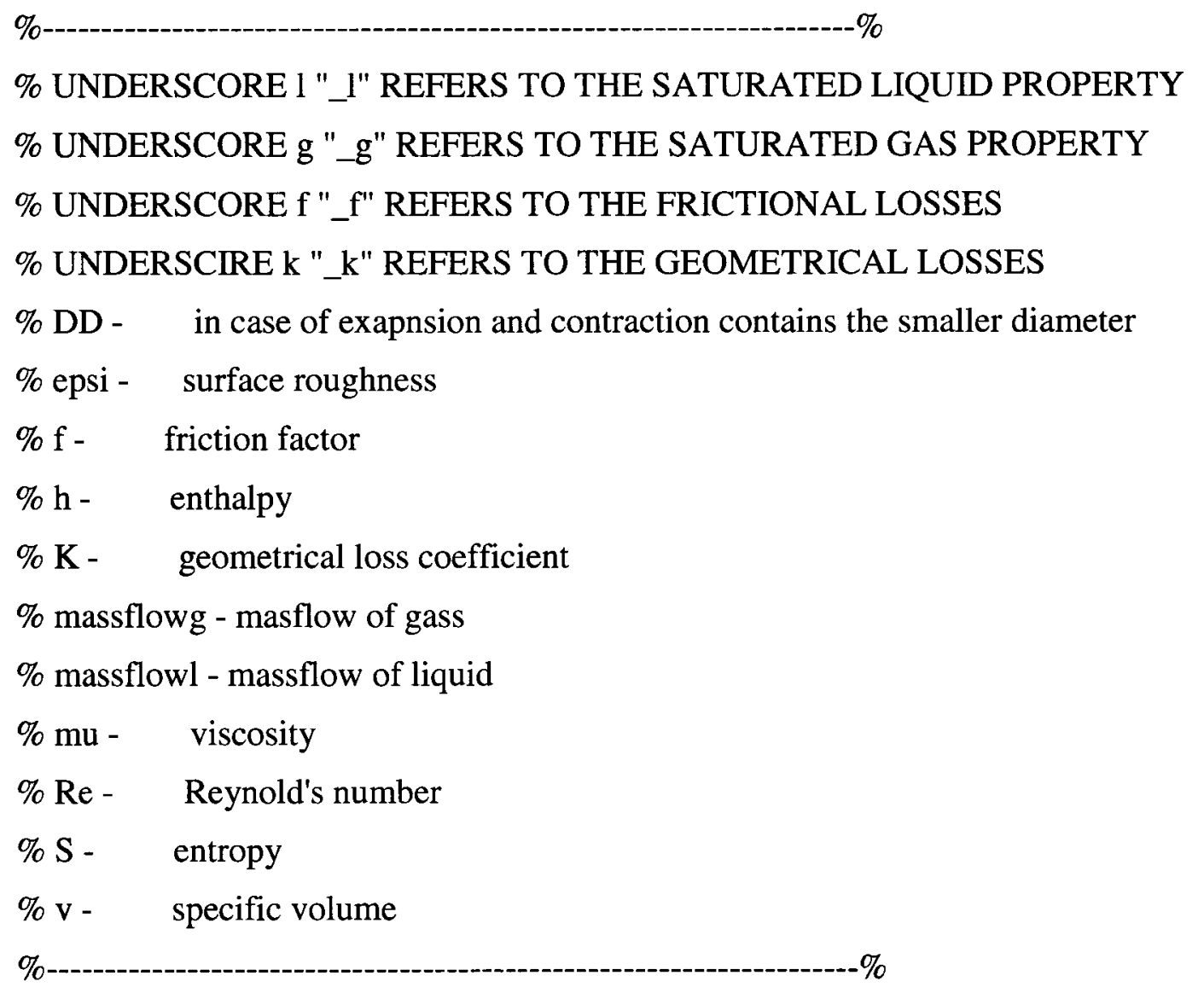

$\%$ for geom e-elbow, ex-expansion, c-contraction u-180degElbow f-45

$\mathrm{K}=0$;

epsi $=0.046^{*} 10^{\wedge}-3 ; \%$ meters: surface roughness

$\mathrm{DD}=\max (\mathrm{D})$;

$\mathrm{D}=\min (\mathrm{D})$;

if qual $<1 \& \&$ qual $>0.01$

massflowg $=$ qual $*$ massflow;

massflowl $=(1$-qual $) *$ massflow;

$\%$ gas viscosity from Yaw's handbook

$\mathrm{mu}$ _g $=\left(-10.861+0.4392 * \mathrm{~T}-1.0316^{*} 10^{\wedge}(-4) * \mathrm{~T}^{\wedge} 2\right)^{*} 10^{\wedge}(-7) ; \%$ pascal seconds $\%$ liquid viscosity 
$\mathrm{mu} \_\mathrm{l}=\left(10^{\wedge}\left(3107.5-\left(3.3361 * 10^{\wedge} 5\right) / \mathrm{T}-9.6102^{*} \mathrm{~T}+\left(9.8587^{*} 10^{\wedge}(-3)\right)^{*} \mathrm{~T}^{\wedge} 2\right)\right)^{*} 10^{\wedge}-3 ; \%$ pascal seconds

$[\mathrm{hg}, \mathrm{sg}, \mathrm{vg}]=\mathrm{t} \_\mathrm{P} \_\mathrm{x}(\mathrm{T}-273, \mathrm{P} / 100000,1)$;

$[\mathrm{hl}, \mathrm{sl}, \mathrm{vl}]=\mathrm{t} \_\mathrm{P} \_\mathrm{x}(\mathrm{T}-273, \mathrm{P} / 100000,0)$;

$\%$ hydraulic diameters-pg 56

D_l=sqrt $\left(D^{\wedge} 2 /(q u a l * v g / v l+1)\right)$;

D_g=sqrt $\left(D^{\wedge} 2-D \_1^{\wedge} 2\right)$;

$\%$ Reynolds numbers

$\operatorname{Re} \_g=4 *$ massflowg/pi/mu_g/D_g;

Re_l = 4*massflowl/pi/mu_1/D_l;

if $\operatorname{Re} \_g<2500$

$\mathrm{f} \_\mathrm{g}=64 / \mathrm{Re} \_\mathrm{g}$;

else

f_g $=1.325 /\left(\log (\text { epsi/3.7/D_g })+5.74 / \operatorname{Re} \_g^{\wedge} 0.9\right)^{\wedge} 2 ; \%$ page 272 of heat transfer end

piploss_fg $=f \_g * 1 / D \_g / 2 *\left(\text { massflow } * 4 * v g /\left(p i * D \_g \wedge 2\right)\right)^{\wedge} 2 * 1 / v g / 9.81$;

if $\operatorname{Re}_{-} 1<2500$

$$
\text { f_l = 64/Re_l; }
$$

else

$$
\mathrm{f} \_l=1.325 /\left(\log (\text { epsi/3.7/D_l })+5.74 / \mathrm{Re} \_l^{\wedge} 0.9\right)^{\wedge} 2 \text {; }
$$

end

piploss_fl $=\mathrm{f} \_1 * 1 / D \_1 / 2 *\left(\text { massflow } * 4 * v l /\left(\mathrm{pi}^{*} \mathrm{D} \_1 \wedge 2\right)\right)^{\wedge} 2 / \mathrm{vl} / 9.61$;

piploss_f $=$ piploss_fl+piploss_fg;

$\mathrm{v}=\mathrm{qual}^{*} \mathrm{vg}+(1-\mathrm{qual}) * \mathrm{vl}$

elseif qual $>1$ 


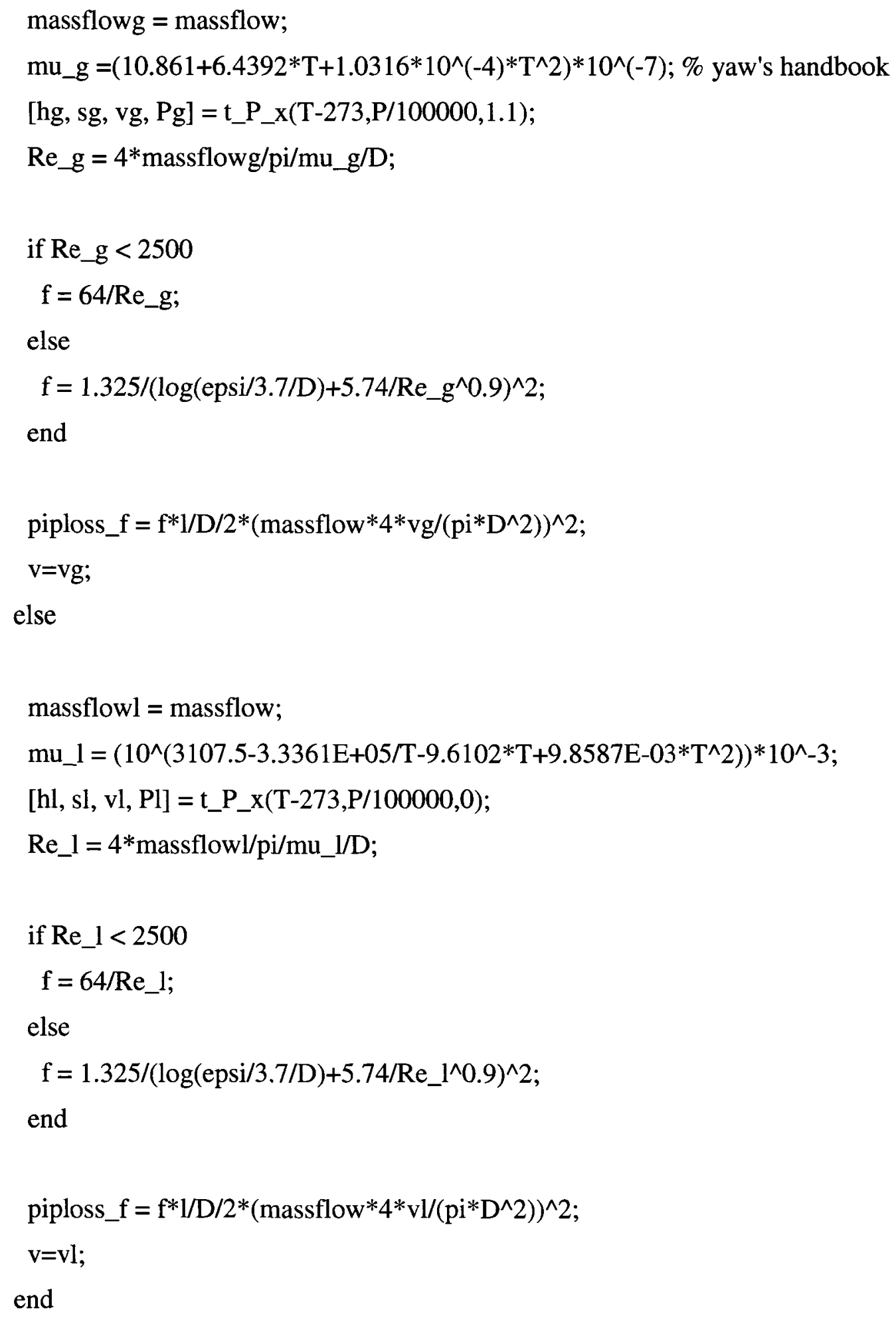




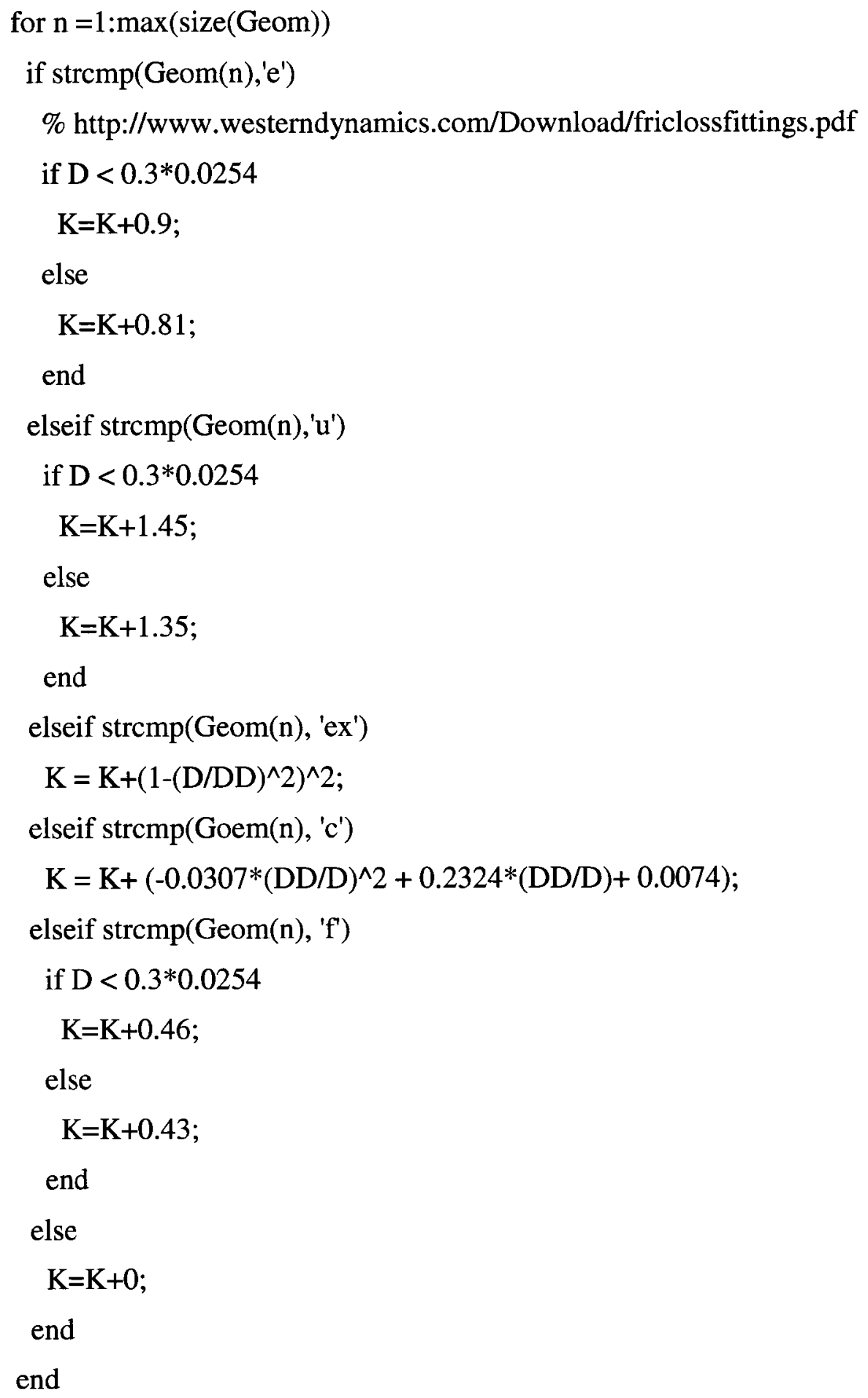


piploss_K $=\mathrm{K}^{*}\left(\operatorname{massflow} * 4 * \mathrm{v} /\left(\mathrm{pi}^{*} \mathrm{D}^{\wedge} 2\right)\right)^{\wedge} 2 / 2$;

piploss $=$ piploss_f + piploss_K;

\section{R134a Property Generator}

function $[\mathrm{h}, \mathrm{s}, \mathrm{v}, \mathrm{P}, \mathrm{miu}, \mathrm{lambda}, \mathrm{cp}]=\mathrm{R} 134 \mathrm{aProp}(\mathrm{tp}, \mathrm{t}, \mathrm{x}$, trans,aaa)

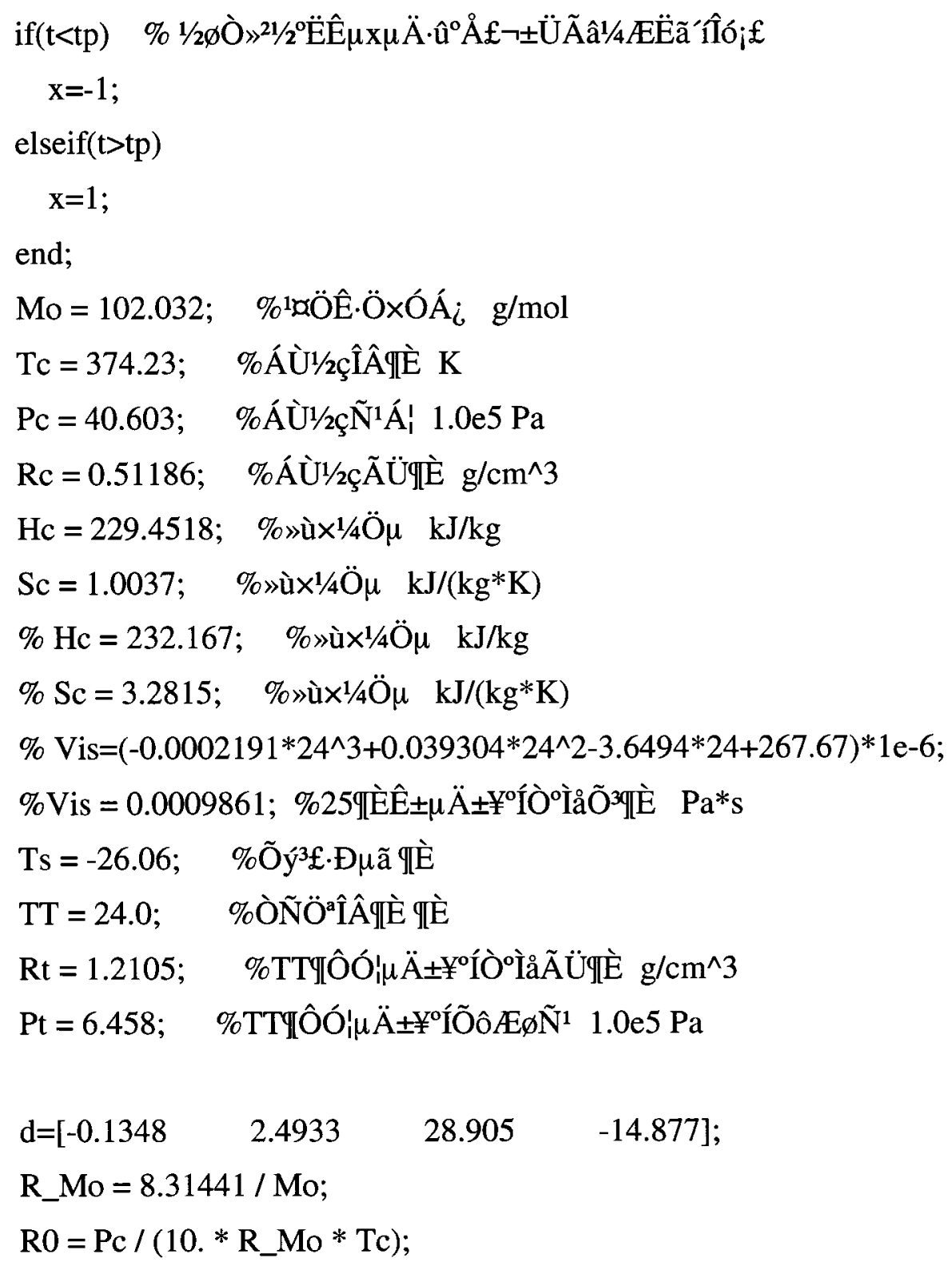




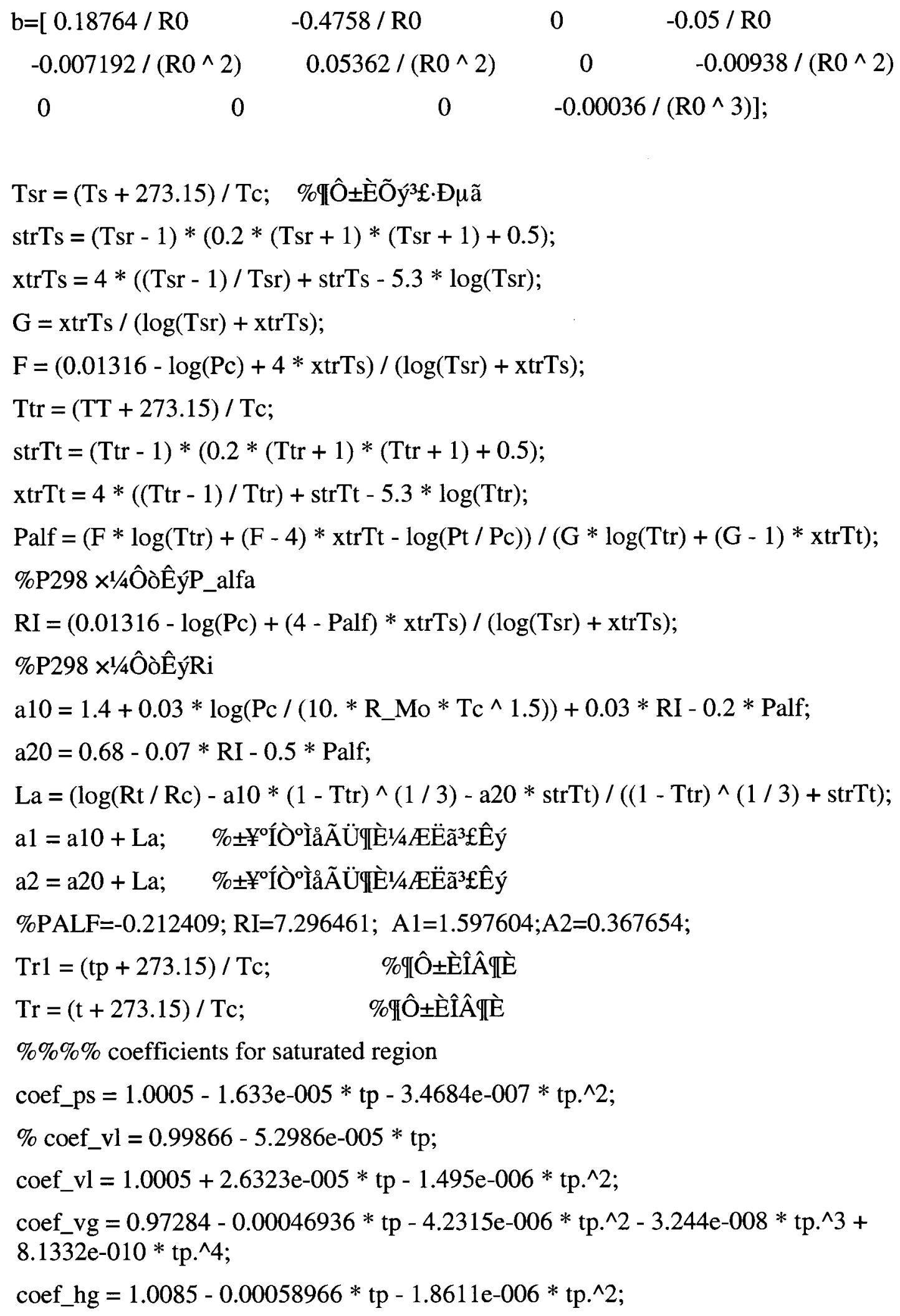




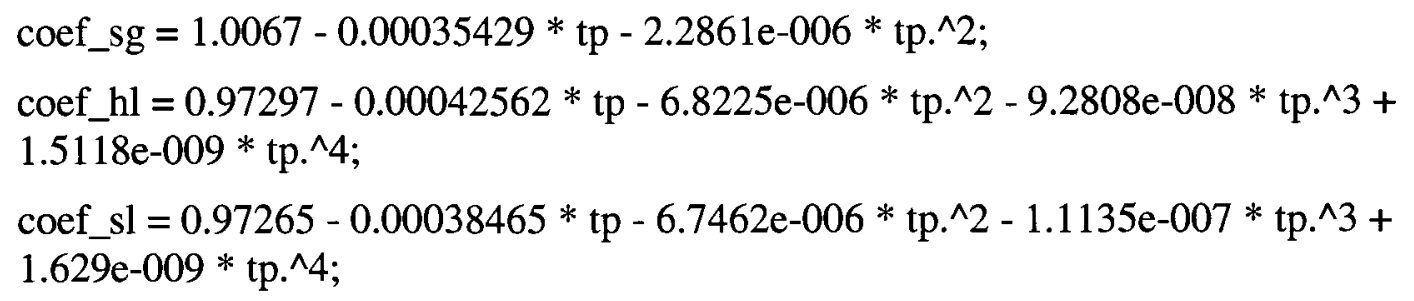


$\operatorname{Tr} 1$ temp=Tr1;

$\operatorname{Tr} 1=\operatorname{Tr} ;$

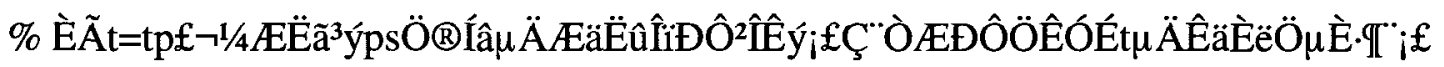

$\operatorname{str}=(\operatorname{Tr}-1) *(0.2 *(\operatorname{Tr}+1) *(\operatorname{Tr}+1)+0.5) ; \% \mathrm{P} 298 \pm ¥^{\circ} \tilde{\mathbb{N}}^{11} 1 / 4$ EËă $\tilde{a}^{3} \hat{\mathrm{E} y} \mathrm{~S}(\mathrm{Tr})$

$\mathrm{xtr}=4 *((\mathrm{Tr}-1) / \mathrm{Tr})+\operatorname{str}-5.3 * \log (\mathrm{Tr}) ; \quad \% \mathrm{P} 298 \pm ¥^{0} \mathbf{I}^{11} 1 / 4 \notin E ̈ \tilde{a}^{3} £ \hat{E} y ́ f f f i(T r)$

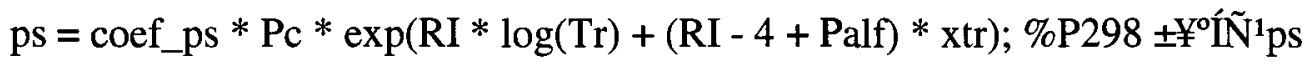

else $\quad \% 1 / 4 Æ E ̈ \tilde{a}^{1}$ ýÈ̀̇

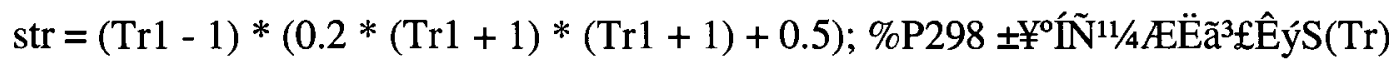

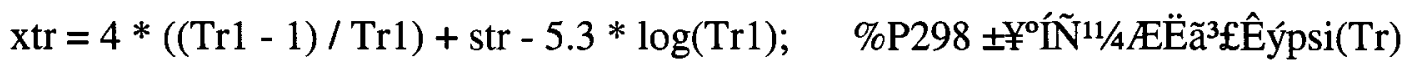

ps $=$ coef_ps $*$ Pc $* \exp (\mathrm{RI} * \log (\mathrm{Tr} 1)+(\mathrm{RI}-4+\mathrm{Palf}) * \mathrm{xtr}) ; \% \mathrm{P} 298 \pm ¥^{\circ}{ }^{\circ} \tilde{\mathrm{N}}^{1} \mathrm{ps}$

end;

P_temp=ps;

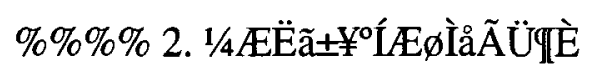

$\mathrm{rw0}=\mathrm{ps} /\left(10 * \mathrm{R} \_\mathrm{Mo} * \mathrm{Tc} * \operatorname{Tr} 1\right)$

$\mathrm{k}=0$;

$\mathrm{bl}=1 \mathrm{e} 5$;

while (bl >0.000001)

\% $\mu$ ü úÇóÆøİãÃÜđİ

$\operatorname{lq} 1=0$

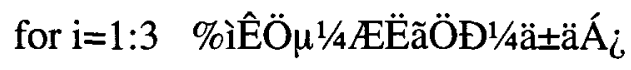

lqa1 $=0$;

for $\mathrm{j}=0: 3$

lqa1 $=\operatorname{lqa} 1+\mathrm{b}(\mathrm{i}, \mathrm{j}+1) * \operatorname{rw0}{ }^{\wedge} \mathrm{i} * \operatorname{Tr} \wedge(-\mathrm{j}) * 1 ;$

end;

$\mathrm{lq} 1=\mathrm{lq} 1+\mathrm{lqa} 1$;

end;

lq11 $=0 ; \%$ lq11 is the derivative of $\mathrm{lq} 1$.

for $\mathrm{i}=1: 3$

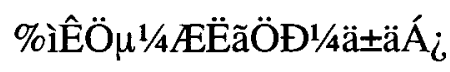


lqa11 =0;

for $\mathrm{j}=0: 3$

$$
\operatorname{lqa} 11=\operatorname{lqa} 11+\mathrm{i} * \mathrm{~b}(\mathrm{i}, \mathrm{j}+1) * \operatorname{rw0} 0^{\wedge}(\mathrm{i}-1) * \operatorname{Tr}^{\wedge}(-\mathrm{j}) ;
$$

end;

lq11 = lq11 + lqa11;

end;

$\mathrm{lz}=\mathrm{ps}-10 * \mathrm{R} \_\mathrm{Mo} * \mathrm{Tr} * \mathrm{Tc} * \mathrm{rw} 0 *(1+\mathrm{lq} 1) ;$

$\mathrm{lza}=-10 * \mathrm{R} \_\mathrm{Mo} * \mathrm{Tr} * \mathrm{Tc} *(1+\mathrm{lq} 1+\mathrm{rw0} * \mathrm{lq} 11)$;

\%If $\mathrm{lz} / \mathrm{lza}<0$ Then $\mathrm{lz}=-\mathrm{lz}$

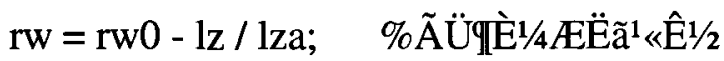

$\mathrm{bl}=\mathrm{abs}((\mathrm{rw}-\mathrm{rw} 0) / \mathrm{rw})$;

if $(\mathrm{k}>50)$

sprintf('Program does not converge, $k>50$. [R134aProp function]');

break;

end;

$\mathrm{rw} 0=\mathrm{rw}$;

$\mathrm{k}=\mathrm{k}+1$;

end;

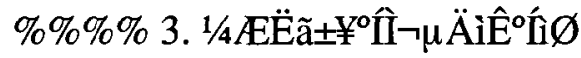

$\operatorname{lq} 2=0$

for $i=1: 3$

\%îิÖ $\mu^{1 / 4 Æ E ̈ E ̃ O ̈ Đ 1 / 4 a ̈+a ̈ A ́ ́ ~}$

lqa2 $=0$;

for $\mathrm{j}=0: 3$

lqa2 $=\operatorname{lqa} 2+\mathrm{b}(\mathrm{i}, \mathrm{j}+1) * \mathrm{rw}^{\wedge} \mathrm{i} * \operatorname{Tr} \wedge(-\mathrm{j}) * 1 / \mathrm{i}$

end;

$\operatorname{lq} 2=\operatorname{lq} 2+\operatorname{lqa} 2$

end;

$\operatorname{lq} 3=0$ 
for $\mathrm{i}=1: 3$

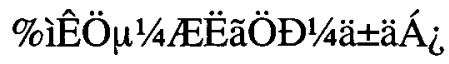

$\operatorname{lqa} 3=0$;

for $\mathrm{j}=0: 3$

lqa3 $=\operatorname{lqa} 3+b(i, j+1) * \operatorname{rw0} 0^{\wedge} \mathrm{i}^{*} \operatorname{Tr} \wedge(-\mathrm{j}) * \mathrm{j} / \mathrm{i} ;$

end;

$\mathrm{lq} 3=\mathrm{lq} 3+\mathrm{lq} \mathrm{a} 3$

end;

$\mathrm{u} 1=0$;

for $\mathrm{n}=1: 3$

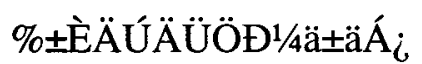

$\mathrm{u} 1=\mathrm{u} 1+\mathrm{d}(\mathrm{n}+1) *(\operatorname{Tr} * \mathrm{Tc} / 1000 .)^{\wedge} \mathrm{n} / \mathrm{n}$;

end;

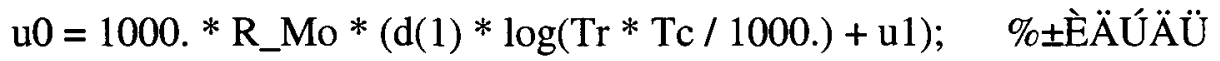

s_ref $=-\mathrm{d}(1) /(\operatorname{Tr} * \mathrm{Tc} / 1000)+.\mathrm{d}(2) * \log (\mathrm{Tr} * \mathrm{Tc} / 1000)+.\mathrm{d}(3) *(\operatorname{Tr} * \mathrm{Tc} / 1000$.$) ;$

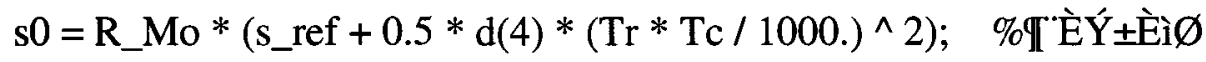

$\%$

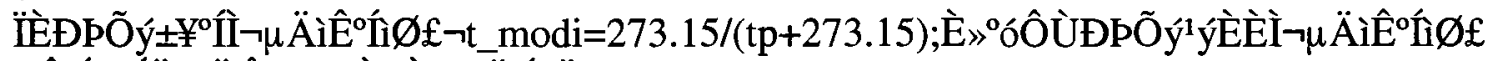

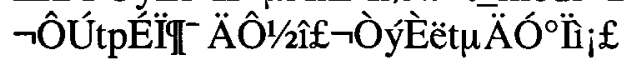

$\% \mathrm{t} \_\operatorname{modi} \mu \ddot{A} O ̈, \hat{E} y ́\left(n \_t+0.38\right)-$

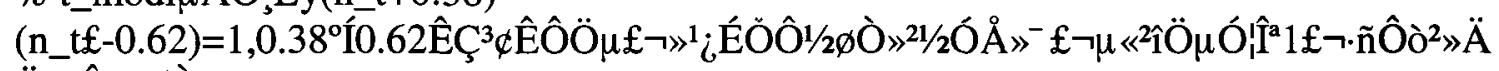

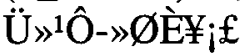

$\% \mu \pm t=t p \hat{E} \pm f \neg t \_m o d i=273.15 /(\mathrm{tp}+273.15)$;

$\% \mu \pm \mathrm{t}=\mathrm{tp}=0 \mathrm{CE} \pm f \neg \mathrm{t} \_$modi $=1$.

$\%$ if $(\mathrm{t}<\mathrm{tp})$

$\%$ t_modi=1;

$\%$ else

$\% \quad \mathrm{n} \_\mathrm{t}=((\mathrm{tp}+273.15) / 273.15)^{\wedge} 4.5$;

$\% \quad t \_m o d i=273.15 *(t+273.15)^{\wedge}\left(\mathrm{n} \_\mathrm{t}-0.62\right) /(\mathrm{tp}+273.15)^{\wedge}\left(\mathrm{n} \_\mathrm{t}+0.38\right)$;

$\%$ end;

$\mathrm{vq}=$ coef_vg $* 1 . /(1000 . *$ rw0 $)$; 


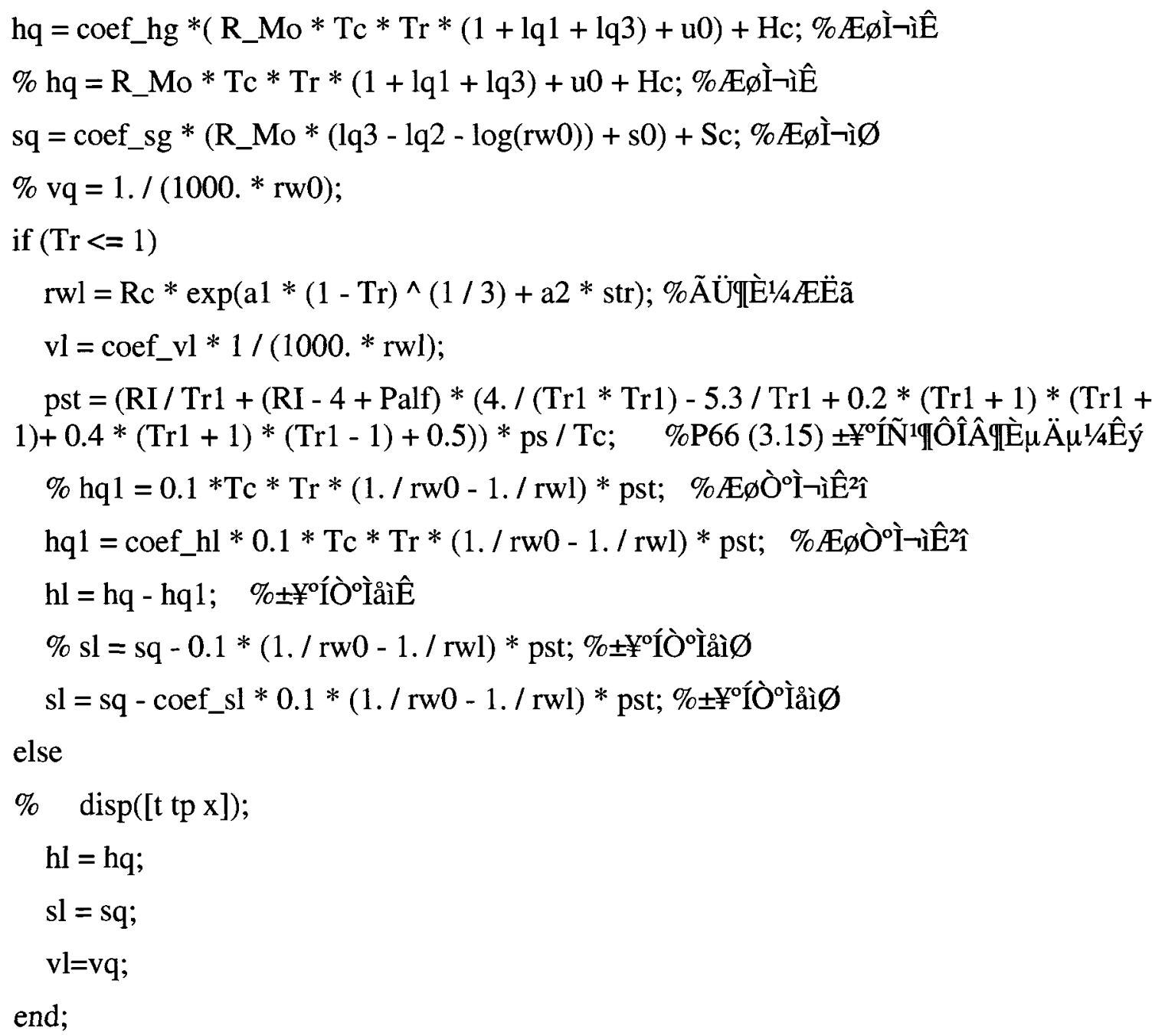

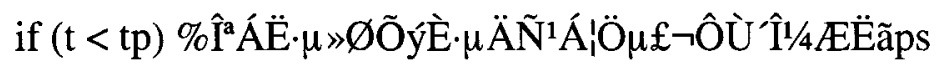

$\operatorname{Tr} 1=\operatorname{Tr} 1 \_$temp;

$\operatorname{str}=(\operatorname{Tr} 1-1) *(0.2 *(\operatorname{Tr} 1+1) *(\operatorname{Tr} 1+1)+0.5) ; \% \mathrm{P} 298 \pm ¥^{\circ} \tilde{I}^{11} 1 / 4 Æ E ̈ \tilde{a}^{3} £ \hat{E} y ́ S(\operatorname{Tr})$

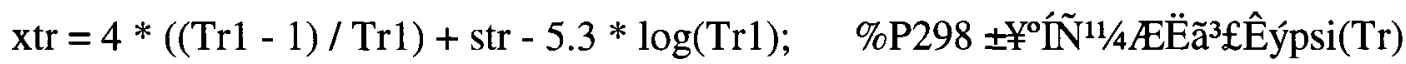

ps $=$ coef_ps $* \mathrm{Pc} * \exp (\mathrm{RI} * \log (\mathrm{Tr} 1)+(\mathrm{RI}-4+\mathrm{Palf}) * \mathrm{xtr}) ; \% \mathrm{P} 298 \pm ¥^{\circ} \tilde{I}^{1} \mathrm{ps}$

end;

$P=p s ;$

if $(\mathrm{t}>\mathrm{tp}) \quad \%$ improve the accuracy of superheated properties.

hq=coef_s_hg*hq;

sq=coef_s_sg*sq; 
$\mathrm{vq}=$ coef_s_vg*vq;

$\mathrm{hl}=\mathrm{hq}$;

$\mathrm{sl}=\mathrm{sq}$;

$\mathrm{vl}=\mathrm{vq}$;

end;

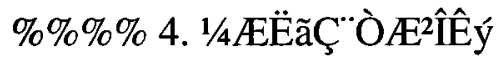

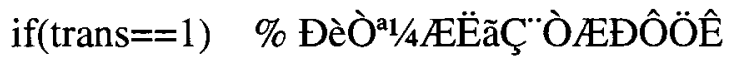

miul $=\left(267.67-3.6494 * t+0.039304 * t^{\wedge} 2-0.0002191 * t^{\wedge} 3\right) * 1 e-6 ; \%-57 \sim 93$ Celsius, $\mathrm{Pa}^{*} \mathrm{~s}$ lambdal $=0.09537-0.000517 * \mathrm{t} ; \quad \%-60 \sim 60$ Celsius, $\mathrm{W} /(\mathrm{m} * \mathrm{~K})$

$\mathrm{cpl}=1.327+0.005509 * \mathrm{t} ; \quad \%<=75$ Celsius, $\mathrm{kJ} /\left(\mathrm{kg}^{*} \mathrm{~K}\right)$

miuq $=(11.021+0.038599 * \mathrm{t}) * 1 \mathrm{e}-6 ; \% 38 \sim 149$ Celsius, under 1 atm pressure

lambdaq $=0.01212+0.000096 * t ; \quad \% 0 \sim 120$ Celsius, under 1 atm pressure

$\mathrm{A}=1.18964495977357 \mathrm{e}-015^{*} \mathrm{P}^{\wedge} 5+(-1.16270847414635 \mathrm{e}-$

$013) * \mathrm{P}^{\wedge} 4+(3.76226762180135 \mathrm{e}-012) * \mathrm{P}^{\wedge} 3+(-4.53118696990504 \mathrm{e}-$

$011)^{*} \mathrm{P}^{\wedge} 2+(1.72871730150034 \mathrm{e}-010)^{*} \mathrm{P}+(-1.59092389499007 \mathrm{e}-010)$;

$\mathrm{B}=-2.37778643602758 \mathrm{e}-013 * \mathrm{P}^{\wedge} 5+(2.56088383960080 \mathrm{e}-011) * \mathrm{P}^{\wedge} 4+(-$ $8.89569623737231 \mathrm{e}-010) * \mathrm{P}^{\wedge} 3+(1.14145097025420 \mathrm{e}-008) * \mathrm{P}^{\wedge} 2+(-4.64954750631232 \mathrm{e}-$ $008) * \mathrm{P}+(4.48093922506703 \mathrm{e}-008)$

$\mathrm{C}=7.56169568504852 \mathrm{e}-012 * \mathrm{P}^{\wedge} 5+(-1.29801706112960 \mathrm{e}-$

$009) * \mathrm{P}^{\wedge} 4+(5.58126596236343 \mathrm{e}-008) * \mathrm{P}^{\wedge} 3+(-8.29533849322757 \mathrm{e}-$

$007)^{*} \mathrm{P}^{\wedge} 2+(3.87042109380753 \mathrm{e}-006) * \mathrm{P}+(-4.07165543554560 \mathrm{e}-006)$;

$\mathrm{D}=7.89347452236300 \mathrm{e}-010 * \mathrm{P}^{\wedge} 5+(-3.68563449097485 \mathrm{e}-$

$008) * \mathrm{P}^{\wedge} 4+(2.76232718274411 \mathrm{e}-007) * \mathrm{P}^{\wedge} 3+(6.41086775064755 \mathrm{e}-006) * \mathrm{P}^{\wedge} 2+(-$

7.29739695578623e-005)*P+(1.06958719354511e-004);

$\mathrm{E}=-3.69336309937985 \mathrm{e}-008 * \mathrm{P}^{\wedge} 5+(2.84609337890151 \mathrm{e}-006) * \mathrm{P}^{\wedge} 4+(-$

$7.89745216490073 \mathrm{e}-005) * \mathrm{P}^{\wedge} 3+(8.88402665459739 \mathrm{e}-004) * \mathrm{P}^{\wedge} 2+(-3.03148726722429 \mathrm{e}-$ $003) * \mathrm{P}+(3.52534577274099 \mathrm{e}-003)$;

$\mathrm{F}=-4.46123039561911 \mathrm{e}-008 * \mathrm{P}^{\wedge} 5+(-3.78671659115701 \mathrm{e}-$

$006) * \mathrm{P}^{\wedge} 4+(3.71373556305082 \mathrm{e}-004) * \mathrm{P}^{\wedge} 3+(-9.17360290065082 \mathrm{e}-$

$003) * \mathrm{P}^{\wedge} 2+(8.48136563492374 \mathrm{e}-002) * \mathrm{P}+(7.49842353513028 \mathrm{e}-001)$;

$\mathrm{cpq}=\mathrm{A}^{*} \mathrm{t}^{\wedge} 5+\mathrm{B} * \mathrm{t}^{\wedge} 4+\mathrm{C}^{*} \mathrm{t}^{\wedge} 3+\mathrm{D}^{*} \mathrm{t}^{\wedge} 2+\mathrm{E}^{*} \mathrm{t}+\mathrm{F}$

else

miul $=100 ; \quad$ miuq=100; lambdal $=100 ;$ lambdaq $=100 ; \quad c p l=100 ; \quad c p q=100 ;$ 
end;

$\%$ if $(\mathrm{x}<0)$

$\% \mathrm{~h}=\mathrm{hl}+\mathrm{vl}{ }^{*}\left(\mathrm{P}-\mathrm{P} \_\right.$temp $) * 100 ; \mathrm{s}=\mathrm{sl} ; \mathrm{v}=\mathrm{vl} ; \mathrm{miu}=\mathrm{miul} ; \mathrm{lambda=lambdal} ; \mathrm{cp}=\mathrm{cpl}$;

$\%$ elseif $(\mathrm{x}==0)$

if $(\mathrm{x}<=0)$

$\mathrm{h}=\mathrm{hl} ; \mathrm{s}=\mathrm{sl} ; \mathrm{v}=\mathrm{vl} ; \mathrm{miu}=\mathrm{miul} ; \mathrm{lambda}=\mathrm{lambdal} ; \mathrm{cp}=\mathrm{cpl}$;

elseif $(x>=1) \%$ Superheated region

$\mathrm{h}=\mathrm{hq} ; \mathrm{s}=\mathrm{sq} ; \mathrm{v}=\mathrm{vq} ; \mathrm{miu}=\mathrm{miuq} ; \mathrm{lambda}=\mathrm{lambdaq} ; \mathrm{cp}=\mathrm{cpq} ;$

else \% two-phase region

$\mathrm{h}=\mathrm{x} * \mathrm{hq}+(1-\mathrm{x}) * \mathrm{hl}$;

$\mathrm{s}=\mathrm{x} * \mathrm{sq}+(1-\mathrm{x}) * \mathrm{sl}$

$\mathrm{v}=\mathrm{x}^{*} \mathrm{vq}+(1-\mathrm{x})^{*} \mathrm{vl}$

$\%$ for the two-phase region, miu is not directly calculated by miu $=1 /(\mathrm{x} / \mathrm{miuq}+(1-\mathrm{x}) / \mathrm{miul})$, but uses a modification for

\% better accordance with experimental data. 1.4 is from experimental data of R12, might not be accurate for R134a

$\%$ though.

miu=miul*miuq $/\left(\right.$ miuq $+($ miul-miuq $\left.) * x^{\wedge} 1.4\right) ;$

lambda $=1 /(\mathrm{x} / \mathrm{lambdaq}+(1-\mathrm{x}) / \mathrm{lambdal})$;

$\mathrm{cp}=1 /(\mathrm{x} / \mathrm{cpq}+(1-\mathrm{x}) / \mathrm{cpl})$;

end;

\section{Relative Velocity}

function Vrel = RelVelocity $($ Omega, theta, R1, R2)

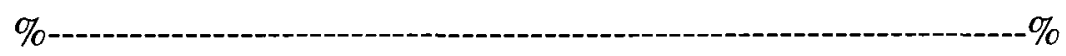

$\%$ This program computes the relative velocity between the vane and the slot

$\%$ as the rotor spins

\% INPUT

$\%$ Omega - rotational speed

$\%$ theta - angle of rotation

$\% \mathrm{R} 1$ - rotor radius 
$\% \mathrm{R} 2$ - Case radius

\% OUTPUT

$\%$ Vrel - relative velocity

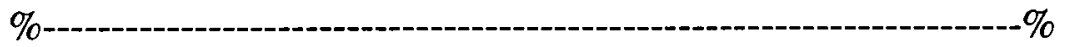

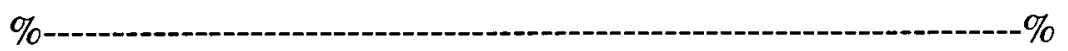

$\%$ e - eccentricity

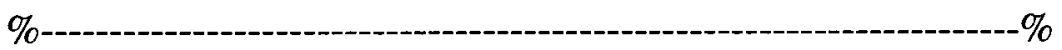

$\%$ calculates the relative velocity of the vane, see page 36

e = R2-R1;

Vrel $=\operatorname{zeros}(\operatorname{size}($ theta $))$;

for $n=1: \max (\operatorname{size}($ theta $))$

theti $=\operatorname{theta}(\mathrm{n})$;

$\mathrm{mm}=1+(\tan (\text { theti }))^{\wedge} 2$;

$B=2 * \tan \left(\right.$ theti) $/ \cos \left(\right.$ theti) $-\mathrm{mm}^{*} \sin ($ thet $\mathrm{i})$;

$\mathrm{D}=\mathrm{mm}^{\wedge} 2^{*}(\cos (\text { theti }))^{\wedge} 2$;

if theti $<\mathrm{pi} / 2 \|$ theti $>3 * \mathrm{pi} / 2$

$\mathrm{A}=-\left(\left(\mathrm{e}^{\wedge} 2-\mathrm{R} 2{ }^{\wedge} 2\right)^{*} \tan (\right.$ theti $\left.) * \mathrm{~mm}\right) /\left(\cos (\right.$ theti $\left.) * \operatorname{sqrt}\left(\mathrm{e}^{\wedge} 2-\mathrm{mm} *\left(\mathrm{e}^{\wedge} 2-\mathrm{R} 2^{\wedge} 2\right)\right)\right)$;

$C=-e+\operatorname{sqrt}\left(e^{\wedge} 2-m m *\left(e^{\wedge} 2-R 2^{\wedge} 2\right)\right)$;

else

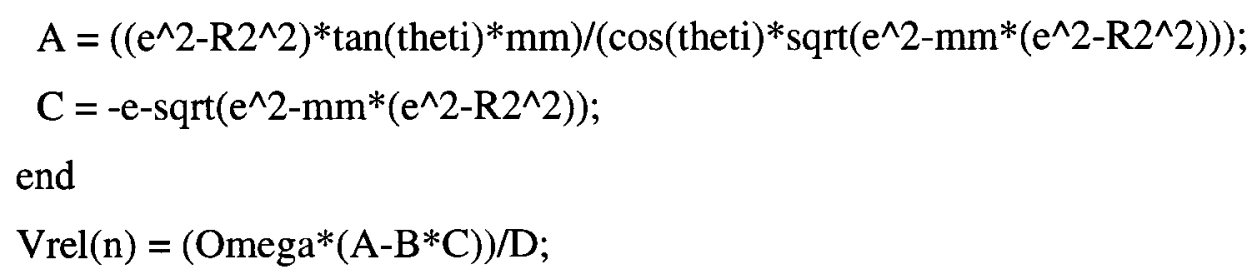

\section{Check for Fluid State}

function [state, Psat, Tsat] $=$ SatCheck $(\mathrm{P}, \mathrm{T}$, conf $)$

$\%$ Conf asks if $\mathrm{u}$ are basing calculation on temperature or pressure $\%$ enter string $\mathrm{T}$ or $\mathrm{P}$ for conf 
$\%$ if $\mathrm{P}$ is conf returns Tsat(P)

$\%$ if $\mathrm{T}$ is conf returns Psat( $\mathrm{T})$

$\%$ Temp in celcius

$\%$ Pres in bar

$\%$ state returns subcooled 0 , saturated 1 , superheated 2

$\%$ State allows $+/-0.2 \mathrm{C}$ and $+/-0.05$ bar uncertainty

$\%$ SatPropPT = dlmread('H: $\operatorname{gard} \backslash T$ hesis $\backslash$ Compressor $\backslash R 134 \mathrm{a}$

databaseltableslsat_pres_temp.txt', 'It');

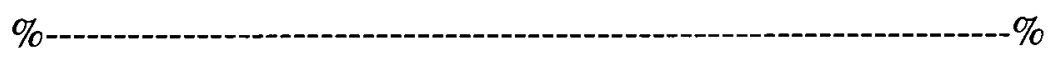

$\%$ This program checks the state of the refriferant given a temperature and

$\%$ pressure

\% INPUT

$\%$ conf - which data are you more confident of

$\% \mathrm{P}$ - refrigerant pressure

$\% \mathrm{~T}$ - refrigerant temperature

\% OUTPUT

$\%$ Psat - saturated pressure

$\%$ state - returns what state the fluid is in

$\%$ Tsat - saturated Temperature

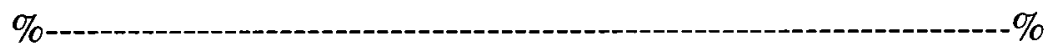

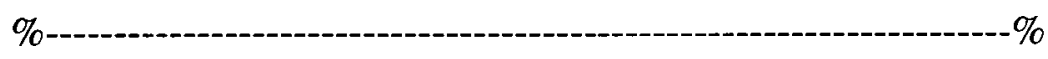

$\%$ DataSize - Size of the saturated propert table

$\%$ Press - Saturated pressure data

$\%$ Psat - Saturated presure

$\%$ Temps - Saturted temperature data

$\%$ Tsat - saturated temperature

$\%$ SatPropPT - reads in the saturated tables

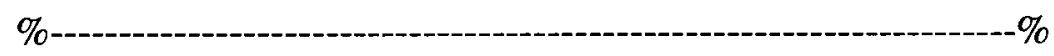

SatPropPT = dlmread('tableslsat_pres_temp.txt', 'It');

DataSize $=\max (\operatorname{size}($ SatPropPT $))$;

Press = SatPropPT $(:, 1)$; 


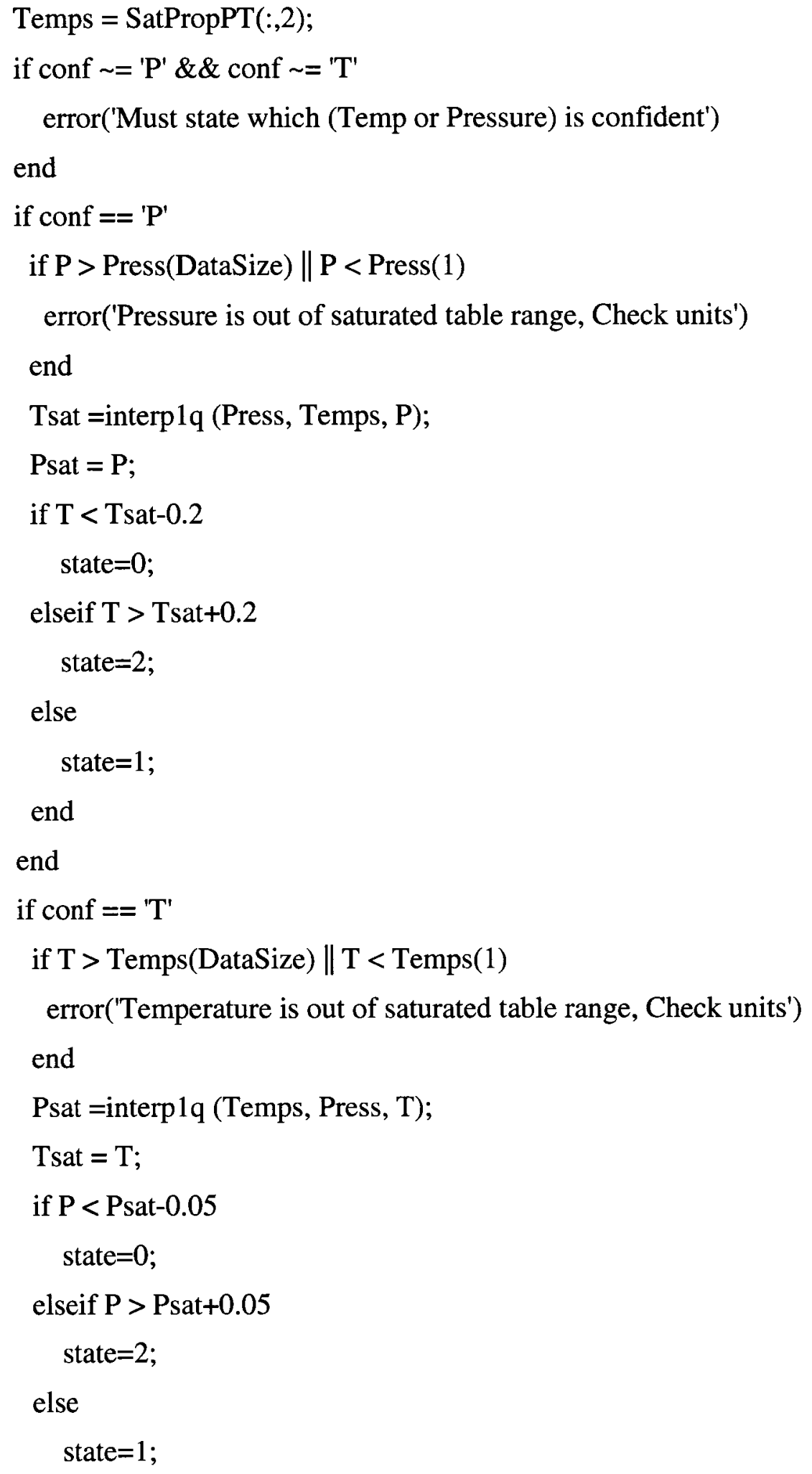


end

end

\section{Temperature, Pressure and Quality Properties}

function $[\mathrm{h}, \mathrm{s}, \mathrm{v}, \mathrm{P}, \mathrm{t}, \mathrm{miu}, \mathrm{lambda}, \mathrm{cp}]=\mathrm{t} \_\mathrm{P} \_\mathrm{x}(\mathrm{t}, \mathrm{P}, \mathrm{x}, \mathrm{trans}, \mathrm{conf})$

$\%$ to get saturated properties, enter a pressure of zero

$\%$ trans gives you other properties such as viscosity etc

$\%$ t- Temp - celcius

$\% \mathrm{P}$ - pres - bar

$\% \mathrm{x}$ - quality

$\% \mathrm{~h}$ - enthalpy $-\mathrm{kJ} / \mathrm{kg}$

$\% \mathrm{v}$ - specific volume $-\mathrm{m}^{\wedge} 3 / \mathrm{kg}$

if nargin $==5$

[state, $\mathrm{P}, \mathrm{t}]=$ SatCheck $\left(\mathrm{P}, \mathrm{t}, \mathrm{P}^{\prime}\right)$;

end

if nargin $<4$

trans $=0$;

end

$\mathrm{kk}=0$;

if $(\mathrm{P}==0 \|(\mathrm{x}>=0 \& \& \mathrm{x}<=1))$

[h1,s1,v1,P1,miu1,lambda1,cp1]=R134aProp(t,t,x,trans);

else

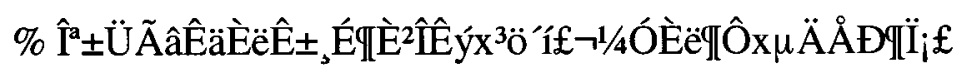

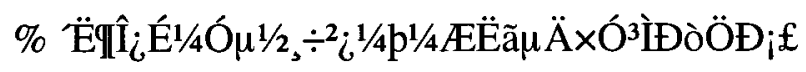

$\mathrm{EPS}=1 \mathrm{e}-6$;

$\operatorname{if}(t>101)$

$\mathrm{x}=2$;

$\mathrm{dt}=1 \mathrm{e}-5$;

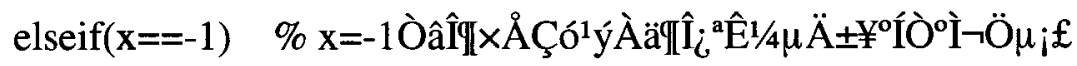

$\mathrm{dt}=-1 \mathrm{e}-5$ 


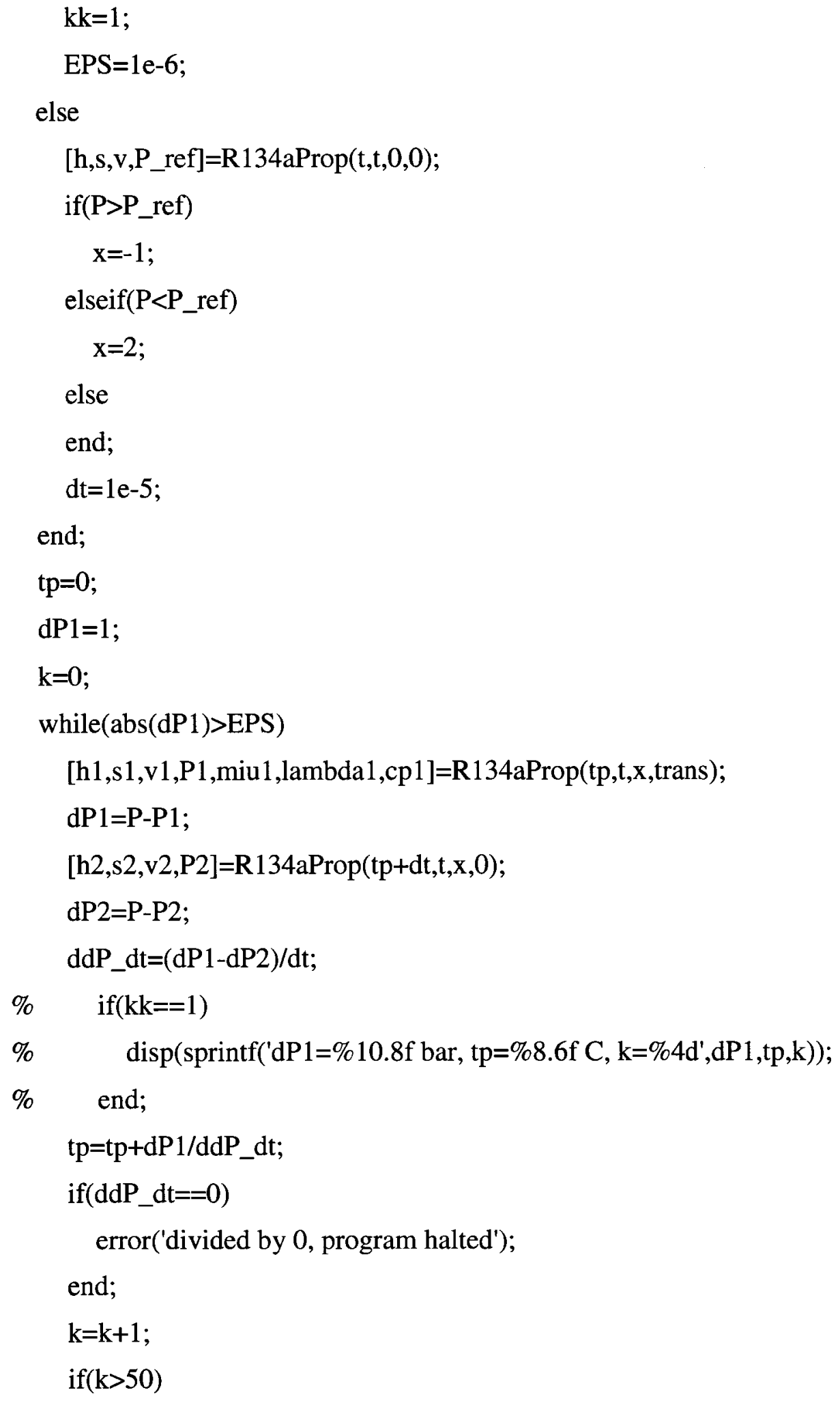


$\operatorname{disp}($ 'ERROR, too many iterations, $\mathrm{k}>50$. [t_P_x function]'); pause;

end;

end;

$\% \operatorname{disp}(\operatorname{sprintf}(' \mathrm{k}=\% 2 \mathrm{~d}$ ',k));

end;

$\mathrm{h}=\mathrm{h} 1 ; \mathrm{s}=\mathrm{s} 1 ; \mathrm{v}=\mathrm{v} 1 ; \mathrm{P}=\mathrm{P} 1 ; \mathrm{miu}=\mathrm{miu} 1 ; \mathrm{lambda}=\mathrm{lambda} 1 ; \mathrm{cp}=\mathrm{cp} 1 ;$

\section{Center of Gravity of the Vane}

function $[\mathrm{rg}]=$ vaneCG $(\mathrm{R} 1, \mathrm{R} 2$, theta, $\mathrm{h})$

$\%$ see page 14 for derivation

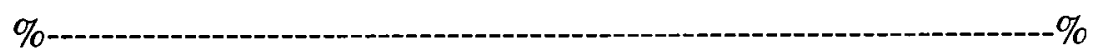

$\%$ This program computes the location of the center of gravity of the vanes

$\%$ as a function of the angular location of the vane.

\% INPUT

$\% \mathrm{~h}$ - vane height

$\% \mathrm{R} 1$ - rotor radius

$\% \mathrm{R} 2$ - case radius

$\%$ theta - angle of rotation

\% OUTPUT

$\% \mathrm{rg}$ - vane center of mass radial location

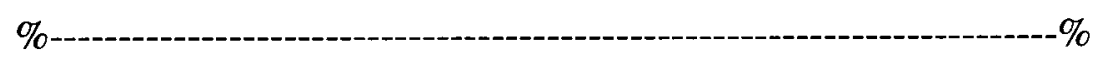

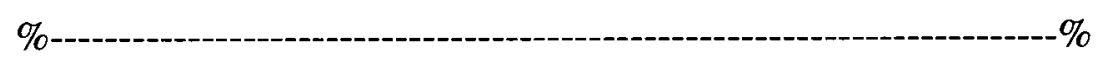

$\%$ e - eccentricity

$\% \mathrm{P}$ - points on the outer cylindeer (radius)

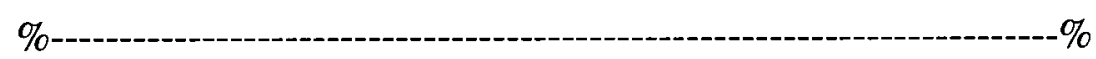

\%---------------------- Sizing variables---------------------------\%

$\mathrm{x} 1$ = zeros(size (theta)); 
$\mathrm{x} 2=\operatorname{zeros}(\operatorname{size}($ theta $))$;

$\mathrm{x}=\operatorname{zeros}(\operatorname{size}($ theta $))$;

$\mathrm{P}=\operatorname{zeros}(\operatorname{size}($ theta $))$;

rg = zeros(size (theta));

$\%$

-Done Sizing Variables $-\%$

e=R2-R1;

$\mathrm{m}=\tan ($ theta); \% dummy variable for calculation (actuall line slope)

$\mathrm{mm}=\mathrm{m} \cdot{ }^{\wedge} 2+1$;

for $\mathrm{n}=1: \max ($ size(theta))

$x 1(n)=\left((-2 * e)+\operatorname{sqrt}\left(4 * e^{\wedge} 2-4 * m m(n) *\left(e^{\wedge} 2-R 2 \wedge 2\right)\right)\right) /(2 * m m(n)) ;$

$\mathrm{x} 2(\mathrm{n})=\left(\left(-2^{*} \mathrm{e}\right)-\operatorname{sqrt}\left(4^{*} \mathrm{e}^{\wedge} 2-4 * \mathrm{~mm}(\mathrm{n})^{*}\left(\mathrm{e}^{\wedge} 2-\mathrm{R} 2^{\wedge} 2\right)\right)\right) /\left(2^{*} \mathrm{~mm}(\mathrm{n})\right) ;$

if theta(n) $<\mathrm{pi} / 2 \|$ theta(n) $>3 * \mathrm{pi} / 2$

$\mathrm{x}(\mathrm{n})=\mathrm{x} \mathbf{l}(\mathrm{n})$;

else

$x(n)=x 2(n) ;$

end

$\mathrm{P}(\mathrm{n})=\operatorname{abs}(\mathrm{x}(\mathrm{n}) / \cos (\operatorname{theta}(\mathrm{n})))$;

$\operatorname{rg}(\mathrm{n})=\mathrm{P}(\mathrm{n})-\mathrm{h} / 2$;

end

\section{Main Vane Compressor Program}

This program is slightly different for the compressor-expnader analysis and for the full system analysis. The program shown is the full system analysis program. The inputs are the same for both programs however the output variables are diffenent.

function [Pout, Tout, mout, mleak, Ploss] = vanecomp1 (qual, RPM, P0, T0, comporexp)

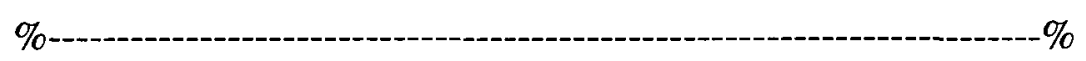

$\%$ This program computes the output of the compressor given the input

$\%$ parameters.

$\%$ $\sim$ INPUT 


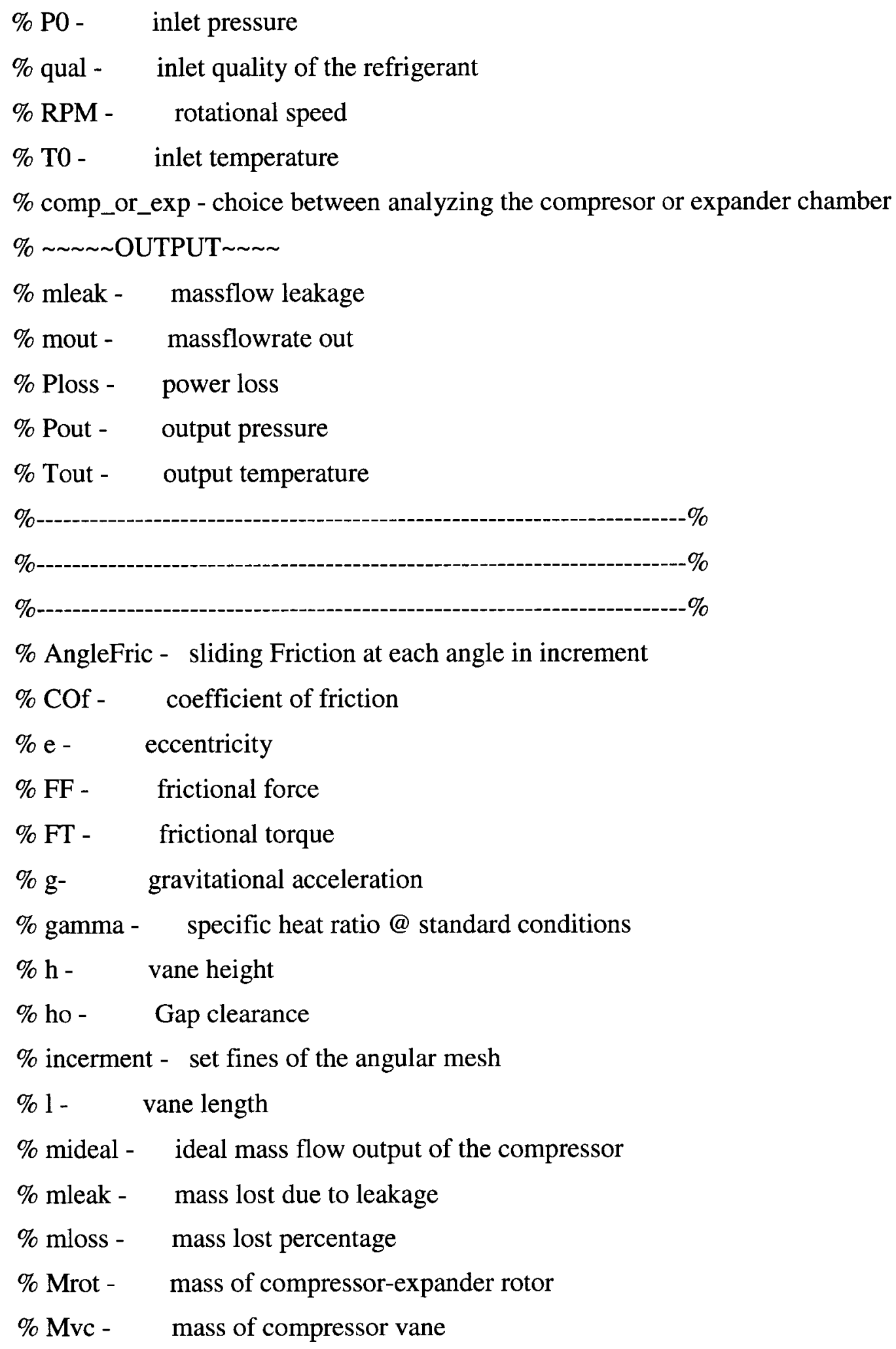




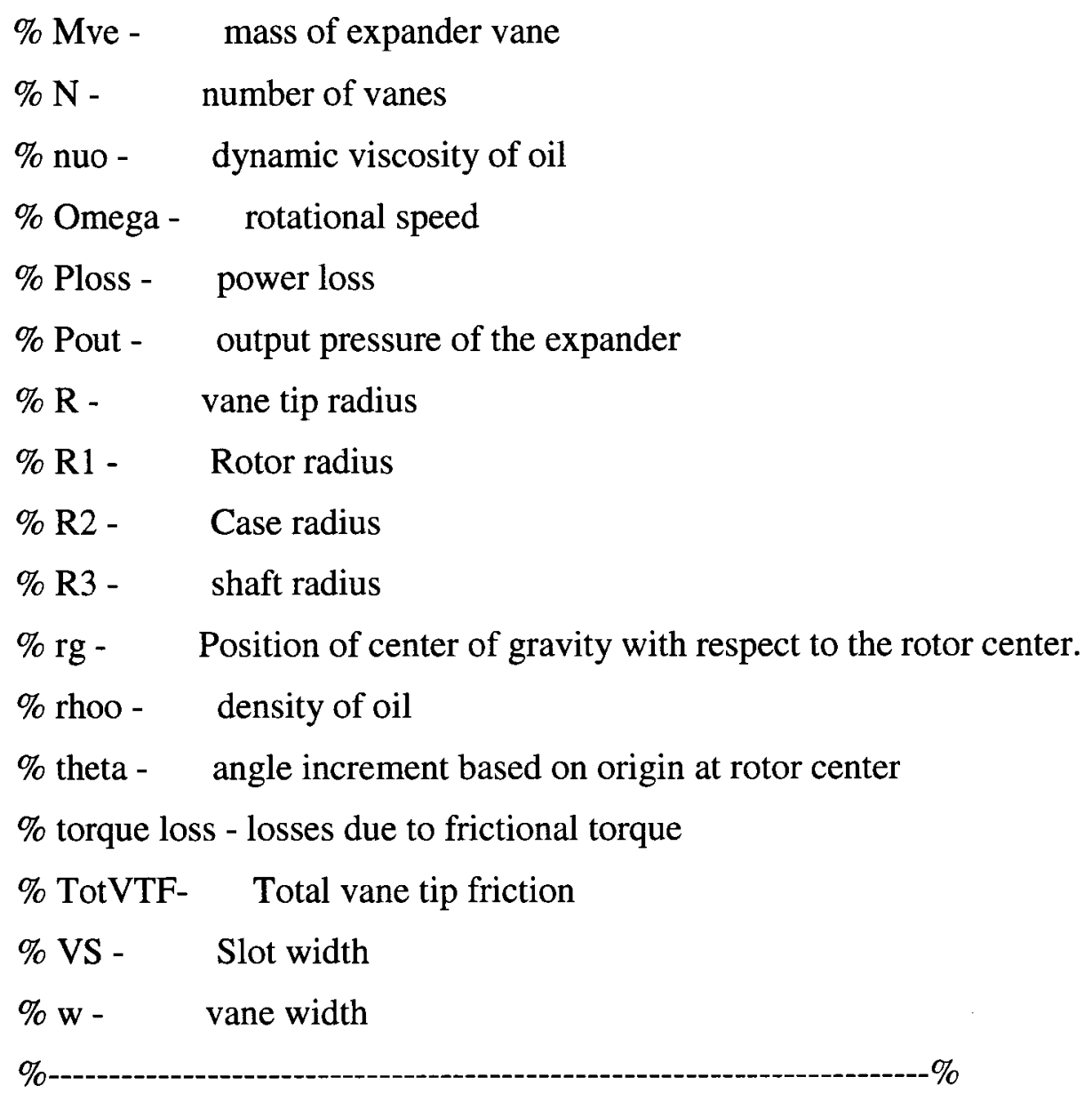

$\%$ to change path : type help path

$\%$ Working predominantly in SI units

global PH TH PL;

$\%$ FF - Frictional Force

$\%$ FT - Frictional Torque

$\%$

$* * * * * * * * * * * * * * * * * * * * * * * * * * * * * * * * * * * * * * * * * * * * * * * * * * * * * * * * * * * * * * * * * * * * * * * * *$

\%--1------ Global variables

$\%$ OPERATING CONDITIONS AND PROPERTIES

$\% \mathrm{RPM}=1500$

$\%$ Omega $=$ RPM ${ }^{*} \mathrm{pi} / 30$;

$\mathrm{g}=9.81 ; \%$ acceleration due to gravity 
COf $=0.08$; \% Measured with slant experiment page 28 , it should be a function of velocity (paper)

$\mathrm{Mvc}=0.03658 ; \%$ compressor vane mass (measured)

Mve $=0.012081 ; \%$ Exmapnder vane mass(measured)

$\mathrm{Mv}=\mathrm{Mvc}+\mathrm{Mve}$

nuo $=45 * 10^{\wedge}-6 ; \% 100$ PAG oil $=100 \mathrm{cst} @ 40 \mathrm{C}$ and $85 \%$ oil

$\%$ might want to consider using graph to get nu_oil(T)

rhoo $=1032.9 ; \%$ measured -- oil density

Mrot $=1.12673 ; \%$ Measured - rotor mass

Gamma = 1.1383411;

$\%$

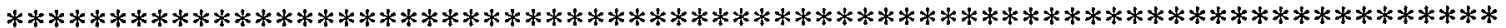

\section{$\%$ GEOMETRY DEFINITIONS}

$\% \mathrm{R} 1$ - Rotor radius

$\% \mathrm{R} 2$ - Case radius

$\% \mathrm{~h}$ - vane height

$\%$ ho - Gap clearance

$\mathrm{h}=0.022873 ; \% 0.9$ inches from drawings

ho $=(0.0035 * 0.0254) ; \% 3.5$ thou: from drawings should be one thou(claearance $b / w$ roator face and case)

$1=0.032741$;

le $=0.01089914 ; \%$ vane length dimension

$\mathrm{R}=0.011999 ; \quad \%$ vane tip radius

$\mathrm{R} 1=0.04252 ; \% 3.48$ inches diameter

$\mathrm{R} 2=0.050781 ; \% 3.9985$ inches diameter

$\mathrm{R} 3=0.015608 ; \%$ Shaft radius-Measured

$\mathrm{VS}=0.006579 ; \% \mathrm{x}$ in page 32

$\mathrm{w}=0.006553$;

Omega $=$ RPM ${ }^{*} \mathrm{pi} / 30$;

$\%$

$* * * * * * * * * * * * * * * * * * * * * * * * * * * * * * * * * * * * * * * * * * * * * * * * * * * * * * * * * * * * * * * * * * * * * * * *$ 


\section{\% 1. ECCENTRIC DEFINITIONS, OUTER WALL FRICTION}

$\%$ standard SI units

$\% \mathrm{~N}$ - number of vanes

$\%$ theta - angle increment based on origin at rotor center

$\%$ Increment - number of angular points between

$\%$ e - eccentricity

$\% \mathrm{P}$ - points on the outer cylindeer (radius)

$\% \mathrm{rg}$ - Position of center of gravity with respect to the rotor center.

$\%$ defining mesh

increment $=40 ; \%$ must be a multiple of Number of vanes

theta $=0: 2 * \mathrm{pi} /$ increment: $2 * \mathrm{pi}$;

$\%$ geometry of compressor

$\mathrm{N}=5 ; \% 5$ vanes

$\mathrm{rg}=\mathrm{vaneCG}(\mathrm{R} 1, \mathrm{R} 2$, theta,h);

\% Calculates sum for $r$ for several configurations of the pump

$\%$ see VaneCG for explanation

$\%$ from previous work for 5 vanes there is minimal friction change with

$\%$ angle of rotation so we can take the compressor and any position

$\%$

$\%$

$\%$ friction forom sliding

$\%$ output pressure

$\%$ tip mass loss

$\%$ ideal mass flow rate

if strcmp(comporexp,'comp')

[AngleFric, Pout, mloss 1 , mideal $]=$ VaneTipFriction $(\mathrm{N}, \mathrm{R}, \mathrm{R} 1, \mathrm{R} 2, \mathrm{~h}, \mathrm{w}, \mathrm{l}, \mathrm{VS}, \ldots$ Mvc, Omega, theta, P0, T0, 'comp'); 
$\%$ compressor friction

elseif strcmp(comporexp, 'exp')

[AngleFric, Pout] = VaneTipFriction (N, R, R1, R2, h, w, le, VS,...

Mve, Omega, theta, P0, T0, 'exp');

end

for $\mathrm{n}=1$ :increment $/ \mathrm{N}$

TotVTF=0; \% Adding up friction in all five vanes

$\mathrm{m}=\mathrm{n}$;

while $\mathrm{m}<=\max (\operatorname{size}($ AngleFric $))$

TotVTF $=$ AngleFric $(\mathrm{m})+$ TotVTF; $\quad$ \%VTF Vane tip Friction

$\mathrm{m}=\mathrm{m}+$ increment/ $\mathrm{N}$;

end

$\operatorname{AngFricTot}(\mathrm{n})=\operatorname{Tot} V T F$;

end

$\mathrm{FF} 1=\max ($ AngFricTot $)$;

$\% \max (\mathrm{rt})$ selects the angle configuration where maximum rtot occurs

$\mathrm{FT}(1)=\mathrm{FF} 1 * \operatorname{mean}(\operatorname{rg}(1:(\max (\operatorname{size}(\mathrm{rg}))-1)))$;

$\%$ Torque is sum of friction force times the average radius they act over..

$\% \max \mathrm{x}$ is the same as max $\mathrm{rg}$ and $\min \mathrm{x}$ is the same as min $\mathrm{rg}$

$\mathrm{A}(1,1)=\mathrm{FT}(1)$;

\%to show contribution of each type of friction

$\%$

$* * * * * * * * * * * * * * * * * * * * * * * * * * * * * * * * * * * * * * * * * * * * * * * * * * * * * * * * * * * * * * * * * * * * * * * * *$

\section{\% 2. SPINNING GAP END FACES}

$\%$ see page $16-17$

$\%$

$\%$ Multiply FT2 by 2 Again

$\%$

$\mathrm{FT}(2)=\left(\mathrm{pi} / 2 / \mathrm{ho}^{*}\right.$ nuo $^{*}$ rhoo $^{*}$ Omega $\left.*\left(\mathrm{R} 1^{\wedge} 4-\mathrm{R} 3^{\wedge} 4\right)\right) ; \%$ two faces: compressor and expander $\mathrm{A}(1,2)=\mathrm{FT}(2) ; \%$ to show contribution of each type of friction 
$\%$

$* * * * * * * * * * * * * * * * * * * * * * * * * * * * * * * * * * * * * * * * * * * * * * * * * * * * * * * * * * * * * * * * * * * * * * * * * *$

\section{\% 3. COMP-EXP SEAL FRICTION}

$\%$ Seal is assumed to bare a third of the load of the rotor.

$\mathrm{FF} 3=\mathrm{COf} *(\mathrm{Mrot} / 3) * \mathrm{~g}$

$\mathrm{FT}(3)=\mathrm{FF} 3 * \mathrm{R} 2$;

$\mathrm{A}(1,3)=\mathrm{FT}(3) ; \%$ shows contribution of each type of friction

$\%$

$* * * * * * * * * * * * * * * * * * * * * * * * * * * * * * * * * * * * * * * * * * * * * * * * * * * * * * * * * * * * * * * * * * * * * * * *$

$\%$ power and mass lost at rotor face

if strcmp(comporexp, 'comp')

[ploss, mloss2] =leakloss (RPM, R1,R2,PH, TH, theta,l,w,h,Pout, ho, P0, T0);

if qual $<0.95$

Pout $=$ Pout $*($ qual $)+(1-$ qual $) *(P 0) ;$

end

Torqueloss=sum(FT);

Ploss $=$ Torqueloss $*$ Omega + ploss; $\%$ total power lost

mloss $3=33.3 / 3600 * 0 ; \%$ torlon seal loss

mloss $=$ mloss $1+$ mloss 2 ; if mloss $<35$, mloss $=35$; end

mout $=$ mideal $*(1-$ mloss $/ 100)-$ mloss 3 ;

mleak = mideal-mout;

Tout $=\mathrm{T} 0 *(\mathrm{Pout} / \mathrm{P} 0)^{\wedge}((\mathrm{Gamma}-1) / \mathrm{Gamma}) ;$

elseif strcmp(comporexp, 'exp')

Torqueloss=sum(FT);

Ploss $=$ Torqueloss* Omega;

$\%$ page 59

Area $=((\operatorname{rg}(1:$ increment $)+h / 2)-R 1) . *$ le;

$\mathrm{PH}=\mathrm{PH}^{\prime}$;

$\mathrm{PL}=\mathrm{PL}$;

$\mathrm{PW}=(\mathrm{PH}-\mathrm{PL}) .{ }^{*}$ Area. ${ }^{\wedge}{ }^{*}$ Omega./le;

Power $=\operatorname{sum}(\mathrm{PW}) * 5 *$ qual; \%times 5 
[state, Psat, Tout $]=$ SatCheck $\left.\left(\text { Pout } / 100000,2,{ }^{\prime}\right)^{\prime}\right) ; \%$ dummy variable for Tsat $=2$

Tout $=$ Tout +273 ;

mout $=$ Power;

mleak=1;

Ploss=1;

end

\% ----------------------

$\%$

$\%$

$\%$ STATIC TORQUE IS $12 \mathrm{IN}-\mathrm{LBF}=1 \mathrm{FT}-\mathrm{LBF}$ must subtract static torque due to

$\%$ torlon coz it changes to dynamic

\section{Vane Tip and Side Friction Force Calculations}

function [Fric, pOut, mloss, mideal] $=$ VaneTipFriction $(\mathrm{N}, \mathrm{R}, \mathrm{R} 1, \mathrm{R} 2, \mathrm{~h}, \mathrm{w}, 1, \mathrm{VS}, \ldots$ mv, Omega, theta, P0, T0, comp_or_exp)

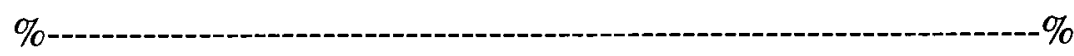

$\%$ This program calculates the friction at the tip on the vane as it rotates

$\%$ with the rotor.

$\%$ INPUT

$\%$ comp_or_exp - Choice between analyzing the compresor or expander chamber

$\%$ h - Vane height

\% 1 - Vane length

$\% \mathrm{mv}$ - $\quad$ Vane mass

$\% \mathrm{~N}$ - Number of vanes

$\%$ Omega - Rotational speed

$\% \mathrm{P0}$ - Inlet pressure

$\% \mathrm{R}$ - $\quad$ Vane tip radius

$\% \mathrm{R} 1$ - $\quad$ Rotor radius

$\% \mathrm{R} 2$ - $\quad$ Case radius 
\% T0 - Inlet temperature

$\%$ theta - Angular location

$\%$ VS - Slot width

$\% \mathrm{w}$ - $\quad$ Vane width

\% OUTPUT

$\%$ Fric - Frictional force

$\%$ mideal - Ideal massflow output of the compressor

$\%$ mloss - Mass leakage

$\%$ pOut - Output pressure

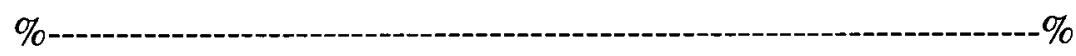

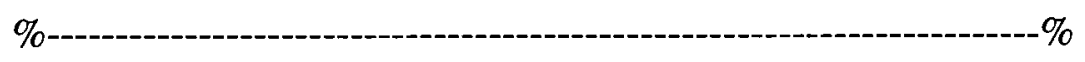

$\%$ g - gravitational acceleration

$\%$ Gamma - specific heat ratio

$\% \mathrm{mu}$ - coefficient of frictioin

$\% \mathrm{PH}$ - pressure on leading face of the vane

$\% \mathrm{PL}$ - Pressure on trailing face of the vane

$\%$ rg - vane center of gravity

$\%$ Vrel - Relative velocity

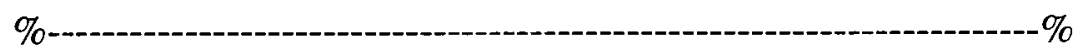

$\%$ See page 36

$\%$ Most variables explained on page 33

$\% \mathrm{x}$--> VS ---------> Page 36

$\%$ Calculating Vrel PH, PL, rg

$\%$ Might consider calculating Gamma

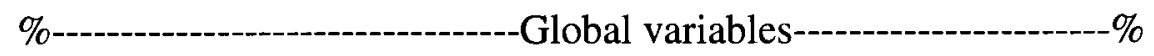

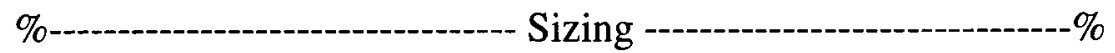

Fric $=\operatorname{zeros}((\max (\operatorname{size}($ theta $))-1), 1)$;

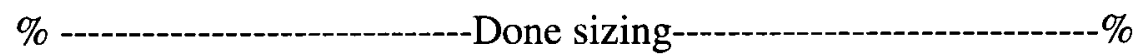

$\mathrm{g}=9.81$;

Gamma = 1.1383411; 
$[\mathrm{rg}]=$ vaneCG $(\mathrm{R} 1, \mathrm{R} 2$, theta,h);

Vrel = RelVelocity (Omega, theta, R1, R2);

mu3 = CoefFric $($ Omega*30/pi);

$\mathrm{mu}=$ CoefFric $($ Omega*30/pi);

$\%$

Compressor $\%$

if strcmp(comp_or_exp, 'comp')

[PL, PH, TL, TH, pOut, mloss, mideal $]=$ FluidPressure $(\mathrm{w}, \mathrm{h}, \mathrm{rg}, \mathrm{R} 2, \mathrm{R} 1, \mathrm{l}, \mathrm{N}$, theta, $\mathrm{P} 0, \ldots$

Gamma, T0, comp_or_exp, Omega);

\% Build matrix:

for $\mathrm{j}=1: \max (\operatorname{size}($ theta $))-1$

$\%$ Coefficient matrix

if theta(j) $<=$ pi $\%$ moving out

$\mathrm{AAA}=\left[1-1 \mathrm{mu} 3 ;-\mathrm{mu},-\mathrm{mu},-1 ; \mathrm{R} 1-\mathrm{rg}(\mathrm{j})+\mathrm{h} / 2+\mathrm{mu}^{*} \mathrm{VS}, 0, \ldots\right.$

$\left.\mathrm{VS} / 2-\mathrm{mu}^{*}(\mathrm{R} 2-\mathrm{R} 1)\right]$;

$$
\begin{aligned}
& \text { BBl }=2 * m v^{*} \text { Omega }{ }^{*} \operatorname{Vrel}(\mathrm{j})-\mathrm{mv}^{*} \mathrm{~g}^{*} \sin (\text { theta }(\mathrm{j}))+(\mathrm{PH}(\mathrm{j})-\mathrm{PL}(\mathrm{j}))^{*} \ldots \\
& \left(\mathrm{w} / 4 / \mathrm{R}^{*}\left(\mathrm{R}-\mathrm{sqrt}\left(\mathrm{R}^{\wedge} 2-\mathrm{w}^{\wedge} 2 / 4\right)\right)\right)^{*}\left(\mathrm{~h}^{* 1}\right) ; \\
& \mathrm{BB} 2=-\mathrm{PH}(\mathrm{j}) * \mathrm{w}^{*} 1-\mathrm{mv}^{*} \mathrm{Omega}^{\wedge} 2 * \mathrm{rg}(\mathrm{j})+\mathrm{mv}^{*} \mathrm{~g} * \cos (\text { theta }(\mathrm{j}))-\ldots \\
& (\mathrm{PH}(\mathrm{j})+\mathrm{PL}(\mathrm{j})) *\left(\mathrm{w}^{*} \mathrm{l} / 2 / \mathrm{R}^{*} \operatorname{sqrt}\left(\mathrm{R}^{\wedge} 2-\mathrm{w}^{\wedge} 2 / 16\right)\right) \text {; } \\
& \text { BB3 }=(\operatorname{rg}(j)-R 1) *\left(-2 * m v^{*} \text { Omega } * \text { Vrel }(j)-m v^{*} g * \sin (\text { theta }(j))+\ldots\right. \\
& \left.(\mathrm{PH}(\mathrm{j})-\mathrm{PL}(\mathrm{j}))^{*} \mathrm{l}^{*} \mathrm{~h}\right)+\mathrm{VS} / 2 *(-\mathrm{mv} * \mathrm{~g} * \cos (\text { theta }(\mathrm{j}))+\ldots \\
& \left.\mathrm{mv}^{*} \text { Omega }{ }^{\wedge}{ }^{*} \operatorname{rg}(\mathrm{j})-\mathrm{PH}(\mathrm{j})^{*} \mathrm{w}^{*} \mathrm{l}\right)-\left(3^{*} \mathrm{PH}(\mathrm{j})-\mathrm{PL}(\mathrm{j})\right)^{*} \ldots \\
& \left(\mathrm{w}^{\wedge} 2 * 1 / 8 * \operatorname{sqrt}\left(\mathrm{R}^{\wedge} 2-\mathrm{w}^{\wedge} 2 / 16\right)\right)+(\mathrm{PH}(\mathrm{j})-\mathrm{PL}(\mathrm{j}))^{*} \ldots \\
& \left(\mathrm{w} / 4 / \mathrm{R}^{*}\left(\mathrm{R}-\mathrm{sqrt}\left(\mathrm{R}^{\wedge} 2-\mathrm{w}^{\wedge} 2 / 4\right)\right)^{*}(\mathrm{R} 1-\mathrm{R} 2)\right) \text {; }
\end{aligned}
$$

$\mathrm{BBB}=[\mathrm{BB} 1 ; \mathrm{BB} 2 ; \mathrm{BB} 3] ;$

else

$\mathrm{AAA}=\left[1-1 \mathrm{mu} 3 ; \mathrm{mu}, \mathrm{mu},-1 ; \mathrm{R} 1-\mathrm{rg}(\mathrm{j})+\mathrm{h} / 2-\mathrm{mu}^{*} \mathrm{VS}, 0, \mathrm{VS} / 2-\mathrm{mu}^{*}(\mathrm{R} 2-\mathrm{R} 1)\right]$;

BB1 $=-2 * m v^{*}$ Omega*Vrel(j) $-m v^{*} g * \sin ($ theta $(j))+(\operatorname{PH}(j)-P L(j)) * \ldots$ 


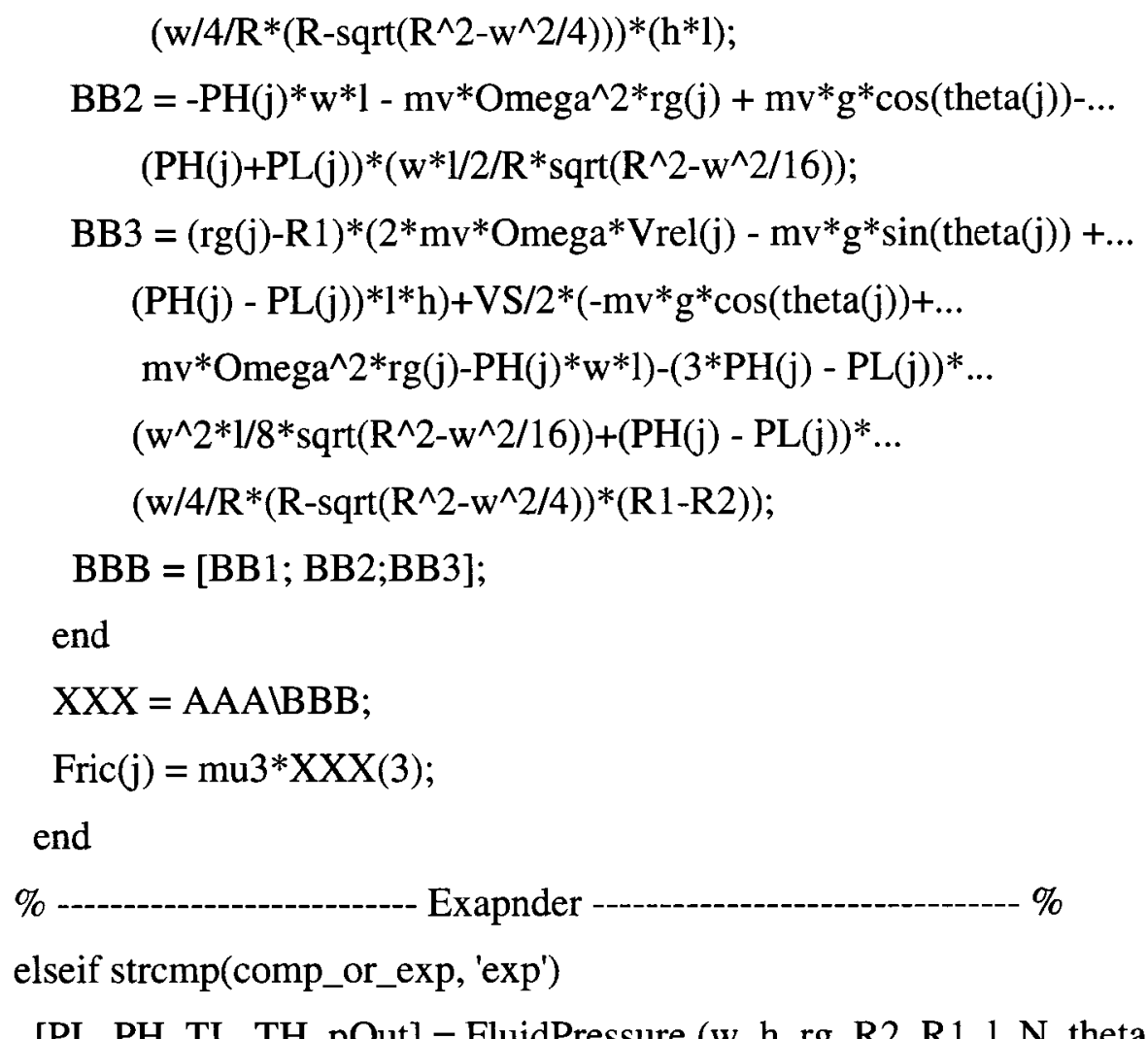

$[\mathrm{PL}, \mathrm{PH}, \mathrm{TL}, \mathrm{TH}, \mathrm{pOut}]=$ FluidPressure $(\mathrm{w}, \mathrm{h}, \mathrm{rg}, \mathrm{R} 2, \mathrm{R} 1, \mathrm{l}, \mathrm{N}$, theta $\mathrm{P} 0, \ldots$

Gamma, T0, comp_or_exp, Omega);

\% Build matrix:

for $\mathrm{j}=1: \max (\operatorname{size}($ theta $))-1$

$\%$ Coefficient matrix

if theta(j) $<=$ pi $\%$ moving out

$\mathrm{AAA}=\left[-11 \mathrm{mu} 3 ;-\mathrm{mu},-\mathrm{mu},-1 ;-\left(\mathrm{R} 1-\mathrm{rg}(\mathrm{j})+\mathrm{h} / 2+m u^{*} \mathrm{VS}\right), 0, \ldots\right.$

-VS/2-mu*(R2-R1)];

BB1 $=2 * m v^{*}$ Omega*Vrel(j) $-m v^{*} g * \sin ($ theta $(\mathrm{j}))-(\mathrm{PH}(\mathrm{j})-\mathrm{PL}(\mathrm{j}))^{*} \ldots$

$\left(\mathrm{w} / 4 / \mathrm{R} *\left(\mathrm{R}-\mathrm{sqrt}\left(\mathrm{R}^{\wedge} 2-\mathrm{w}^{\wedge} 2 / 4\right)\right)\right)^{*}\left(-\mathrm{h}^{*} \mathrm{l}\right)$;

$\mathrm{BB} 2=-\mathrm{PH}(\mathrm{j}) * \mathrm{w}^{*} 1-\mathrm{mv}^{*}$ Omega ${ }^{\wedge}{ }^{*} \mathrm{rg}(\mathrm{j})+\mathrm{mv}^{*} \mathrm{~g}^{*} \cos (\operatorname{theta}(\mathrm{j}))+\ldots$

$(\mathrm{PH}(\mathrm{j})+\mathrm{PL}(\mathrm{j}))^{*}\left(\mathrm{w}^{*} \mathrm{l} / 2 / \mathrm{R}^{*} \operatorname{sqrt}\left(\mathrm{R}^{\wedge} 2-\mathrm{w}^{\wedge} 2 / 16\right)\right)$; 
BB3 $=(\operatorname{rg}(\mathrm{j})-\mathrm{R} 1) *\left(-2 * m v^{*}\right.$ Omega $* \operatorname{Vrel}(\mathrm{j})+\mathrm{mv}^{*} \mathrm{~g} * \sin (\operatorname{theta}(\mathrm{j}))-\ldots$

$\left.(\operatorname{PH}(\mathrm{j})-\mathrm{PL}(\mathrm{j}))^{*} \mathrm{l}^{*} \mathrm{~h}\right)+\mathrm{VS} / 2 *(-\mathrm{mv} * \mathrm{~g} * \cos (\operatorname{theta}(\mathrm{j}))-\ldots$

$\left.\mathrm{mv}^{*} \mathrm{Omega}^{\wedge} 2 * \mathrm{rg}(\mathrm{j})+\mathrm{PH}(\mathrm{j}) * \mathrm{w}^{*} \mathrm{l}\right)+(3 * \mathrm{PH}(\mathrm{j})-\mathrm{PL}(\mathrm{j}))^{*} \ldots$

$\left(\mathrm{w}^{\wedge} 2 * 1 / 8 * \operatorname{sqrt}\left(\mathrm{R}^{\wedge} 2-\mathrm{w}^{\wedge} 2 / 16\right)\right)+(\mathrm{PH}(\mathrm{j})-\mathrm{PL}(\mathrm{j}))^{*} \ldots$

$\left(\mathrm{w} / 4 / \mathrm{R}^{*}\left(\mathrm{R}-\mathrm{sqrt}\left(\mathrm{R}^{\wedge} 2-\mathrm{w}^{\wedge} 2 / 4\right)\right)^{*}(\mathrm{R} 1-\mathrm{R} 2)\right)$;

$\mathrm{BBB}=[\mathrm{BB} 1 ; \mathrm{BB} 2 ; \mathrm{BB} 3]$;

else

$\mathrm{AAA}=\left[-11 \mathrm{mu} 3 ; \mathrm{mu}, \mathrm{mu},-1 ;-\left(\mathrm{R} 1-\mathrm{rg}(\mathrm{j})+\mathrm{h} / 2-\mathrm{mu}^{*} \mathrm{VS}\right), 0, \ldots\right.$

-VS/2-mu*(R2-R1)];

BB1 $=-2 * m v^{*}$ Omega*Vrel(j) $-m v^{*} g^{*} \sin (\operatorname{theta}(\mathrm{j}))-($ PH(j)-PL(j))*...

$\left(\mathrm{w} / 4 / \mathrm{R} *\left(\mathrm{R}-\mathrm{sqrt}\left(\mathrm{R}^{\wedge} 2-\mathrm{w}^{\wedge} 2 / 4\right)\right)\right) *(-\mathrm{h} * 1) ;$

$\mathrm{BB} 2=-\mathrm{PH}(\mathrm{j}) * \mathrm{w}^{*} \mathrm{l}-\mathrm{mv}^{*} \mathrm{Omega} \mathrm{a}^{\wedge}{ }^{*} \mathrm{rg}(\mathrm{j})+\mathrm{mv}^{*} \mathrm{~g} * \cos (\operatorname{theta}(\mathrm{j}))+\ldots$

$(\mathrm{PH}(\mathrm{j})+\mathrm{PL}(\mathrm{j}))^{*}\left(\mathrm{w}^{*} \mathrm{l} / 2 / \mathrm{R}^{*} \operatorname{sqrt}\left(\mathrm{R}^{\wedge} 2-\mathrm{w}^{\wedge} 2 / 16\right)\right) ;$

BB3 $=(\operatorname{rg}(\mathrm{j})-\mathrm{R} 1) *\left(2 * m v^{*}\right.$ Omega*Vrel $(\mathrm{j})+\mathrm{mv} * \mathrm{~g} * \sin (\operatorname{theta}(\mathrm{j}))-\ldots$

$\left.(\mathrm{PH}(\mathrm{j})-\mathrm{PL}(\mathrm{j}))^{*} \mathrm{l}^{*} \mathrm{~h}\right)+\mathrm{VS} / 2 *(-\mathrm{mv} * \mathrm{~g} * \cos (\operatorname{theta}(\mathrm{j}))-\ldots$

$\left.\mathrm{mv}^{*} \mathrm{Omega}^{\wedge} 2 * \mathrm{rg}(\mathrm{j})+\mathrm{PH}(\mathrm{j}) * \mathrm{w}^{*} \mathrm{l}\right)+(3 * \mathrm{PH}(\mathrm{j})-\mathrm{PL}(\mathrm{j}))^{*} \ldots$

$\left(\mathrm{w}^{\wedge} 2 * 1 / 8^{*} \operatorname{sqrt}\left(\mathrm{R}^{\wedge} 2-\mathrm{w}^{\wedge} 2 / 16\right)\right)+(\mathrm{PH}(\mathrm{j})-\mathrm{PL}(\mathrm{j}))^{*} \ldots$

$\left(\mathrm{w} / 4 / \mathrm{R}^{*}\left(\mathrm{R}-\mathrm{sqrt}\left(\mathrm{R}^{\wedge} 2-\mathrm{w}^{\wedge} 2 / 4\right)\right)^{*}(\mathrm{R} 1-\mathrm{R} 2)\right)$;

$\mathrm{BBB}=[\mathrm{BB} 1 ; \mathrm{BB} 2 ; \mathrm{BB} 3]$;

end

$\mathrm{XXX}=\mathrm{AAAlBBB}$

$\operatorname{Fric}(\mathrm{j})=\operatorname{mu} 3 * \mathrm{XXX}(3)$;

end

mloss $=1$;

mideal $=1$;

else

error ('chose neither compressor nor expander')

end 


\section{REFERENCES}

[1] Bhatti M. S., (1998) Global warming impact of automotive air conditioning systems, VII International Mobility Technology Conference And Exhibition, Nov. 9-11,

[2] Rubenstein J. M., (2001), Making and Selling Cars. Innovation and change in the US automotive industry. Maryland: The John Hopkins University Press.

[3] Cooper G., (1998), Air Conditioning America, Engineers and the controlled environment 1900-1960, Maryland: The John Hopkins University Press.

[4] Jones W. P., (1973), Air Conditioning Engineering (4th Ed). , London: Bell and Bain Ltd.

[5] Sir Pullinger A., (1980), Low Energy Air Conditioning. A challenge for the industry. Conference on Air Conditioning and Energy Conservation, (A.F.C Sherratt, Ed.) Wellington England.

[6] Answers.com, (n.d), Refrigeration: Definition and Much More from Answers.com, Retrived April 12, 2007. From: http://content.answers.com/ main/content/wp/en/5/5d/Refrigeration.png

[7] Althouse A.D., Turnquist C.H., Bracciano A.F., (1996), Modern Refrigeration and Air Conditioning, Michigan: The Goodheart-Willcox Company, inc. 
[8] Wang S., Gu J., (2004) Vapour quality and performance of an automotive air conditioning system. Journal of Experimental Thermal and Fluid Science, 13(1), 59-66.

[9] Wang S., Gu, J., Dickson T., (2006) Investigation of the effects of vapour quality and oil concentration on performance of a swash plate compressor. International Journal of Energy Research, 30, 835-849.

[10] Wang S., Gu J., Dickson T.,(2006) Modelling and experimental investigation of accumulators for automotive air conditioning systems. International Journal of Refrigeration, 29(7), 1109-1118.

[11] Hillier V.A.W., (1991), Fundamentals of Motor Vehicle Technology (4th Ed), Cheltenham, England: Stanley Thomas Ltd.

[12] Zhang C.A., Graham B.L., (2002), How To Improve Vehicle R-134a A/C System Performance With Liquid Line Suction Line Heat Exchanger, SAE 2002 World Congress Detroit, Michigan.

[13] Von Sauers R., (n.d.), Heating Ventilation \& A/C System- Dun Devil Auto Diagrams. Retrived April 15, 2007, from http://www.sundevilauto.com/autodiagrams-heating-cooling-system.asp\#heating-system

[14] Kim H., Ahn J., (2006, July 17), Numerical simulaton on scroll expandercompressor unit for $\mathrm{CO}_{2}$ trans-critical cycles. International Compressor Engineering Conference, Perdue, IN retrieved November 7, 2006.

[15] Huff H.J., Radermarcher R., (2003), $\mathrm{CO}_{2}$ Compressor-expander Analysis ARTI 21-CR Research project 611-10060, Maryland. 
[16] Fukuta M., Yanagisawa T., Ogi Y., Radermacher R, (2001), Cycle performance of $\mathrm{CO}_{2}$ cycle with vane compressor-expander combination, International Conference on Compressors and Their Systems, Bury St. Edmunds, 315-324

[17] Hiwata A., Lida, N., Sauai K., (2003), A study of cycle performance improvement with expander- compressor in air conditioning systems. International Conference on Compressors and Their Systems. Bury St. Edmunds, 339-348

[18] Brasz J.J., (2003), Screw Expressor testing on an R-134a chiller - efficiency, liquid carry-over and chiller benefit. International Conference on Compressors and Their Systems. Bury St. Edmunds, 325-338

[19] Brasz J.J. (2003) Throttle loss power recovery in refrigeration and cryogenics. Proceedings of the 21st International Congress of Refrigeration. Washington, Short Courses.

[20] Driver R.W., Davidson D.P., (1999) Application for the hinge vane positive displacement compressor-expander. International Conference on Compressors and Their Systems. Bury St Edmunds, 339-353

[21] Nickl J., Will G., Quack H., Kraus W.E., (2005) Integration of a three stage expander into a $\mathrm{CO} 2$ refrigeration system. International Journal of Refrigeration, 28, 1219-1224.

[22] Henderson P.C., Hewitt N.J., Mongey B., (2000) An economic and technical case for a compressor/expander unit for heat pumps. International Journal of Energy research, 24, 831-842 
[23] Stosic N., Smith I., Kovacevic A., (2002) A twin screw combined compressor and expander for $\mathrm{CO} 2$ refrigeration systems. (Soedel W. ed.), Proceedings of the International Compressor Engineering Conference, Perdue. West Lavette, IN, 703-710.

[24] Kovacevic A., Stosic N., Smith I., (2006) Numerical simulation of combined screw compressor-expander machines for use in high pressure refrigeration systems. Simulation Modelling and Practice Theory, 14, 1143-1154.

[25] Li.L., Zhao Y., Guo B., Shu P., Shen J., He S., (2003), Wrap of cylinder and its effect on main features of rotary vane compressor for automobile air conditioning system. International Journal of Refrigeration. 26, 566 - 574

[26] Wu J., Zhang L., Huang L., Tang Y., (2004), Numerical simulation and performance analysis of rotary vane compressor for automotive air conditioner, Proceedings of the International Compressor Engineering Conference, Perdue. West Lavette, IN, C124, 1-8

[27] Inaguma Y., Hibi A., (2005), Vane pump theory for mechanical efficiency. Proceedings of the Institution of Mechanical Engineers. 219, 1269-1278

[28] Wang S., (2007), Modeling and Experimental study of Automotive Air Conditioning Systems with Consideration of two-Component Two-Phase Flow. Unpublished PhD thesis. Ottawa, Canada: Carleton University.

[29] MEK CoolPack v 1.33. (2005) By: Department of Mechanical Engineering, Technical University of Denmark. http://www.et.web.mek.dtu.dk/Coolpack/UK/ [30] Shih I.P., (1977), Two Phase Flows. (Oswatitsch K. ed.) Viwewg \& Sohn 
braunschweig.

[31] Kundu P.K., Cohen I. M., (2002), Fluid Mechanics (2nd Ed). Academic Press, San-Diego, Califonia.

[32] Yaws C. L., (2003), Yaws' Handbook of Thermodynamic and Physical Properties of Chemical Knovel: http://www.knovel.com.proxy.library.carleton.ca/knovel2/Toc.jsp?BookID=667 $\&$ VerticalID $=0$

[33] Hsu Y. Y., Graham R. W., (1976), Transport Process in Boiling and Two-Phase Systems, Hemisphere Publishing Corporation.

[34] Holman J. P., (2002), Heat Transfer (9th Ed). McGraw Hill, New York

[35] Western Dynamics, (2006), Friction losses in Pipe Fittings Resistance Coefficient K. Retrieved February 29, 2007 From: http://www.westerndynamics.com/Download/friclossfittings.pdf

[36] Incropera F. P., DeWitt D. P., (2002), Fundamentals of Heat and Mass Transfer (5th Ed.), John Wiley \& Sons

[37] Akers W.W., Deans H.A., Corsser O. K., (1958), Condensing heat transfer with horizontal tubes, Chem. Eng. Prog. Symp Ser., 55(29), 171

[38] Koury R.N.N., Machado L., Ismail K.A.R., (2001) Numerical simulation of a variable speed refrigeration system, International Journal of Refrigeration, 24(1) $192-200$

[39] Rohsenow W. M., Hartnett J.P., Cho Y.I., (1998), Handbook of Heat Transfer (3rd Ed.) McGraw-Hill Companies, New York 
[40] Bjorge R. W., Hall G. R., Rohsenow W. M., (1982), Correlation of forced convective boiling heat transfer data. International Journal of Heat and Mass Transfer. 25(6) 753-757

[41] Dupont P. E., Dunlap. E. P., (1993), Friction modelling and control in boundary lubrication. Proceedings of the 1993 American Control Conference. San Francisco CA. 1910-1914

[42] Glen I., Refrigeration Development Company Ltd. P.O.Box 1138, 250 Thomas Street, Deep River, Ontrio, Canada.

[43] Refrigeration Laboratory. Room 6214-F Visualization and Simulation Building, Carleton University, Ottawa Canada.

[44] Olivera C. M., Wakeham W. A., (1993) The Viscosity of liquid R-134a. International Journal of Thermophysics. 14(1) 33-44 